Florida International University FIU Digital Commons

FIU Electronic Theses and Dissertations

University Graduate School

$1-12-1998$

\title{
An experimental study of micro-end-milling operations
}

Tug Tacku Arkan

Florida International University

DOI: $10.25148 /$ etd.FI14032346

Follow this and additional works at: https://digitalcommons.fiu.edu/etd

Part of the Mechanical Engineering Commons

\section{Recommended Citation}

Arkan, Tug Tacku, "An experimental study of micro-end-milling operations" (1998). FIU Electronic Theses and Dissertations. 1313. https://digitalcommons.fiu.edu/etd/1313

This work is brought to you for free and open access by the University Graduate School at FIU Digital Commons. It has been accepted for inclusion in FIU Electronic Theses and Dissertations by an authorized administrator of FIU Digital Commons. For more information, please contact dcc@fiu.edu. 


\section{FLORIDA INTERNATIONAL UNIVERSITY}

Miami, Florida

\section{AN EXPERIMENTAL STUDY OF MICRO-END-MILLING OPERATIONS}

A thesis submitted in partial satisfaction of the

requirements for the degree of

MASTER OF SCIENCE

IN

MECHANICAL ENGINEERING

by

Tug Tacku Arkan 
To: Dean Gordon Hopkins

College of Engineering and Design

This thesis, written by Tug Tacku Arkan, and entitled An Experimental Study of MicroEnd-Milling Operations, having been approved in respect to style and intellectual content, is referred to you for judgement.

We have read this thesis and recommend that it be approved.

Sabri Tosunoglu

Tachung Yih

Ibrahim Tansel, Major Professor

Date of Defense: January 12, 1998

The thesis of Tug Tacku Arkan is approved.

Dean Gordon Hopkins

College of Engineering and Design

Dr. Richard L. Campbell

Dean of Graduate Studies

Florida International University, 1998 


\section{ACKNOWLEDGEMENTS}

I wish to thank the members of the committee for their patience and helpful observations. I wish to thank also my colleague Wei-Yu Bao in Mechatronics Laboratory for his help and cooperation since the beginning of this project.

Especially I thank my major professor Dr. Ibrahim Tansel for having confidence in me to give me the chance to do this project. I learned and gained a lot of experience for recent manufacturing applications in a real industrial manufacturing environment while working in this project with him. I thank him again for encouraging and guiding my efforts in the pursuit of this goal.

This project is partially supported by Engineering Prototype Center at Motorola Radio Technology Division. The majority of the data was collected at the Motorola facilities. The author would like to thank Mr. Bob Shisler, Chris Nelson, Derek Smith, and Michael McCool of Motorola Corp. for their generous financial support and technical recommendations. 


\title{
AN EXPERIMENTAL STUDY OF MICRO-END-MILLING OPERATIONS
}

\author{
by \\ Tug Tacku Arkan \\ Florida International University, 1998 \\ Miami, Florida

\section{Professor Ibrahim Tansel, Major Professor}

Cutting tools less than $2 \mathrm{~mm}$ diameter can be considered as micro-tool. Microtools are used in variety of applications where precision and accuracy are indispensable. In micro-machining operations, a small amount of material is removed and very small cutting forces are created. The small cross sectional area of the micro-tools drastically reduces their strength and makes their useful life short and unpredictable; so cutting parameters should be selected carefully to avoid premature tool breakage. The main objective of this study is to develop new techniques to select the optimal cutting conditions with minimum number of experiments and to evaluate the tool wear in machining operations. Several experimental setups were prepared and used to investigate the characteristics of cutting force and AE signals during the micro-end-milling of different materials including steel, aluminum and graphite electrodes. The proposed optimal cutting condition selection method required fewer experiments than conventional approaches and avoided premature tool breakage. The developed tool wear monitoring technique estimated the used tool life with $\pm 10 \%$ accuracy from the machining data collected during the end-milling of non-metal materials. 


\section{TABLE OF CONTENTS}

CHAPTER

PAGE

I. Introduction

II. Theoretical Background . . . . $\quad$. 3

II. 1. Modeling End-Milling Operations . . . . . . 3

II.2. Acoustic Emission Generation . . . . . 6

II.3. Neural Networks _ . . . . . . . . . 12

II.3.1. Backpropagation Neural Networks . . . . . . . 14

II.3.2. Probabilistic Neural Networks . . . . . . 15

II.4. Wavelet Transformations . . . . . . . . 17

II.5. Static and Dynamic Characteristics of Micro-Tools . . . 19

II.6. On-line Monitoring of Tool Condition during Cutting Operations . 21

II.6.1. Wear-Cutting Force Relationship in Micro-Machining . 22

III. Selection of Cutting Conditions and Monitoring of Tool Wear For Industrial Applications . $\quad$. $\quad$. . . . . $\quad 25$

III.1. A New Method for Machinability Analysis . . . . 25

III.2. Studied Static and Dynamic Behaviors of Micro-Tools . . 28

III.3. Development of an Estimation Method for Tool Wear Monitoring by using Neural Networks ( $\left.\mathrm{N}^{2} \mathrm{PTI}\right)$. . . . . . 29

III.4. Improvement of the Neural Network Based Tool Inspector . . 33 
IV. Experimental Set-Up and Procedures . . . . . 35

IV.1. Cutting Force - AE Data Collection for Machinability and

Wear Analysis $\quad$. $\quad$. $\quad$. . . . . . . 35

- Graphite Electrodes . . . . . 37

- Aluminum. . . . . . . . . 41

- Steel (NAK 55) . . . . . . . . . . 42

IV.2. Static Test . . . . . . . . . . . . 44

IV.3. Dynamic Test . . . . . . . . . . . . . . 46

V. $\quad$ Results and Discussions $\quad$. $\quad$. $\quad$. $\quad$. $\quad$. $\quad$. 48

V.1. Characteristics of Cutting Force at Different Tool Wear Levels . 48

- Graphite Electrodes . . . . . . 48

- Aluminum. . . . . . . . 63

- Steel (NAK 55) . . . . . . . . . . 71

V.2. Performance and Reliability of the $\mathrm{N}^{2} \mathrm{PTI}$. . 79

- Graphite Electrodes . . . . . . . 79

- Aluminum. . . . . . . . . 94

V.3. Performance of the Improved of the $\mathrm{N}^{2} \mathrm{PTI} \ldots \quad 101$

- Graphite Electrodes . . . . . . . 101

- Aluminum . . . . . . . . . 112

V.4. Dynamic Behavior of Micro Tools . . . . . 121

V.5. Static Behavior of Micro Tools _ . . . . . . 126

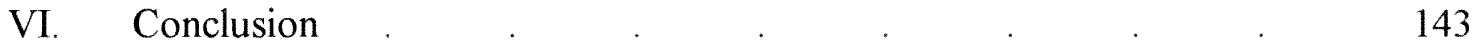

LIST OF REFERENCES _ _ . . . . . . . . 147 


\section{List of Figures}

FIGURE

Figure 1. Backpropagation type Neural Network . . $\quad 15$

Figure 2. PNN type Neural Network . . . . . 16

Figure 3. Proposed Machinability Method . . . . 26

Figure 4. Flow Diagram of the New Machinability Method . . 27

Figure 5. Vibration Test with Laser Vibrometer . . . 29

Figure 6. Neural Network Training Model . . . . 31

Figure 7. Operation of $\mathrm{N}^{2} \mathrm{PTI}$. . . . . . 32

Figure 8. CNC Fadal Machining Center . . . . 36

Figure 9. Climb Milling Technique . . . . . 38

Figure 10. Experimental Set-Up for Tool Wear Test on .

POCOEDMC-3 . . . . . . . . 40

Figure 11. NAK 55 Steel Machining with 0.0625" Diameter End-Mill . 43

Figure 12. Static Behavior Experiment of the Micro-Tools . . 45

Figure 13. Dynamic Behavior Experiment of the Micro-Tools . . 47

Figure 14. Experimental Setup of the Dynamic Test . . . 47

Figure 15. Thrust Direction Cutting Force on POCOEDM-C3 after 40 Passes . . . . . . 50

Figure 16. Feed Direction Cutting Force on POCOEDM-C3 after 40 Passes . . . . . . . 50

Figure 17. Slots from Perfect to Worn out Cutting Tool . 51

Figure 18.a. X Direction Cutting Force of Perfect Tool (Slot 1) . . 52

Figure 18.b. Y Direction Cutting Force of Perfect Tool (Slot 1) . . 52

Figure 19. Slots \#1, \#2, and \#3 . . . . . 53

Figure 20.a. X Direction Cutting Force of the Tool (Slot 4) . . $\quad 54$

Figure 20.b. Y Direction Cutting Force of the Tool (Slot 4) . . $\quad 54$

Figure 21. Slots \#6, \#7, \#8 and \#9 . . . 55

Figure 22.a. X Direction Cutting Force of the Tool (Slot 8) . . 56 
Figure 22.b. Y Direction Cutting Force of the Tool (Slot 8)

Figure 23.a. X Direction Cutting Force Variation with Usage of the Tool

Figure 23.b. Y Direction Cutting Force Variation with Usage of the Tool

Figure 24.a. Linear Curve Fitting of the Experimental X Direction Cutting Force .

Figure 24.b. Exponential Curve Fitting of the Experimental X Direction Cutting Force .

Figure 25.a. Linear Curve Fitting of the Experimental Y Direction Cutting Force .

Figure 25.b. Exponential Curve Fitting of the Experimental Y Direction Cutting Force .

Figure 26.a. Comparison of the Experimental and the Forecasted .

Data for X Direction Cutting Force (POCOEDMC-3)

Figure 26.b. Comparison of the Experimental and the Forecasted .

Data for Y Direction Cutting Force (POCOEDMC-3)

Figure 27. The Relation between X and Y Direction Cutting Force with respect to Tool Life (POCOEDMC-3) .

Figure 28.a. X Direction Cutting Force Variation with Usage of the Tool on Aluminum.

Figure 28.b. Y Direction Cutting Force Variation with Usage of the Tool on Aluminum.

Figure 29.a. Linear Curve Fitting of the Experimental X Direction Cutting Force on Aluminum.

Figure 29.b. Exponential Curve Fitting of the Experimental X Direction Cutting Force on Aluminum. .

Figure 30.a. Linear Curve Fitting of the Experimental Y Direction Cutting Force on Aluminum. 
Figure 30.b. Exponential Curve Fitting of the Experimental Y Direction

Cutting Force on Aluminum. .

Figure 31.a. Comparison of the Experimental and the Forecasted.

Data for X Direction Cutting Force (Aluminum)

Figure 31.b. Comparison of the Experimental and the Forecasted .

Data for Y Direction Cutting Force (Aluminum)

Figure 32. The Relation between $\mathrm{X}$ and $\mathrm{Y}$ Direction Cutting Force

with respect to Tool Life (Aluminum)

Figure 33.a. Thrust Direction Cutting Force Variation with Tool .

Usage on NAK 55 Steel

Figure 33.b. Feed Direction Cutting Force Variation with Tool

Usage on NAK 55 Steel

Figure 34.a. X Direction Cutting Force of 1/16" Diameter

Carbide End-Mill (Tool Breakage)

Figure 34.b. Y Direction Cutting Force of 1/16" Diameter

Carbide End-Mill (Tool Breakage)

Figure 35.a. Acoustic Emission Signal of 1/16" Diameter

Carbide End-Mill (Tool Breakage)

75

Figure 35.b. FFT of the Acoustic Emission Signal of 1/16" Diameter

Carbide End-Mill (Tool Breakage) .

75

Figure 36.a. Linear Curve Fitting of the Experimental X Direction

Cutting Force (NAK 55 Steel)

Figure 36.b. Exponential Curve Fitting of the Experimental X Direction

Cutting Force (NAK 55 Steel)

Figure 37.a. Linear Curve Fitting of the Experimental Y Direction

Cutting Force (NAK 55 Steel)

78

Figure 37.b. Exponential Curve Fitting of the Experimental Y Direction Cutting Force (NAK 55 Steel)

Figure 38. Tool Usage and Cutting Force Relation-Experimental Results

Figure 39.a. Estimated Results of the Training Cases with Analog BP NN 
Figure 39.b. Estimated Results of the Training Cases with PNN BASIC

Figure 39.c. Estimated Results of the Training Cases with PNN SEPVAR

Figure 40.a. Estimated Results of the Test Cases with Analog BP NN

Figure 40.b. Estimated Results of the Test Cases with PNN BASIC

Figure 40.c. Estimated Results of the Test Cases with PNN SEPVAR

Figure 41.a. Estimation Accuracy Comparison of the $3 \mathrm{NN}$ (Training Data)

Figure 41.b. Estimation Accuracy Comparison of the 3 NN (Test Data) .

Figure 41.c. Estimation Accuracy Comparison of the 3 NN (All Data) .

Figure 42. Small Tool Usage and Cutting Force Relation-

Experimental Results .

Figure 43.a. Estimated Results of the Training Cases with Analog BP NN (0.030" Carbide End-Mill)

Figure 43.b. Estimated Results of the Training Cases with

PNN BASIC (0.030" Carbide End-Mill)

Figure 43.c. Estimated Results of the Training Cases with

PNN SEPVAR (0.030" Carbide End-Mill)

Figure 44.a. Estimated Results of the Test Cases with Analog

BP NN (0.030" Carbide End-Mill)

Figure 44.b. Estimated Results of the Test Cases with

PNN BASIC (0.030" Carbide End-Mill)

Figure 44.c. Estimated Results of the Test Cases with

PNN SEPVAR (0.030" Carbide End-Mill)

Figure 45.a. Estimation Accuracy Comparison of the 3 NN (Training Data) 92

Figure 45.b. Estimation Accuracy Comparison of the 3 NN (Test Data) . 93

Figure 45.c. Estimation Accuracy Comparison of the 3 NN (All Data) . 93

Figure 46. Tool Usage and Cutting Force Relation for Aluminum

Experimental Results .

Figure 47.a. Estimated Results of the Training Cases with Analog BP NN 95

Figure 47.b. Estimated Results of the Training Cases with PNN BASIC . 96

Figure 47.c. Estimated Results of the Training Cases with PNN SEPVAR 96 
Figure 48.a. $\quad$ Estimated Results of the Test Cases with Analog BP NN . 97

Figure 48.b. Estimated Results of the Test Cases with PNN BASIC . 97

Figure 48.c. Estimated Results of the Test Cases with PNN SEPVAR . 98

Figure 49.a. Estimation Accuracy Comparison of the 3 NN (Training Data) 99

Figure 49.b. Estimation Accuracy Comparison of the 3 NN (Test Data) . 99

Figure 49.c. Estimation Accuracy Comparison of the 3 NN (All Data) . 100

Figure 50.a. Estimation Accuracy of Analog BP for Training Cases with Improved N ${ }^{2}$ PTI (Segmental Averaging)

Figure 50.b. Estimation Accuracy of Analog BP for Test Cases with Improved N ${ }^{2}$ PTI (Segmental Averaging)

Figure 51.a. Estimation Accuracy of Analog BP for Training Cases with Improved N ${ }^{2}$ PTI (Wavelet Transformation)

Figure 51.b. Estimation Accuracy of Analog BP for Testing Cases. with Improved $\mathrm{N}^{2} \mathrm{PTI}$ (Wavelet Transformation)

Figure 52. Representation of the original cutting force with 10 local parameters obtained with Segmental Averaging technique

Figure 53. Representation of the original cutting force after wavelet transformation

Figure 54. Experimental Cutting Force Data

Figure 55.a. Estimation Accuracy of Analog BP for Training Cases with Improved N²PTI (Segmental Averaging) [Aluminum]

Figure 55.b. Estimation Accuracy of Analog BP for Test Cases with Improved N ${ }^{2}$ PTI (Segmental Averaging) [Aluminum]

Figure 56.a. Estimation Accuracy of Analog BP for Training Cases with Improved N ${ }^{2}$ PTI (Wavelet Transformation) [Aluminum]

Figure 56.b. Estimation Accuracy of Analog BP for Test Cases with Improved N ${ }^{2}$ PTI (Wavelet Transformation) [Aluminum]

Figure 57.a. 0.0625" Diameter HSS Tool Vibration (Tip was hit).

Figure 57.b. 0.0625" Diameter HSS Tool Vibration (Bottom was hit) 
Figure 58.b. $\quad 0.020 "$ Diameter HSS Tool Vibration (Bottom was hit)

Figure 59. Frequency Response of the 1/16" Diameter Carbide .

End-Mill - ARV Computer Program output

Figure 60.a. Cutting Edges of the Tool (0.020 HSS) Parallel

to the Workpiece

Figure 60.b. Cutting Edges of the Tool (0.020 HSS) Vertical

to the Workpiece

Figure 60.c. Cutting Edges of the Tool (0.020 HSS) 45 Degree to the Workpiece

Figure 60.d. Tool breakage (0.020 HSS)

Figure 61.a. Cutting Edges of the Tool (0.0625 HSS) Parallel to the Workpiece

Figure 61.b. Cutting Edges of the Tool (0.0625 HSS) Vertical to the Workpiece

Figure 61.c. Cutting Edges of the Tool (0.0625 HSS) 45 Degree to the Workpiece

Figure 61.d. Tool breakage (0.0625 HSS) .

Figure 62.a. Cutting Edges of the Tool (0.020 Carbide) Parallel to the Workpiece

Figure 62.b. Cutting Edges of the Tool (0.020 Carbide) Vertical to the Workpiece

Figure 62.c. Cutting Edges of the Tool (0.020 Carbide) 45 Degree to the Workpiece

Figure 62.d. Tool breakage (0.020 Carbide)

Figure 63.a. Cutting Edges of the Tool (0.0625 Carbide) Parallel . to the Workpiece

Figure 63.b. Cutting Edges of the Tool (0.0625 Carbide) Vertical . to the Workpiece

Figure 63.c. Cutting Edges of the Tool (0.0625 Carbide) 45 Degree to the Workpiece 
Figure 63.d. Tool breakage ( 0.0625 Carbide)

Figure 64.a. Cutting Edges of the Tool (0.020 HSS) Parallel to the Steel Workpiece

Figure 64.b. Cutting Edges of the Tool (0.020 HSS) Vertical to the Steel Workpiece

Figure 64.c. Cutting Edges of the Tool (0.020 HSS) 45 Degree to the Steel Workpiece

Figure 64.d. Tool breakage (0.020 HSS)

Figure 65.a. Cutting Edges of the Tool (0.020 Carbide) Parallel to the Steel Workpiece

Figure 65.b. Cutting Edges of the Tool (0.020 Carbide) Vertical to the Steel Workpiece

Figure 65.c. Cutting Edges of the Tool (0.020 Carbide) 45 Degree to the Steel Workpiece

Figure 65.d. Tool breakage (0.020 Carbide)

Figure 66.a. Cutting Edges of the Tool (0.0625 HSS) Parallel to the Steel Workpiece

Figure 66.b. Cutting Edges of the Tool (0.0625 HSS) Vertical to the Steel Workpiece

Figure 66.c. Cutting Edges of the Tool (0.0625 HSS) 45 Degree . to the Steel Workpiece

Figure 67.a. Cutting Edges of the Tool (0.0625 Carbide) Parallel . to the Steel Workpiece

Figure 67.b. Cutting Edges of the Tool (0.0625 Carbide) Vertical. to the Steel Workpiece

Figure 67.c. Cutting Edges of the Tool (0.0625 Carbide) 45 Degree to the Steel Workpiece

Figure 67.d. Tool breakage (0.0625 Carbide) 
List of Tables

TABLE

PAGE

Table 1 Different Approaches in the Study of the AE for Tool Wear.

Table 2

Tool Wear Sensing Methods

Table 3

Test Conditions for POCO-3 Machinability

Table 4

Test Conditions in POCOEDMC-3: Tool Wear Experiments

Table 5

Test Conditions for Aluminum Machinability

Table 6

Test Conditions for NAK 55 Steel Machinability

Table 7

Results of the Proposed Machinability Method

Table 8

Optimal Cutting Conditions obtained for Aluminum

with New Machinability Method

Table 9 Cutting Force Variation - Tool Life Results in Tool .

Wear Experiment (Aluminum)

Table 10 Optimal Cutting Conditions obtained for NAK 55 Steel

with New Machinability Method

Table 11 Cutting Force Variation - Tool Life Results in Tool .

Wear Experiment (NAK 55 Steel)

Table 12 Cutting Force Variation - Tool Life Results in Tool .

Wear Experiment (POCOEDMC-3) .

Table 13 Comparison of the Experimental Data and NN

Estimation Data for POCOEDMC-3 .

Table 14 Characteristics of the 3 Different NN used For $N^{2}$ PTI

Table 15 Comparison of the Experimental Data and NN

Estimation Data for Aluminum

Table 16 Characteristics of the 3 Different NN used For $N^{2}$ PTI (Al)

Table 17 Characteristics of the 3 Different NN used For Improved $N^{2}$ PTI (POCOEDMC-3) [Local Averaging] .

Table 18 Estimation for the Training Data for POCOEDMC-3 
Table 19 Estimation for the Test Data for POCOEDMC-3

[Local Averaging]

Table 20 Characteristics of the 3 Different Neural Network used

for Improved N ${ }^{2}$ PTI (Wavelet Transformation)

Table 21 Estimation for the Training Data for POCOEDMC-3

[Wavelet Transformation]

Table 22 Estimation for the Test Data for POCOEDMC-3

[Wavelet Transformation]

Table 23 Characteristics of the 3 Different NN used For Improved $\mathrm{N}^{2}$ PTI (Aluminum) [Local Averaging]

Table 24 Estimation for the Training Data for Aluminum

[Local Averaging]

Table 25 Estimation for the Test Data for Aluminum

[Local Averaging]

Table 26 Characteristics of the 3 Different Neural Network used for Improved $N^{2}$ PTI (Wavelet Transformation)

Table 27 Estimation for the Training Data for Aluminum

[Wavelet Transformation]

Table 28 Estimation for the Test Data for Aluminum

[Wavelet Transformation]

Table 29 Performance of the $\mathrm{N}^{2} \mathrm{PTI}$ - POCOEDMC-3

Table 30 Performance of the N $\mathrm{N}^{2} \mathrm{PTI}-$ Aluminum 


\section{Chapter I}

\section{Introduction}

Cutting tool less than $2 \mathrm{~mm}$ diameter can be considered as micro-tool. Micro-tools are used in variety of applications where precision and accuracy are indispensable. Today many products use complex parts. Even the manufacturers of common consumer products aim to miniaturize their products to increase their profit margin and market share. Micro-tools have been finding many new applications in these market conditions. Conventional cutting tools have been used in metal cutting operations for a longtime and machine operators know their behavior on different workpieces as steel, aluminum, and some non-metals. In addition, databases are available to find the optimum cutting conditions easily. The small cross sectional area of the micro-tools drastically reduces their strength and makes their useful life short and unpredictable. Also very limited machinability data is available on micro-tools.

Due to the facts stated above, the need of on-line or off-line monitoring of microtools during micro machining operations is indispensable for better product quality with less work time, less expense. To maximize the productivity and product quality, best cutting conditions have to be selected and used in the micro-machining operations. Different parameters can be monitored during machining operations to obtain the optimum conditions. Cutting forces can be measured during cutting operations and can be used by using various techniques to estimate and prevent premature tool breakage. Tool life (wear) and cutting forces relationships can be analyzed by using acoustic emission (AE) techniques. 
In conventional machining operations, machinability of a material is evaluated based on the following three factors:

1. Surface finish and integrity

2. Tool life

3. Force and power requirements

Thus good machinability indicates good surface finish and integrity, long tool life and low force and power requirements. However, in micro machining, the main goal is to avoid premature breakage.

The objectives of this study are the following:

1. To develop a new experimental procedure to select the optimal cutting conditions for machining of different materials including metals (steel, aluminum) and non-metals (electric discharge machining electrodes) experimentally.

2. To investigate the relationship between the wear of carbide tools and cutting force.

3. To evaluate feasibility of computational tools (neural networks), to estimate tool wear from the characteristics of experimental cutting force data.

4. To propose a new method to estimate tool wear in industrial applications. The method is developed to require a low cost hardware, to use a reliable and simple computer program. 


\section{Chapter II}

\section{Theoretical Background}

The modeling end-milling operations, cutting forces, acoustic emission (AE) generation, neural networks (Backpropagation, PNN), wavelet transformations and dynamic response of structures will be briefly introduced in this section.

\section{II.1. Modeling End-Milling Operations}

Several researchers $[1,2,3]$ have developed deterministic models for the simulation of cutting forces in end milling. An accurate model of cutting forces in milling is indispensable in the machinability analysis and the prediction of tool life. In milling, a cutting edge will create two components of force while cutting. These are called as tangential and radial forces. Tlusty and MacNeil [1], modeled the dynamics of cutting forces in end milling, for a steady state cutting, at a constant depth of cut and width. In this model, the instantaneous cutting force at cutting angle is assumed to be proportional to the chip thickness. The instantaneous tangential cutting force in end milling can be approximated by:

$$
\mathrm{F}_{\mathrm{T}}=\mathrm{kb} \mathrm{h}
$$

Where, $\mathrm{b}$ is the axial depth of cut; $\mathrm{k}$ is the cutting force coefficient that depends on the material of the workpiece, geometry of the tool and average chip thickness; $h$ is the instantaneous chip thickness at angle $\phi$, as shown below: 


$$
\mathrm{h}=\mathrm{S}_{\mathrm{t}} \sin \phi
$$

where, $S_{t}$ is the feed rate per tooth.

In this model, the radial component of cutting force is assumed to be $30 \%$ of the tangential component:

$$
\mathrm{F}_{\mathrm{R}}=0.3 \mathrm{~F}_{\mathrm{T}}
$$

The total resultant cutting force is assumed to be the equivalent of the sum of the components over the differential rotation angles, $\mathrm{d} \phi$.

$$
\begin{aligned}
& \mathrm{dF}_{\mathrm{T}}=\mathrm{KS}_{\mathrm{t}} \sin \phi \\
& \mathrm{dF}_{\mathrm{R}}=0.3 \mathrm{KS}_{\mathrm{t}} \sin \phi
\end{aligned}
$$

where, dy is the differential cutting edge.

The differential components of the cutting force on two fixed perpendicular directions are:

$$
\begin{aligned}
& \mathrm{dF}_{\mathrm{x}}=-\mathrm{dF}_{\mathrm{T}} \cos \phi-\mathrm{dF}_{\mathrm{R}} \sin \phi \\
& \mathrm{dF}_{\mathrm{y}}=-\mathrm{dF}_{\mathrm{T}} \sin \phi-\mathrm{dF}_{\mathrm{R}} \cos \phi
\end{aligned}
$$

For the case of non-helical teeth, the cutting forces may be represented by: 


$$
\begin{aligned}
& \mathrm{F}_{\mathrm{x}}=-\mathrm{F}_{\mathrm{T}}(\cos \phi+0.3 \sin \phi) \\
& \mathrm{F}_{\mathrm{y}}=-\mathrm{F}_{\mathrm{T}}(-\sin \phi+0.3 \cos \phi)
\end{aligned}
$$

where $F_{t}$ is the tangential force.

Tlusty and Ismail [4] improved this model to study chatter in end milling. This model allowed for tool deflection in both the $x$ and $y$ directions. The tangential cutting force in equation 2.1 is modified to include the displacement,

$$
\mathrm{F}_{\mathrm{T}}=\mathrm{K}_{\mathrm{b}}(\mathrm{h}-\mathrm{Z}+\mathrm{Z} \min )
$$

Where, $\mathrm{Z}$ is the displacement of the tool normal to the machined surface. $Z_{\min }$ lowest undulation left behind in the preceding cuts at angle, $\phi$. The $F x$ and $F y$ components of the cutting force excite vibrations in the $X$ and $Y$ directions.

Models of cutting forces, which include the influence of cutter offset (run-out) on the cutting force $[5,6]$ have also been developed. The effects of cutter offset can be included by adding a term when determining the normal $z$ displacement, which adjusts for the eccentricity,

$$
\mathrm{Z}=\mathrm{x} \sin \phi+y \cos \phi+t_{e c}
$$


where $t_{e c}$ adjusts for the eccentricity. For a four flute end mill, the first and third, and the second and fourth flute values of $t_{e c}$ average one. For a six flute end mill, the first and fourth, second and fifth, and third and sixth flute values of $t_{e c}$ average one.

\section{II.2. Acoustic Emission Generation}

During the machining operations, a series of spherical elastic stress waves are generated by the rapid release of strain energy within the material. These waves travel until they reach the surface of the material, where they can be detected with piezoelectric transducers in intimate contact with the body and transformed into an electrical signal for processing and analysis purposes. This release of strain energy can be due to a material undergoing deformation, fracture or a combination of both factors.

The sources of acoustic emission during peripheral milling [7], are the following:

1. Plastic deformation in the shear zone near the cutting edges of the cutting teeth.

2. Rubbing between the rake faces of the cutting teeth and chips.

3. Rubbing between the flank faces of the cutting teeth and the workpiece.

4. Rubbing between the flank faces of the end teeth of the cutter and the machined workpiece surface.

6. Chip breakage (less important).

5. Entanglement (less important).

During a cutting operation [8], dislocation in primary shear zone and the sliding friction in the secondary shear zone primarily generate acoustic emission. As the cutting tool wears, 
additional frictional action between the tool flank and the workpiece also creates acoustic emission. The portion of $\mathrm{AE}$ that is attributed to friction on the wear land becomes more important when flank/ workpiece contact area increases as a result of tool wear. Acoustic emission generated from shearing and friction exhibit different signal characteristics since the mechanisms by which $\mathrm{AE}$ is produced in these occasions are fundamentally different. As a result, the signal characteristics of $\mathrm{AE}$ are expected to change when tool wear-land progresses.

The relationship between the AE signal and tool wear is not as direct or as simple as the relationship between the cutting force and cutting edge condition (tool wear). The major advantage of using $\mathrm{AE}$ to monitor tool wear is that the frequency range of the $\mathrm{AE}$ signal is much higher than that of the machine vibrations and environmental noises. Therefore, a relatively, uncontaminated signal can be easily obtained by the use of a highpass filter. AE can be measured by simply mounting a piezoelectric transducer on tool holder. In addition, the characteristics of the AE signal are independent of cutting direction. However, due to its high frequency nature and the sensitivity to micro-structural behavior of material, acoustic emission signals often have to be treated with additional signal processing schemes so that the most useful information can be extracted.

Many studies have been carried out to study the acoustic emission during metal cutting and different ways to process the signals have been experimented. Table 1 illustrates these different approaches. 
Table 1. Different approaches in the study of the acoustic emission for Tool Wear Analysis

\begin{tabular}{|c|c|c|c|}
\hline Document & Process & Signal processing method & $\begin{array}{l}\mathrm{Y} \\
\mathrm{e} \\
\mathrm{a} \\
\mathrm{r}\end{array}$ \\
\hline $\begin{array}{l}\text { - Zheng, L., Luo, Z. B., Wu, Y., et } \\
\text { al., "Research and Development on } \\
\text { Synthetic Cutting Tool Monitoring } \\
\text { with AE Signal," Transactions of } \\
\text { NAMRI/SME, 1990. [9] }\end{array}$ & All processes & $\begin{array}{l}\text { Signal amplified band-pass } \\
\text { filtered between } 1000 \mathrm{kHz} \\
\text { and } 1 \mathrm{MHz} \text {. Ring count, } \\
\text { envelope, spectral and } \\
\text { correlation analyses were } \\
\text { used. }\end{array}$ & $\begin{array}{l}1 \\
9 \\
9 \\
0\end{array}$ \\
\hline $\begin{array}{l}\text { - Koning, W., Kutzner K., Shehl, U., } \\
\text { "Tool Monitoring of Small Drills } \\
\text { With Acoustic Emission," } \\
\text { International Journal of Machine } \\
\text { Tools Manufacture Vol. 32, No. 4, } \\
\text { pp. 487-493, Pergamon Press, } \\
\text { Great Britain, 1992. [10] }\end{array}$ & Drilling & $\begin{array}{l}\text { Band-pass filtered signal, } \\
\text { rectified, and low pass } \\
\text { filtered. The original high } \\
\text { frequency is converted to } \\
\text { low frequency. RMS } \\
\text { analyzed }\end{array}$ & $\begin{array}{l}1 \\
9 \\
9 \\
2\end{array}$ \\
\hline $\begin{array}{l}\text { - Vajpayee S., Sampath, A., } \\
\text { "Acoustic Emission as an Indirect } \\
\text { Parameter for Tools Monitoring," } \\
\text { Proceedings of Manufacturing } \\
\text { International '88, Symposium on } \\
\text { Product and Process Design, Vol. } \\
\text { 1, Atlanta, Georgia, 1988. [11] }\end{array}$ & Turning & $\begin{array}{l}\text { Transducer with resonance } \\
\text { of } 200 \text { kHz, signal } \\
\text { amplified and filtered at } \\
100 \mathrm{kHz} \text { high-pass, } 2 \mathrm{MHz} \\
\text { low-pass and a pulse } \\
\text { counter. } \\
\text { Count and count rate } \\
\text { analyzed. }\end{array}$ & $\begin{array}{l}1 \\
9 \\
8 \\
8\end{array}$ \\
\hline $\begin{array}{l}\text { - Liu M., Liang, S. Y., "Analytical } \\
\text { Modeling of Acoustic Emission for } \\
\text { Monitoring of Peripheral Milling } \\
\text { Process," International Journal of } \\
\text { Machine Tools Manufacture, Vol. } \\
\text { 31, No. 4, pp. 589-606, Pergamon } \\
\text { Press. 1991. [12] }\end{array}$ & Peripheral milling & $\begin{array}{l}\text { An analytical model } \\
\text { relating the acoustic } \\
\text { emission energy content to } \\
\text { the cutting parameters is } \\
\text { developed. }\end{array}$ & $\begin{array}{l}1 \\
9 \\
9 \\
1\end{array}$ \\
\hline
\end{tabular}




\begin{tabular}{|c|c|c|c|}
\hline $\begin{array}{l}\text { - Liu, M., Liang, S. Y., "Monitoring } \\
\text { of Peripheral Milling Using } \\
\text { Acoustic Emission," Transactions } \\
\text { of NAMRI/SME, 1990. [13] }\end{array}$ & Peripheral milling & $\begin{array}{l}\text { Bridgeport vertical milling } \\
\text { machine. A wide band }(0.1- \\
1.0 \mathrm{MHz}) \text { transducer } \\
\text { followed by an amplifier. } \\
\text { TMS was analyzed. }\end{array}$ & $\begin{array}{l}1 \\
9 \\
9 \\
0\end{array}$ \\
\hline $\begin{array}{l}\text { Klaiber, J. R., Dornfeld, D. A., Liu, } \\
\text { J. J., "Acoustic Emission Feedback } \\
\text { for Diamond } \quad \text { Turning," } \\
\text { Transactions of NAMRI/SME, } \\
\text { 1990. [14] }\end{array}$ & Diamond turning & $\begin{array}{l}\text { Signal amplified and sent to } \\
\text { RMS voltage filter. RMS } \\
\text { analyzed. }\end{array}$ & $\begin{array}{l}1 \\
9 \\
9 \\
0\end{array}$ \\
\hline $\begin{array}{l}\text { - Liu, J. J., Dornfeld, D. A., } \\
\text { "Monitoring of Micro-machining } \\
\text { Process Using Acoustic Emission," } \\
\text { Transactions of NAMRI/SME. } \\
\text { Vol. XX, 1992. [15] }\end{array}$ & $\begin{array}{l}\text { Micro-machining } \\
\text { simulated by end } \\
\text { milling with very } \\
\text { small feed and } \\
\text { high spindle } \\
\text { speed }\end{array}$ & $\begin{array}{l}\text { A piezoelectric transducer } \\
\text { with resonance frequencies } \\
\text { at } 125 \mathrm{kHz} \text { and } 375 \mathrm{kHz} \\
\text { was used. The signal was } \\
\text { pre-amplified high-pass } \\
\text { filtered at } 50 \mathrm{kHz} \text {, then } \\
\text { amplified, stored and } \\
\text { finally digitized at } 2 \mathrm{MHz} \\
\text { sampling rate. Analyzed } \\
\text { with power spectrum } \\
\text { estimation, zero crossing } \\
\text { rate, and kurtosis of the } \\
\text { signal. }\end{array}$ & $\begin{array}{l}1 \\
9 \\
9 \\
2\end{array}$ \\
\hline $\begin{array}{l}\text { Diniz, A. E., Liu, J. J., Dornfeld, } \\
\text { D. A., "Correlating Tool Life, } \\
\text { Tool, Wear and Surface Roughness } \\
\text { by Monitoring Acoustic Emission } \\
\text { in Finish Turning," Wear No. 152, } \\
\text { pp. 395-407, 1992. [16] }\end{array}$ & $\begin{array}{l}\text { Turning } \\
\text { (finishing) }\end{array}$ & $\begin{array}{l}\text { Signal pre-amplified, high- } \\
\text { passed, amplified, recorded, } \\
\text { digitized and band-passed } \\
\text { at } 50-500 \mathrm{kHz} \text { and at } 200- \\
300 \mathrm{kHz}, \mathrm{RMS} \text {. Analyzed } \\
\text { the frequency spectrum. }\end{array}$ & $\begin{array}{l}1 \\
9 \\
9 \\
2\end{array}$ \\
\hline $\begin{array}{l}\text { - Hutton, D. V., "A Non-contact } \\
\text { Acoustic Emission Sensing System } \\
\text { For Rotating-Cutter Machining } \\
\text { Process," r Experimental } \\
\text { Techniques, Nov/Dec, 1991. [17] }\end{array}$ & Rotating tools & $\begin{array}{l}\text { Proposes a chamber, } \\
\text { surrounding the spindle, } \\
\text { filled with a liquid, which } \\
\text { links the spindle with the } \\
\text { acoustic emission sensor }\end{array}$ & $\begin{array}{l}1 \\
9 \\
9 \\
1\end{array}$ \\
\hline $\begin{array}{l}\text { - Osuri, R. H., Chatterjee, S., } \\
\text { Chandrashekhar, S., "On-Line } \\
\text { Condition Monitoring of Tools } \\
\text { Wear in End Milling Using } \\
\text { Acoustic Emission," International } \\
\text { Journal of Research, Vol. 29, No. } \\
\text { 7, pp. 1339-1353, 1991. [18] }\end{array}$ & End Milling & $\begin{array}{l}\text { Bridgeport vertical milling } \\
\text { machine. The signal was } \\
\text { amplified, high passed at } 20 \\
\mathrm{kHz} \text { and recorded. RMS } \\
\text { analyzed. }\end{array}$ & $\begin{array}{l}1 \\
9 \\
9 \\
1\end{array}$ \\
\hline
\end{tabular}




\begin{tabular}{|c|c|c|c|}
\hline $\begin{array}{l}\text { - Rangwala, S., Dornfeld, D., "A } \\
\text { Study of Acoustic Emission } \\
\text { Generated During Orthogonal } \\
\text { Metal Cutting - 1:Energy } \\
\text { Analysis," International Journal of } \\
\text { Mechanical Science Vol. 33, No. } 6 \\
\text { pp. 471-487, Pergamon Press, } \\
\text { Great Britain, 1991. [19] }\end{array}$ & $\begin{array}{l}\text { Orthogonal metal } \\
\text { cutting }\end{array}$ & $\begin{array}{l}\text { The signal was amplified } \\
\text { and recorded. The RMS } \\
\text { was analyzed. }\end{array}$ & $\begin{array}{l}1 \\
9\end{array}$ \\
\hline $\begin{array}{l}\text { - Tansel, I.N., Bao, W.Y., Medardo, } \\
\text { E.T., Arkan, T.T, " Detection of } \\
\text { Tool Breakage in Micro-End- } \\
\text { Milling Operations by Monitoring } \\
\text { Acoustic Emission," Technical } \\
\text { Conference Paper, NAMRI, SME } \\
{[28]}\end{array}$ & End - Milling & $\begin{array}{l}\text { The tool breakage } \\
\text { mechanism of micro-end } \\
\text { mills, wear-induced stress, } \\
\text { is explained by evaluating } \\
\text { the thrust direction cutting } \\
\text { force characteristics. }\end{array}$ & $\begin{array}{l}1 \\
9 \\
9\end{array}$ \\
\hline 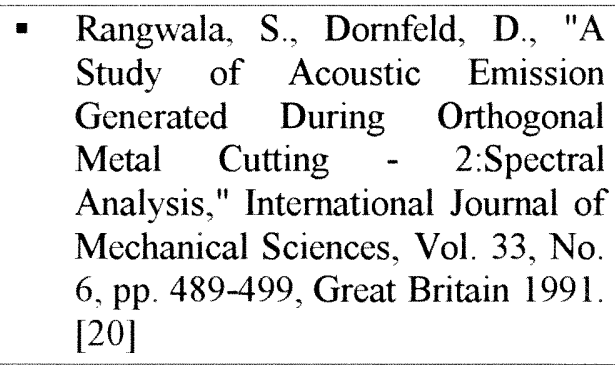 & $\begin{array}{l}\text { Orthogonal } \\
\text { cutting }\end{array}$ & $\begin{array}{l}\text { The signal was amplified } \\
\text { and recorded, low-pass } \\
\text { filtered and sampled at } 5 \\
\text { MHz. Was analyzed the } \\
\text { RMS distribution in the } \\
\text { signal power spectrum. }\end{array}$ & $\begin{array}{l}1 \\
9 \\
9\end{array}$ \\
\hline $\begin{array}{l}\text { - Liang, S. Y., Dornfeld, D. A., } \\
\text { "Tool Wear Detection Using Time } \\
\text { Series Analysis of Acoustic } \\
\text { Emission," Journal of Engineering } \\
\text { for Industry, Vol. 111, pp. 199- } \\
\text { 205, August 1989. [21] }\end{array}$ & Turning & $\begin{array}{l}\text { Signal amplified, high- } \\
\text { passed at } 50 \mathrm{kHz} \text {, sent to a } \\
\text { RMS meter, modulated to } \\
\text { remove the D.C. } \\
\text { component and digitized at } \\
5 \mathrm{kHz} \text {. } \\
\text { AR time-series modeling of } \\
\text { the acoustic emission RMS } \\
\text { signal bas } \\
\text { implemented. }\end{array}$ & $\begin{array}{l}1 \\
9 \\
8 \\
9\end{array}$ \\
\hline $\begin{array}{l}\text { Carolan, T.A., Hand, D.P., Barton } \\
\text { J.S., "Assessment of Tool Wear in } \\
\text { Milling Using Acoustic Emission } \\
\text { Detected by a Fiber-Optic } \\
\text { Interferometer," Journal of } \\
\text { Manufacturing Science and } \\
\text { Engineering, 1996, Vol. 118, } \\
\text { Transaction of the ASME [31] }\end{array}$ & Milling & $\begin{array}{l}\text { It describes the use of a } \\
\text { robust fiber optic } \\
\text { interferometer for the in- } \\
\text { process measurement of AE } \\
\text { during face milling of steel } \\
\text { to provide tool wear } \\
\text { information via analysis of } \\
\text { the rms. AE signal }\end{array}$ & $\begin{array}{l}1 \\
9 \\
9\end{array}$ \\
\hline
\end{tabular}




\begin{tabular}{|c|c|c|c|}
\hline $\begin{array}{l}\text { - Principe, J.C., Yoon, T., "A New } \\
\text { Algorithm for the Detection of } \\
\text { Tool Breakage in Milling," Int. } \\
\text { Journal of Machine Tools \& } \\
\text { Manufacturing, Vol. 31 No. } 4 \text { pp. } \\
\text { 443-454, Great Britain, } 1991 \text { [32] }\end{array}$ & Milling & $\begin{array}{l}\text { A novel signal processing } \\
\text { system is presented for the } \\
\text { detection of tool breakage } \\
\text { using the displacement } \\
\text { signal (RORPA). The } \\
\text { algorithm extracts } \\
\text { information from } \\
\text { consecutive revolutions to } \\
\text { decrease dependencies on } \\
\text { runout conditions and ideal } \\
\text { noise by creating a more } \\
\text { robust signal. }\end{array}$ & $\begin{array}{l}1 \\
9 \\
9 \\
1\end{array}$ \\
\hline $\begin{array}{l}\text { - Emel, E., Kannatey-Asibu, E. Jr., } \\
\text { "Acoustic Emission and Sensor } \\
\text { Fusion for Monitoring the Cutting } \\
\text { Process," International Journal of } \\
\text { Mechanical Sciences, Vol. 31, No. } \\
\text { 11/12, pp. 795-809, Great Britain, } \\
\text { 1989. [22] }\end{array}$ & Turning & $\begin{array}{l}\text { Three force components } \\
\text { measured with a } \\
\text { dynamometer, amplified, } \\
\text { digitized at } 2 \mathrm{kHz} \text { and low- } \\
\text { pass filtered at } 1 \mathrm{kHz} \text {. The } \\
\text { AE and the force signal are } \\
\text { used to monitor the cutting } \\
\text { process. }\end{array}$ & $\begin{array}{l}1 \\
9 \\
8 \\
9\end{array}$ \\
\hline
\end{tabular}




\section{II.3. Neural Networks}

A directed graph is a geometrical object consisting of a set of points (called nodes or neurons) along with a set of directed line segments (called links) between them. A neural network is a parallel-distributed information processing structure in the form of a directed graph, with the following sub-definitions and restrictions: [33]

1. The nodes of the graph are called processing elements.

2. The links of the graph are called connections. Each connection functions as an instantaneous unidirectional signal-conduction path.

3. Each processing element can receive any number of incoming connections (also called input connections).

4. Each processing element can have any number of outgoing connections, but the signal in all of these must be the same. In effect, each processing element has a single output connection that can branch of fan out into copies to form multiple output connections, each of which carries the same identical signal (the processing element output signal).

5. Processing elements can have local memory.

6. Each processing element possesses a transfer function which can use (and alter) local memory, can use input signals, and which produces the processing element's output signal. The only inputs that allowed to the transfer function are the values stored in the processing element's local memory and the current values of the input signals in the connections received by the processing element. The only outputs allowed from the transfer function are values to be 
stored in the processing element's local memory and the processing element's output.

Transfer functions can operate continuously or episodically. If they operate episodically, there must be an input called "activate" that causes the processing element's transfer function to operate on the current input signals and local memory values and to produce an updated output signal (and possibly modify local memory values). Continuous processing elements are always operating. The "activate" input arrives via a connection from a scheduling processing element that is a part of the network.

7. Input signals to a neural network from outside the network arrive via connections, which originate the outside world. Outputs from the network to the outside world are connections that leave the network.

Neural networks can be classified in information domain as:

1. Time independent information (mapping problem)

2. Time dependent information (prediction problem)

3. Self learning information (induction and deduction problem)

4. Others (creation problem)

In this section, Backpropagation (BP) and Probabilistic Neural Networks (PNN) will be introduced. 


\section{II.3.1. Backpropagation Neural Networks (BP)}

The backpropagation is the well known and the most commonly used neural network. Figure 1 presents the structure of BP. Each link between the neurons represents a weight and a simple (most commonly sigmoid) function. The user selects the number of hidden layers and hidden neurons. BP can be used for mapping or characterization. The backward propagation neural network is a kind of construction model. Construction methods base on the biology theory. It tries to build a physical brain model to imitate the think or behavior of a human being. During the training process, the weights of neurons are adjusted. At the beginning weights are selected randomly.

In this study, "Neurashell" is used. The network has two drawbacks. First the user should have knowledge and experience to select the number of hidden layers and number of neurons in each layer. Second, training of the original algorithm is extremely slow. BP is a very effective method when the characteristics of large number of training data are represented with a small network. 


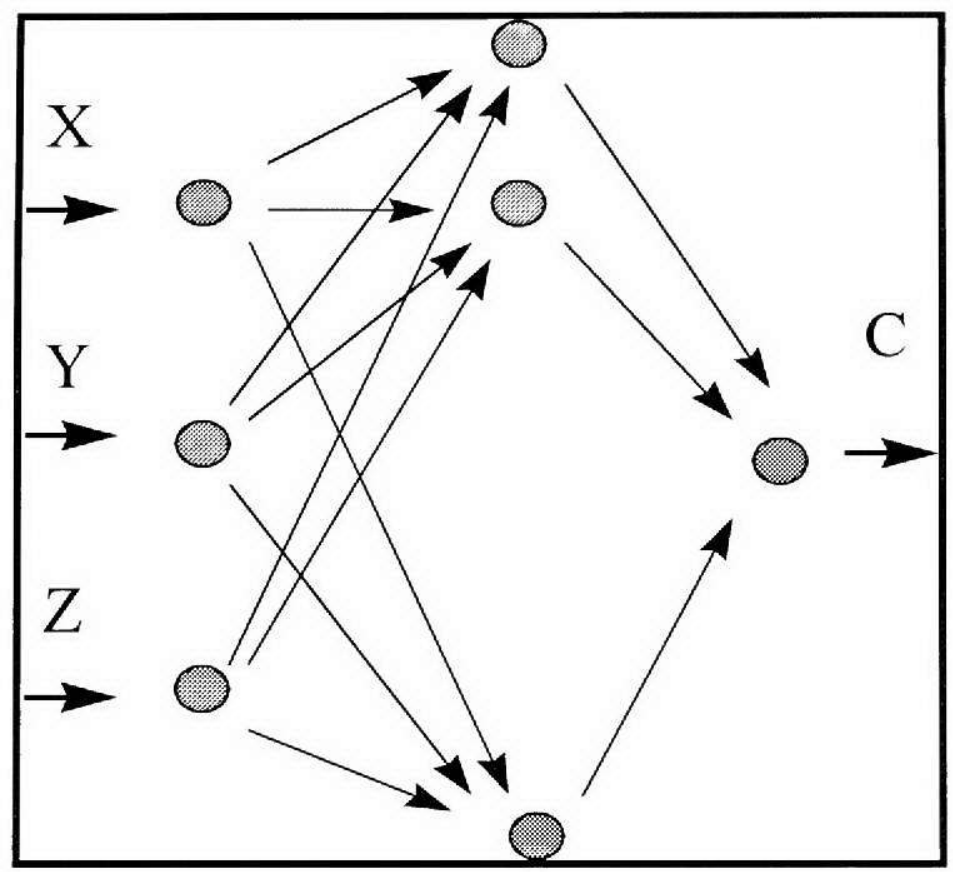

Figure 1. Backpropagation type of neural network

\section{II.3.2. Probabilistic Neural Networks (PNN)}

Probabilistic neural networks are based on the distribution theory and Bayes' theorem. It is a statistical model and it assumes that general information is obeyed a normal distribution and uses the Bayes' theorem to assume the prior probabilities, PNN optimizes the distribution model factors (mean and standard deviation) by using judge the post probabilities. There are two problems in this kind of model. First one is the time independent information problem and the other is normal distribution. It is difficult process in small sample information cases and non-normal distribution information cases. Figure 2 represents the structure of a PNN. For each training case, one neuron is assigned to the pattern layer. Pattern layer neurons create an output according to the distance between the input and the training case they represent. There is one summation neuron 
for each class. In this type of neural networks, training is very fast compared to BP, however, the size of the network could be too large, if there are too many training cases. In PNN, for each training case, one neuron is assigned to the pattern layer. Pattern layer neurons create an output according to the distance between the input and the training case they represent. There is one summation neuron for each class.

There are two kinds of PNN used in this study PNN Basic and PNN SEPVAR [25]. The PNN Basic is the simplest probabilistic neural network. One sigma is used to cover all variables. Training is the fastest of all PNN models, but quality is usually lowest. The PNN Sepvar uses a separate sigma for each variable. During the training phase, this model is identical to the Basic (single sigma model).

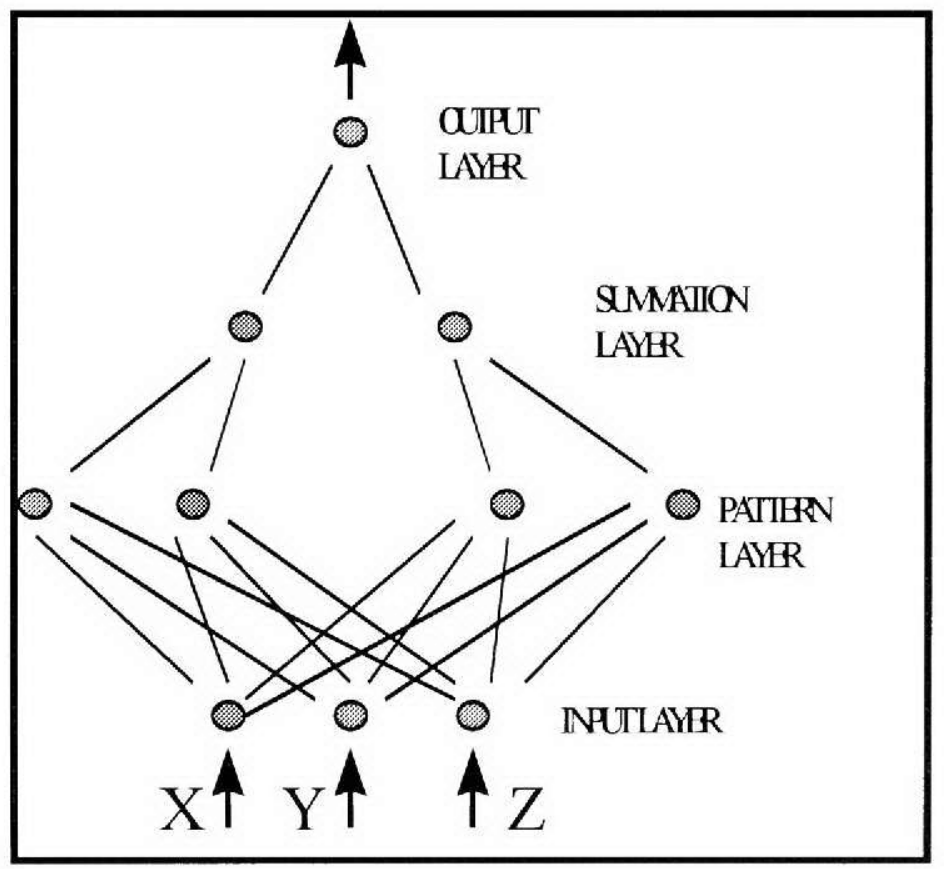

Figure 2. PNN type of neural network 


\section{II.4. Wavelet Transformations}

The wavelet transformation analysis is based on particular curves called wavelets. In the recent years, new families of orthonormal basis functions have been discovered that lead to transformations, which can translate a time-domain function into a representation that is localized not only in frequency, but in time as well (39).

There are two basic functions that form the core of the wavelet transformation. The scaling function $\Phi(t)$, (also called dilation function or fundamental recursion) and the basic (or primary wavelet) $\Psi_{\mathrm{i}, \mathrm{j}}(t)$ shown below:

$$
\begin{aligned}
& \Phi(t)=\sum_{j \in Z} a_{j} \Phi(2 t-j) \\
& \Psi_{i, j}(t)=\sum_{j \in Z}\left(-1^{j}\right) a_{j+1} \Phi(2 t+j)
\end{aligned}
$$

Where the parameter $j$ controls the compression-expansion in time scale and amplitude, and $k$ controls the translation of the function in time. The set of fundamental functions defined by $\Phi(t)$ and $\Psi_{\mathrm{i}, j}(t)$ is a system of scaled and translated wavelets.

This orthonormal basis of functions, called wavelets, can be combined to represent any given signal $f(t)$ by translating and scaling a custom designed mother wave $(40,41)$. The original $f(t)$ function can be calculated according to the following expression:

$$
f(t)=\sum_{n=-\infty}^{\infty} c(n) \Phi_{n}(t)+\sum_{i=0}^{\infty} \sum_{j=-\infty}^{\infty} d(i, j) \Psi_{i, j}(t)
$$


Where the coefficients $c(n)$ and $d(i, j)$ can be calculated by using the following expressions

$$
\begin{aligned}
& c(n)=\int f(t) \Phi_{n}(t) d t \\
& d(i, j)=\int f(t) \Psi_{i j}(t) d t
\end{aligned}
$$

Here the $c(n)$ are the approximation coefficients. They represent the approximation of the original signal $f(t)$, with a resolution of one point per every $2^{n}$ points of the original signal. The $d(i, j)$ coefficients are called the detail coefficients of the wavelet transform. They represent details of the original signal at different levels of resolution.

It can be said that, the wavelet transformation is the process of determining the values of the $\mathrm{c}(n)$ and $d(i, j)$ coefficients, for a given $f(t)$ and a chosen wavelet system (39) 1992). 


\section{II.5. Static and Dynamic Characteristics of Micro-Tools}

The relationship between the cutting force and tool displacement can be represented with a simple coefficient (static) or a transfer function (dynamic) depending on the considered frequency range. This relationship is important to evaluate the accuracy of cutting and tool breakage probability. The static relationship can be obtained easily by using least squares method. Frequency and time-domain techniques can be used effectively to obtain the dynamic characteristics. Frequency-domain techniques may perfect their frequency response estimation by averaging the spectrums of incoming data many times if the data set is long enough $(5,000$ or more). Frequency-domain identification techniques have been widely used today for the experimental investigation of the dynamic characteristics of planes, buildings, machine tools, and many other systems thanks to dedicated Fast Fourier Transformation (FFT) hardware of the real-time analyzers. However, the resolution and accuracy of frequency-domain methods are limited if the data sequence is short (less than 500 points). For short data sequences time-domain methods work effectively without lowering resolution, having leakage-related errors, and having noise-related fluctuations. It is possible to estimate the dynamic characteristics from the estimated parameters of these methods. Autoregressive Vector (ARV) models have been used on simulated and experimental data.

The Recursive Multichannel Maximum Entropy Method (RMMEM) is a fast ARV model estimation technique and has been used for the estimation of the frequency response of the metal cutting process, structural dynamics, and unified transfer functions (which represent both cutting and structural dynamics) of machining operations. The RMMEM starts from a first-order model and estimates the parameters of all the ARV models up to 
desired highest order. The main advantages of the RMMEM are its computational speed and acceptable accuracy (less than $10 \%$ frequency response estimation error for a 3 degrees-of-freedom [DOF] system).

The Autoregressive model of a one-output system is written as:

$$
y(i)=\sum_{k=1}^{n} \phi_{k} y(i-k)
$$

where the $y(i)$ is the output of a system, and $n$ is the order of the Autoregressive (AR) model. Burg has proposed the Maximum Entropy Method (MEM) for the estimation of the $\phi_{\mathrm{k}}$ AR parameters by minimizing the forward and backward prediction errors.

For multi-input systems, Autoregressive Vector (ARV) models can be used to identify multi- input and multi-output systems. The ARV model of a system with one output and several inputs can be written as:

$$
\underline{\mathrm{u}(\mathrm{i})}=\sum_{\mathrm{k}=1}^{\mathrm{n}} \Phi_{\mathrm{k}} \underline{\mathrm{u}(\mathrm{i}-\mathrm{k})}
$$

where,

$$
\begin{aligned}
& \underline{u}(\mathrm{i})=\left[\mathrm{y}(\mathrm{i}), \mathrm{x}_{1}(\mathrm{i}), \mathrm{x}_{2}(\mathrm{i}), \ldots \ldots \mathrm{x}_{\mathrm{m}}(\mathrm{i})\right]^{\mathrm{T}} \\
& \Phi_{\mathrm{k}}: \text { parameters },(\mathrm{m}+1) *(\mathrm{~m}+1) \text { matrix } \\
& \mathrm{y}(\mathrm{i}): \text { output } \\
& \mathrm{x}_{1}(\mathrm{i}), \mathrm{x}_{2}(\mathrm{i}), \ldots \ldots \mathrm{x}_{\mathrm{m}}(\mathrm{i}): 1 \mathrm{st}, 2 \mathrm{nd} \ldots \mathrm{mth} \text { inputs } \\
& \mathrm{m} \text { : number of inputs } \\
& \mathrm{n} \text { : order of the model }
\end{aligned}
$$


Or for a one-input/one-output system, the same model can be written as:

$$
\left|\begin{array}{r}
\mathrm{y}(i) \\
\mathrm{x}_{1}(i)
\end{array}\right|=\sum_{\mathrm{k}=1}^{\mathrm{n}}\left|\begin{array}{ll}
\phi_{\mathrm{k} 11} & \phi_{\mathrm{k} 12} \\
\phi_{\mathrm{k} 21} & \phi_{\mathrm{k} 22}
\end{array}\right|\left|\begin{array}{l}
\mathrm{y}(i-\mathrm{k}) \\
\mathrm{x}_{1}(i-\mathrm{k})
\end{array}\right|
$$

If the input $\left[\mathrm{x}_{1}(\mathrm{i})\right]$ and the output $[\mathrm{y}(\mathrm{i})]$ of a system are known, the $\phi_{\mathrm{k}}$ parameter matrices can be estimated for various approaches.

The RMMEM was used to obtain the frequency response (dynamic behavior) of microtools in this study.

\section{II.6. On-line Monitoring of Tool Condition during Cutting Operations}

Tool condition monitoring is based on tool wear measuring during cutting operation. Tool wear measuring techniques fall into two categories: direct and indirect. The direct method which is also called off-line monitoring involves optical measurement of wear, such as by periodically observing changes in tool profile. This is the most common and reliable technique and is done using a microscope. This procedure, however, requires that cutting operation be stopped which is not suitable for industrial applications. Indirect methods, which are also called on-line methods, to measure the wear involve the correlation of wear with process variables such as forces, AE, power, temperature rise, surface finish, and vibrations. Since the direct observation methods interrupt the machining operation, increase the cost; implementing on-line methods for 
monitoring the tool wear, is more attractive. [37]. Table 2 listed below summarizes the general techniques used for tool condition monitoring for machining operations.

\section{II.6.1. Wear - Cutting Force Relationship in Micro-Machining Operations}

[Tool Breakage Mechanism and Wear Induced Stress (WIS) Relation]

Conventional tools wear out gradually and the quality of surface finish deteriorates. It is beneficial to estimate wear and to change these tools before the surface quality and accuracy become unacceptable. On the other hand, the life of micro-tools is very short and unpredictable. Touching them with a prop similar to conventional tool inspection methods cannot be used to inspect the condition of these tiny tools. In previous studies, chip clogging was observed as the main cause of tool breakage in micro-drilling operations for some materials [36]. Tool breakage mechanism can be investigated during machining of different workpiece materials by evaluating the cutting force data.

Various changes occur on cutting tool, while they are used for machining operations. Some of these changes are loss of tool material, deposition of small workpiece particles on tool surfaces and change of tool geometry with deflection. Microscopic damages at the cutting edges, gradually developing dullness, filling of the empty spaces around the cutting edges with deposition of small particles can be also be considered as wear. The relation between these changes (wear) and the related stress variation at the tool shaft was called Wear Induced Stress (WIS). The WIS causes tool failure as a result of excessive stress beyond the strength of shaft or fatigue depending on the magnitude of the cutting force. 
If a chip clogging occurs, cutting forces and stresses increase beyond the endurance limit of the tool and breakage will occur in a few rotations. In such a case, a sharp increase is expected at the cutting force. Tool wear does not have any influence on the breakage mechanism. Breakage is very unpredictable and fast. It is almost impossible to predict chip clogging ahead of time.

WIS causes fatigue-related breakage if the cutting force and stress (at the tool shaft) increase for a while as a result of tool wear, but they stay at a constant level. The stress is below the endurance limit of the shaft, but it is above the normal level. The tool will not be broken immediately. It will be deflected in the opposite direction to the feed while it is rotating. This means that the stress and strain distribution will be periodically change at the tool shaft and create fatigue. The increase of cutting force in the feed direction beyond the normal force range will indicate the existence of WIS. The tool will eventually break with fatigue.

The breakage happens very quickly if the wear related problems are extensive and the cutting force continuously increases beyond the strength of the tool. For example, if the cutting edges of the tool are partially damaged or deposition of workpiece particles filled the tiny groves (or build-up edge is created), metal removal rate decreases. In this case, the cutting edges cannot remove enough material to open satisfactory space for the central section (shaft) of the tool. The workpiece starts to push the shaft of the tool against the workpiece and it deflects. The workpiece will push the tool a little more at each rotation and a linear increase is expected at the absolute value of the static part of the feed direction force until the tool breaks. The main reason of breakage in this case is the excessive stress beyond the endurance limit of the tool. [26, 27, 28, 29] 
Table 2. Tool wear-sensing methods

\begin{tabular}{|c|c|c|c|}
\hline & Procedure & Measurement & Transducer \\
\hline \multirow{6}{*}{ Direct } & Optical $[7,32]$ & $\begin{array}{l}\text { Shape or position of } \\
\text { cutting edge }\end{array}$ & $\begin{array}{l}\text { TV camera, optical } \\
\text { transducer }\end{array}$ \\
\hline & & & \\
\hline & $\begin{array}{l}\text { Wear particles and } \\
\text { radioactivity }\end{array}$ & $\begin{array}{l}\text { Particle size and } \\
\text { concentration }\end{array}$ & $\begin{array}{l}\text { Spectrophotometer, } \\
\text { scintillator }\end{array}$ \\
\hline & $\begin{array}{l}\text { Tool/work junction } \\
\text { resistance }\end{array}$ & $\begin{array}{l}\text { Changes of junction } \\
\text { resistance }\end{array}$ & Voltmeter \\
\hline & Workpiece size & $\begin{array}{l}\text { Dimension of } \\
\text { workpiece }\end{array}$ & $\begin{array}{l}\text { Micrometer, optical, } \\
\text { pneumatic, ultrasonic, } \\
\text { electromagnetic } \\
\text { transducers }\end{array}$ \\
\hline & Tool/work distance & $\begin{array}{l}\text { Distance of workpiece } \\
\text { and tool or tool holder }\end{array}$ & $\begin{array}{l}\text { Micrometer, } \\
\text { pneumatic gauge, } \\
\text { displacement } \\
\text { transducer }\end{array}$ \\
\hline \multirow{8}{*}{ Indirect } & Cutting force $[1,6]$ & $\begin{array}{l}\text { Changes of cutting } \\
\text { force }\end{array}$ & $\begin{array}{l}\text { Dynamometer, strain } \\
\text { gauges }\end{array}$ \\
\hline & Acoustic emission [20] & Stress wave energy & $\mathrm{AE}$ transducer \\
\hline & Sound & Acoustic waves & Microphone \\
\hline & Light reflection & $\begin{array}{l}\text { Reflection by cutting } \\
\text { edge }\end{array}$ & Phototransistor \\
\hline & Vibration [34] & $\begin{array}{l}\text { Vibration of tools } \\
\text { and/or tool posts }\end{array}$ & Accelerometer \\
\hline & Temperature [35] & $\begin{array}{l}\text { Variation of cutting } \\
\text { temperature on tool }\end{array}$ & $\begin{array}{l}\text { Thermocouple, } \\
\text { pyrometer }\end{array}$ \\
\hline & Power input [36] & $\begin{array}{l}\text { Power or current } \\
\text { consumption of spindle } \\
\text { or feed motor }\end{array}$ & $\begin{array}{l}\text { Ampere meter, } \\
\text { dynamometer }\end{array}$ \\
\hline & $\begin{array}{l}\text { Roughness of machined } \\
\text { surface }\end{array}$ & $\begin{array}{l}\text { Changes in surface } \\
\text { roughness of workpiece }\end{array}$ & $\begin{array}{l}\text { Mechanical stylus, } \\
\text { optical transducer }\end{array}$ \\
\hline
\end{tabular}




\section{Chapter III}

\section{Selection of Cutting Conditions and Monitoring of Tool Wear for}

\section{Industrial Applications}

In this chapter, a new machinability test and wear estimation methods are proposed for micro-tools. This new analysis technique requires less experiment and it is accurate.

\section{III.1. A New Method for Machinability Analysis}

In conventional milling operations, the main goal is to reduce the cost, to improve the quality and to increase the productivity. Various databases, machinability handbooks and experienced operators are available to select optimal tool conditions in conventional cutting operations with bigger then $1 / 4$ inch diameter tools. In the case of micro machining, the main goal is to prevent the premature tool breakage. The life of micro tools is very unpredictable. Since the machinability handbooks are prepared with other goals, they cannot be used directly for micro-machining applications.

A new method is proposed to select optimal conditions to machine graphite electrodes used in electric discharge machining, special injection molding steel and aluminum workpieces, with High Speed Steel (HSS) and Carbide cutting tools from $0.020-0.0625$ inches diameter. The architecture and process flow diagram of the proposed method is presented in Figure 3 and 4. Experiments were repeated until the most aggressive cutting conditions, which have static cutting force below the critical values observed with static test. Then tool life is evaluated with a new micro-tool. 

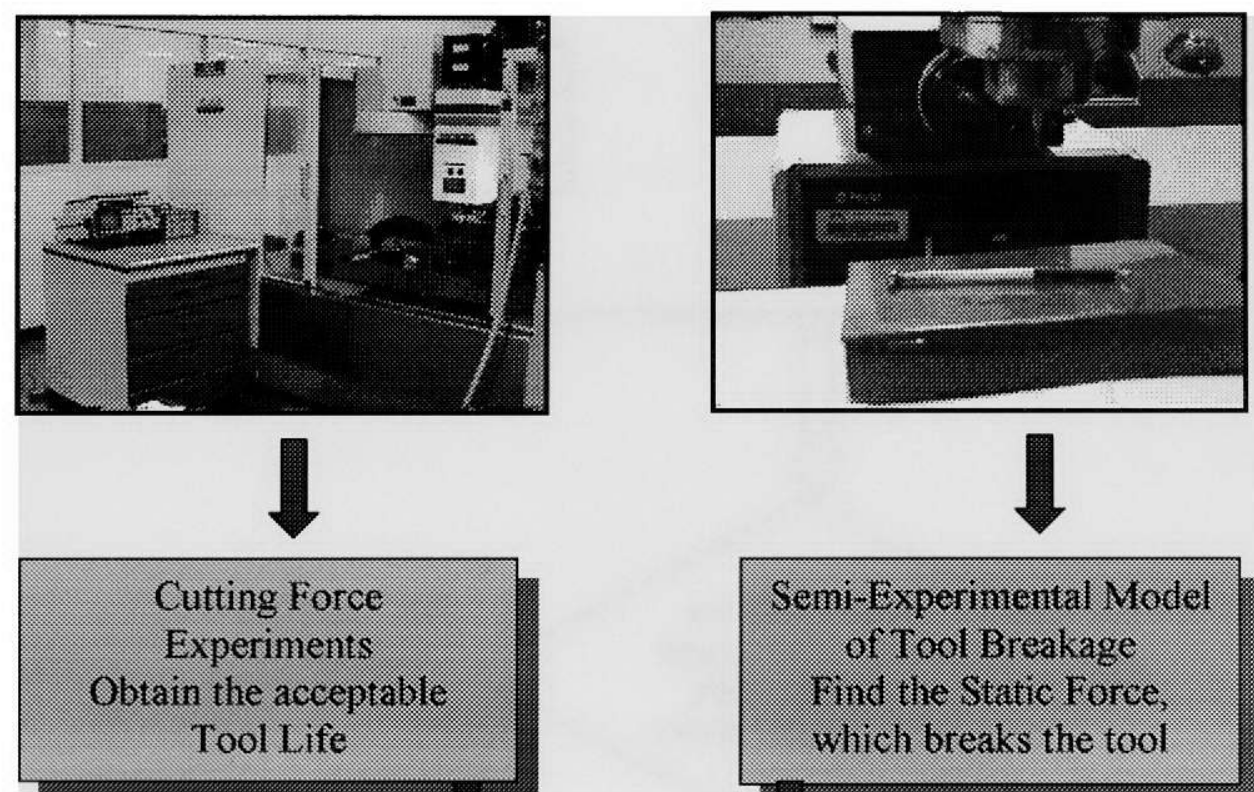

Semi-Experinental Model of Tool Breakage Find the Static Force: which breaks the tool

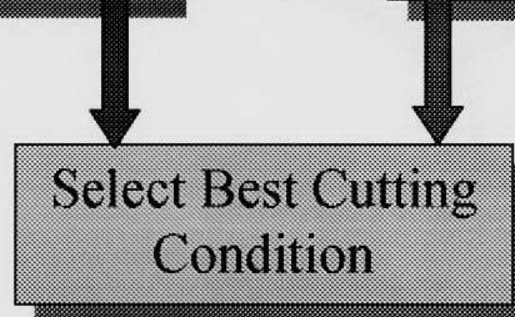

Figure 3. Proposed Machinability Method 
Figure 4. Flow Diagram of the New Machinability Method

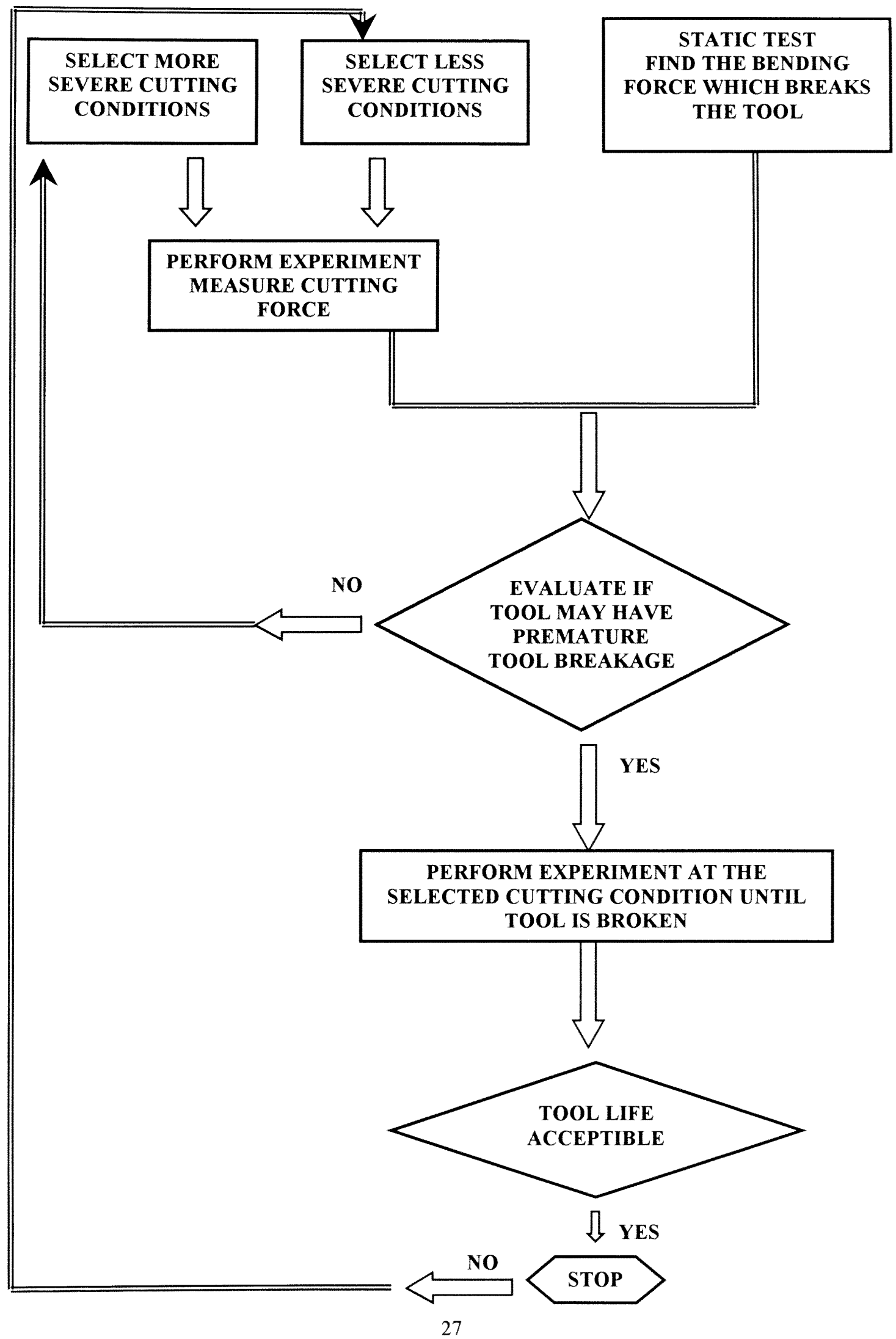




\section{III.2. Studied Static and Dynamic Behaviors of Micro-Tools}

The new machinability method required the testing of the static maximum allowable bending force. For this reasons a series of experiments were performed. HSS and Carbide end-mills were deflected with a bending force to obtain the stiffness of the tools. All workpiece-tools combinations were tested to evaluate the effect of workpiece hardness on tool deflection. High-Speed Steel and Carbide tools have very different material proprieties and stiffness. The main goal of the static test realized was to obtain the allowable maximum bending force, which can be applied to the tool.

A series of impact tests also were conducted to study the dynamic behavior of the tools. The goal was to find the natural frequency of the micro-tools. The results obtained from the static and dynamic behavior of the tools were used for the developed new machinability method. Static and dynamic experiments were performed on a Bridgeport Milling Machine. Tool was not rotating in these experiments. Figure 5 presents the experimental setup. 


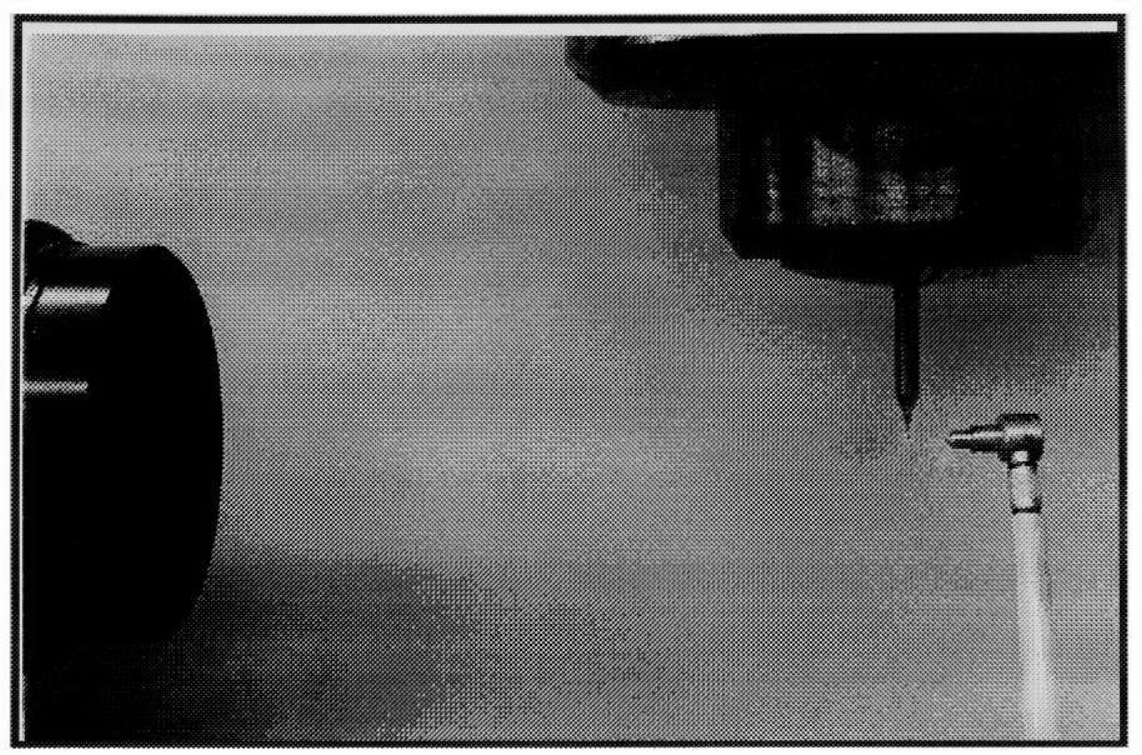

Figure 5. Laser Vibrometer and the Impact Hammer during the Dynamic Behavior Study Experiment

\section{III.3. Development of an Estimation Method for Tool Wear Monitoring [Estimation of Wear by Using Neural Networks ( $\left.\mathrm{N}^{2} \mathrm{PTI}\right)$ ]}

Micro-end mills with less than 2-mm diameter have a short and unpredictable tool life [30]. However, it is possible to use these tools for hours when non-metal materials such as plastics and electrodes are machined by using conservative cutting conditions. After a long machining operation, micro-tools wear out, lose material, and their dimensions change. The quality of the surface finish deteriorates, burr is created, and the dimensional accuracy of the manufactured parts is ruined when the tool is very badly worn out. The Neural Network based Periodic Tool Inspector $\left(\mathrm{N}^{2} \mathrm{PTI}\right)$ is introduced in this section. The $\mathrm{N}^{2} \mathrm{PTI}$ requires the tool to cut a test piece, which is attached to a 
dynamometer. The variation of the feed and thrust direction cutting force is measured while the test piece is cut. Neural networks estimate the tool's wear from these two inputs. (Figure 6) The performances of three different networks are discussed in this section.

The $\mathrm{N}^{2} \mathrm{PTI}$ was developed with the following goals:

- To have the cutting force signal of micro machining with an acceptable $\mathrm{S} / \mathrm{N}$ ratio. Typically the cutting forces are very small when the electrodes and plastic materials are cut. The inertia forces are almost equal or larger than the cutting forces. The Signal-toNoise $(\mathrm{S} / \mathrm{N})$ ratio of the cutting force readings is very low. The material of the test piece and the cutting conditions can be selected to have the cutting forces at least two or three times larger than the inertia forces.

- To have a low cost, reliable system convenient for industrial applications: The characteristics of the cutting forces continuously change during the machining of a workpiece if the metal removal rate and machining parameters change. The $\mathrm{N}^{2} \mathrm{PTI}$ uses a test piece and cuts the material exactly at the same cutting conditions. In this test, the characteristics of the cutting forces are only affected by the tool wear. The encoding and interpretation of the signal becomes much simpler and the cost of the system is reduced. 


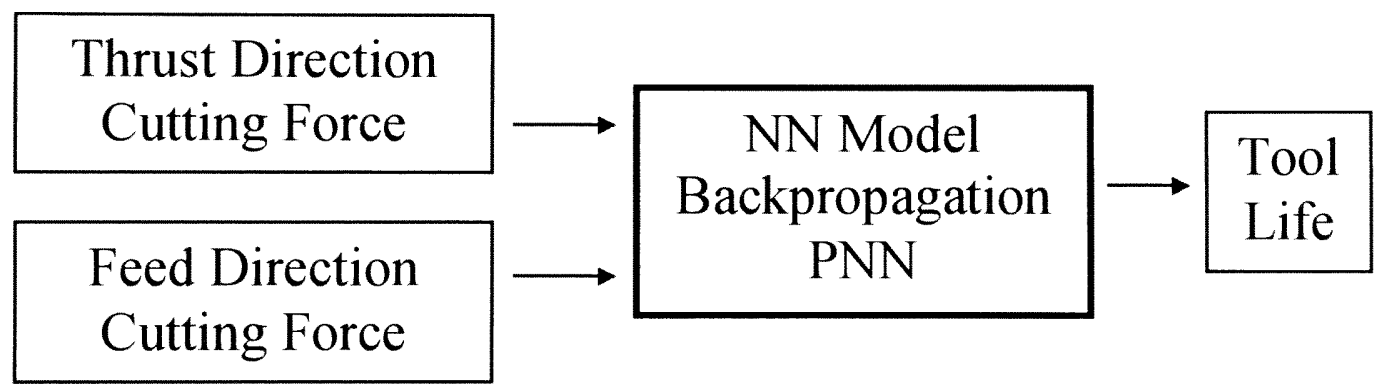

Figure 6. Neural Network Training Model

The operation of the $\mathrm{N}^{2} \mathrm{PTI}$ is outlined in Figure 7. The $\mathrm{N}^{2} \mathrm{PTI}$ evaluates the tool wear with periodic intervals. The workpiece is attached to the table of the milling machine. A test piece is installed on a dynamometer, which is attached to the table next to workpiece. The user prepares the part program to cut the workpiece and periodically move the tool to the test piece to cut a slot on it. The feed and thrust direction cutting forces are measured while the test piece is cut. The difference of the measured average maximum and minimum cutting forces are given to the neural network. In the rest of the study this difference will be called variation. The neural network is run first during the training, and later in the testing mode. During the training mode two inputs (feed and thrust direction cutting force variation) and one output (the tool life) are given to the network. The network establishes a model between the inputs and the outputs. In the testing mode only 
two inputs are given to the network. The network estimates the tool life by inspecting the variation of the feed and thrust direction cutting force variations.

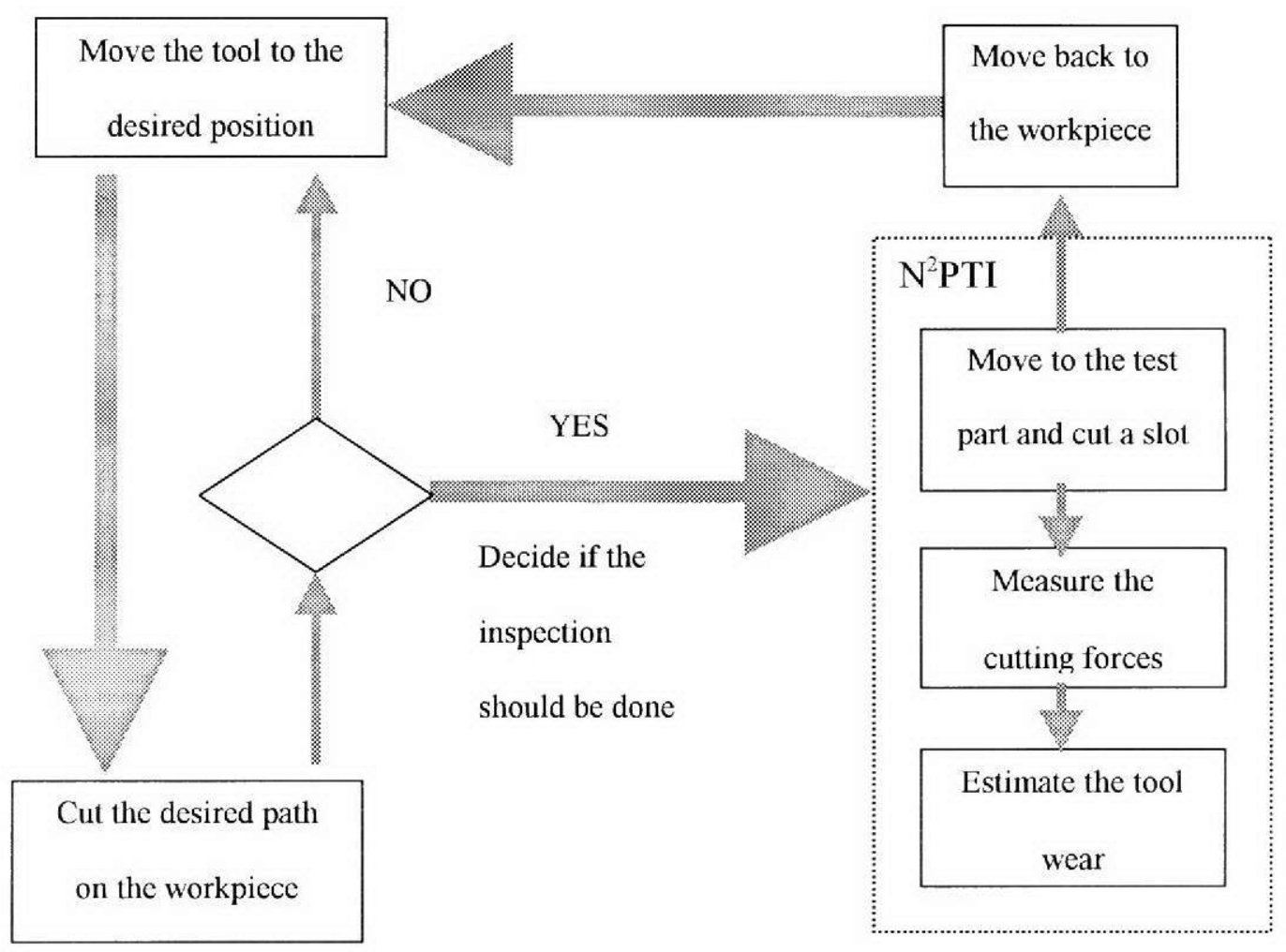

Figure 7. Operation of $\mathrm{N}^{2} \mathrm{PTI}$ 


\section{III.4. Improvement of the Neural Network based Periodic Tool Inspector}

Neural Network Based Tool Inspector was designed to work with the amplitude of the cutting forces. The network was trained with the amplitude of the cutting forces in $X$ (Thrust) and $Y$ (Feed) directions. The $\mathrm{N}^{2} \mathrm{PTI}$ could work for only at the specific spindle speed, feed rate and depth of cut. To improve the capability of the $\mathrm{N}^{2} \mathrm{PTI}$, a new approach is proposed. The new approach estimates the tool wear by evaluating the relationship between the $X$ and $Y$ direction cutting forces and eliminates the dependence of the method to constant depth of cut. The new procedure can work with two different techniques to select the parameters for the neural network training:

\section{Segmental Averaging:}

The new procedure first finds the maximum cutting force for each period which corresponds to one revolution. The data is averaged for a certain number of points (up to the spindle speed and sampling frequency of the digital oscilloscope) between the maximum value of the first period and the one in the second period. After the averaging, 10 local parameters are obtained to represent the cutting forces in each direction. The parameters are normalized, by dividing them by the maximum parameter. After normalization, all the parameters are between 1 and 0 .

\section{Wavelet Transformation:}

To obtain the local parameters that will represent the data profile better, wavelet transformation is also used. Data is given to wavelet and 64 coefficients are chosen for transformation. Data can only be given as number of $2^{\mathrm{n}}$ to wavelet. 2048 and 1024 data points are used for the analysis. After wavelet transformation, 64 coefficients, which represent best the original signal, are obtained and the inverse wavelet transformation is 
taken. Cutting force data is filtered of noise after wavelet transformation. One period is presented with 8 local parameters. The parameters are normalized by dividing them by the maximum parameter.

The parameters obtained with wavelet transformation are more precise than local avearging to represent the original collected cutting force data 


\section{Chapter IV}

\section{Experimental Set-Up and Procedures}

\section{IV.1. Cutting force - AE Data Collection for Machinability and Tool Wear Analysis}

The experiments were conducted on a Fadal 3-axis CNC Machining Center. (Figure 8) This milling machine had a maximum 50,000-rpm spindle speed. The microtools used during the work had 1/16, 1/32 and 0.020 inches diameter. High Speed Steel (HSS) and Carbide tools were used. Three different workpiece materials were cut:

1. Graphite Electrodes used in electric discharge machining (POCO-3, POCOEDMC-3)

2. Aluminum

3. Steel (NAK55 molding steel)

The tool path generation code was generated by using SmartCAM. (Production Milling Version10)

First phase of the experiments was the machinability analysis of the workpiece materials with the developed machinability test technique. Optimal cutting conditions for each tool-workpiece combination were selected with the machinability study. Second phase of the experiments was the tool wear monitoring, This phase was conducted on the specific workpieces, which were found abrasive by the first phase or reported by the users. 


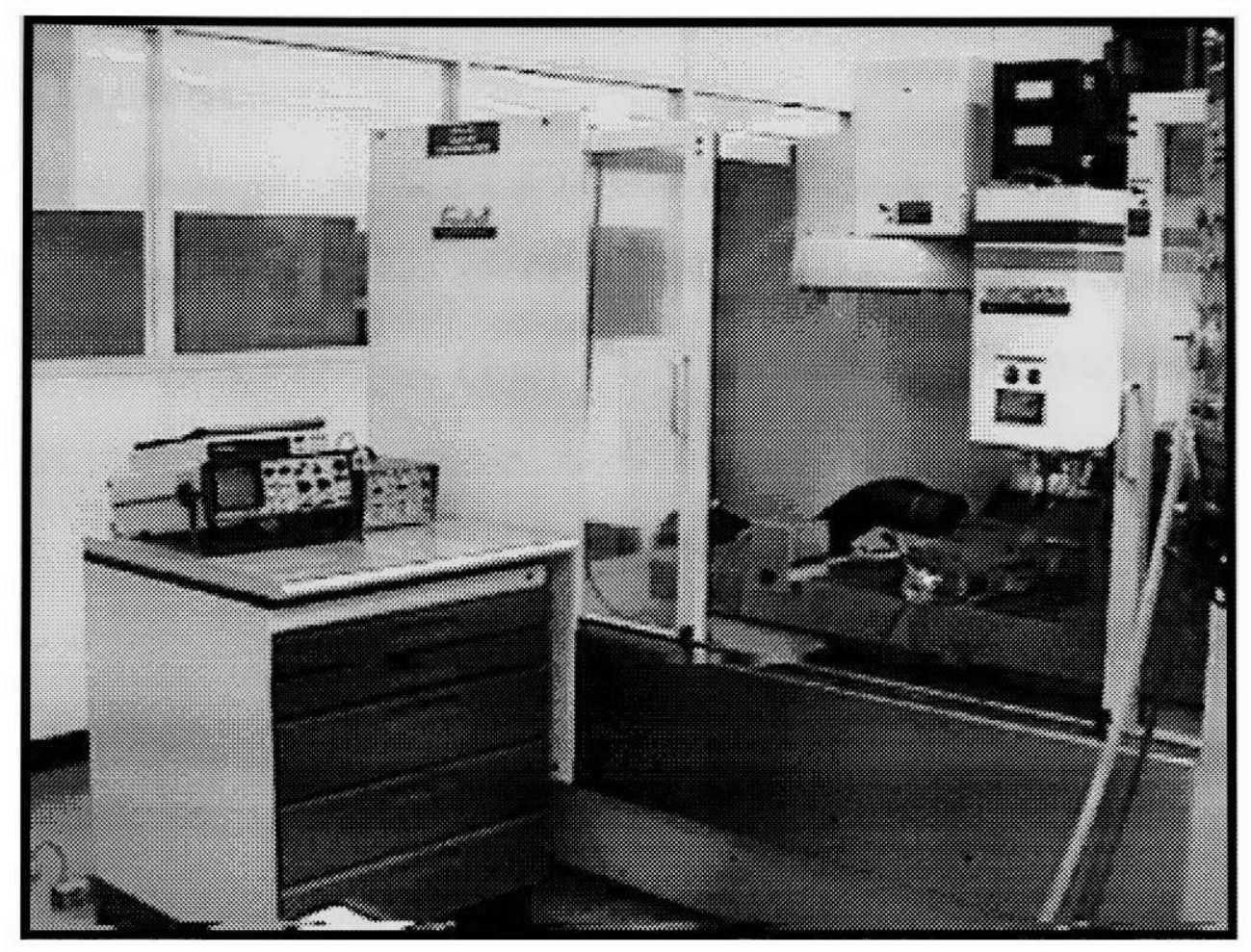

Figure 8. Experimental Setup

Cutting force data was collected with a Kistler 9257B dynamometer and Kistler three channel charge amplifier. Real time cutting force signal was digitized and recorded with a Nicolet Integra model four channel 1MS/s 12-bit digitizer and a Nicolet 310 two channels oscilloscope. Low Frequency Acoustic emission signal was collected with an AE sensor attached to the dynamometer and recorded with the same oscilloscope.

The experimental setups and procedures followed for 3 different workpiece materials are presented in the following sections: 


\section{Graphite Electrodes (POCO-3, POCOEDMC-3):}

\section{- Machinability:}

First phase of the experiments was the machinability analysis of copper implemented electrode graphite (POCO-3). This electrode is used widely in electric discharge machining operations. Electric Discharge Machining (EDM) is a process that utilizes electrical discharges or sparks, to machine any electrically conductive workpiece material, including carbide, high alloy steels and hardened metals of many types. So POCO-3 is very suitable and highly desirable electrode graphite for EDM. During electric discharge machining very high voltages are created between the workpiece and the electrode itself. The electrode is moved toward the workpiece within an ionizing fluid allowing a discharge to occur when the gap is sufficiently small. The discharge, with the aid of dielectric fluid, melts and removes metal from the workpiece. During each energy discharge stock is removed from the end and sides of the electrode as well as from the workpiece. Under normal operating conditions the stock removed from the workpiece exceeds that removed from the electrode, but the ratio of wear is different for each material. By knowing the wear ratios, it is possible to manufacture electrodes to the exact size and quantity required for a particular job. Preparation of electrodes for EDM is a very time consuming and difficult machining process due to the complexity of molds and required precision.

POCO-3 is very abrasive and very conductive copper implemented carbon graphite. The machinability analysis of POCO-3 was conducted with HSS end-mills with 0.0625 and 0.020 inch diameter. The workpiece $(3 \times 4 \times 1$ inches $)$ dimensions was clamped on the dynamometer. The dynamometer was hold by a vise that is bolted on the 
linear table of the milling machine. Dynamometer was connected to the charge amplifier, which amplifies the cutting force signal. BNC cables connected the amplifier to digital oscilloscope. Thrust $(X)$ and feed $(Y)$ direction forces were recorded. Climb milling operation was performed. (Figure 9) $50 \%$ overlapping was used in face milling of the graphite. Test conditions were listed in Table 3. Optimal cutting conditions were found after a series of experiments and used it the rest of the study.

- Tool Wear:

Second phase of the experiments with electrode was conducted on POCO EDMC3. Since POCO EDMC-3 is much more abrasive than POCO-3, it was used for wear analysis.

Workpiece moves with the same vector direction of the tool
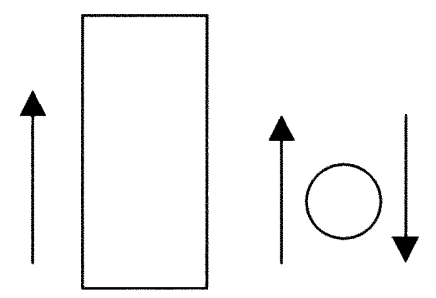

Tool turns clockwise $(\mathrm{CW})$

Figure 9. Climb Milling 
Table 3. Test Conditions for POCO-3 Machinability

\begin{tabular}{|l|c|c|}
\hline Tool type & HSS 2 Flutes End-Mill & HSS 2 Flutes End-Mill \\
\hline Tool diameter & $0.0625 \mathrm{inch}$ & $0.020 \mathrm{inch}$ \\
\hline Spindle speed & $15,000 \mathrm{rpm}$ & $15,000 \mathrm{rpm}$ \\
\hline Feed rate & $30,65,100 \mathrm{ipm}$ & $20,70,120 \mathrm{ipm}$ \\
\hline Depth of cut & $0.0625,0.1,0.15 \mathrm{inch}$ & $0.01,0.03,0.05$ inch \\
\hline Workpiece & POCO -3 & POCO -3 \\
\hline
\end{tabular}

The main purpose of this second phase work was to measure the tool wear while POCO EDMC-3 was machined. The graphite workpiece was climb milled with certain amount of passes on the face of the POCO EDMC-3 and then a slot was cut on the aluminum workpiece to record the cutting force of the tool. This process was repeated periodically until the tool got worn out. The overlapping on the graphite machining was $50 \% .0 .0625$ and 0.030 inches diameter Carbide two flute end-mills were used. The experiment was done with a brand new tool. Different cutting parameters were used on the abrasive POCO EDMC-3 and aluminum test piece. The dimensions of the POCO EDMC-3 workpiece was $(3.75 \times 8 \times 1)$. The dimensions of the aluminum test piece was $(0.5 \times 4 \times$ 0.2). The experimental setup is presented in Figure 10. Numerical control tool path generation of the experiment for the $\mathrm{CNC}$ machining center was prepared with SmartCAM (Production Milling Version 10). The cutting parameters were listed for two different diameters sized carbide end-mill in Table 4. 
Table 4. Test Conditions in POCO EDMC-3 - Tool Wear Experiments

\begin{tabular}{|l|c|c|}
\hline Tool type & Carbide 2 Flutes End-Mill & Carbide 2 Flutes End-Mill \\
\hline Tool diameter & 0.0625 inch & $0.030 \mathrm{inch}$ \\
\hline Spindle speed & $15,000 \mathrm{rpm}$ & $15,000 \mathrm{rpm}$ \\
\hline Feed rate & 5 ipm (electrode) & 5,7 ipm (Electrode) \\
& 2.5 ipm (Aluminum) & $1.25,2.5$ (Aluminum) \\
\hline Depth of cut & 0.015 inch & 0.015 (Electrode) \\
& (Both same) & 0.0075 (Aluminum) \\
\hline Workpiece & POCO EDMC -3 & POCO EDMC -3 \\
& Aluminum & Aluminum \\
\hline
\end{tabular}

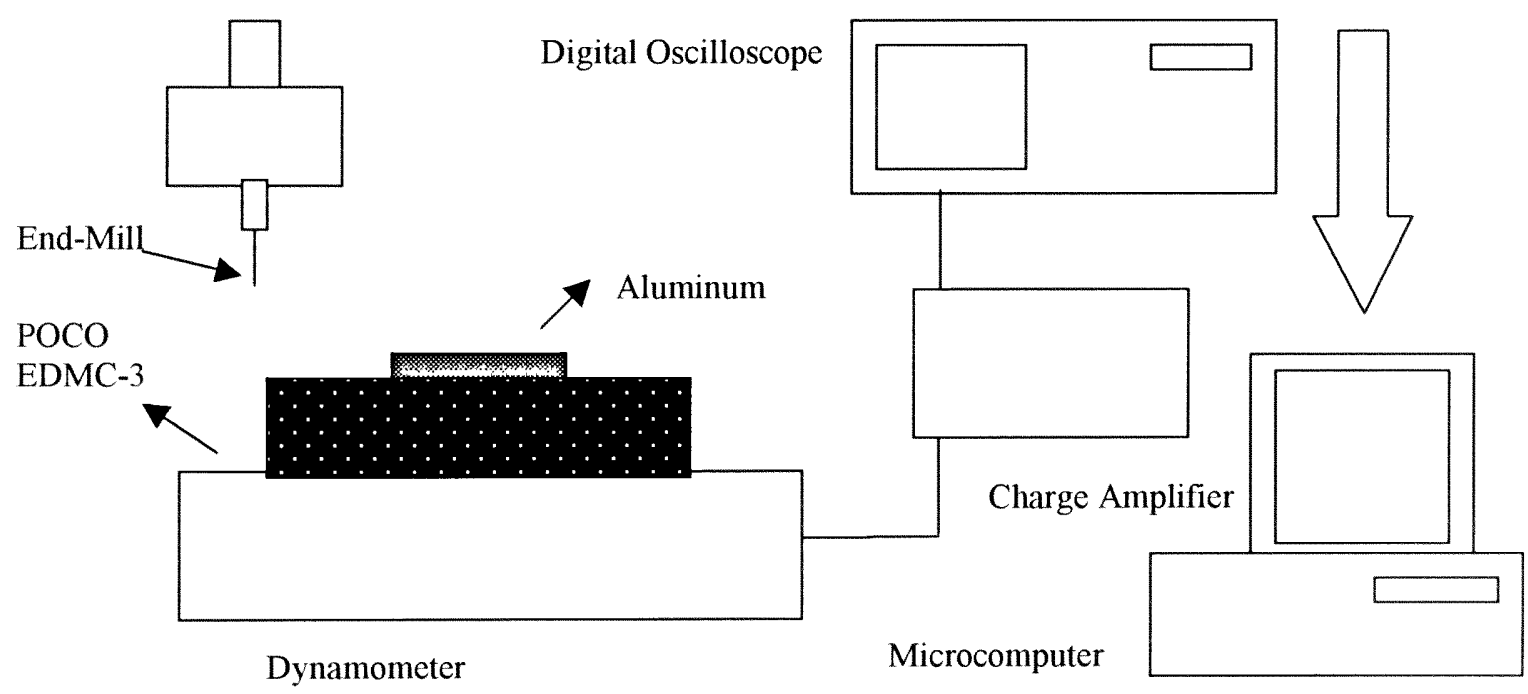

Figure 10. The diagram of the experimental set-up for Tool Wear on POCO EDMC-3 


\section{Aluminum:}

The aluminum workpiece machinability and tool wear experiments were realized within the same data collecting instruments but with different cutting tools and cutting parameters. Cutting force data on aluminum workpiece was larger than the electrode graphite and easier to monitor. For the first stage on these experiments, different cutting conditions were chosen and applied within the face milling of aluminum workpiece. Optimal cutting conditions were obtained and several experiments were repeated to analyze the machinability of aluminum with carbide 0.0625 and 0.03125 inches diameter two flute micro-end-mills. The workpiece dimensions were ( $3 \times 4 \times 1$ inches). The tests were performed, by using $50 \%$ overlapping end milling. Climb milling was used.

The cutting parameters used in the experiments for machinability of the aluminum workpiece is presented in Table 5.

Table 5. Test Conditions in Aluminum Machinability Experiments

\begin{tabular}{|l|c|c|}
\hline Tool type & Carbide 2 Flutes End-Mill & Carbide 2 Flutes End-Mill \\
\hline Tool diameter & $0.0625 \mathrm{inch}$ & $0.03125 \mathrm{inch}$ \\
\hline Spindle speed & $15,000-32,000-50,00 \mathrm{rpm}$ & $15,000-32,000-50,00 \mathrm{rpm}$ \\
\hline Feed rate & $15,22.5,30,32,48,50$, & $9,18,27,30,60,90 \mathrm{ipm}$ \\
& $64,75,100 \mathrm{ipm}$ & \\
\hline Depth of cut & $0.015,0.020,0.030 \mathrm{inch}$ & $0.015,0.020,0.030 \mathrm{inch}$ \\
\hline Workpiece & Aluminum & Aluminum \\
\hline
\end{tabular}




\section{Steel (NAK 55):}

NAK 55 is specially developed with variety of heat treatment (age hardened, not quenched and tempered) techniques for injection molding processes. It has an excellent uniformity of hardness throughout even heavy sections. Internal stresses are minimized. The chemistry of NAK 55 was specially formulated to produce the most desired features in mold steel. It is working perfectly with machining process and EDM. [International Mold Steel, Inc. 1997 Product Catalogue]

The experiment was conducted with the same experimental setup presented above except a new digital four-channel digitizer (Figure 11). Addition to the cutting force data in feed and thrust direction (2-channel record) acoustic emission signal of the cut was also collected and recorded. (1-chnanel) The steel NAK 55 workpiece $(4 \times 3 \times 1$ inches) was clamped to the dynamometer and the acoustic emission sensor was magnetically attached to the dynamometer to ensure the closest contact. The experiment was performed with a variety of cutting parameters to find out the optimal cutting conditions as spindle speed, feed rate and depth of cut for this specific workpiece NAK $55.50 \%$ overlapping, climb end milling operations were performed to monitor the force variation at different stages of the tool life. Table 6 presents the cutting conditions. 
Table 6. Test Conditions in NAK 55 Steel Machinability Experiments

\begin{tabular}{|l|c|c|}
\hline Tool type & Carbide 2 Flutes End-Mill & Carbide 2 Flutes End-Mill \\
\hline Tool diameter & 0.0625 inch & 0.0300 inch \\
\hline Spindle speed & 15,$000 ; 30,000 ; 45000$ & 15,$000 ; 30,000 ; 45000$ \\
\hline Feed rate & $1.25,2.5,5,7.5$ & $1.25,2.5,5$ \\
\hline Depth of cut & $\mathrm{d} / 2,3 \mathrm{~d} / 4, \mathrm{~d}, 1.5 \mathrm{~d}$ & $\mathrm{~d} / 2,3 \mathrm{~d} / 4, \mathrm{~d}, 1.5 \mathrm{~d}$ \\
\hline Workpiece & NAK 55 steel & NAK 55 steel \\
\hline
\end{tabular}

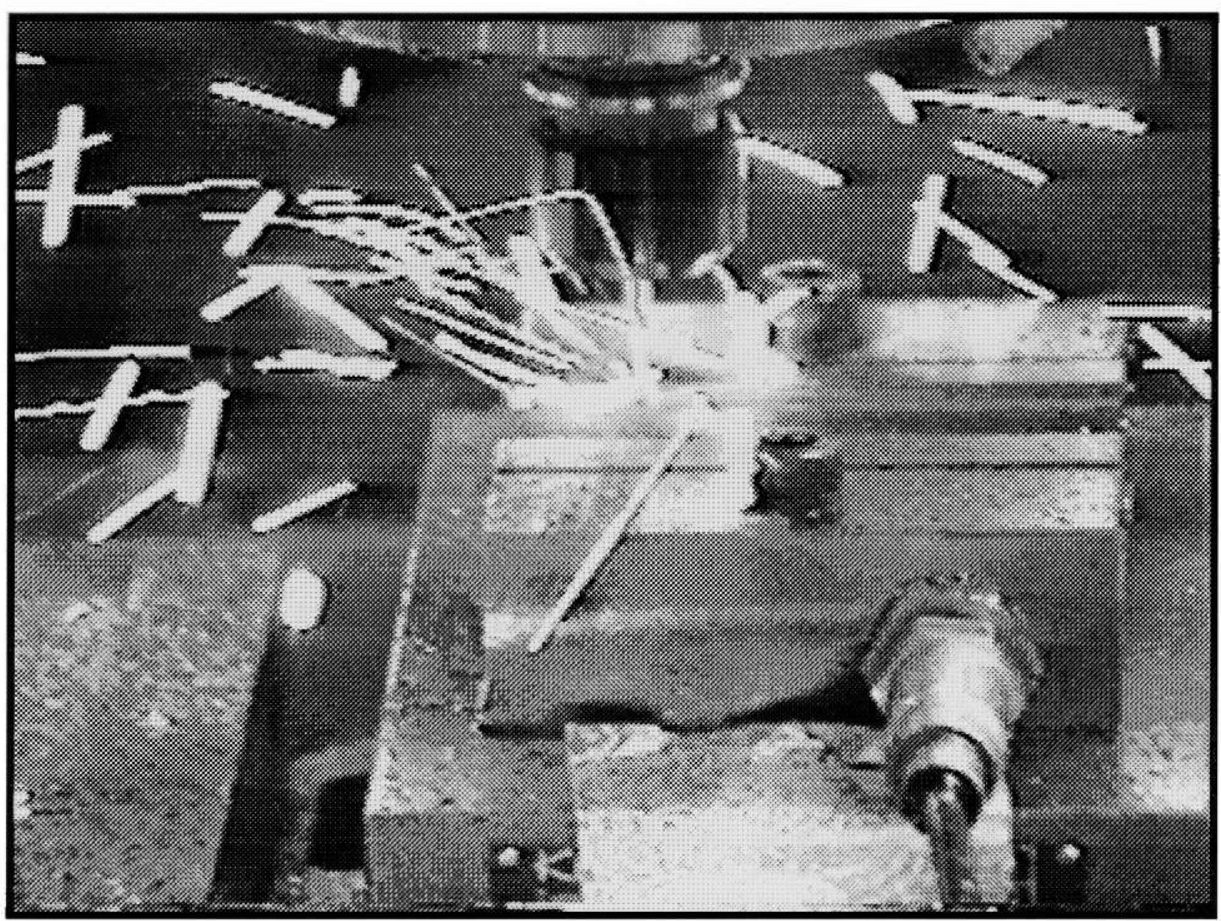

Figure 11. NAK55 Steel Workpiece Machining with 0.0625" Diameter End-Mill 


\section{IV.2. Static test}

The same kind of micro tools used in the machinability experiments were used in static test. High speed steel (HSS) and carbide $0.0625,0.03125,0.020$ inches diameter two flutes end-mills were analyzed under the static loading conditions. The tool was attached to a Bridgeport Milling machine with an end-mill holder. The workpiece was clamped to the dynamometer. The dynamometer was tightened to a vise that is fixed on the X-Y table of the milling machine. A linear displacement sensor was clamped on the vise with respect to the tool holder. The sensor supposed to measure the linear table displacement during the experiment. The sensor with its signal conditioner was connected to a Nicolet 310 digital oscilloscope. The dynamometer was connected to a charge amplifier and to the oscilloscope also. Figure 12 presents the experimental setup. Force and displacement data were collected and recorded.

Table was fed manually within the thrust direction ( $X$ direction) against the microtool applying a bending force to the tool itself. Tool was deflecting towards the same direction of the loading. Bending forces and linear displacements respectively were collected continuously until the tool broke down. Experiment was conducted with static conditions, spindle of the milling machine was off. Thrust direction bending force was recorded within the linear small displacement in $X$ direction.

Experiments were repeated with different static bending moment loading to measure the stiffness of the micro-end-mill. The collected data were analyzed and manipulated to find out the stiffness coefficient of HSS and Carbide micro-tool for the 
specified diameter and type. The bending moment loading limits of the tools also were measured with extreme loading conditions.

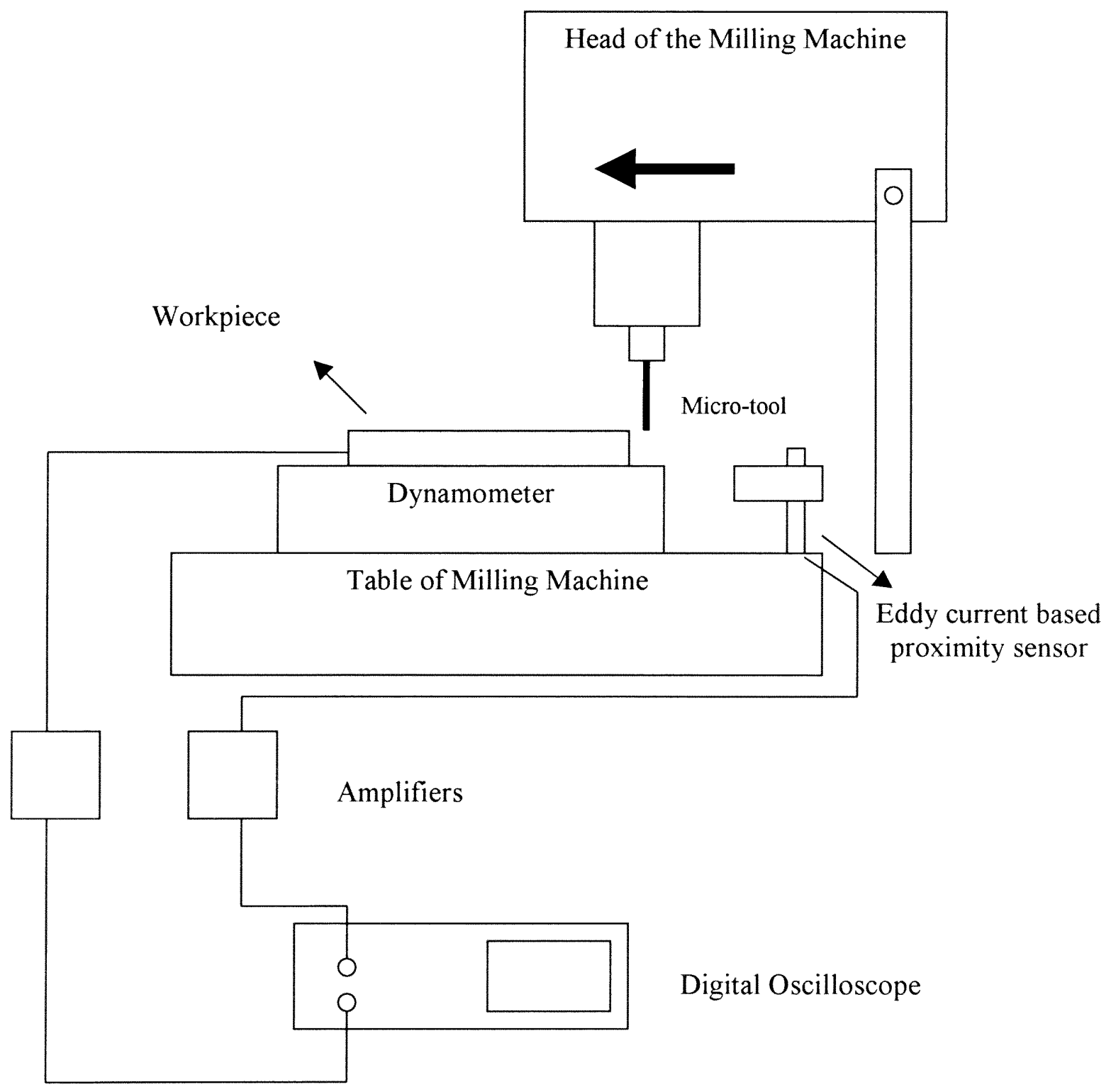

Figure 12. Static experiment of the Micro-Tool 


\section{IV.3. Dynamic test}

In order to find out the dynamic behavior of micro-tools, some experiments were conducted. HSS and Carbide $0.0625,0.02135$ and 0.020 inches diameter two flute micro end-mills were used. End-mills were connected to a Bridgeport Milling machine with a tool holder. The experimental setup is presented in Figure 13 and 14. A Polyter OFV 2500 Laser Vibrometer controller and OFV 350 Sensor Head were used to measure the vibration of the tools. As an exciter, a miniature impact-hammer used. A digital Nicolet 310 oscilloscope was used to collect and record data. Digitizer was pre-triggered to catch the input impact and the dynamic response of the tool at the same time.

The tip and the bottom of the micro end-mill were hit with the impact hammer to analyze the dynamic response. When the tool was excited, it was vibrating and the vibration was measured with a vibrometer. The vibrometer was directing a laser beam to the tip of the end-mill. Once the tip was hit with the impact hammer, the impact was digitized and recorded to the oscilloscope. The response of the tool to this excitation was a typical dynamic vibration signal. Input and output signals were recorded as 4,000 data points.

The data was studied and graphs were prepared. The dynamic characteristics of the end-mills were calculated from the variation of the output signal amplitude versus time. The natural-angular frequency and the damping factor of the tools were calculated analytically and numerically. Transfer function of the system was established with the aid of a computer program. 


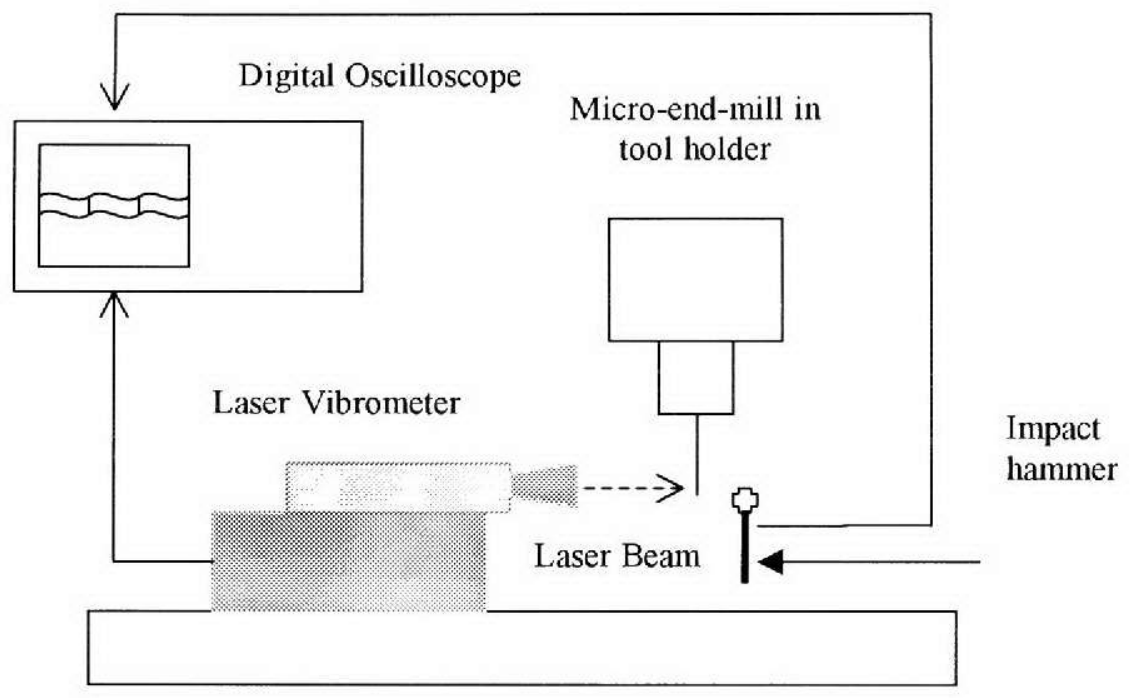

Figure 13. Dynamic Experiment of Micro-Tools

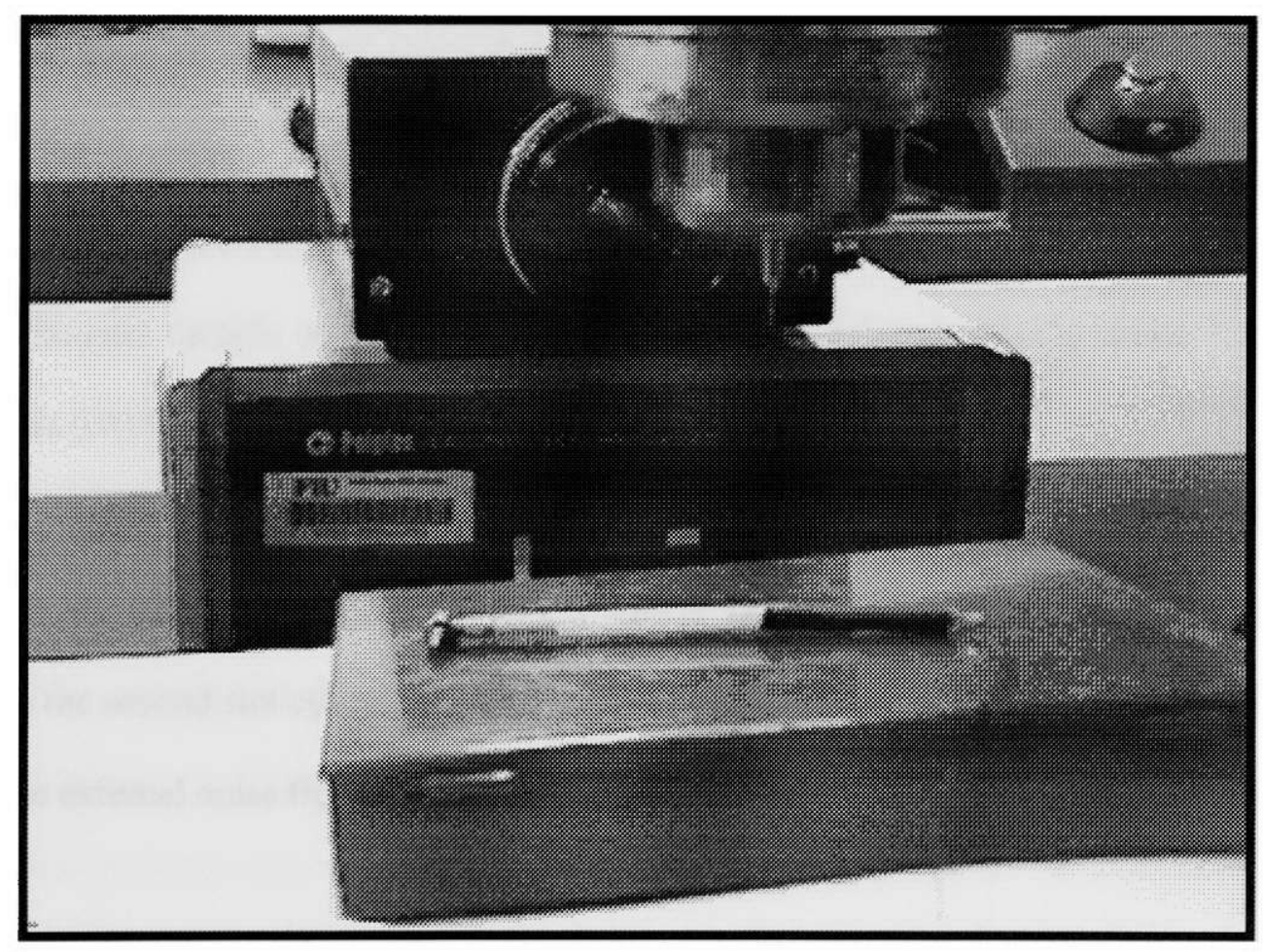

Figure 14. Experimental setup of Dynamic Test 


\section{Chapter V}

\section{Results and Discussions}

In this section, the performance of the new machinability test method, characteristics of the cutting force at different tool wear levels, the accuracy of the developed neural network based tool wear estimators are discussed.

\section{V.1. Characteristics of Cutting Force at Different Tool Wear Levels} Graphite Electrodes (POCO3, POCOEDMC-3):

A series of experiments were conducted to study the tool wear related cutting force variation during the end milling of graphite electrodes. POCO 3 and POCO EDMC-3 workpieces were used. POCOEDMC-3 was reported to be more abrasive by the users. At the first stage of the study, the optimal cutting conditions were experimentally found by using the developed procedure. Later, these cutting conditions were used to study tool wear. Table 7 shows a summary of the proposed machinability method results with $0.0625-$ inch diameter carbide end-mill for POCOEDMC-3. 15,000-rpm spindle speed, $5 \mathrm{ipm}$ feed rate and 0.015 inches depth of cut, were used in the experiments.

Figure 15 and 16 shows the thrust and feed direction cutting force after 120 inches of tool life when POCOEDMC-3 is cut with a carbide micro-tool. This is just one pass before the second slot cut on the aluminum test piece. The small magnitude of cutting force and the external noise from the machine itself make the data very difficult to interpret. 
Table 7. Results of the Proposed Machinability Method for POCOEDMC-3

\begin{tabular}{|c|c|c|c|}
\hline Experiment & $\begin{array}{c}\text { Cutting } \\
\text { Conditions } \\
\end{array}$ & $\begin{array}{l}\text { Maximum Cutting } \\
\text { Forces } \\
\end{array}$ & Acceptability \\
\hline 1 & $\begin{array}{c}15,000 \mathrm{rpm} \\
15 \mathrm{ipm} \\
0.030 \text { " doc }\end{array}$ & $\begin{array}{l}X-40 N \\
Y-25 N\end{array}$ & Tool is broken \\
\hline 2 & $\begin{array}{c}15,000 \mathrm{rpm} \\
10 \mathrm{ipm} \\
0.030 \mathrm{doc}\end{array}$ & $\begin{array}{l}X-31 N \\
Y-19 N\end{array}$ & $\begin{array}{l}\text { not acceptable } \\
\text { Tool Survived }\end{array}$ \\
\hline 4 & $\begin{array}{c}15,000 \mathrm{rpm} \\
5 \mathrm{ipm} \\
0.015 \mathrm{doc}\end{array}$ & $\begin{array}{l}X-20 N \\
Y-12 N\end{array}$ & $\begin{array}{c}\text { Tool is OK } \\
\text { Conditions are } \\
\text { optimal }\end{array}$ \\
\hline 5 & $\begin{array}{c}15,000 \mathrm{rpm} \\
7.5 \mathrm{ipm} \\
0.015 \mathrm{doc}\end{array}$ & $\begin{array}{l}X-25 N \\
Y-16 N\end{array}$ & $\begin{array}{c}\text { Tool is OK } \\
\text { conditions are severe }\end{array}$ \\
\hline
\end{tabular}

To overcome this problem, and to be able to monitor the tool wear during the machining of non-metals, an aluminum piece was used to inspect cutting force variation at different stages of tool wear. A slot was cut on the aluminum test piece. The machining operation continued on the non-metal workpiece. Periodically, aluminum test piece was cut at the same cutting conditions and cutting data was collected. The magnitude of the $X$ and $Y$ direction cutting forces had the tendency to increase as the tool began to wear out. Even without monitoring of the cutting force, tool wear could be estimated from the burr on the aluminum test piece. After the third and fourth slots on the test piece burr appeared and increased with tool wear. The carbide end-mill with $1 / 16$ inches diameter gave more consistent results than 0.030 ones. The amplitude of the cutting force increased when the tool wears out.

The pictures of the slots are presented in Figure 17, 19 and 21. The variation of the cutting force at different stages of the tool wear is presented in Figure 18, 20 and 22. 


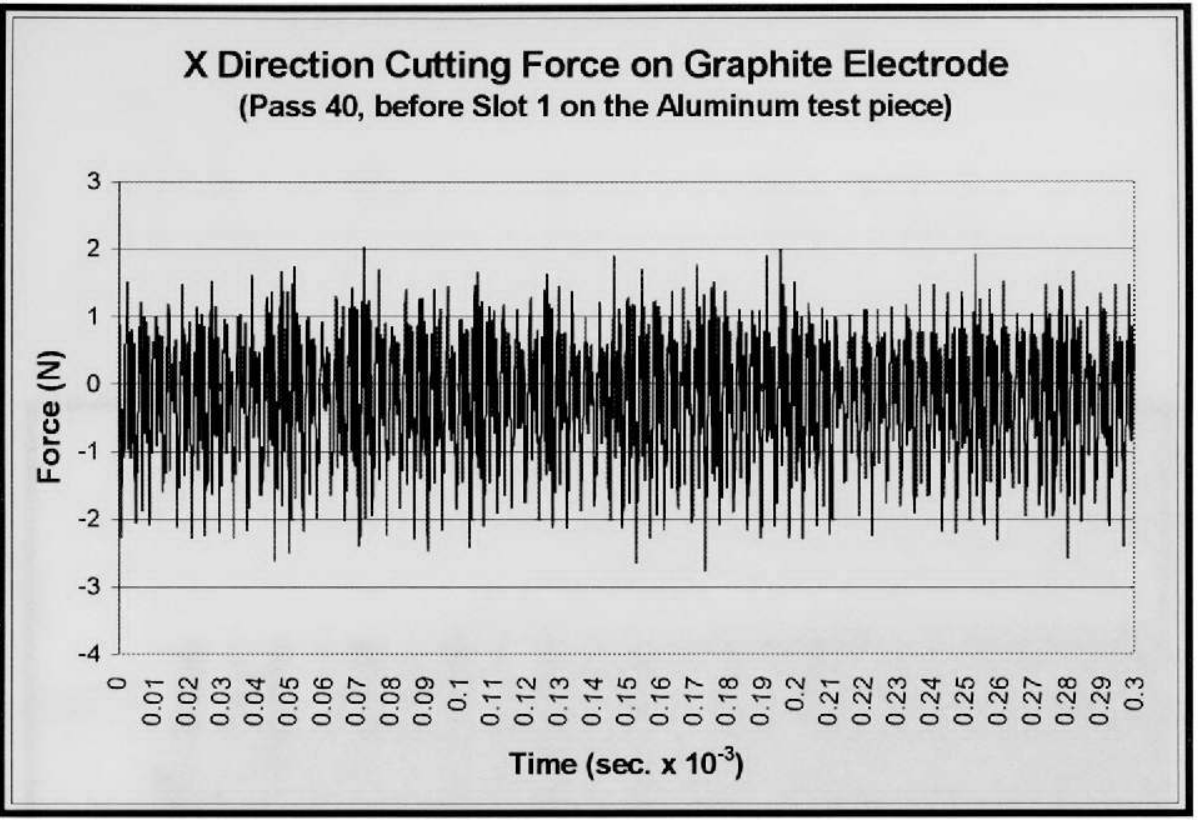

Figure 15. Thrust Direction Cutting Force on POCOEDMC-3 after 40 Pass

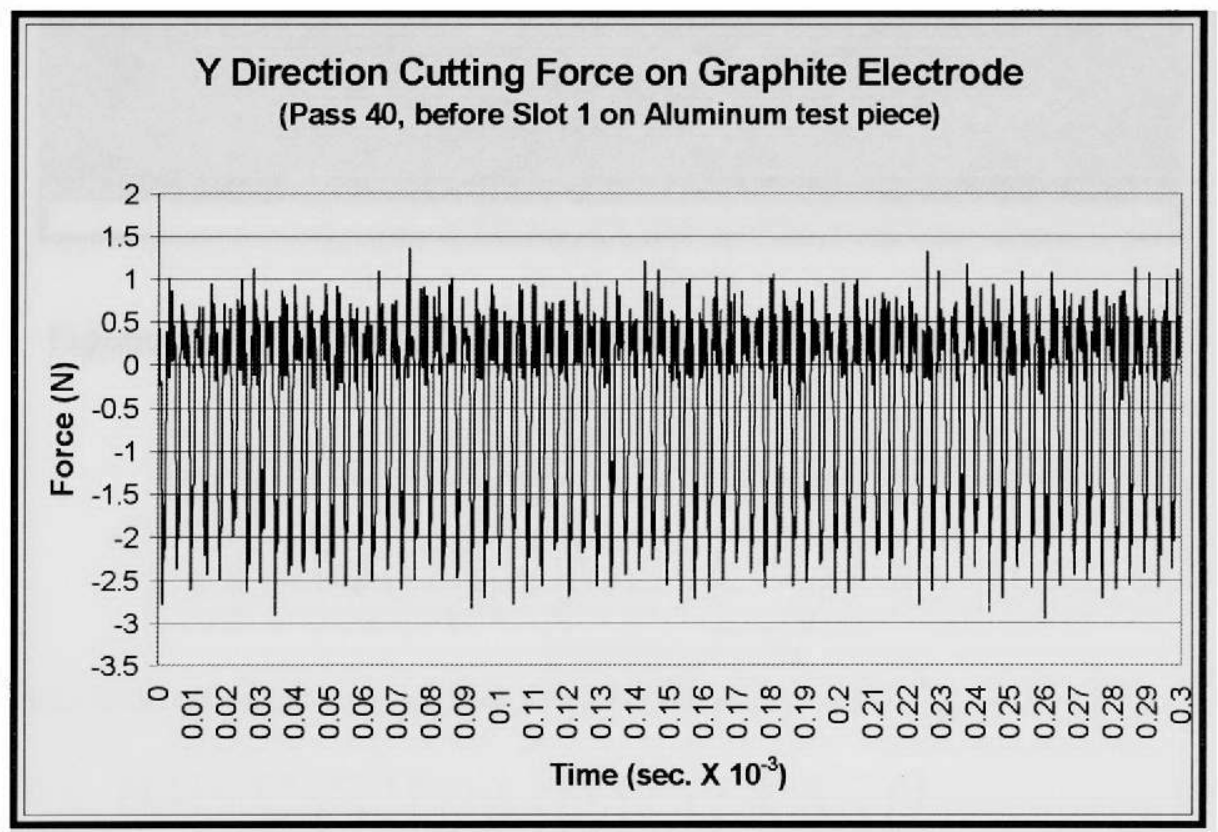

Figure 16. Feed Direction Cutting Force on POCOEDMC-3 after 40 Passes 


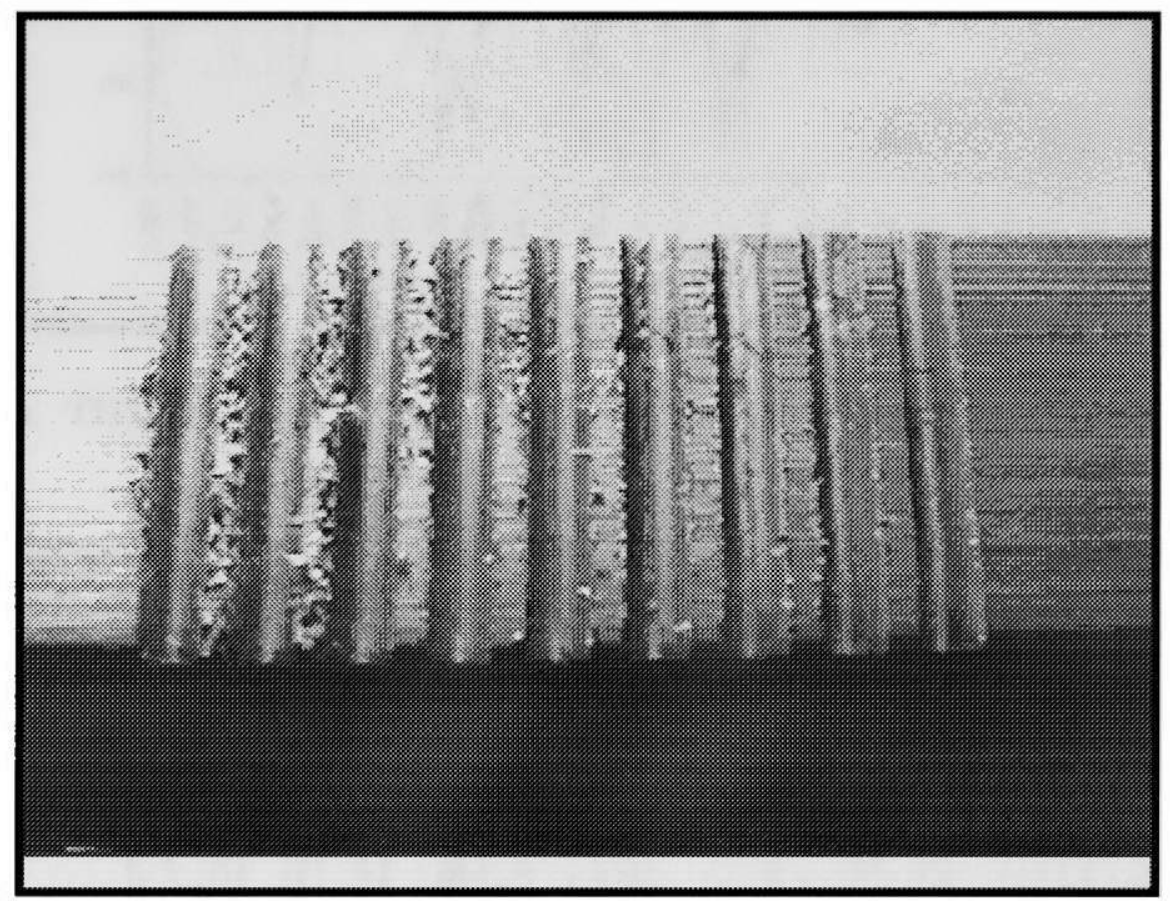

Figure 17. THE SLOTS FROM PERFECT TO WORN OUT TOOL 


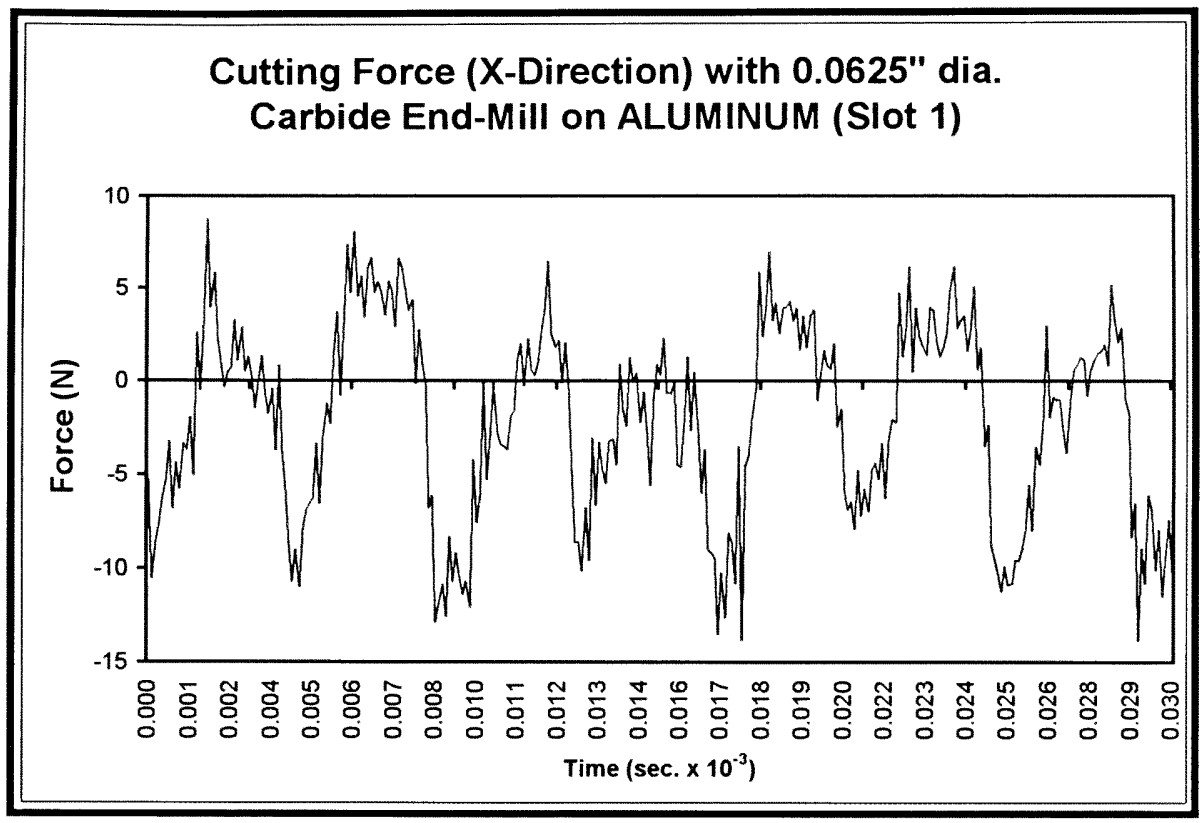

Figure 18.a. THRUST DIRECTION CUTTING FORCE OF PERFECT TOOL (SLOT1)

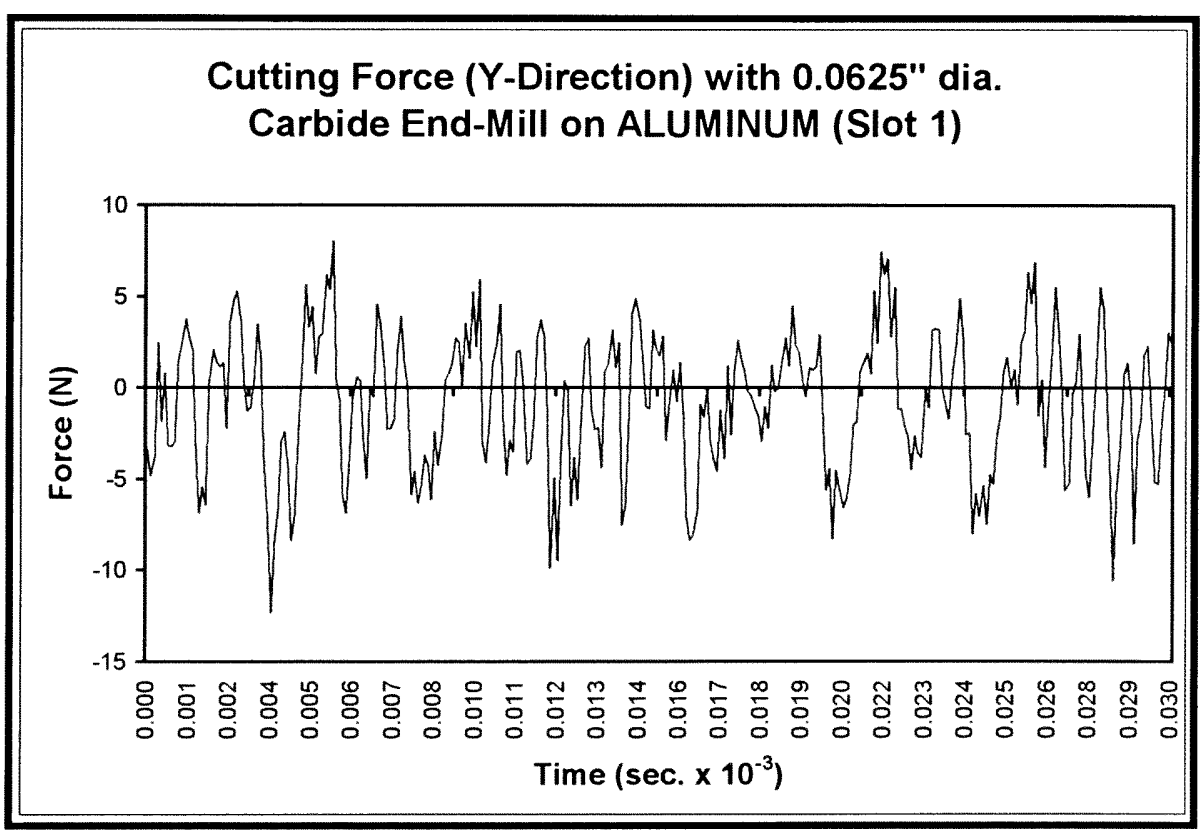

Figure 18.b. FEED DIRECTION CUTTING FORCE OF PERFECT TOOL (SLOT 1) 


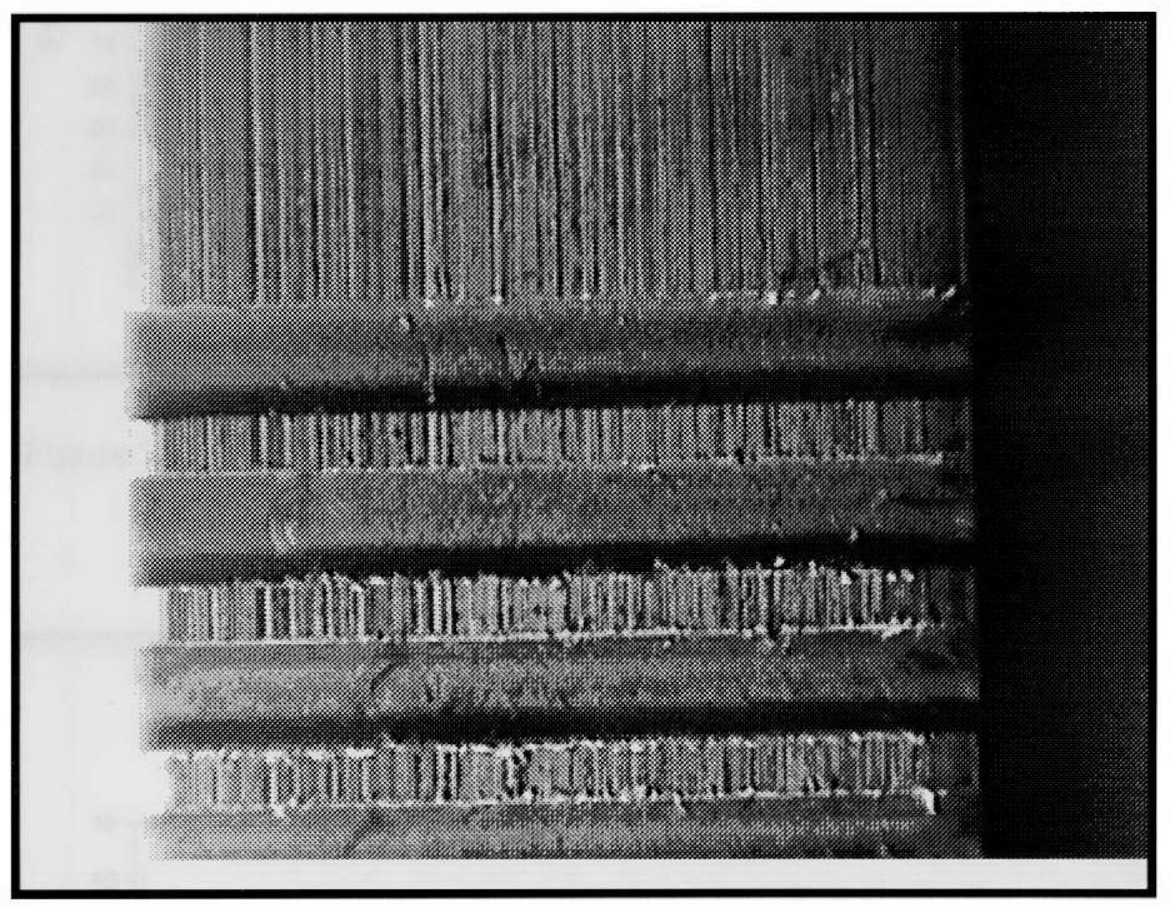

Figure 19. PICTURE OF THE SLOTS $\# 1, \# 2, \# 3$ 


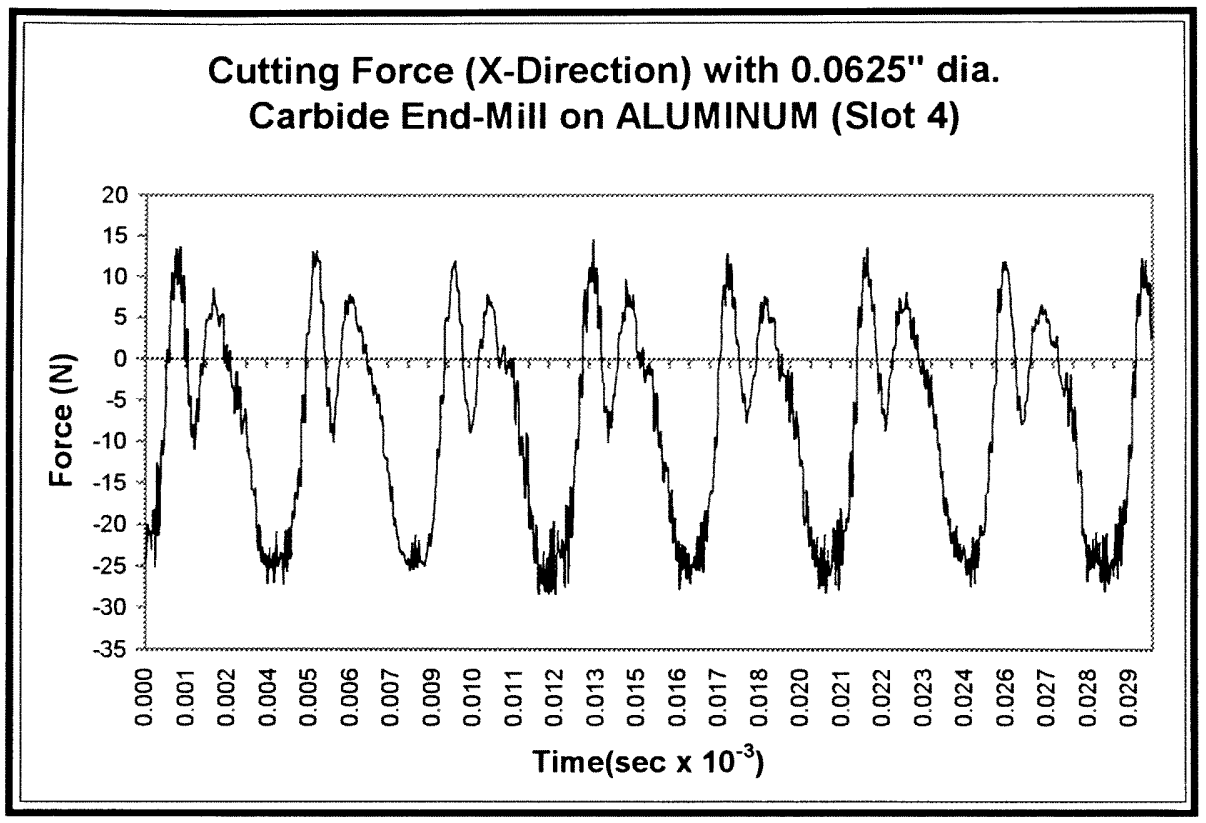

Figure 20.a. THRUST DIRECTION CUTTING FORCE OF TOOL (SLOT 4)

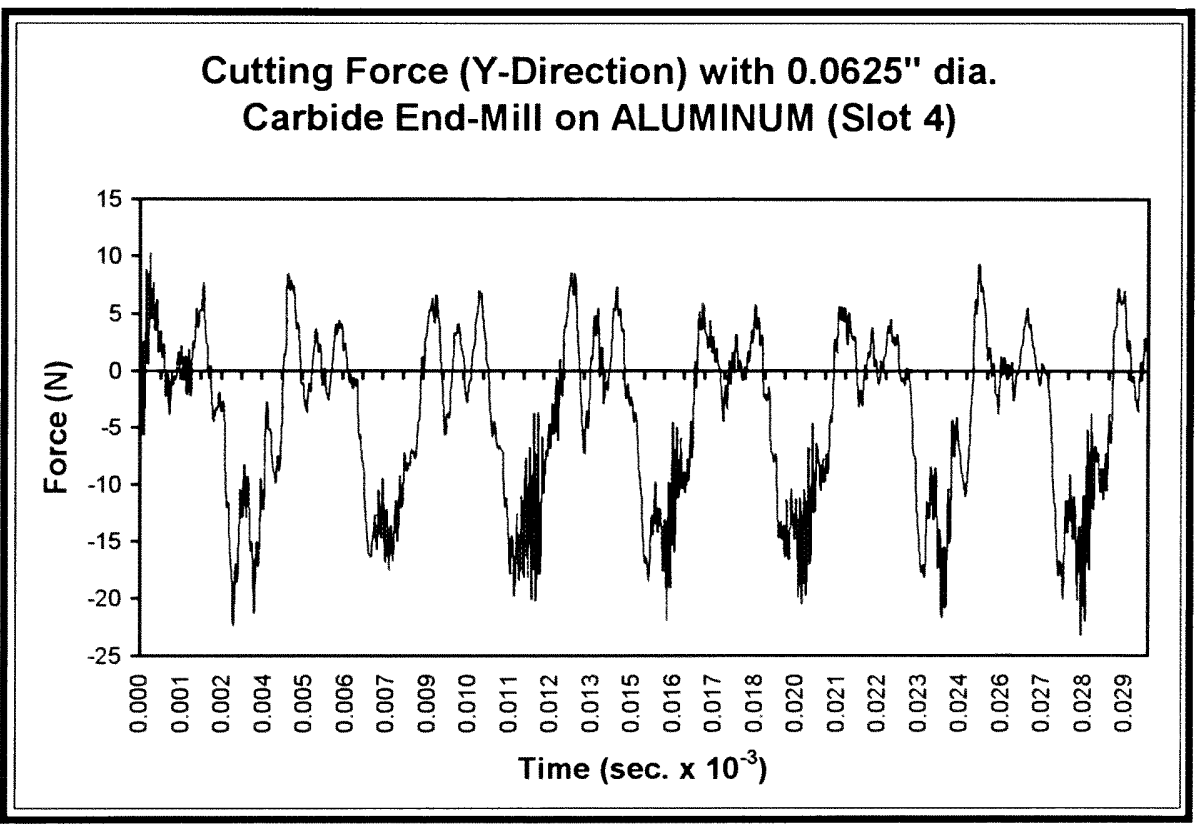

Figure 20.b. FEED DIRECTION CUTTING FORCE OF TOOL (SLOT 4) 


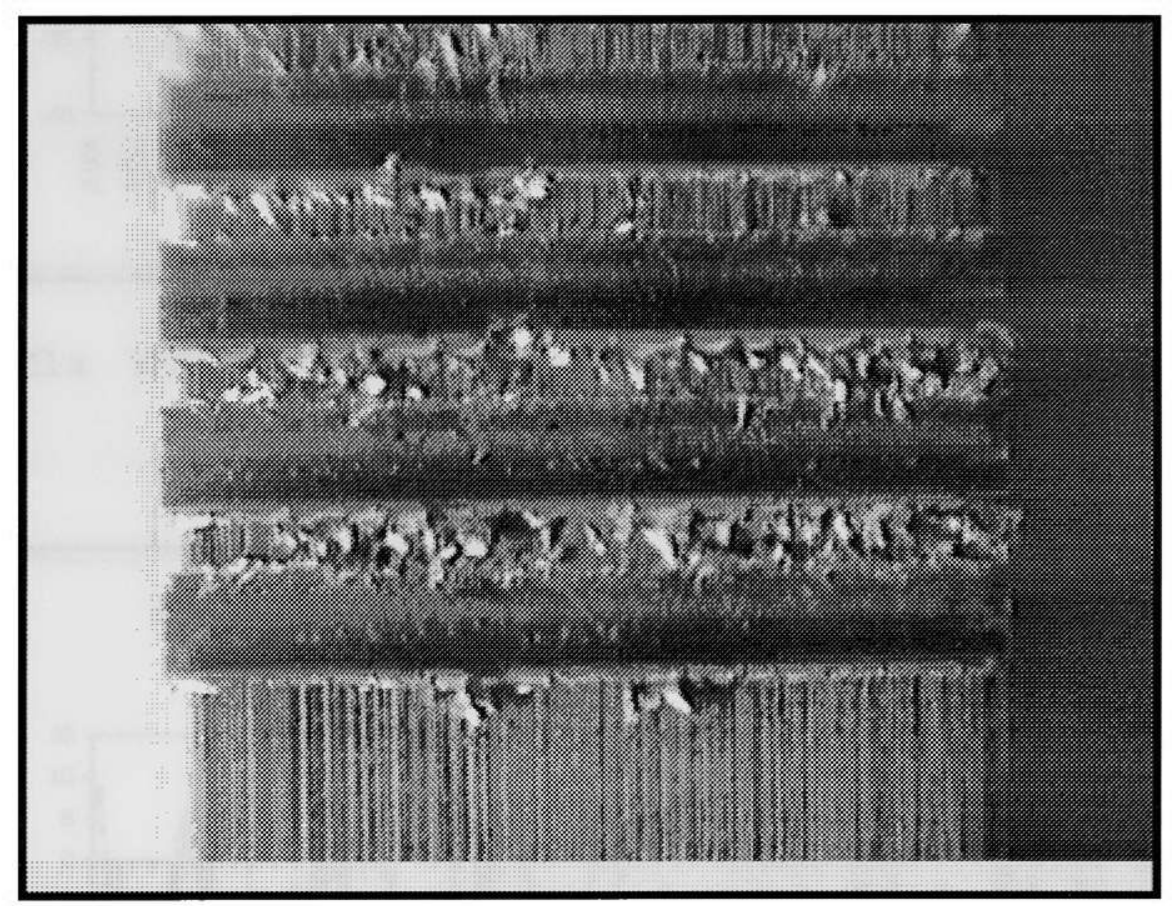

Figure 21. PICTURE OF THE SLOTS \#6, \#7, \#8. \#9 


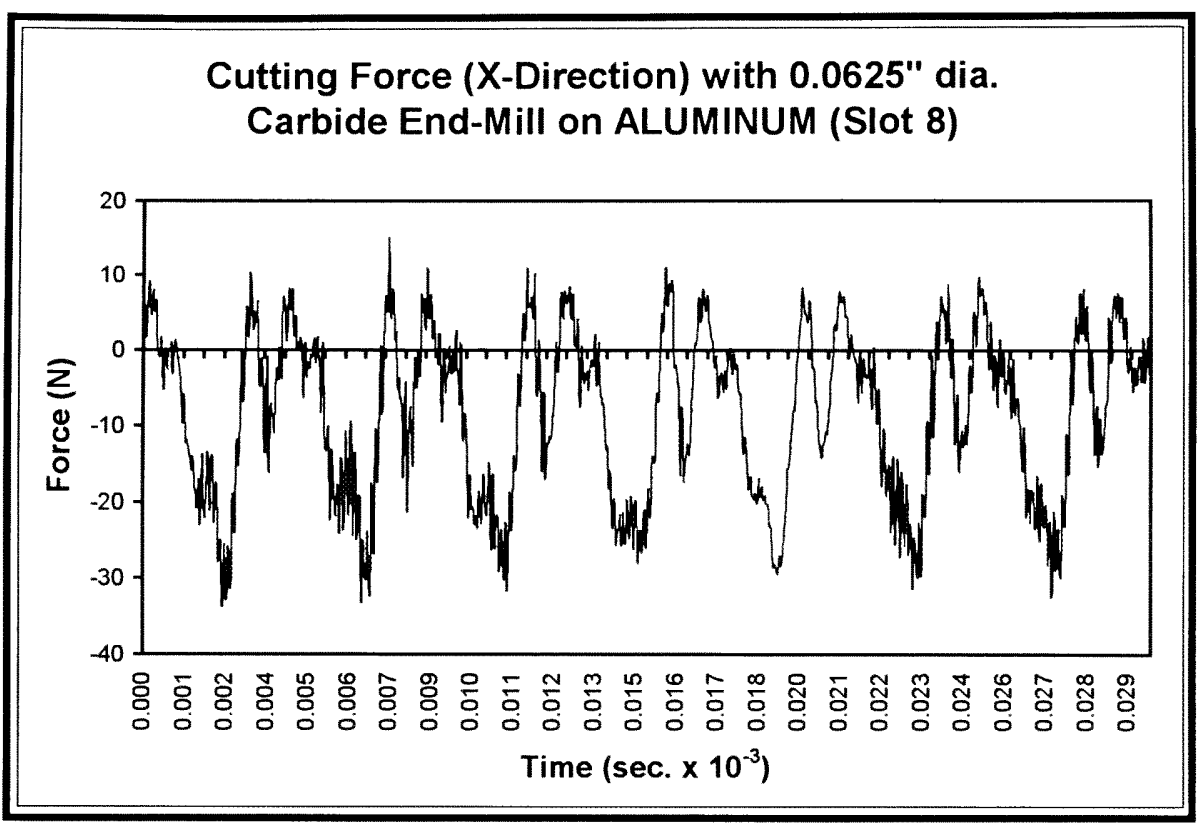

Figure 22.a. THRUST DIRECTION CUTTING FORCE OF TOOL (SLOT 8)

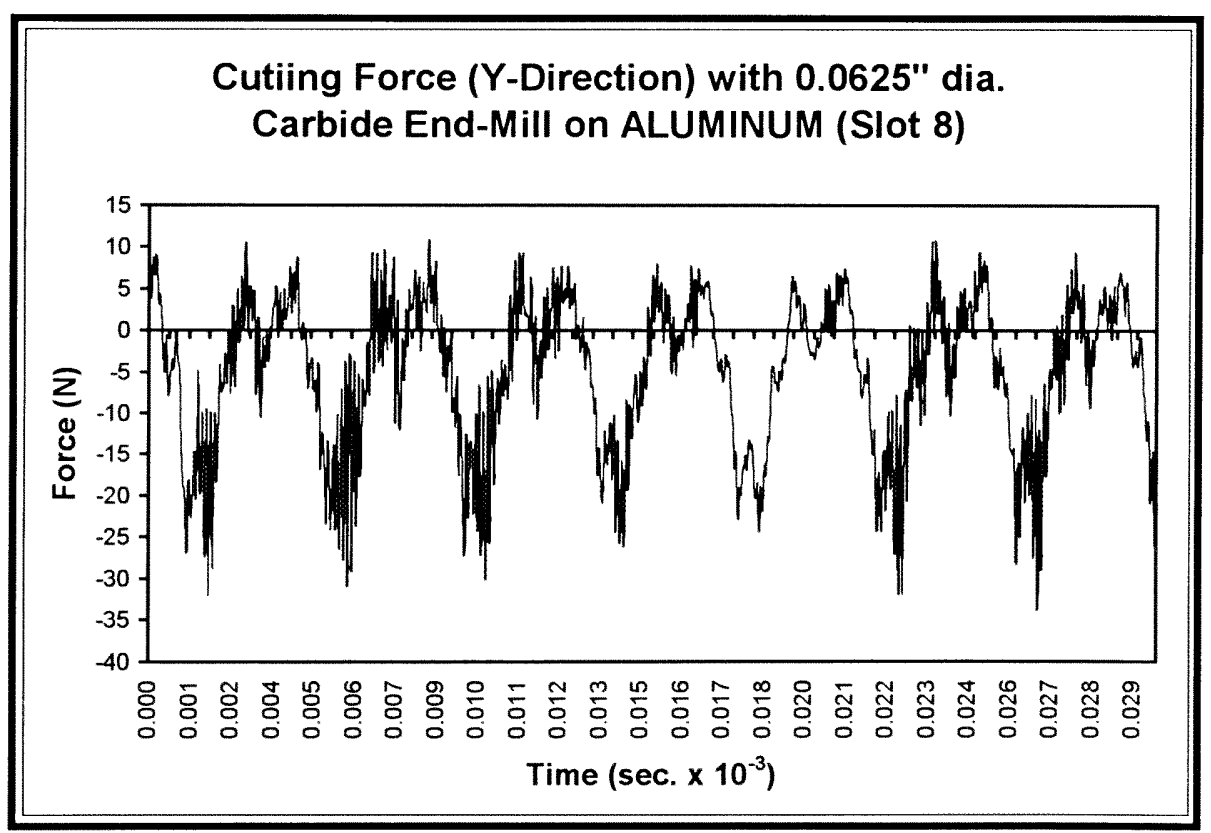

Figure 22.b. FEED DIRECTION CUTTING FORCE OF TOOL (SLOT 8) 
The amplitudes of the Thrust and Feed direction cutting force variation of the 1/16 inches diameter carbide end-mill are represented in Figure 23.a. and 23.b. This cutting forces belong to ten slots cut on the aluminum test piece during the wear test of POCOEDMC-3. Cutting forces had the tendency to increase with the usage of the tool. Linear and exponential models were fitted to the data. The results were presented in Figure 24.a., 24.b., 25.a., and 25.b. The result of the study showed that linear curve fitted better than the exponential curve.

The following equation was used to represent the wear and cutting force relationship.

$$
y=a+b x
$$

$a$ nad $b$ were calculated from the following equations:

$$
a=[Y]-b[X]
$$

and

$$
\mathrm{b}=\frac{n \sum x y-\left(\sum x\right)\left(\sum y\right)}{n \sum x^{2}-\left(\sum y\right)^{2}}
$$

where $y=$ wear, $x=$ magnitude of cutting force.

The results of the curve fitting study are presented in Figure 26.a. and 26.b. 
Tool Wear Testing (Cutting Force in Thrust Direction)

$0.0625^{\prime \prime}$ dia. Carbide tool, 15,000rpm spindle speed, 0.015" doc

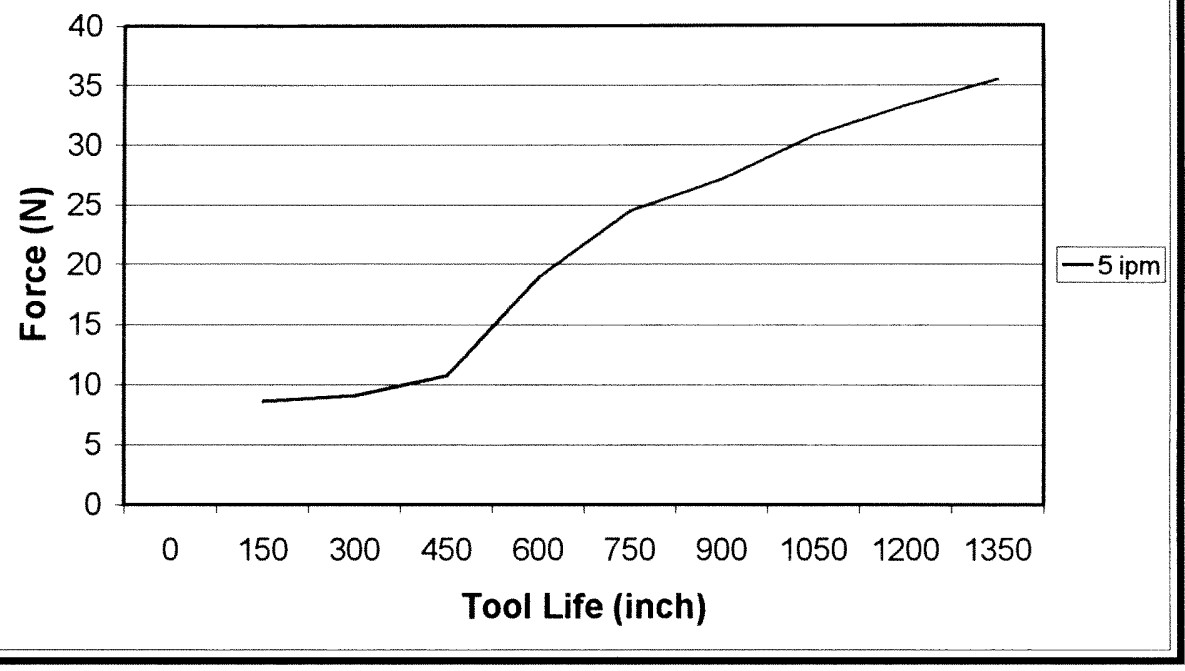

Figure 23.a. Thrust Direction Cutting Force Variation with the Usage of the End-Mill

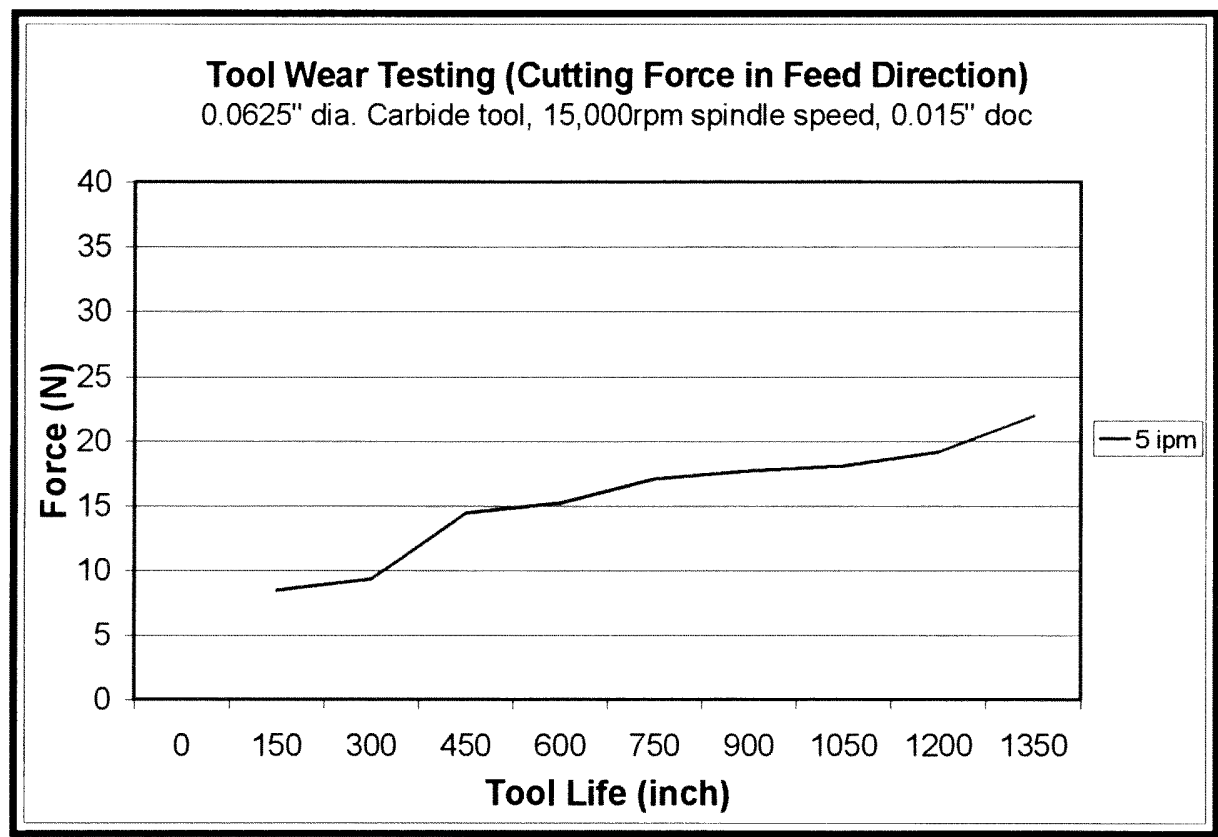

Figure 23.b. Feed Direction Cutting Force Variation with the Usage of the End-Mill 


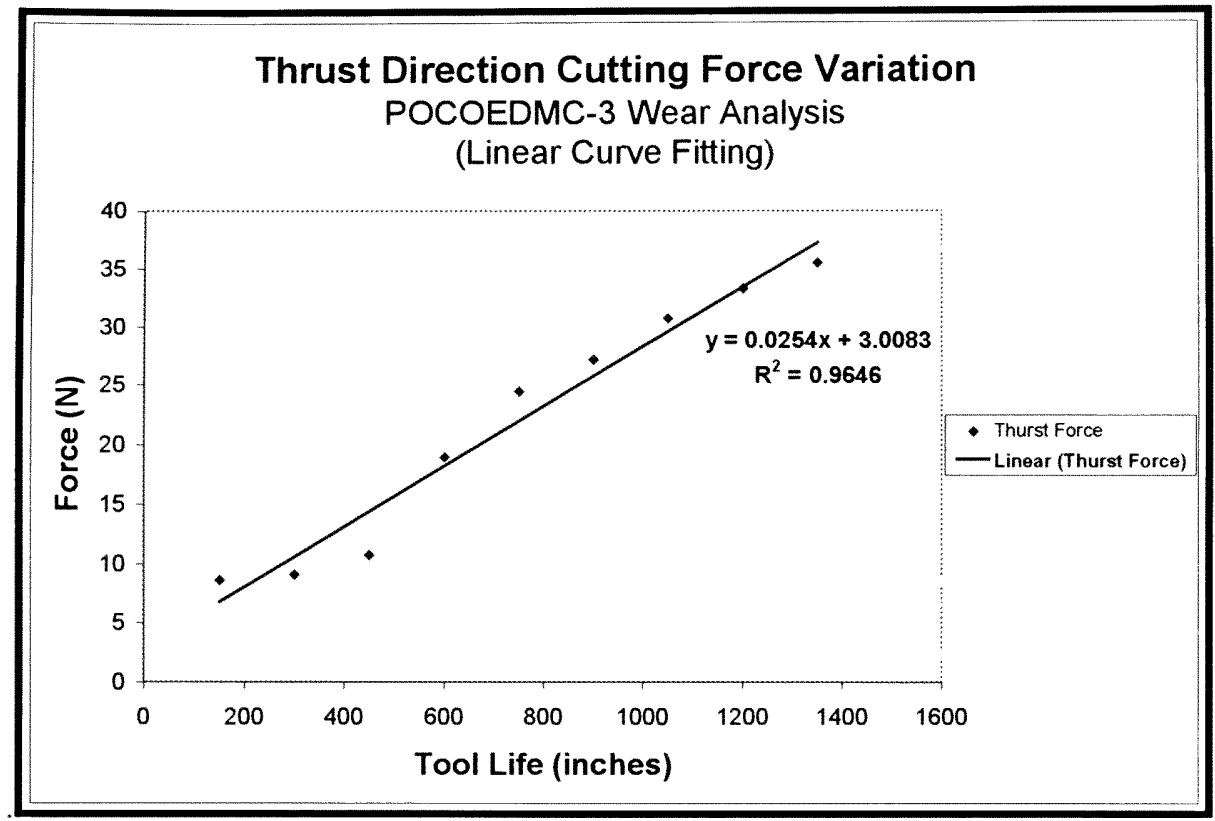

Figure 24.a. Linear Curve Fitting to the Experimental Thrust Direction Cutting Force

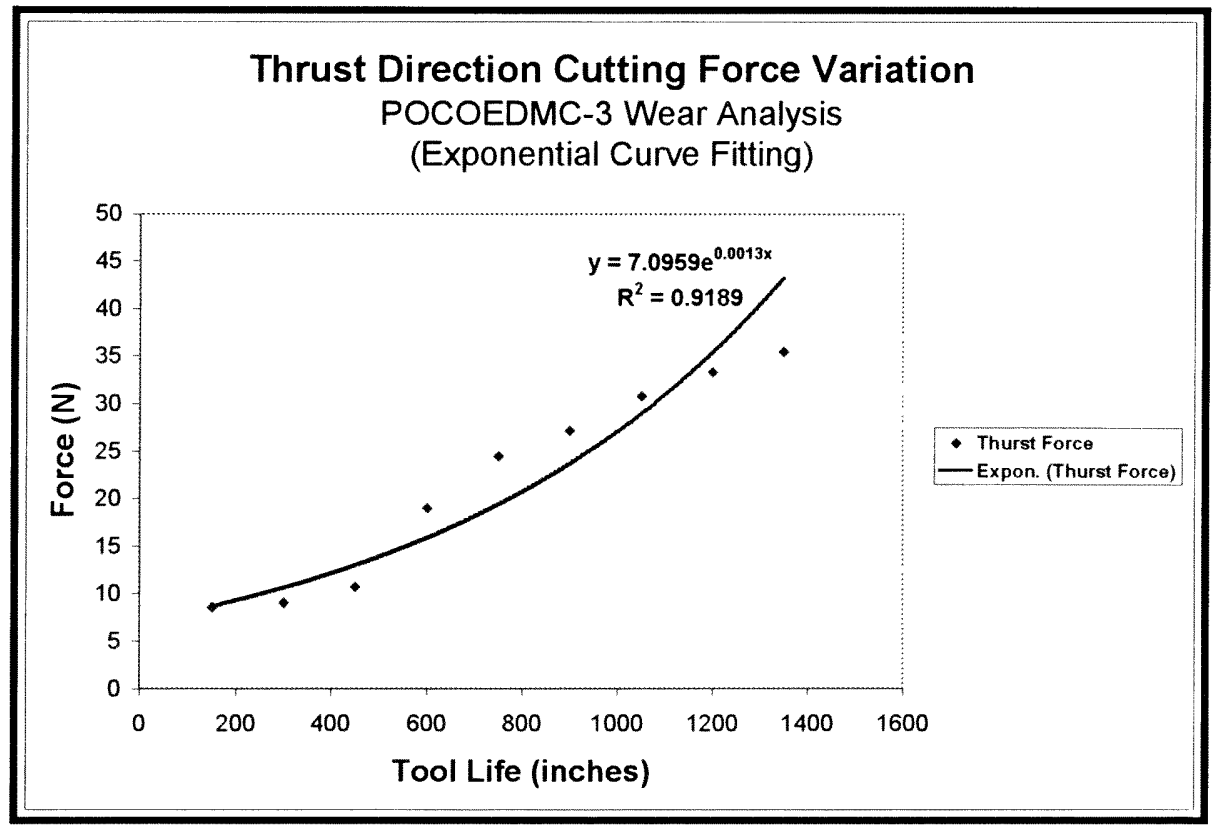

Figure 24.b. Exponential Curve Fitting to the Experimental Thrust Direction Cutting Force 


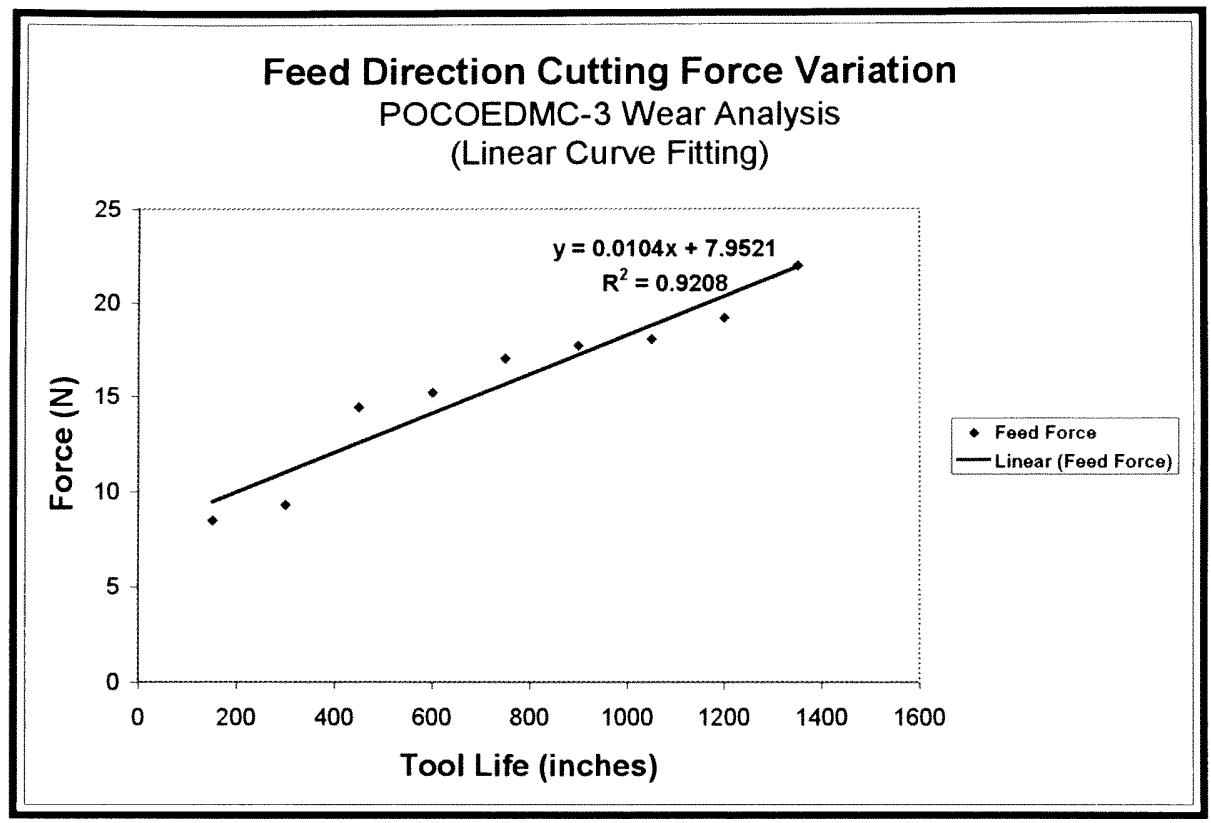

Figure 25.a. Linear Curve Fitting to the Experimental Feed Direction Cutting Force

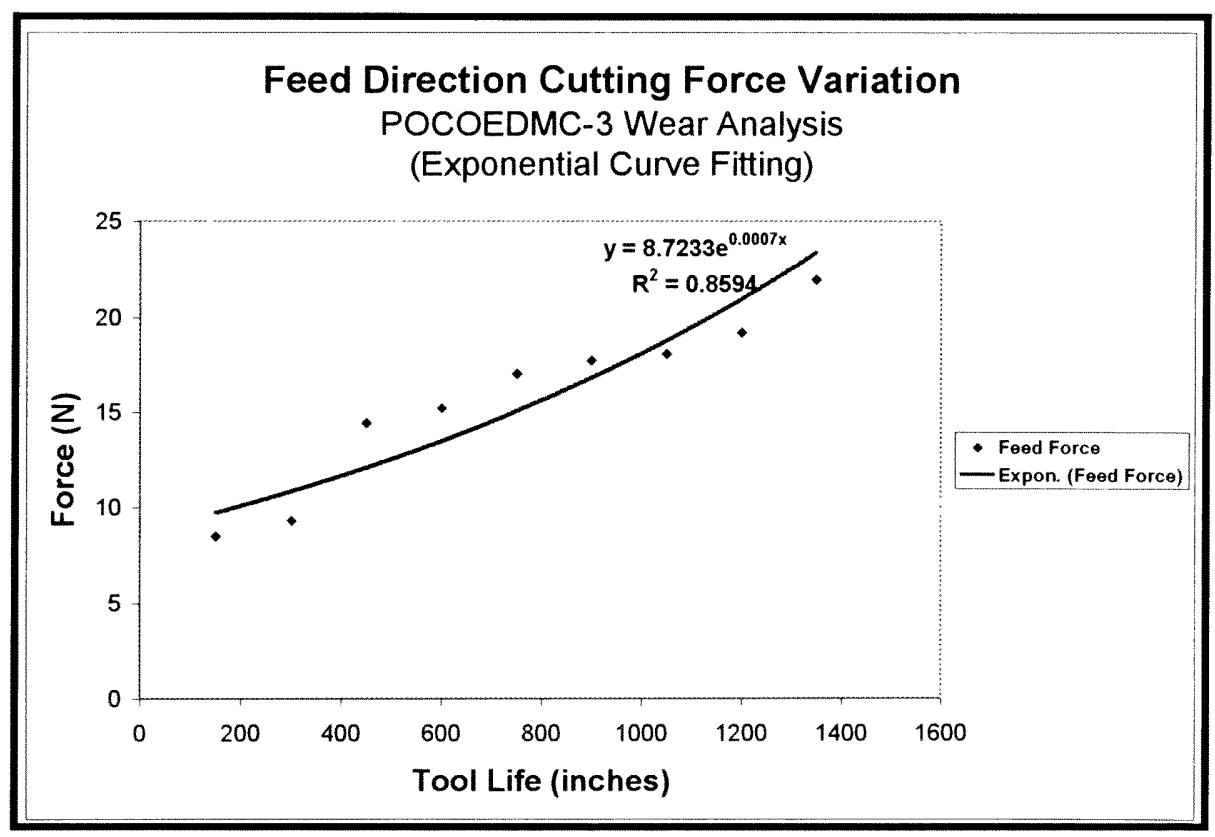

Figure 25.b. Exponential Curve Fitting to the Experimental Feed Direction Cutting Force 


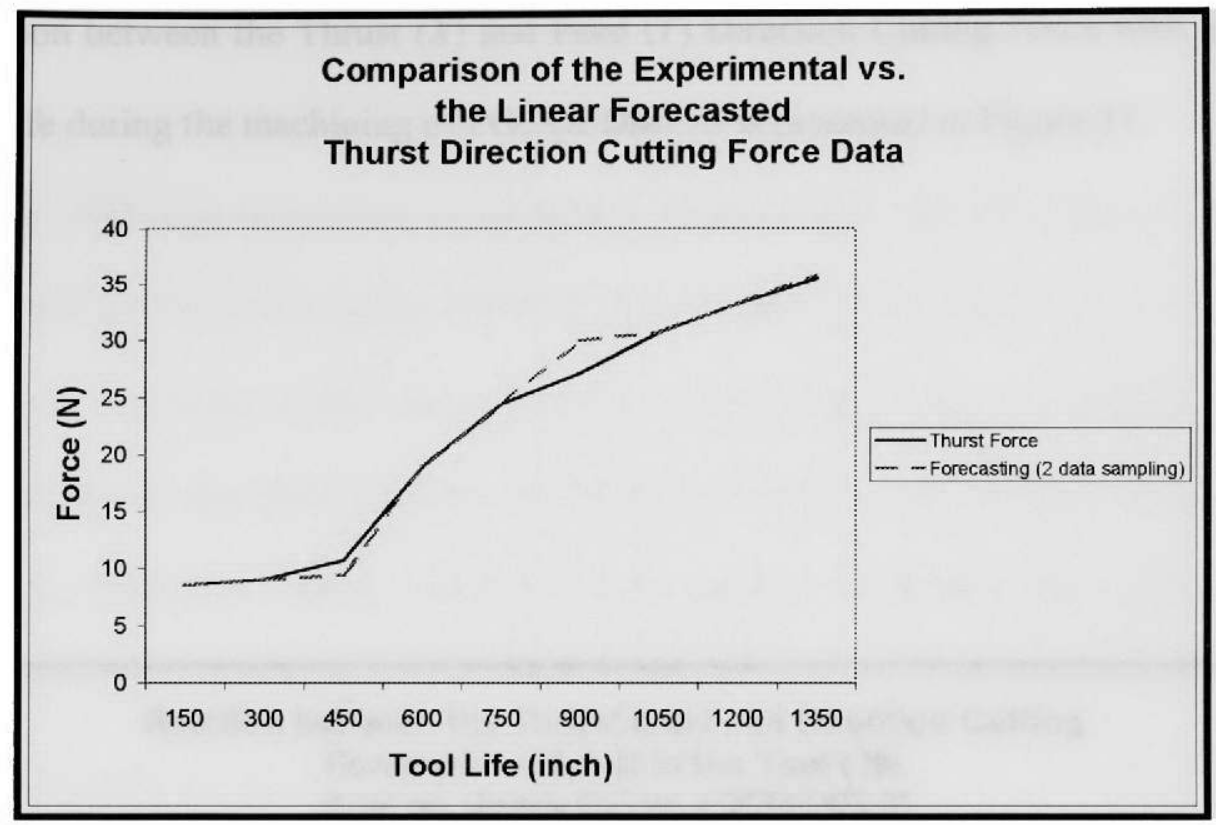

Figure 26.a. Comparison of the Experimental and the Forecasted Data for Thrust Direction Cutting Force (POCOEDMC-3 Workpiece)

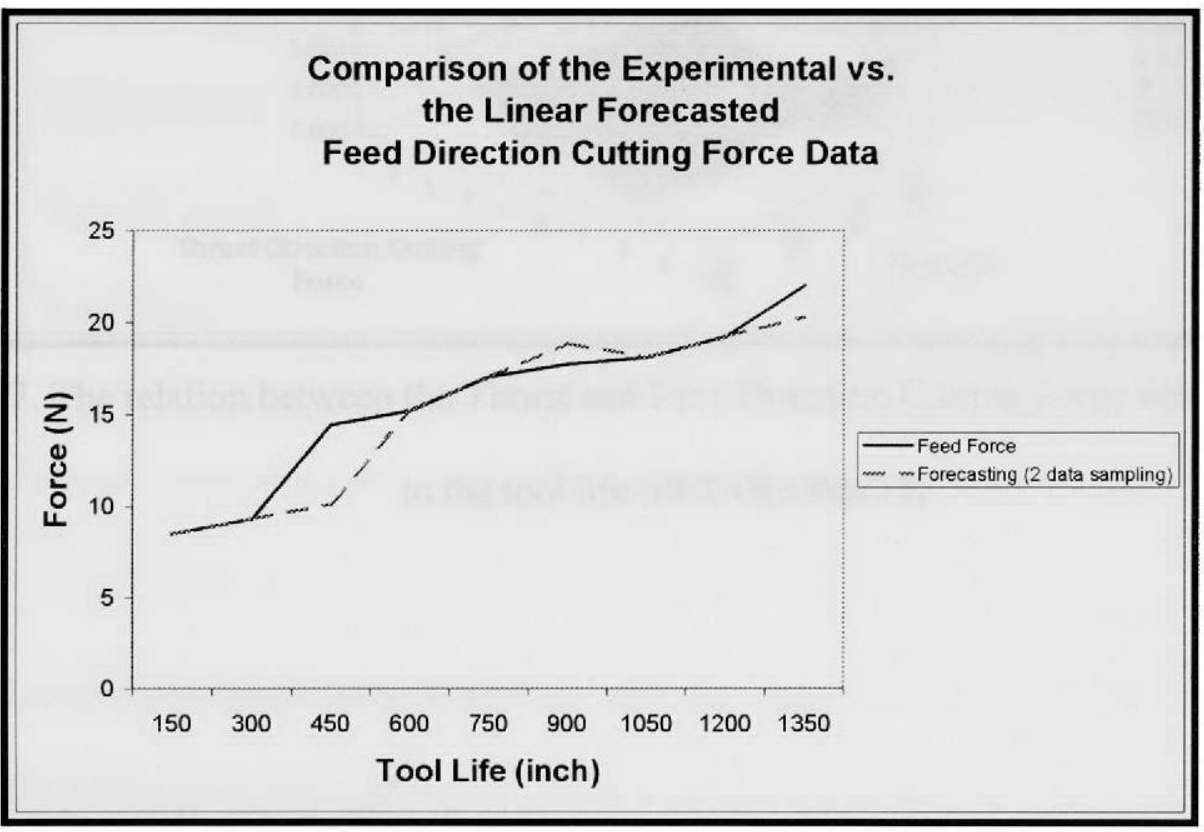

Figure 26.b. Comparison of the Experimental and the Forecasted Data for Feed Direction Cutting Force (POCOEDMC-3 Workpiece) 
The relation between the Thrust $(X)$ and Feed $(Y)$ Direction Cutting Force with respect to the tool life during the machining of POCOEDMC-3 is presented in Figure 27.

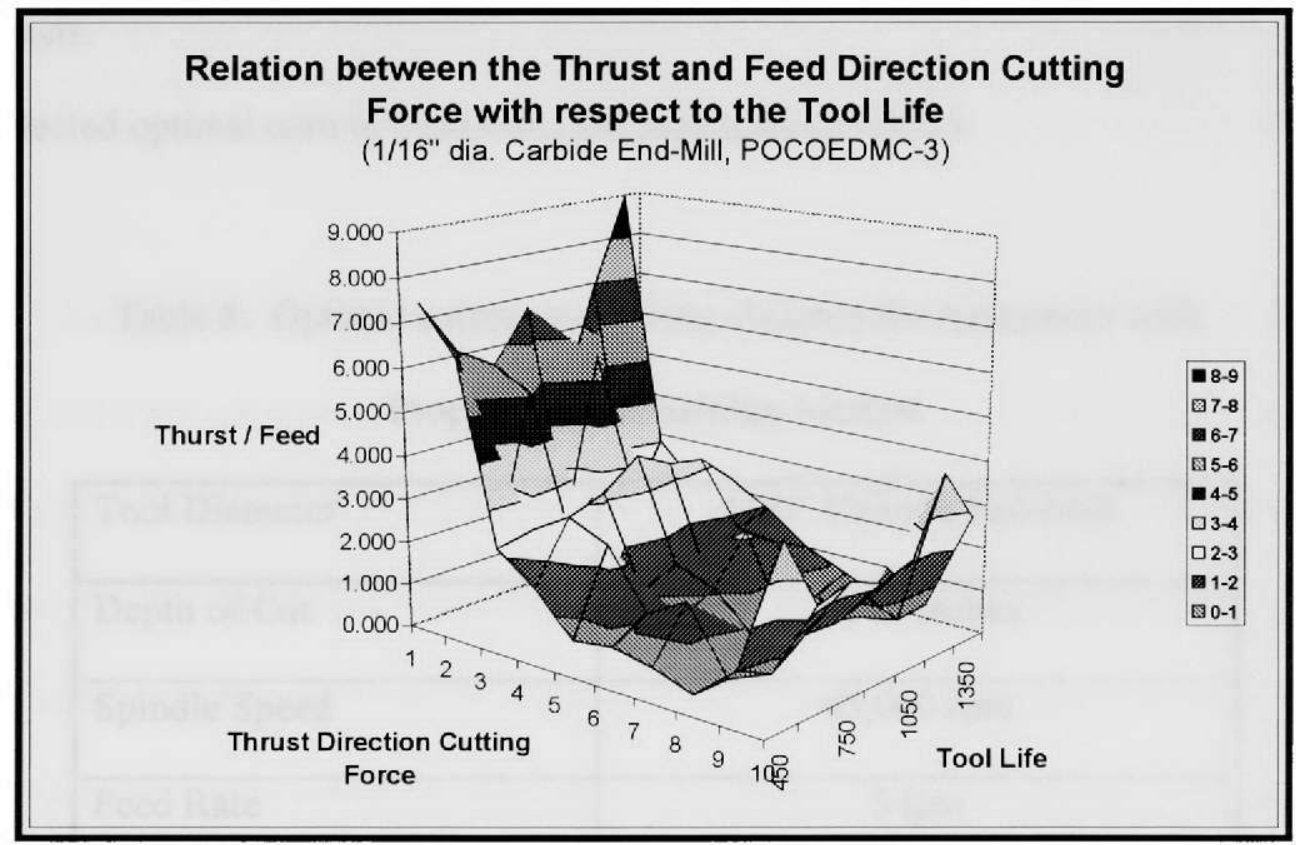

Figure 27. The relation between the Thrust and Feed Direction Cutting Force with respect to the tool life (POCOEDMC-3) 


\section{Aluminum:}

The machinability and tool wear experiments were performed on aluminum workpiece. Although machining of aluminum is easier than the other harder metal with conventional cutting tools, fuzzy behavior and premature tool breakage are commonly encountered. The value of the cutting force was larger than the forces encountered during the machining of electrode graphite and easier to monitor. At the first stage on these experiments, different cutting conditions were applied to identify the optimal cutting conditions.

The selected optimal cutting conditions are presented in Table 8 .

Table 8. Optimal cutting conditions obtained for Aluminum with Proposed Machinability Method

\begin{tabular}{|l|c|}
\hline Tool Diameter & $1 / 32$ " Carbide End-Mill \\
\hline Depth of Cut & 0.015 inches \\
\hline Spindle Speed & $45,000 \mathrm{rpm}$ \\
\hline Feed Rate & $5 \mathrm{ipm}$ \\
\hline Tool Life obtained & 156 inches \\
\hline
\end{tabular}

The tool wear experiments were conducted with the cutting conditions stated above. The thrust and feed direction cutting force variation with tool usage for the $1 / 32$ inches diameter carbide end-mill was shown in Table 9. 
Table 9. Cutting Forces -Tool Life Results in Tool (1/32" Carbide End-Mill)

Wear Experiment (Aluminum Workpiece)

\begin{tabular}{|c|c|c|c|}
\hline Cutting Force in Thrust Dir. (N) & $\begin{array}{c}\text { Feed Rate } \\
5 \mathrm{ipm}\end{array}$ & Cutting Force in Feed Dir. (N) & $\begin{array}{c}\text { Feed Rate } \\
5 \mathrm{ipm}\end{array}$ \\
\hline Tool Life (inch) & Force & Tool Life (inch) & Force \\
\hline 30 & 6.6 & 30 & 9.78 \\
\hline 45 & 7.1 & 45 & 10.11 \\
\hline 60 & 10.42 & 60 & 14.62 \\
\hline 62 & 8.56 & 62 & 11.23 \\
\hline 75 & 10.11 & 75 & 12.5 \\
\hline 90 & 12.23 & 90 & 13.47 \\
\hline 105 & 16.86 & 105 & 16.78 \\
\hline 107 & 14.78 & 107 & 14.96 \\
\hline 120 & 16.74 & 120 & 16.41 \\
\hline 135 & 18.35 & 135 & 18.54 \\
\hline 156 & 20.13 & 156 & 21.75 \\
\hline
\end{tabular}

Thrust and Feed direction cutting force variation of the 1/32 inches diameter carbide end-mill are represented in Figure 28.a. and 28.b. As it can be seen from the graphs that cutting forces are increasing with a certain of amount usage of the tool. Within this trend, some of the cutting force data were larger than the usual ones. This phenomenon is not related with the tool wear; the reason for this instantaneous increase in the data is the chip of the aluminum workpiece stocked to the cutting edges of the tool. Aluminum is a soft material and chips are created during the machining. Cutting tool used for the experiment was carbide steel. During the test, for certain passes of the tool on the workpiece, the aluminum temperature increased and the chips got melted and stocked to the teeth of the end-mill. For most of the data, chips were released after certain amount of tool usage after the specified pass. So for these reasons, when the cutting forces are monitored larger than the usual ones, the data record was repeated after a while. The linear increment trend can be seen if these abnormalities were ignored. 
Data was also studied with curve fitting analysis technique to evaluate the trend of the increase in cutting forces. Linear and exponential models were fitted to the data. The results were presented below in Figure 29.a., 29.b., 30.a., and 30.b. The interpolation method was used for the curve fitting. The result of the study showed that linear curve fitted better than the exponential curve. After the observation of the study, a linear forecasting analysis is conducted to interpret the cutting force data. Forecasting method used is based on the linear interpolation of the collected data. The equations 5.1 to 5.3 were used for forecasting. The results are shown in Figure 31. 


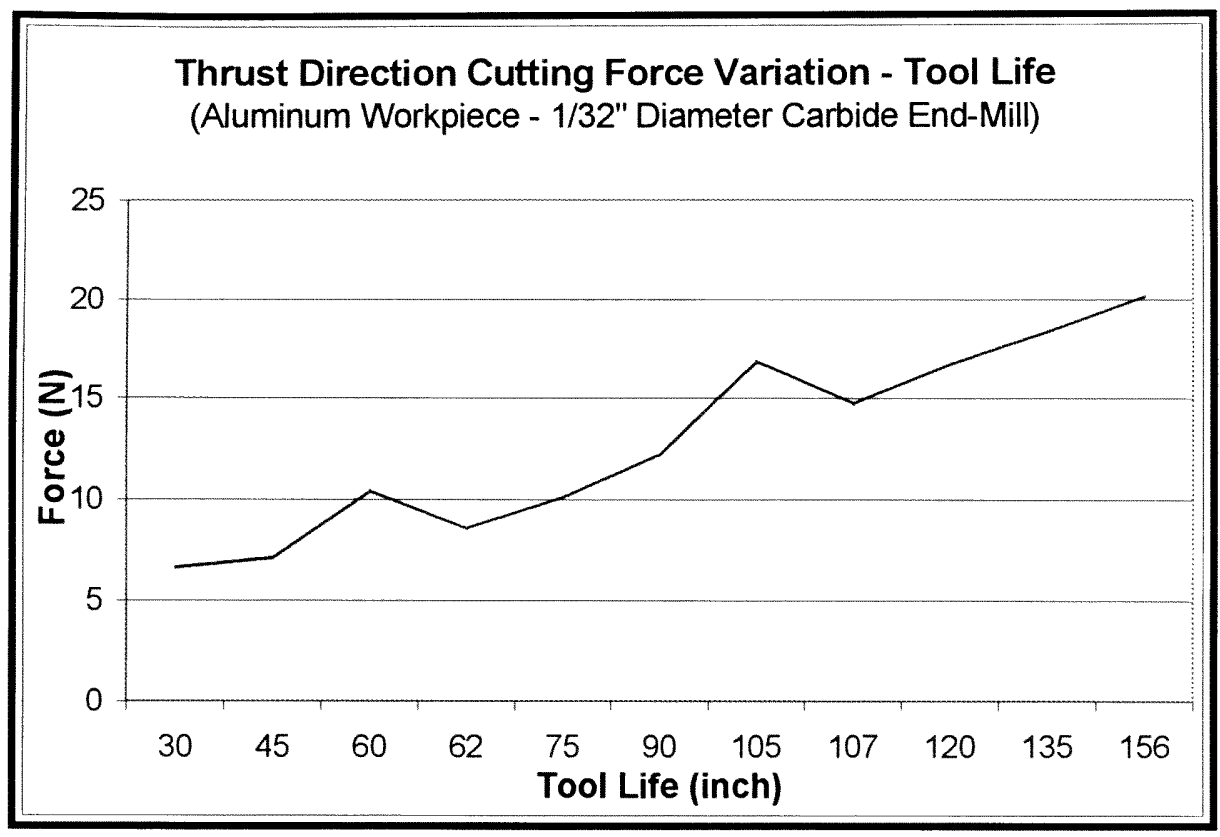

Figure 28.a. Thrust Direction Cutting Force Variation with Tool Usage on Aluminum

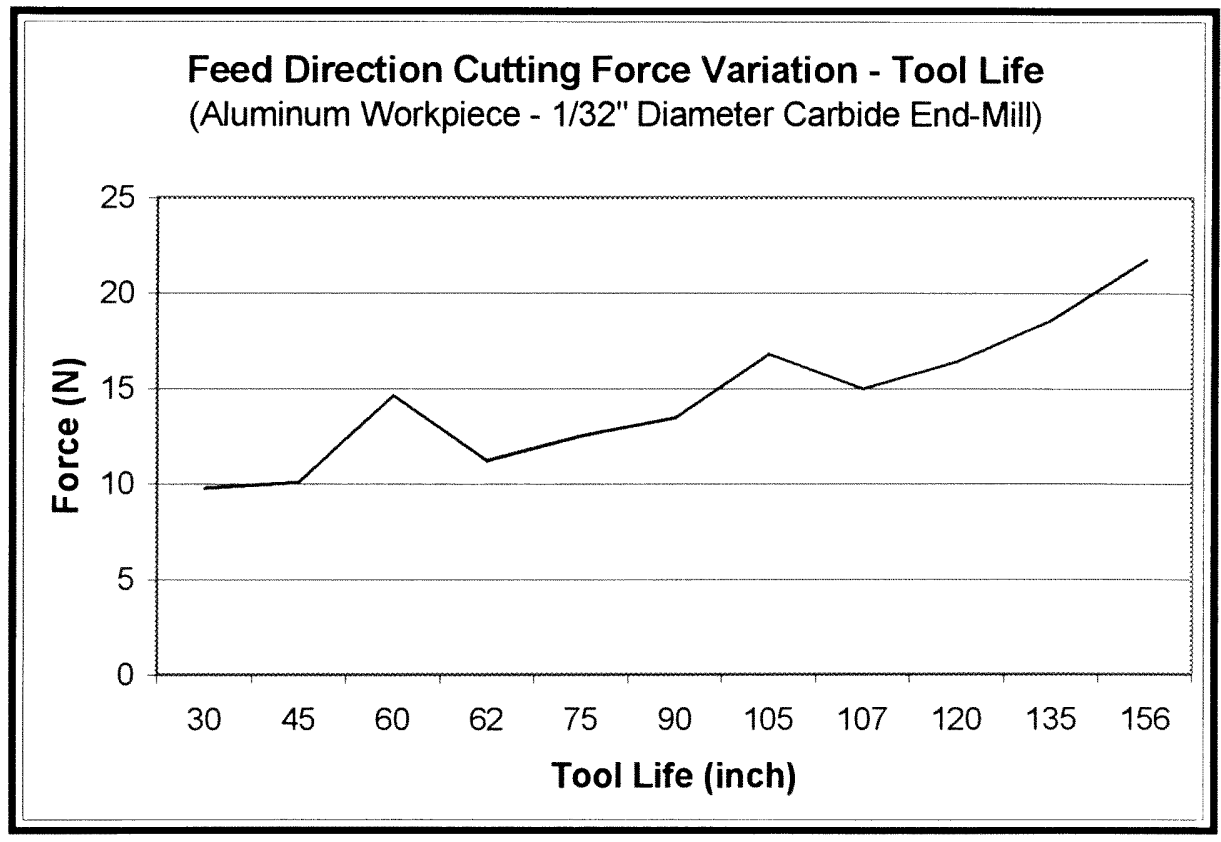

Figure 28.b. Feed Direction Cutting Force Variation with Tool Usage on Aluminum 


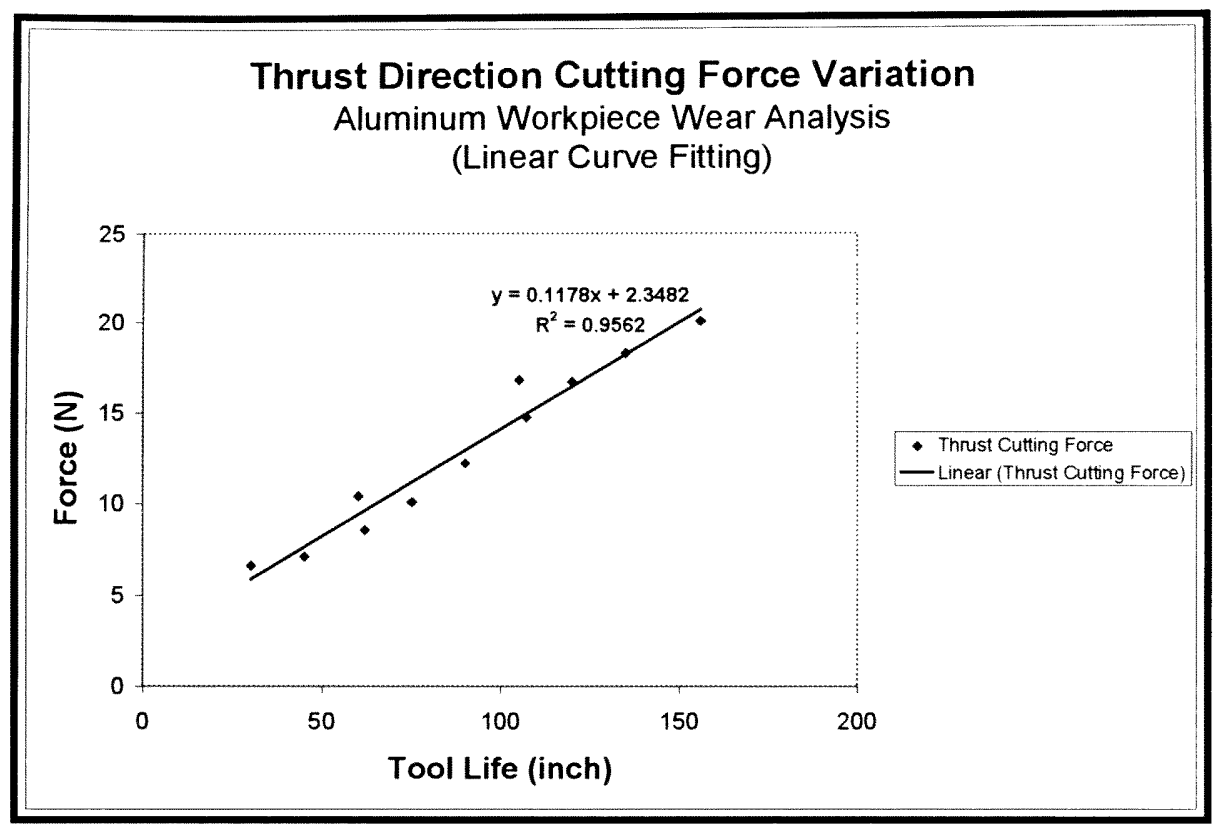

Figure 29.a. Linear Curve Fitting to the Experimental Thrust Direction Cutting Force (Aluminum Workpiece)

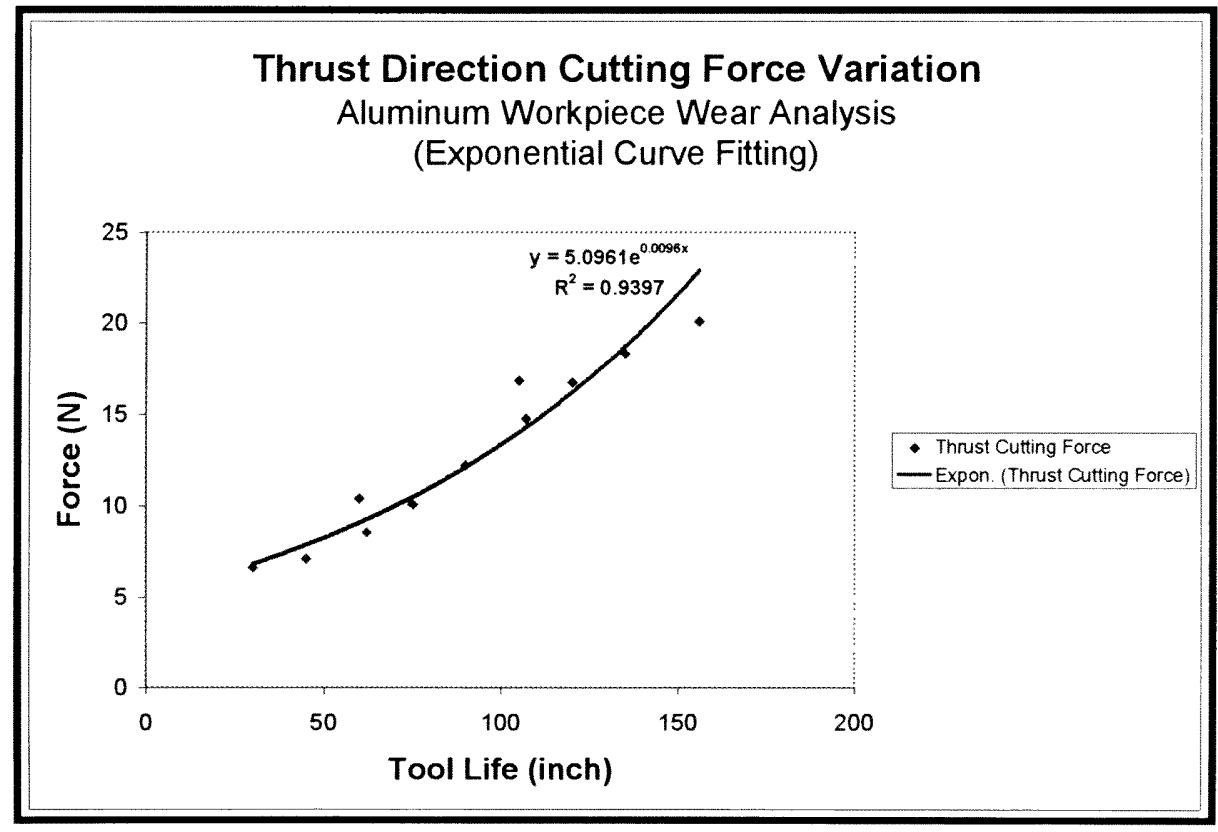

Figure 29.b. Exponential Curve Fitting to the Experimental Thrust Direction Cutting Force (Aluminum Workpiece) 


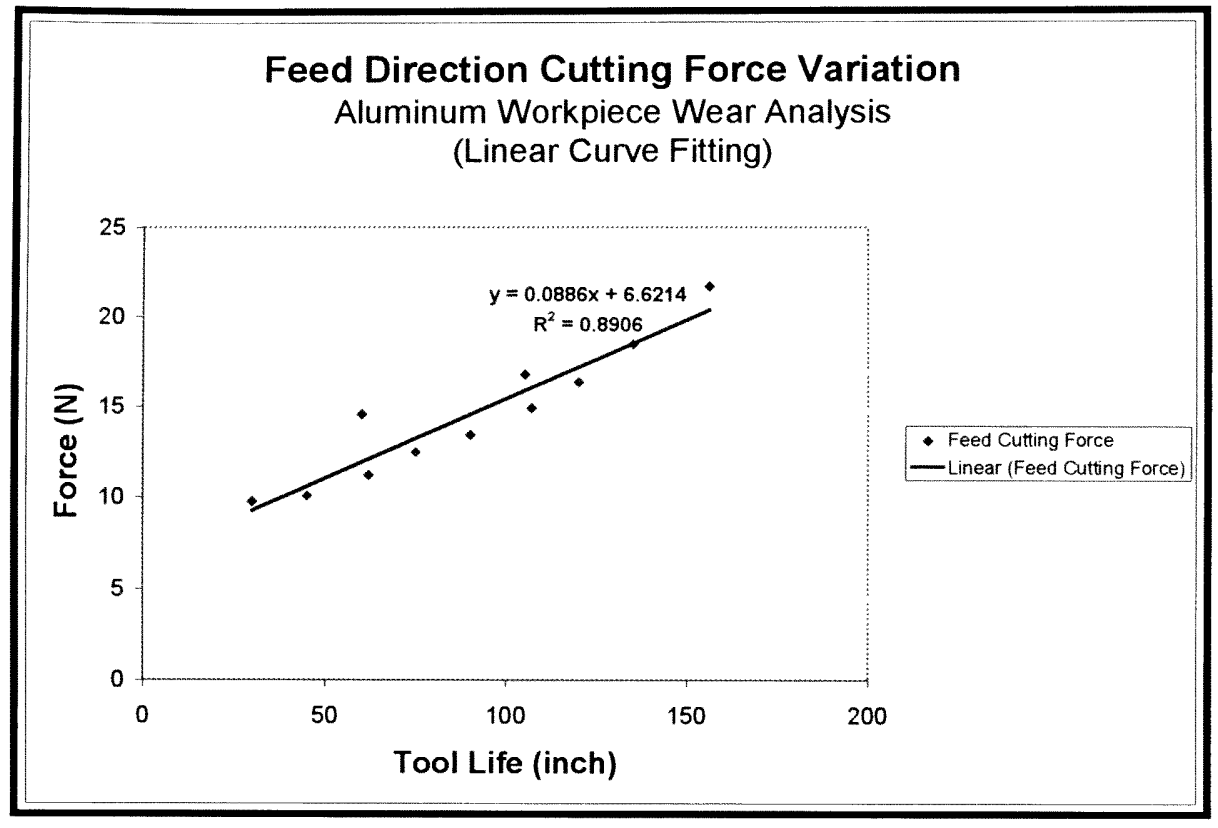

Figure 30.a. Linear Curve Fitting to the Experimental Feed Direction Cutting Force (Aluminum Workpiece)

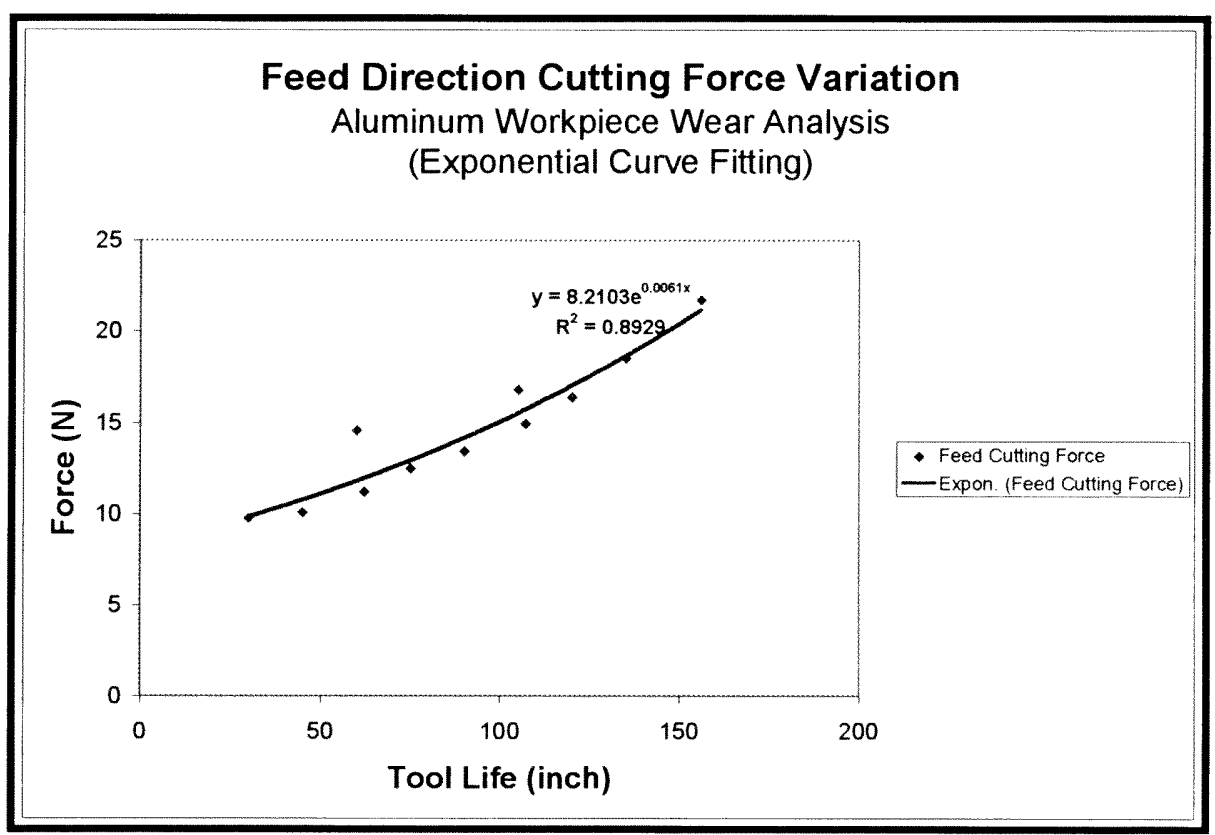

Figure 30.b. Exponential Curve Fitting to the Experimental Feed Direction Cutting Force (Aluminum Workpiece) 


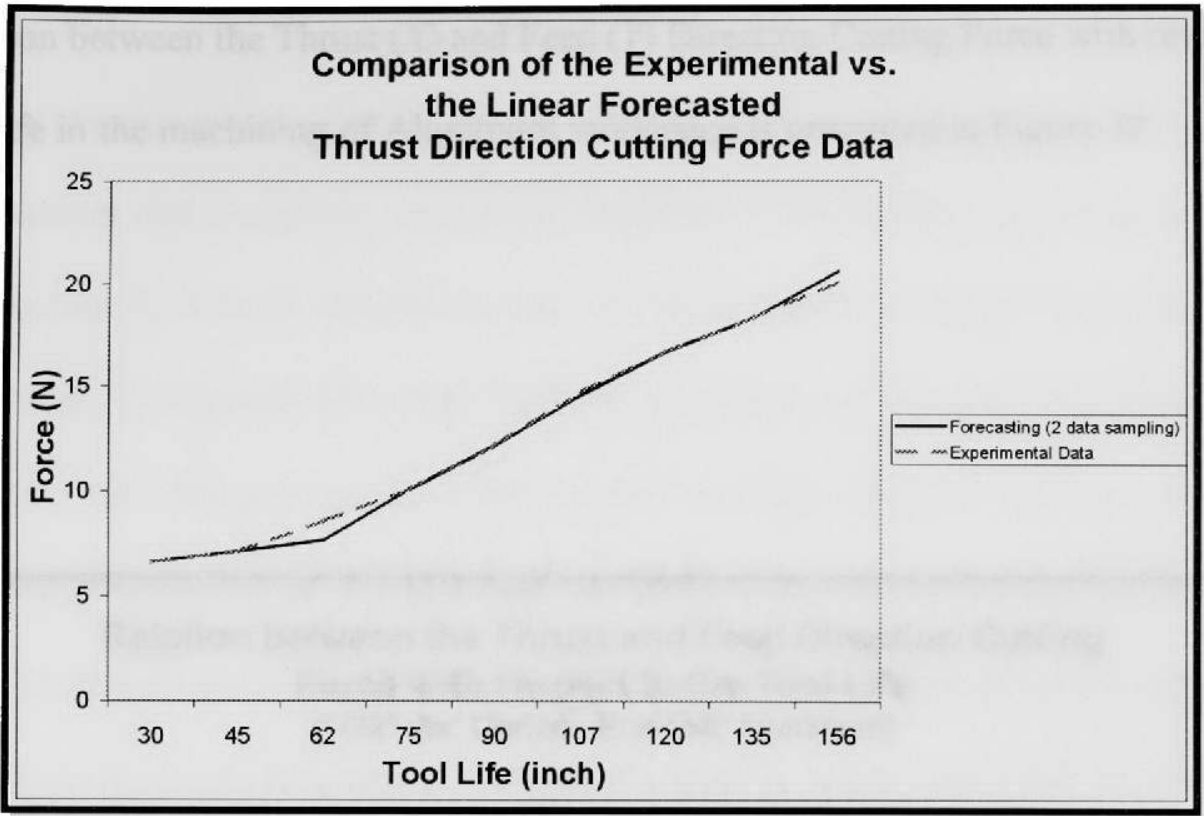

Figure 31.a. Comparison of the Experimental and the Forecasted Data for Thrust Direction Cutting Force (Aluminum Workpiece)

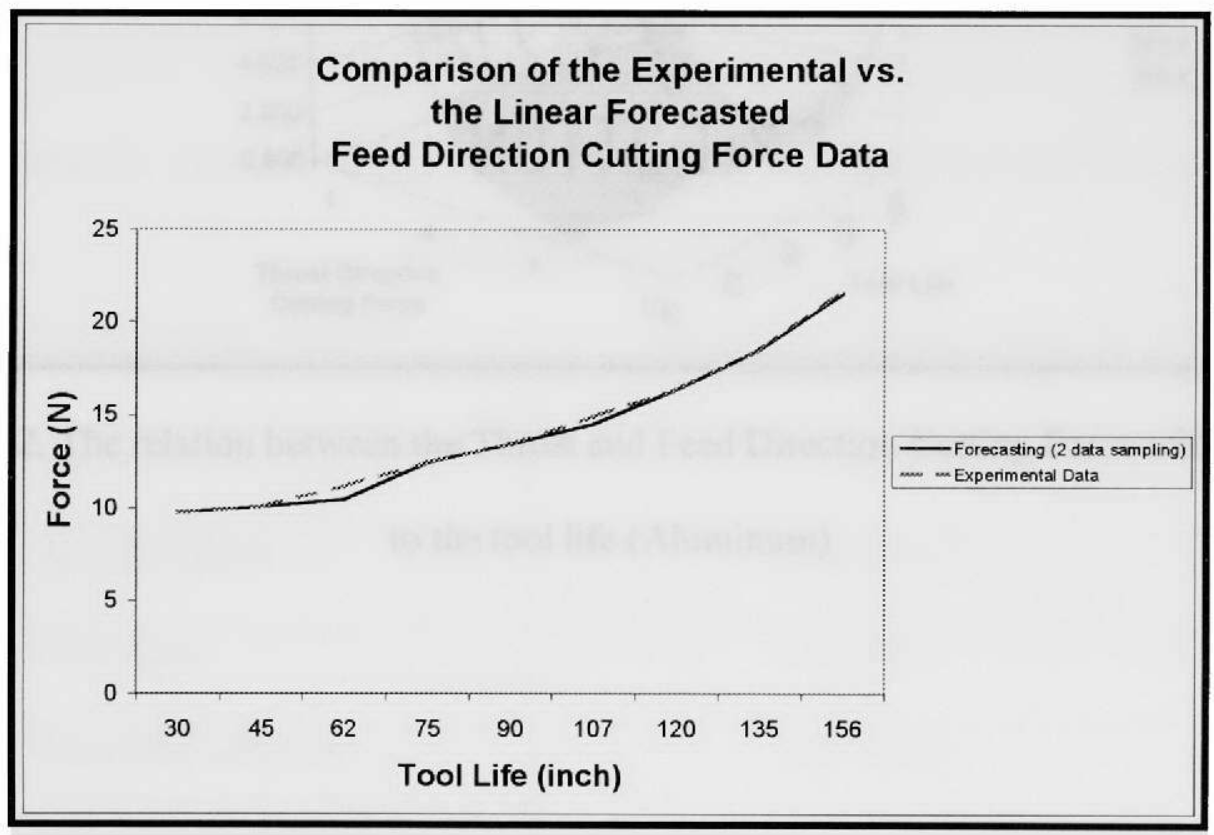

Figure 31.b. Comparison of the Experimental and the Forecasted Data for Feed Direction Cutting Force (Aluminum Workpiece) 
The relation between the Thrust $(X)$ and Feed $(Y)$ Direction Cutting Force with respect to the tool life in the machining of Aluminum workpiece is presented in Figure 32.

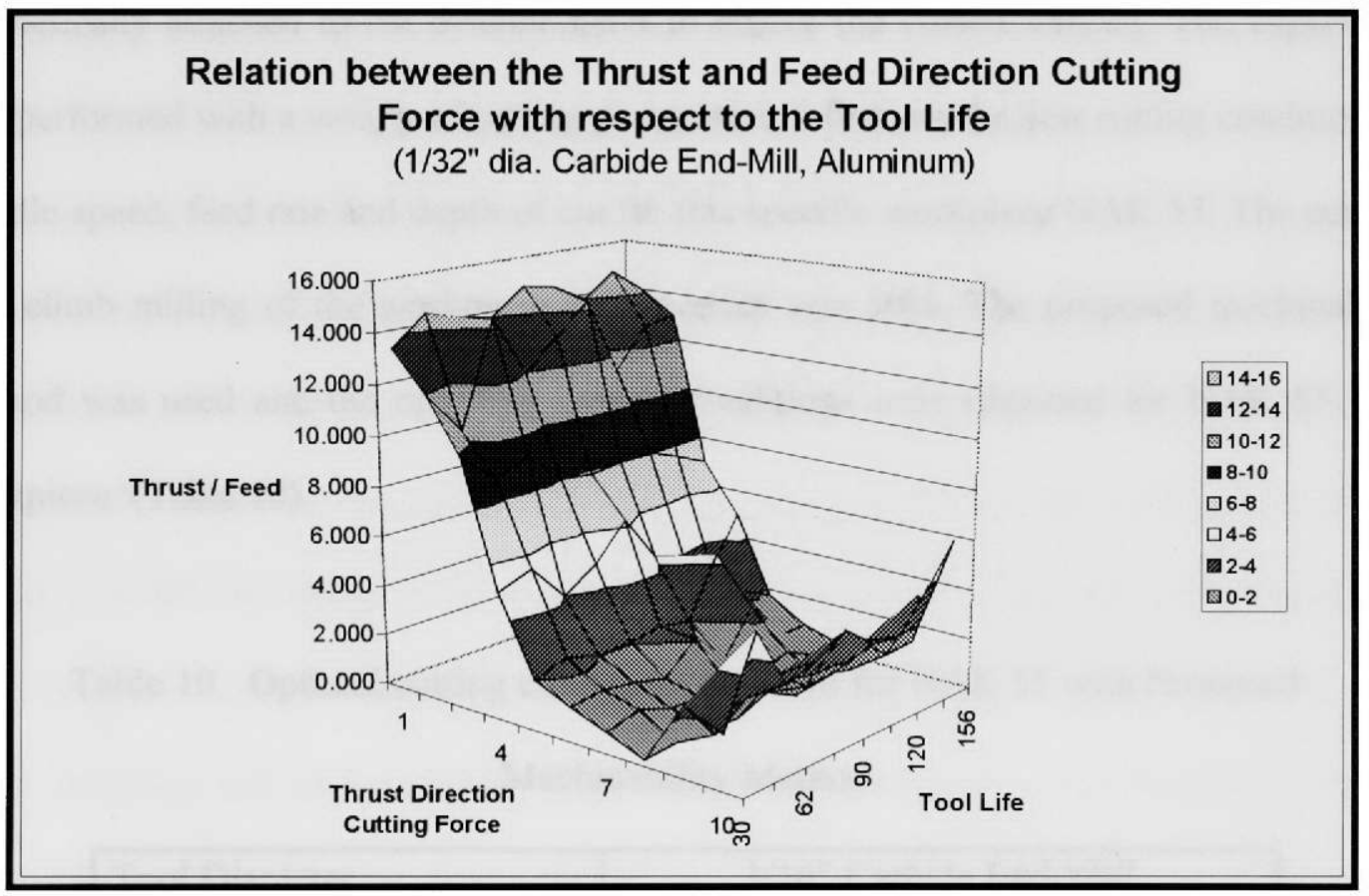

Figure 32. The relation between the Thrust and Feed Direction Cutting Force with respect to the tool life (Aluminum) 
The machinability of NAK 55 was studied. Carbide tools with 0.0625 and 0.030 inches diameter and two flutes were used. Addition to the cutting force data in feed and thrust direction (2-channel record) acoustic emission signal of the cut was also collected and recorded. (1-chnanel) The steel NAK 55 workpiece which has $(4 \times 3 \times 1$ inches) dimensions, was clamped to the dynamometer and the acoustic emission sensor was magnetically attached to the dynamometer to ensure the closest contact. The experiment was performed with a variety of cutting parameters to find out the best cutting conditions as spindle speed, feed rate and depth of cut for this specific workpiece NAK 55. The cut was face climb milling of the workpiece. The overlap was $50 \%$. The proposed machinability method was used and the optimum cutting conditions were obtained for NAK 55 Steel workpiece. (Table 10).

Table 10. Optimal cutting conditions obtained for NAK 55 with Proposed Machinability Method

\begin{tabular}{|l|c|}
\hline Tool Diameter & 1/16" Carbide End-Mill \\
\hline Depth of Cut & $3 \mathrm{~d} / 4$ \\
\hline Spindle Speed & $15,000 \mathrm{rpm}$ \\
\hline Feed Rate & $2.5 \mathrm{ipm}$ \\
\hline Tool Life obtained & 250 inches \\
\hline
\end{tabular}


For 0.0625 inches diameter carbide end-mill, 15,000-rpm spindle speed, $2.5 \mathrm{ipm}$ feed rate and $3 \mathrm{~d} / 4$ depth of cut were chosen as optimized conditions and tool wear analysis was conducted with these conditions. 250 inches tool life was obtained with the optimized cutting conditions.

Cutting force variation during the micro end milling of NAK 55 did not have the same trend that graphite electrodes had. The cutting force in $X$ and $Y$ directions slightly fluctuated but did not increase with the usage of the tool. These results are presented in Figure 33. Table 11 presents the cutting force variation with the usage of the tool. The thrust and feed direction cutting force during the tool breakage pass on the workpiece are presented in Figure 34. Cutting forces were larger for a certain amount of tool life at the beginning of the experiment and later tool became dull and cutting force slightly decreased. The overall analysis of the data showed that the characteristics of the cutting force of the cutting tool did not change. The reason for this phenomenon is that the tool material and the workpiece material have similar material characteristics. Tool and workpiece have closer hardness and tool probably wears out the tool gradually. Tool breakage happens when an excessive bending force applied to the tool. Also the low-frequency acoustic emission signal of the machining process and its frequency domain representation were shown in Figure 35. Cutting Forces and Acoustic Emission data during the experiments had a constant trend to be stable, but when the excessive bending force passed the limits of the tool, the breakage occurred. 


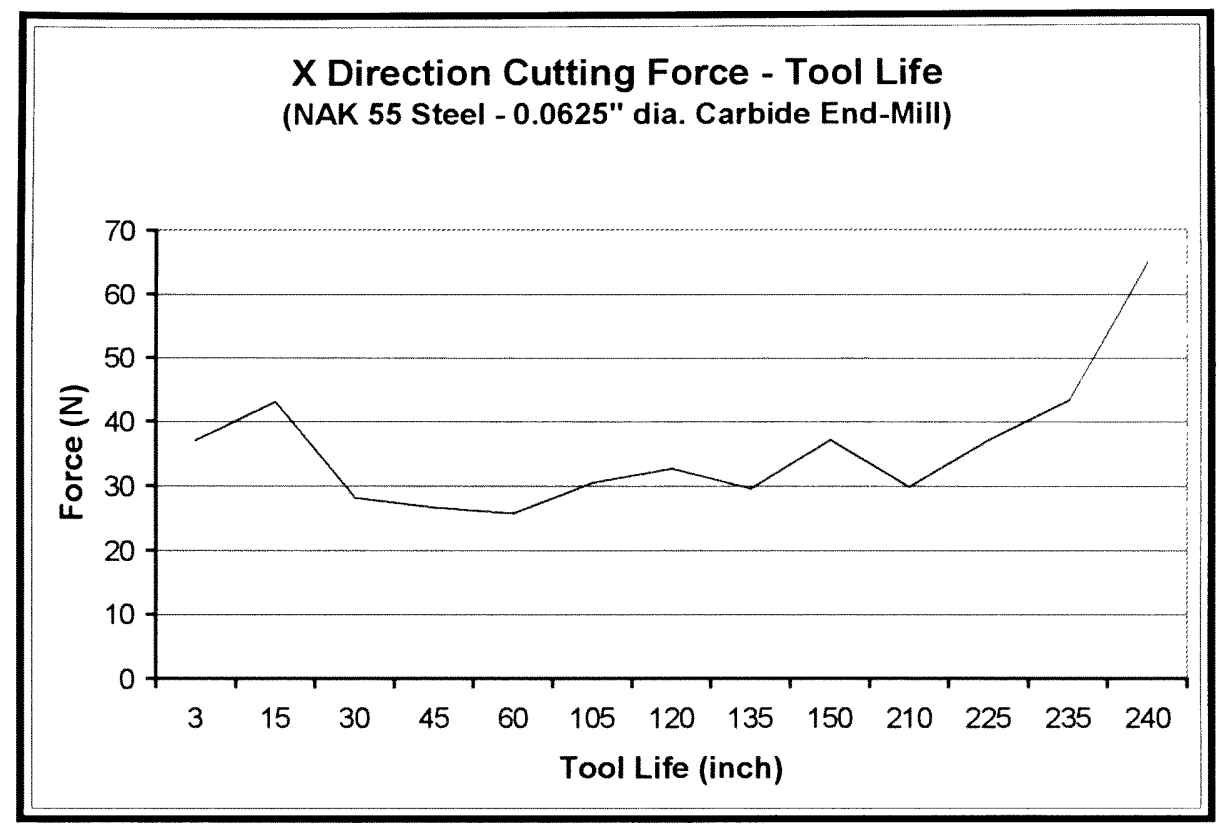

Figure 33.a. Thrust Direction Cutting Force Variation with Tool Usage on NAK 55 Steel

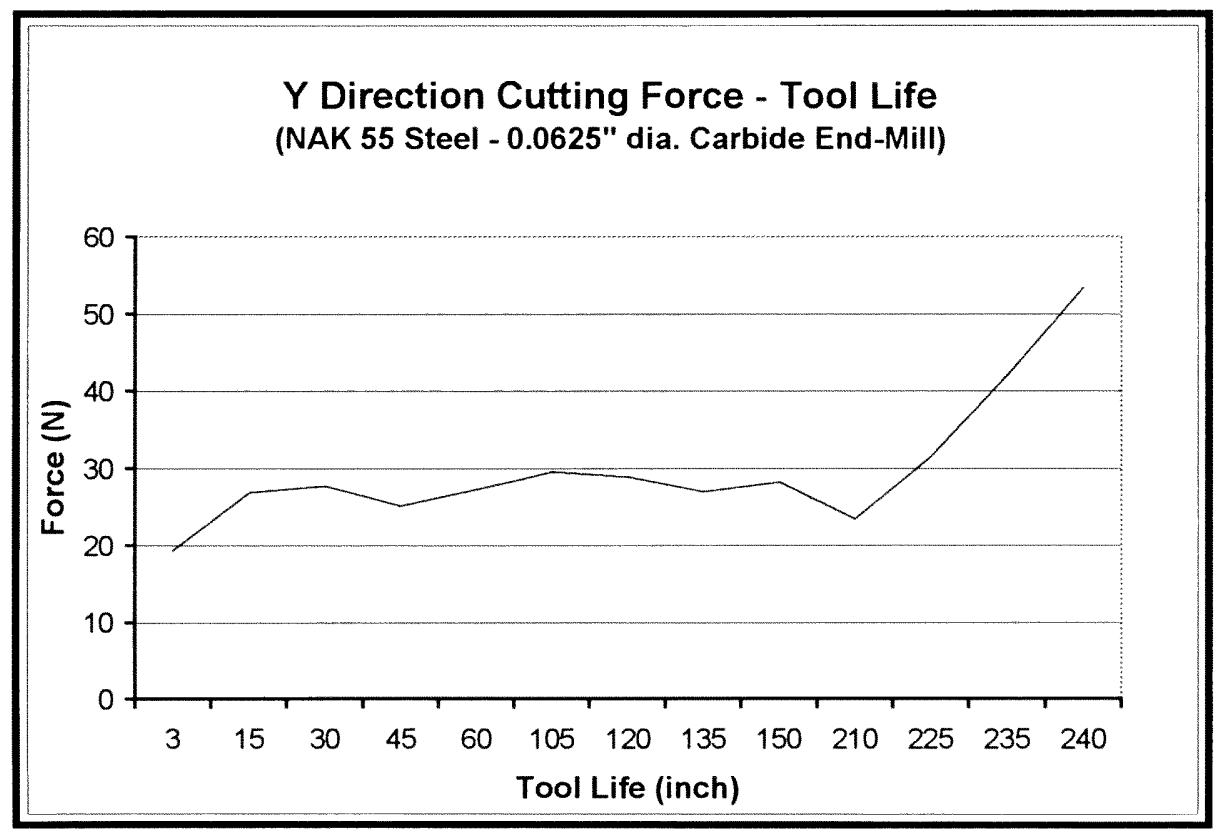

Figure 33.b. Feed Direction Cutting Force Variation with Tool Usage on NAK 55 Steel 


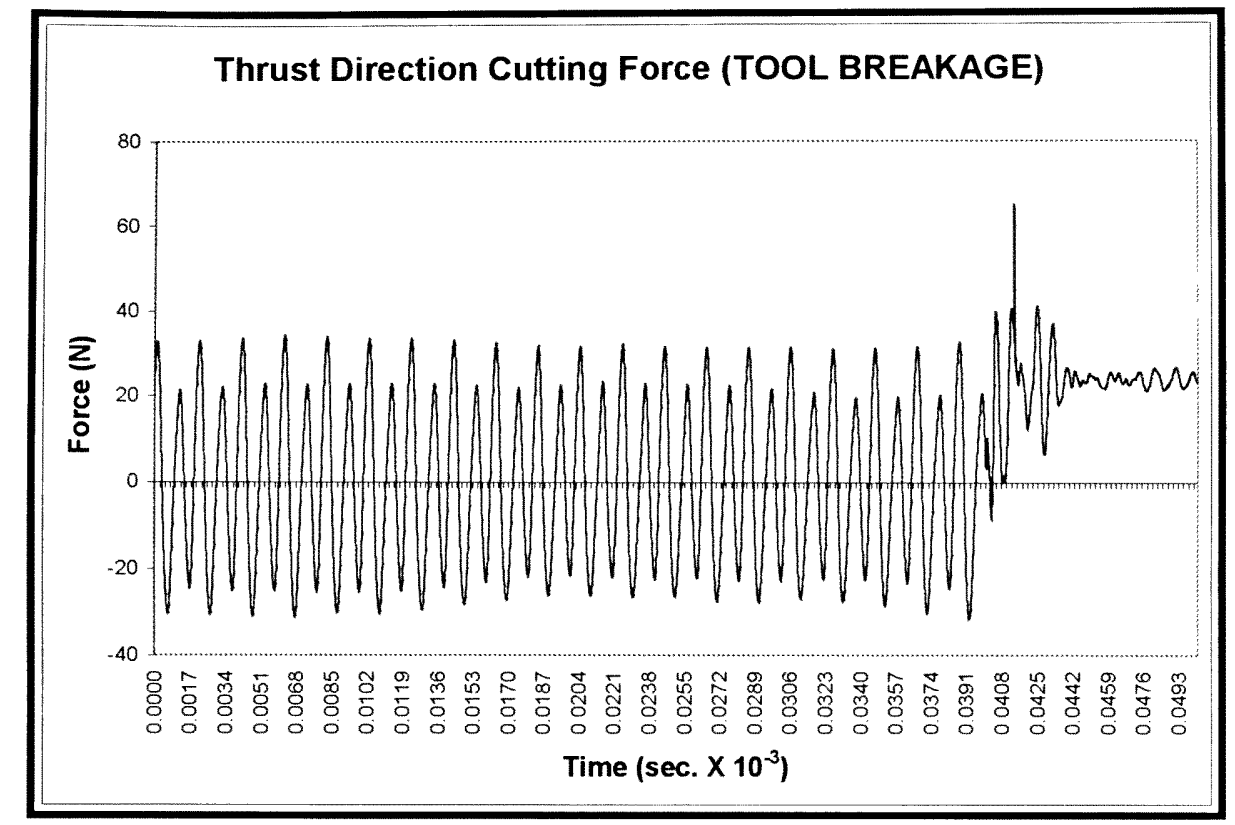

Figure 34.a. Thrust Direction Cutting Force of 1/16" Diameter Carbide End-Mill (Tool Breakage)

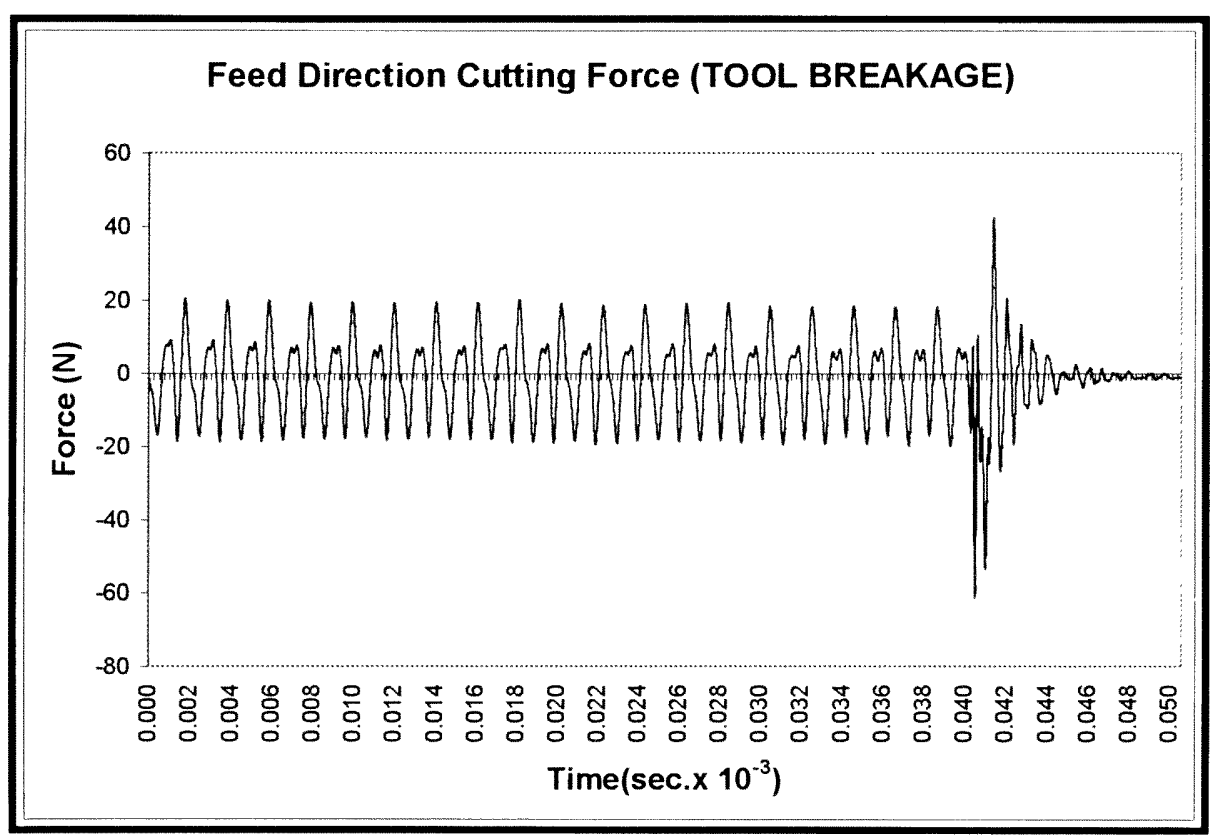

Figure 34.b. Feed Direction Cutting Force of 1/16" Diameter Carbide End-Mill (Tool Breakage) 


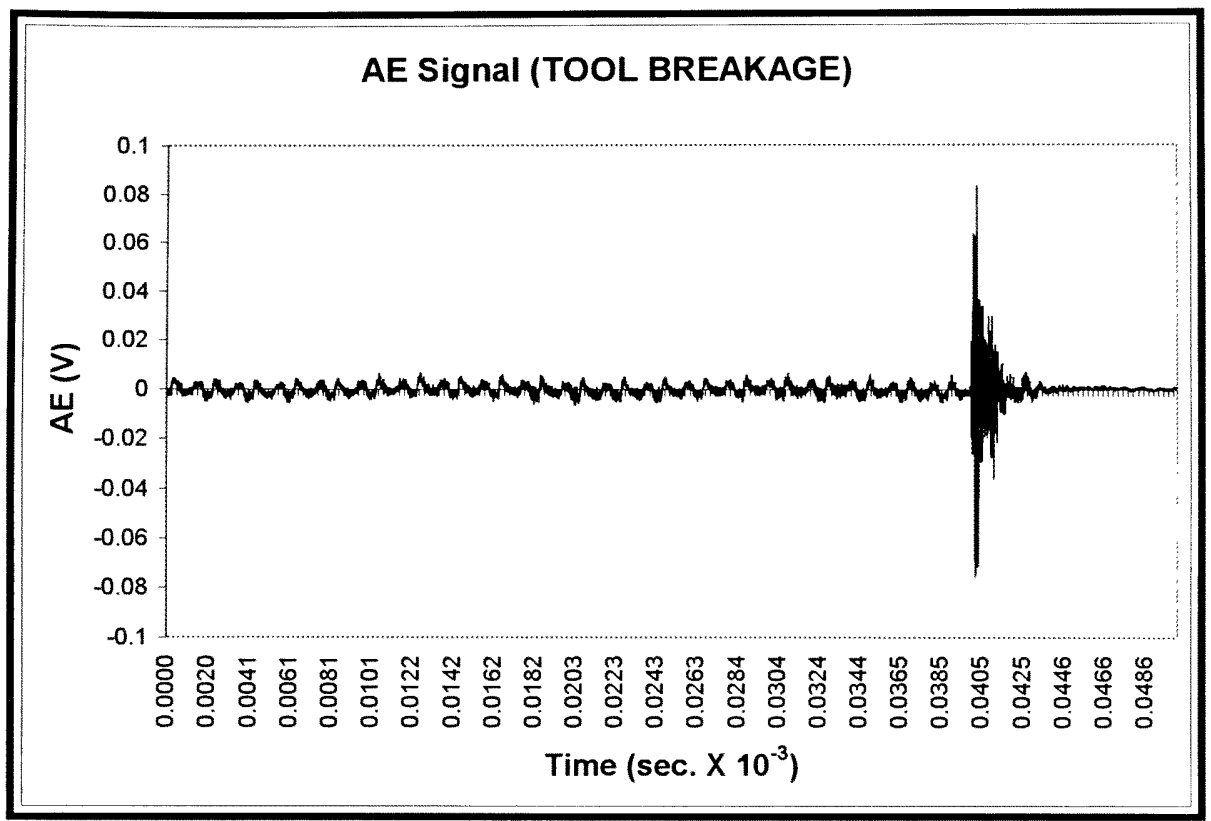

Figure 35.a. Acoustic Emission Signal of 1/16" Diameter Carbide End-Mill (Tool Breakage)

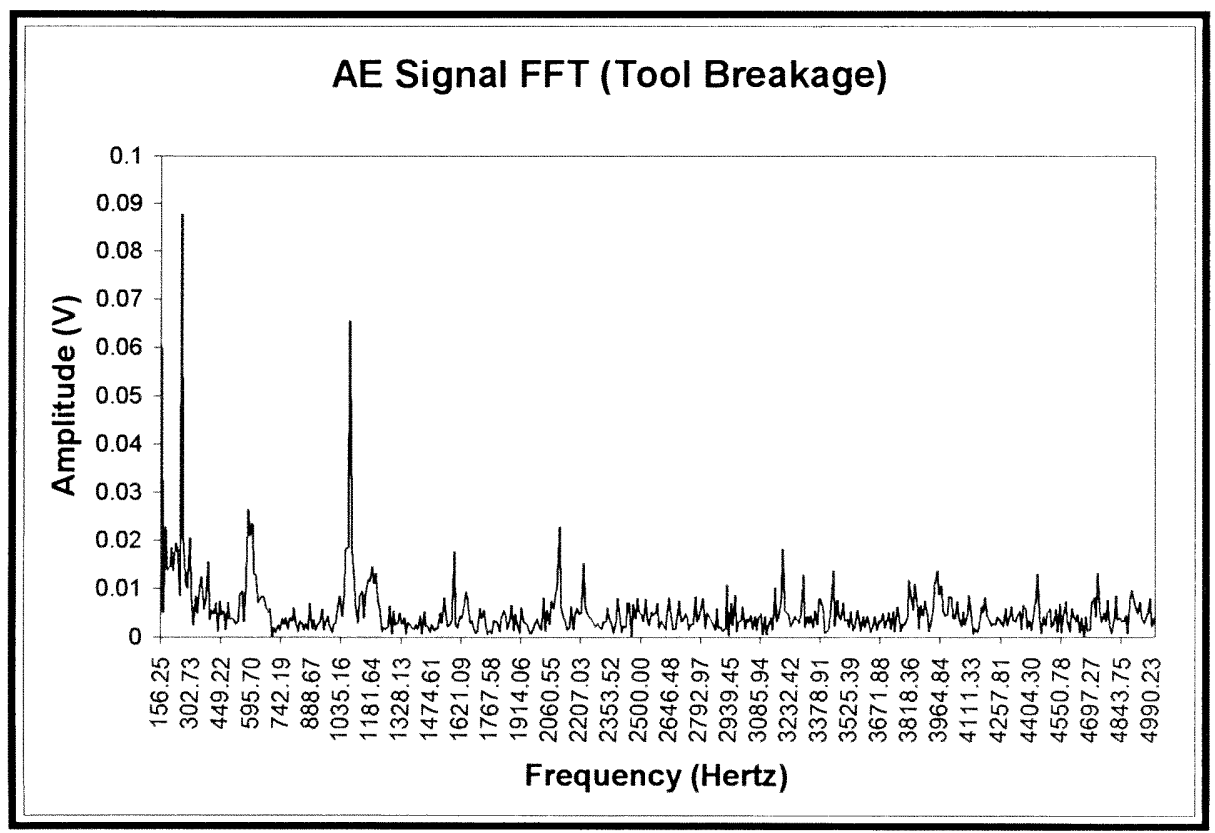

Figure 35.b. FFT of the Acoustic Emission Signal for 1/16" Diameter Carbide End-Mill (Tool Breakage) 
Table 11. Cutting Forces -Tool Life Results in Tool Wear Experiment (NAK 55 Steel)

\begin{tabular}{|r|c|c|r|}
\hline Cutting Force in Thrust Dir. (N) & $\begin{array}{c}\text { Feed Rate } \\
2.5 \text { ipm }\end{array}$ & Cutting Force in Feed Dir. (N) & $\begin{array}{c}\text { Feed Rate } \\
2.5 \text { ipm }\end{array}$ \\
\hline \multicolumn{1}{|c|}{ Tool Life (inch) } & \multicolumn{1}{|c|}{ Force } & Tool Life (inch) & Force \\
\hline 3 & 37.05 & 3 & 19.35 \\
\hline 15 & 43.1 & 15 & 26.85 \\
\hline 30 & 28.25 & 30 & 27.7 \\
\hline 45 & 26.65 & 45 & 25.2 \\
\hline 60 & 25.8 & 60 & 27.25 \\
\hline 105 & 30.5 & 105 & 29.5 \\
\hline 120 & 32.75 & 120 & 28.95 \\
\hline 135 & 29.6 & 135 & 27 \\
\hline 150 & 37.15 & 150 & 28.25 \\
\hline 210 & 29.85 & 210 & 23.4 \\
\hline 225 & 37.15 & 225 & 31.5 \\
\hline 235 & 43.24 & 225 & 42 \\
\hline 240 & 65 & 240 & 53.35 \\
\hline & & &
\end{tabular}

NAK 55 Steel workpiece cutting force data was also studied with curve fitting analysis technique to evaluate the trend of the increase in cutting forces. Linear and exponential curve fitting techniques were applied to the data. The results are presented in Figure 36.a., 36.b., 37.a., and 37.b. The result of the study showed that linear curve fitted better than the exponential curve. An approximate interpolated cutting force variation equation is obtained from this analysis.

Also, the experiment was repeated with 0.030 inches diameter carbide end-mill. The trend of the cutting force was the same. 


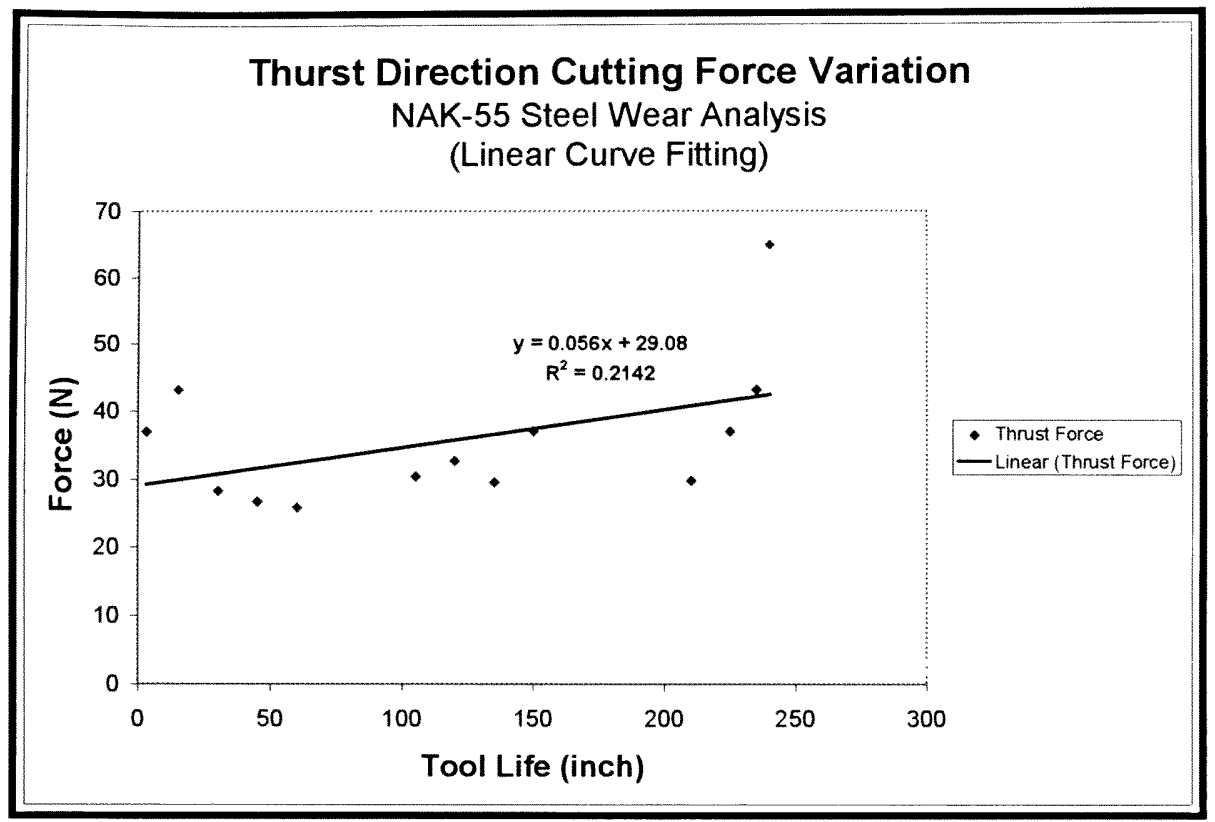

Figure 36.a. Linear Curve Fitting to the Experimental Thrust Direction Cutting Force (NAK 55 Steel)

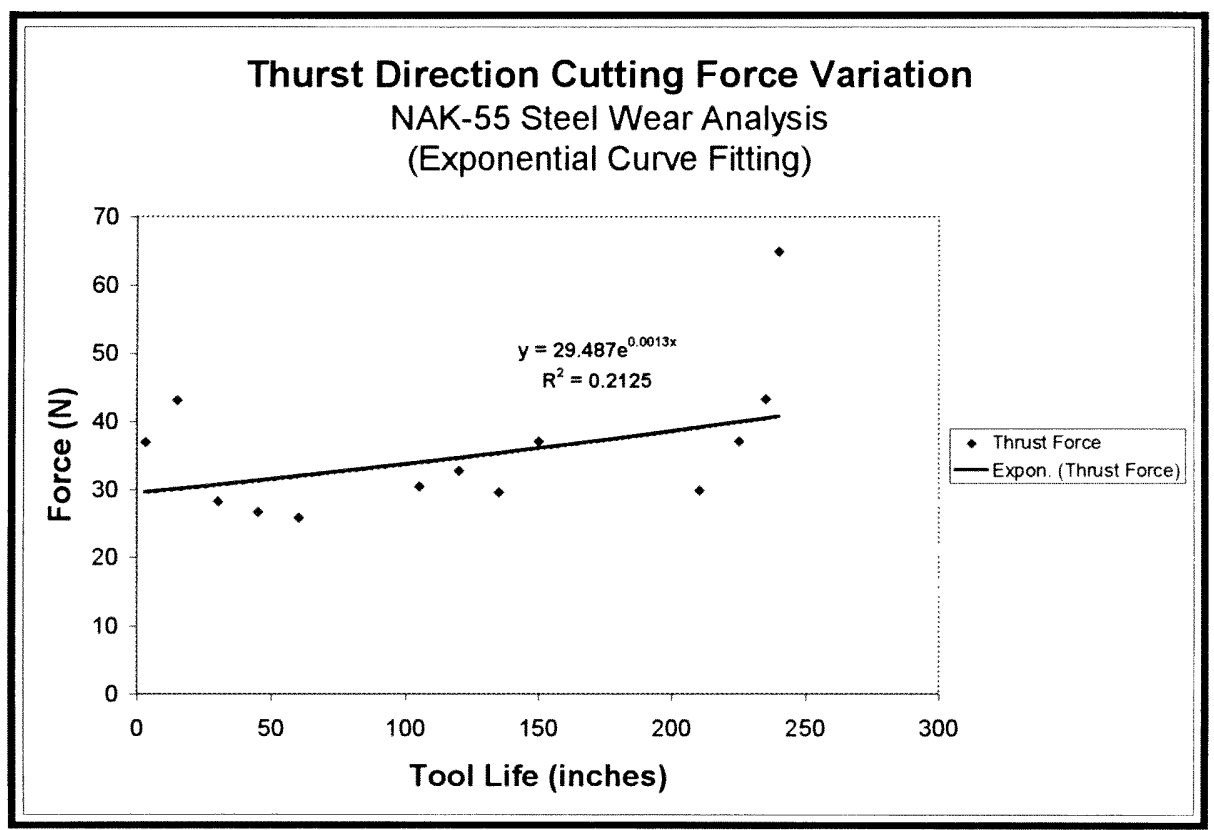

Figure 36.b. Exponential Curve Fitting to the Experimental Thrust Direction Cutting Force (NAK 55 Steel) 


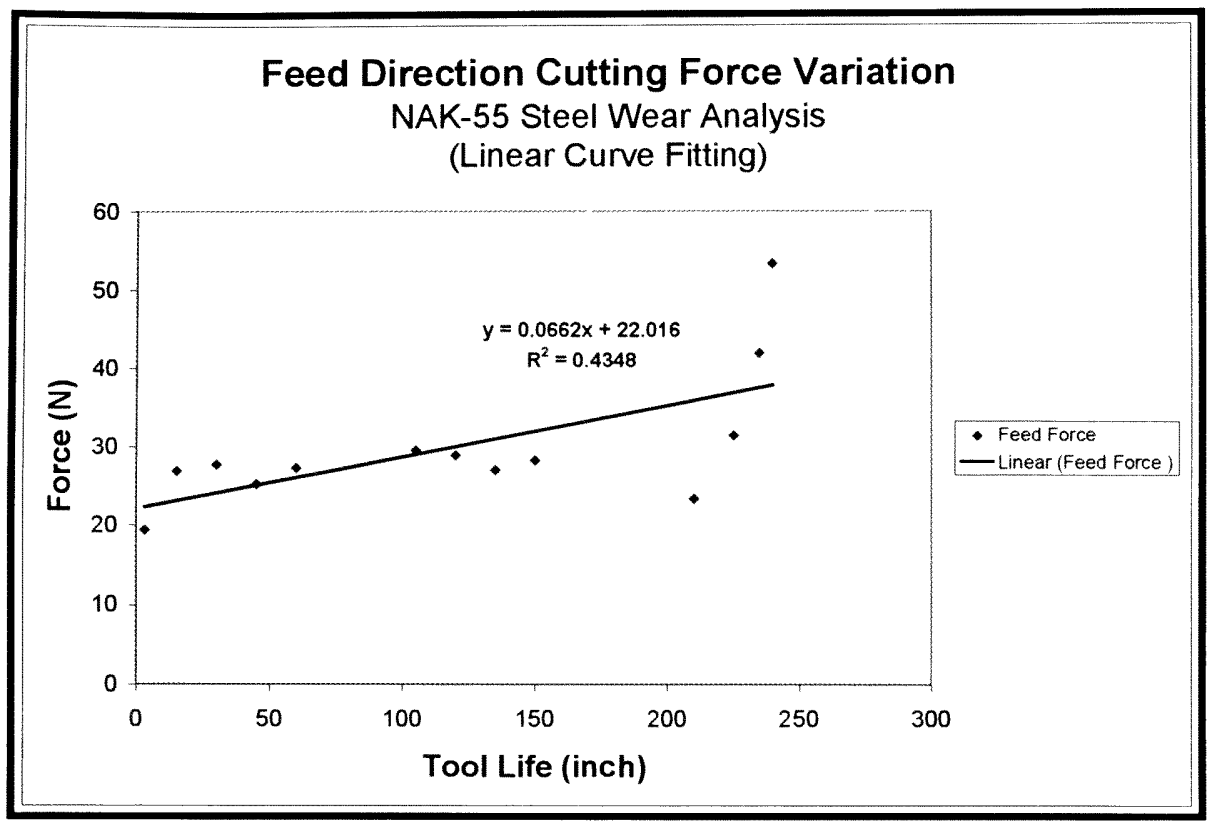

Figure 37.a. Linear Curve Fitting to the Experimental Feed Direction Cutting Force (NAK 55 Steel)

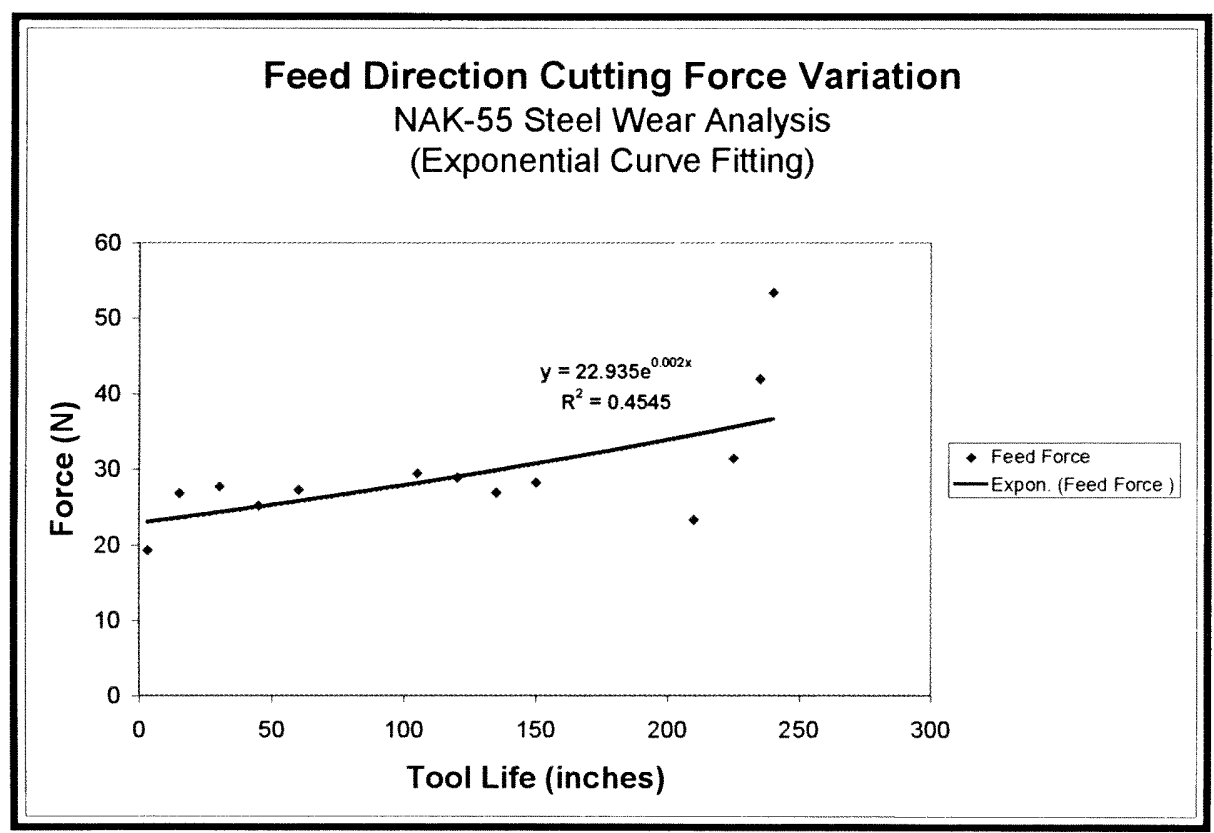

Figure 37.b. Exponential Curve Fitting to the Experimental Feed Direction Cutting Force (NAK 55 Steel) 


\section{V.2. Performance and Reliability of the Neural Network Based Periodic}

Tool Inspector $\left(\mathrm{N}^{2} \mathrm{PTI}\right)$

The Neural Network based Periodic Tool Inspector $\left(\mathrm{N}^{2} \mathrm{PTI}\right)$ was introduced to estimate the tool wear in end-milling operations. The proposed method is used to estimate the tool life during the micro end milling of graphite electrodes (POCOEDMC-3), aluminum and steel (NAK 55). The results are presented in the following sections.

\section{Graphite Electrodes (POCOEDMC-3):}

The $\mathrm{N}^{2} \mathrm{PTI}$ requires the tool to cut a test piece, which is attached to a dynamometer. The variation of the feed and thrust direction cutting force is measured while the secondary part is cut. Neural networks estimate the tool's wear from these two inputs. Three different networks are used in this study: Backpropagation NN (ANALOG), Probabilistic NN (BASIC, SEPVAR).

The main workpiece, a POCO-EDM-C3 electrode, and an aluminum test piece are attached on a 9257B three-component Kistler dynamometer. The dynamometer is connected to a charge amplifier. The feed and thrust direction forces were digitized, by using a Nicolet 310 digital oscilloscope. Experimental setup, which was used to collect the training data, was presented in Figure 10.

A 1/16" carbide tool was used to collect the experimental data. The spindle speed was $15,000 \mathrm{rpm}$. The tool was worn by cutting POCO EDM-C3 electrode material with a 20 inch $/ \mathrm{min}$ feed rate and 0.030 inch depth of cut. To test the tool condition, an aluminum test piece was cut at $15,000 \mathrm{rpm}$ with a $5 \mathrm{inch} / \mathrm{min}$ feed rate and a 0.015 -inch depth of cut. Experimental results are listed in Table 12. 
The experimentally observed cutting force variation readings are presented in Figure 38 by using bubble diagrams. The size of the bubble corresponds to the tool life. The observed thrust and feed direction force variations are shown on the $X$ and $Y$ axes, respectively. The diagram showed that both of the cutting force variations increased while the tool wore out.

Table 12. Cutting Forces -Tool Life Results in Tool Wear Experiment (0.0625")

\begin{tabular}{|c|c|c|c|}
\hline Cutting Force in Thrust Dir. (N) & $\begin{array}{c}\text { Feed Rate } \\
5 \mathrm{ipm}\end{array}$ & Cutting Force in Feed Dir. (N) & $\begin{array}{c}\text { Feed Rate } \\
5 \mathrm{ipm}\end{array}$ \\
\hline Tool Life (inch) & Force & Tool Life (inch) & Force \\
\hline 150 & 8.6 & 150 & 8.5 \\
\hline 300 & 9.05 & 300 & 9.325 \\
\hline 450 & 10.725 & 450 & 14.475 \\
\hline 600 & 18.95 & 600 & 15.225 \\
\hline 750 & 24.5 & 750 & 17.05 \\
\hline 900 & 27.15 & 900 & 17.725 \\
\hline 1050 & 30.75 & 1050 & 18.1 \\
\hline 1200 & 33.3 & 1200 & 19.2 \\
\hline 1350 & 35.5 & 1350 & 22 \\
\hline
\end{tabular}




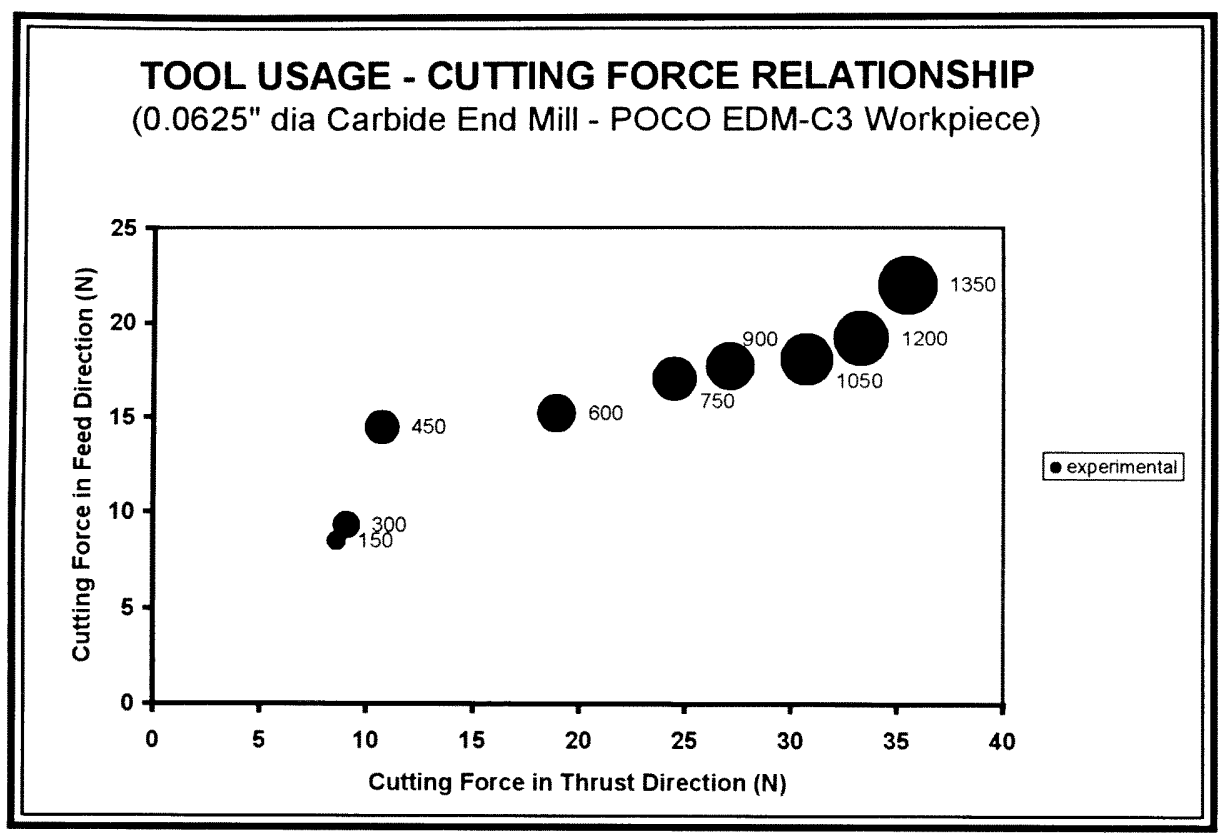

Figure 38. Tool Usage and Cutting Force Relation - Experimental Test Results

Five cases were given to three different neural networks for training. One of the networks was a backpropagation type neural network and the other two were Probabilistic Neural Networks (PNN). The BASIC PNN used single sigma for both inputs. The SEPVAR used different sigma for each input. After the training, the neural networks estimated the tool life of the training data (Figure 39) and four other cases they have never seen before (Figure 40). The estimated results are presented in Table 13. 


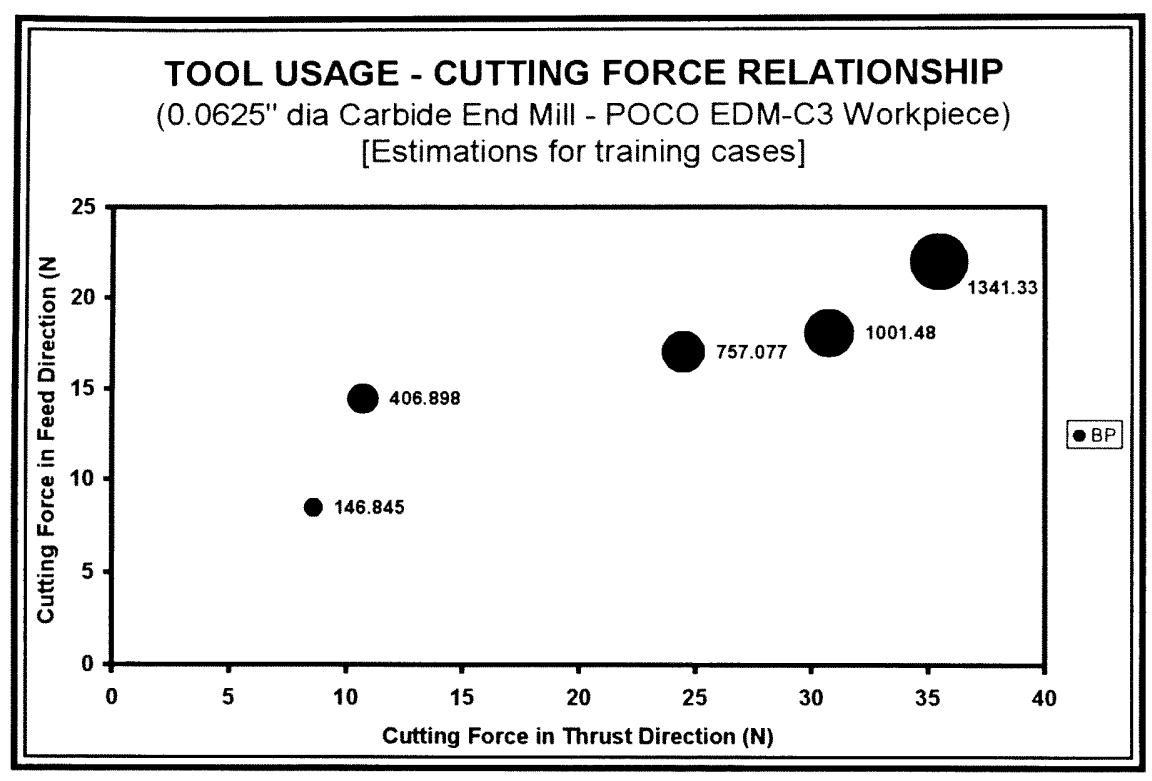

Figure 39.a. Estimated Results of the Training Cases with Analog BP NN

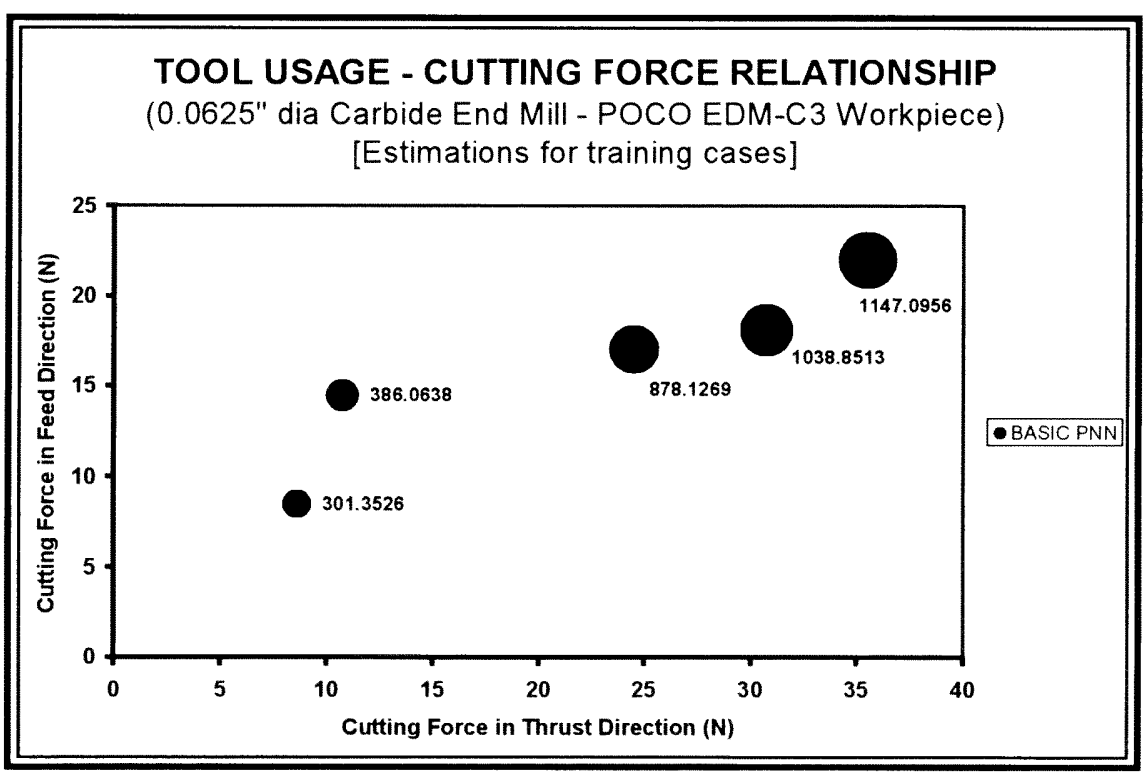

Figure 39.b. Estimated Results of the Training Cases with PNN BASIC 


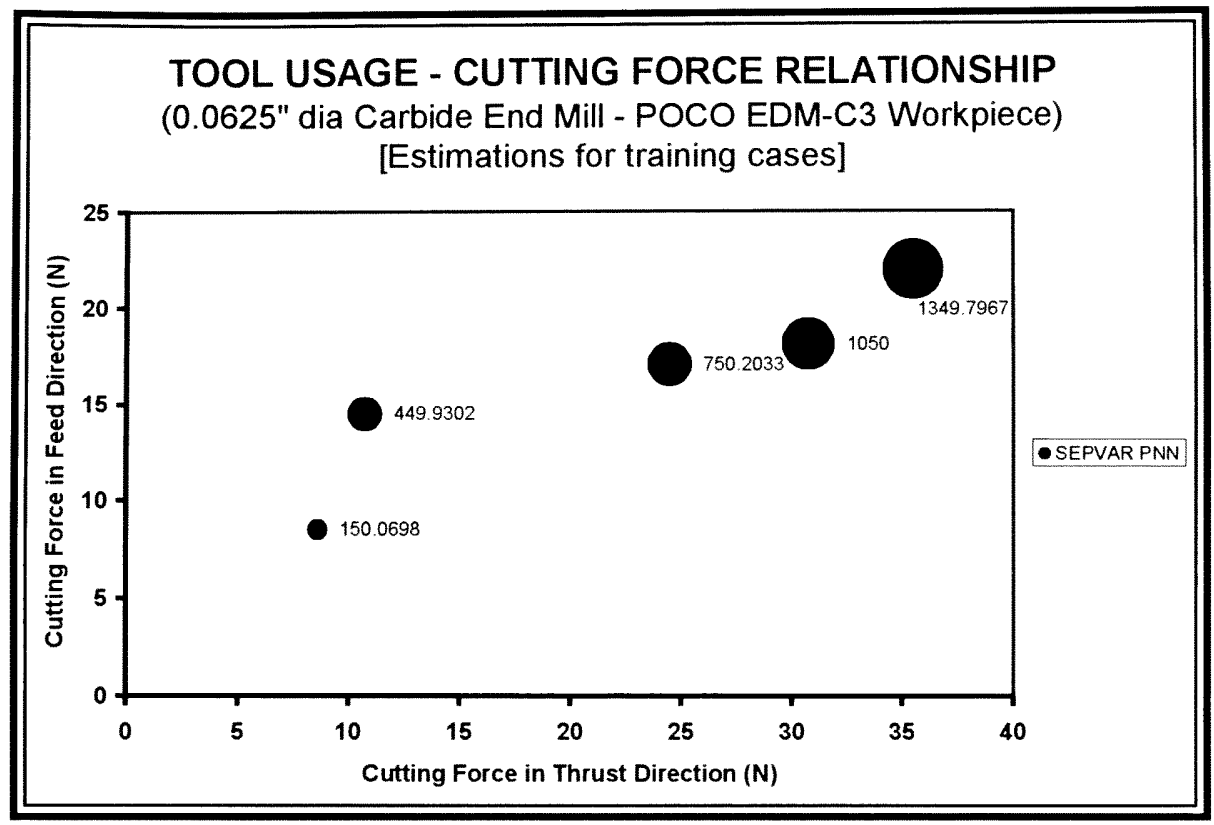

Figure 39.c. Estimated Results of the Training Cases with PNN SEPVAR

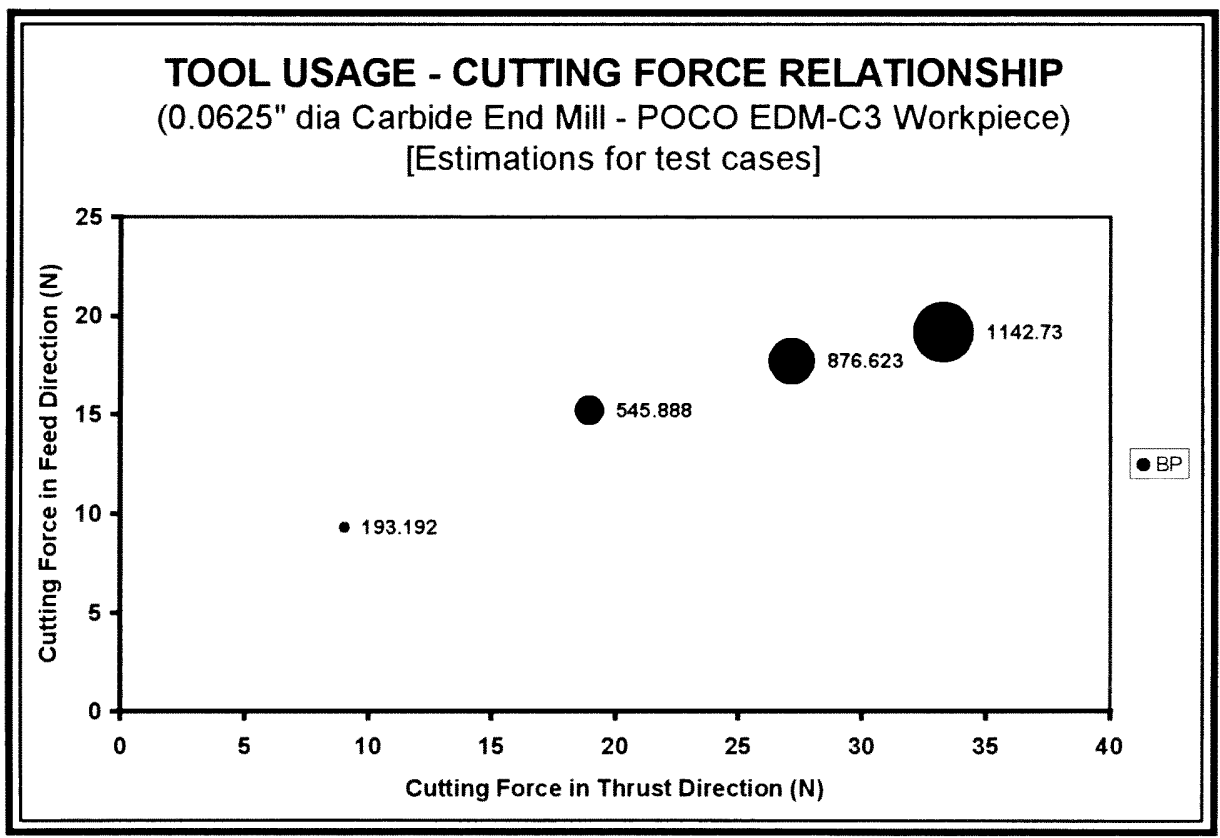

Figure 40.a. Estimated Results of the Test Cases with Analog BP NN 


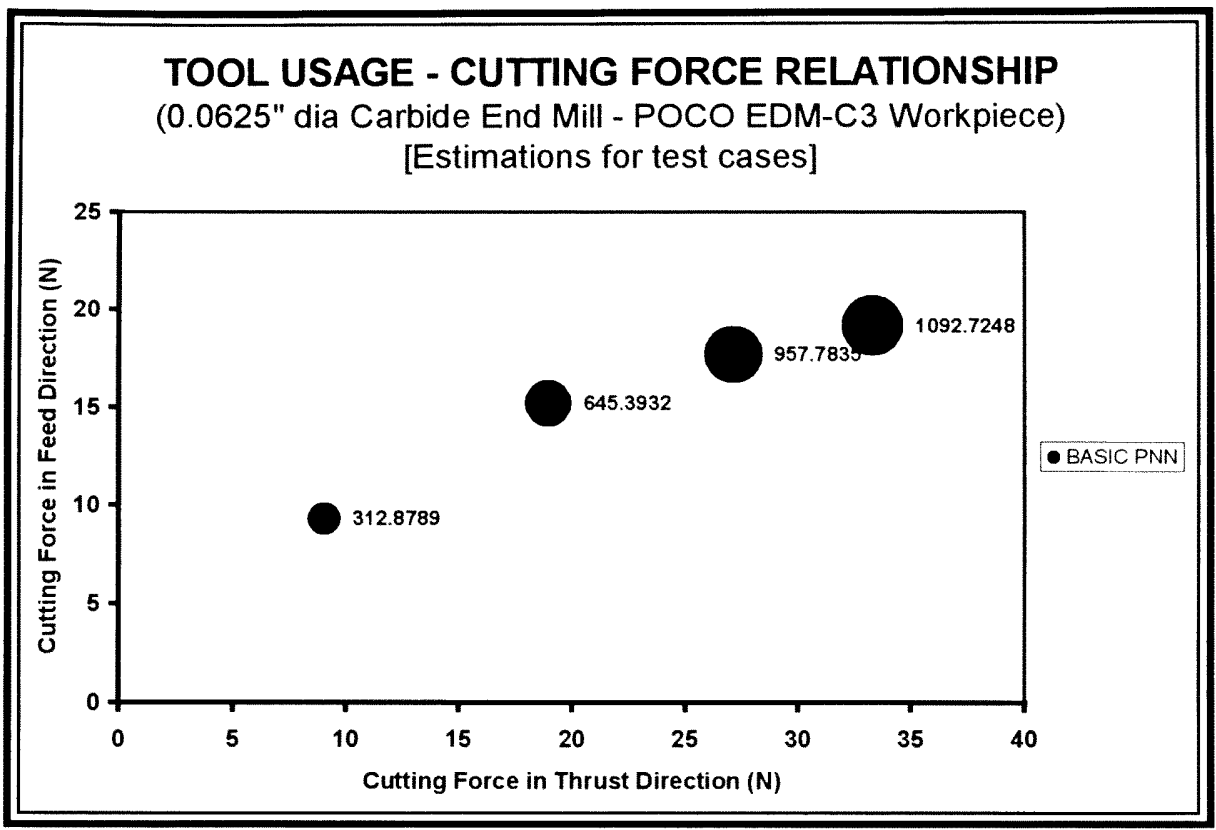

Figure 40.b. Estimated Results of the Test Cases with PNN BASIC

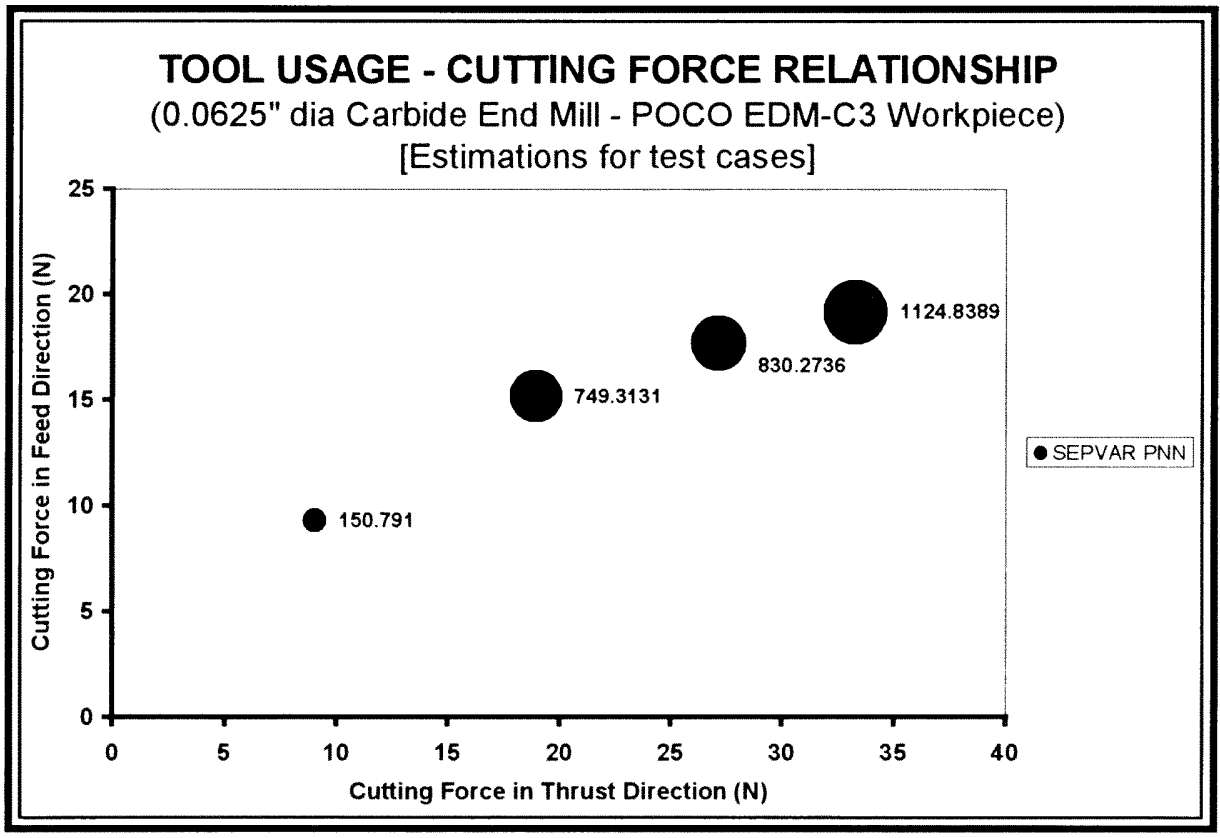

Figure 40.c. Estimated Results of the Test Cases with PNN SEPVAR 
Table 13. Comparison of the Experimental Data and Neural Network Estimation Data

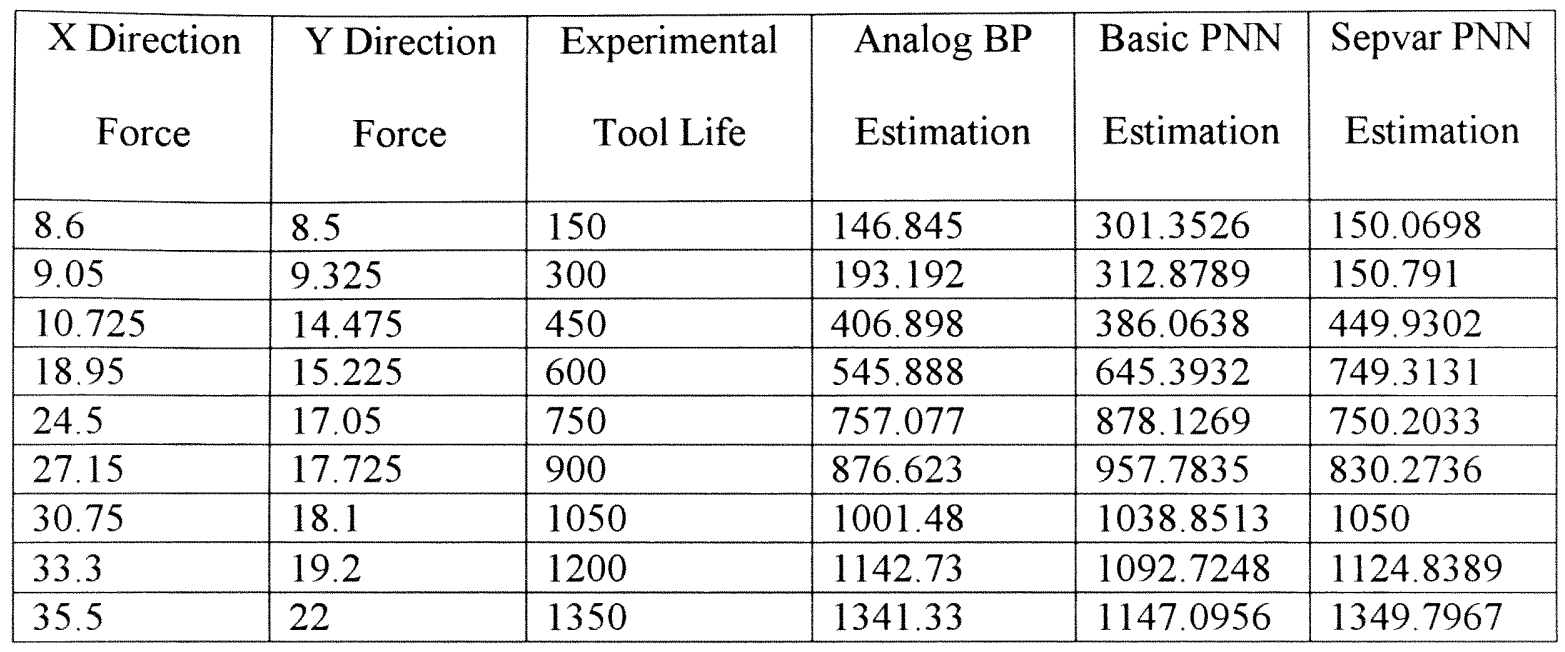

The performances of all the networks were very similar. All of them estimated the test cases with acceptable accuracy. The training process of the PNN is almost completely automated and takes much a shorter time than backpropagation. Backpropagation can create much more compact neural networks than PNN and generalizes the given information much more effectively. The performance of the used neural networks and the experimental data was compared and plotted together for training and test cases. (Figure 41) 


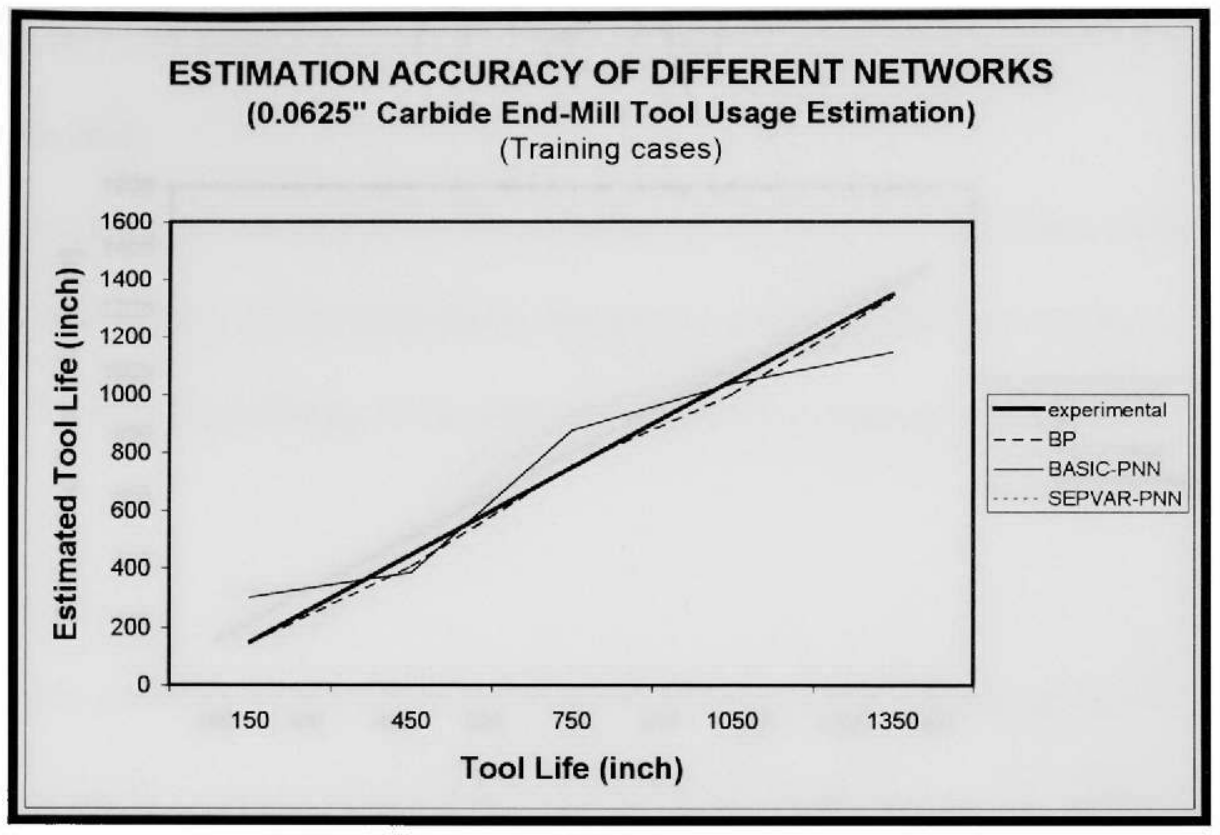

Figure 41.a. Estimation Accuracy Comparison of the Three Different Neural Network with Training Case Cutting Force Data

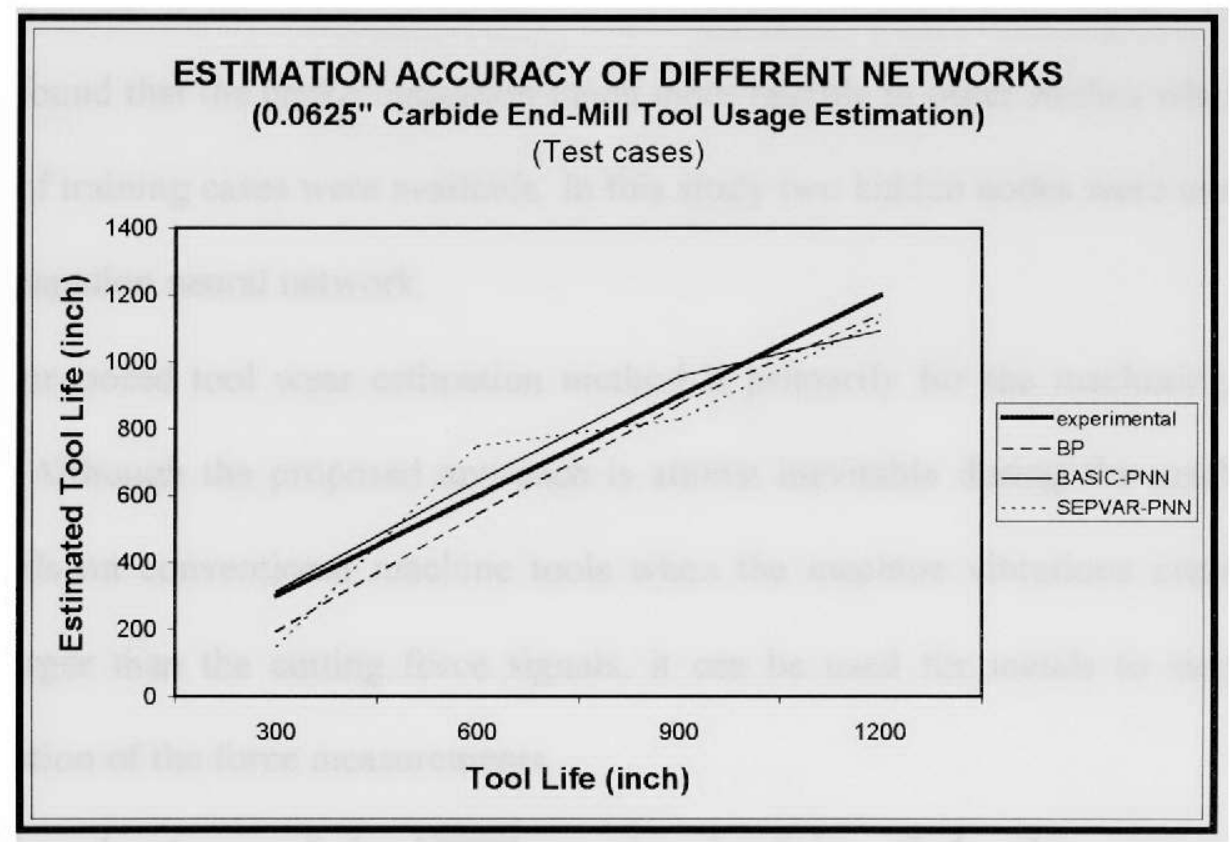

Figure 41.b. Estimation Accuracy Comparison of the Three Different Neural Network with Test Case Cutting Force Data 


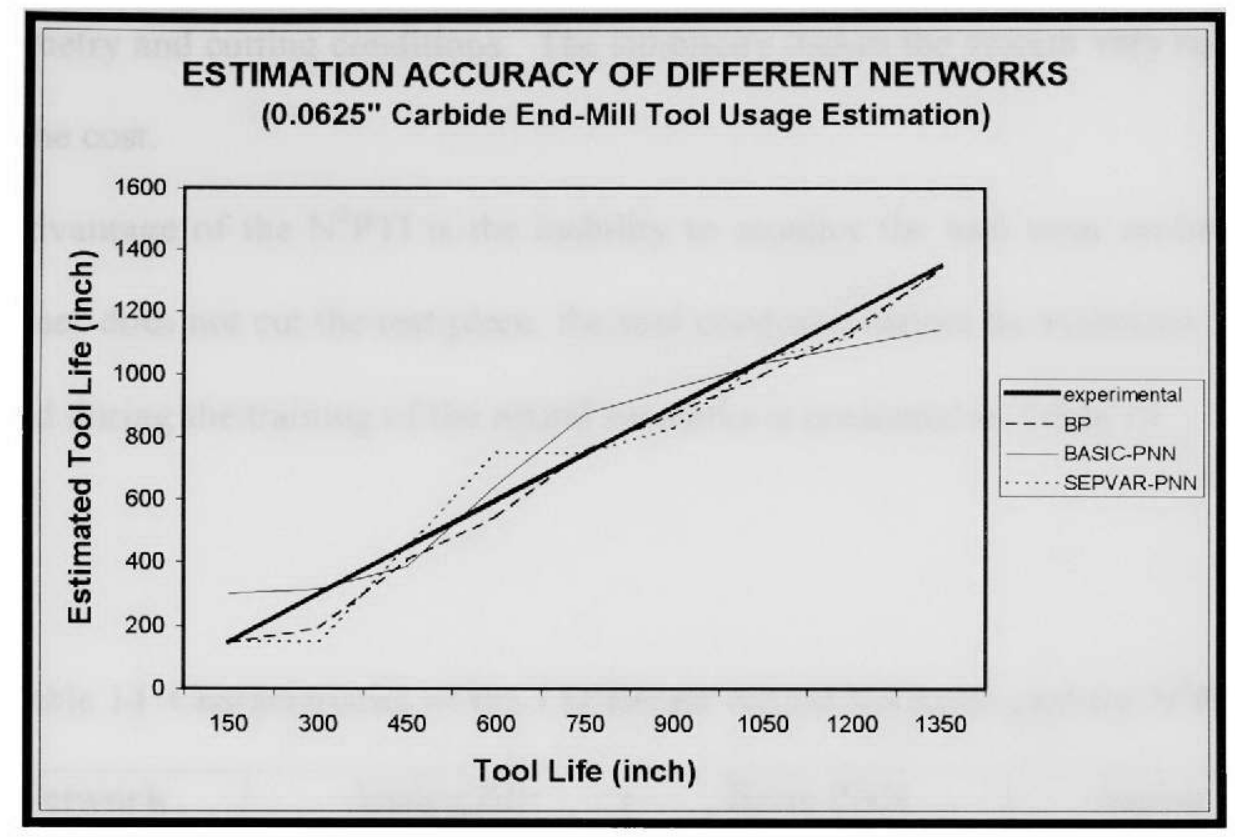

Figure 41.c. Estimation Accuracy of the Three NN for the Tool Life

It is found that the backpropagation much more reliable in other studies when a small number of training cases were available. In this study two hidden nodes were used for the backpropagation neural network.

The proposed tool wear estimation method is primarily for the machining of nonmetals. Although the proposed approach is almost inevitable during the machining of non-metals on conventional machine tools when the machine vibrations create inertia forces larger than the cutting force signals, it can be used for metals to simplify the classification of the force measurements.

The main advantages of the $\mathrm{N}^{2} \mathrm{PTI}$ are the simplicity of the data processing and classification. Because the cutting condition is the same, the only factor, which affects the cutting force, is the tool wear. There is no force variation related to a change of the 
chip geometry and cutting conditions. The simplicity makes the system very reliable and reduces the cost.

The disadvantage of the $\mathrm{N}^{2} \mathrm{PTI}$ is the inability to monitor the tool wear on-line. If the programmer does not cut the test piece, the tool condition cannot be evaluated. The final setup used during the training of the neural networks is presented in Table 14.

Table 14. Characteristics of the 3 Different Neural Network used for $\mathrm{N}^{2} \mathrm{PTI}$

\begin{tabular}{|c|c|c|c|}
\hline Neural Network & Analog BP & Basic PNN & Sepvar PNN \\
\hline Input Nodes & 2 & 2 & 2 \\
\hline Output Nodes & 1 & 1 & 1 \\
\hline Training Cases & 5 & 5 & 5 \\
\hline Test Cases & 4 & 4 & 4 \\
\hline Training Time & 11 seconds & 1.54 seconds & 1.63 seconds \\
\hline $\begin{array}{l}\text { Network } \\
\text { Proprieties }\end{array}$ & $\begin{array}{l}2 \text { Hidden Nodes } \\
0.6 \text { Learning Rate } \\
0.9 \text { Momentum }\end{array}$ & $\begin{array}{c}\text { 0.0 Sigma Low } \\
\text { 5.0 Sigma High } \\
5 \text { Sigma Tries }\end{array}$ & $\begin{array}{l}0.003 \text { Sigma Low } \\
\text { 5.0 Sigma High } \\
\text { 5 Sigma Tries }\end{array}$ \\
\hline
\end{tabular}

The same analysis was repeated by using a carbide end-mill with 0.030 inches diameter. The experimental results are presented in Figure 42. The $\mathrm{N}^{2} \mathrm{PTI}$ estimated the tool wear with acceptable accuracy. The measured cutting forces were smaller than the ones recorded with the bigger tool and some deviation existed. The results are presented in Figure 43 and 44 and 45. 


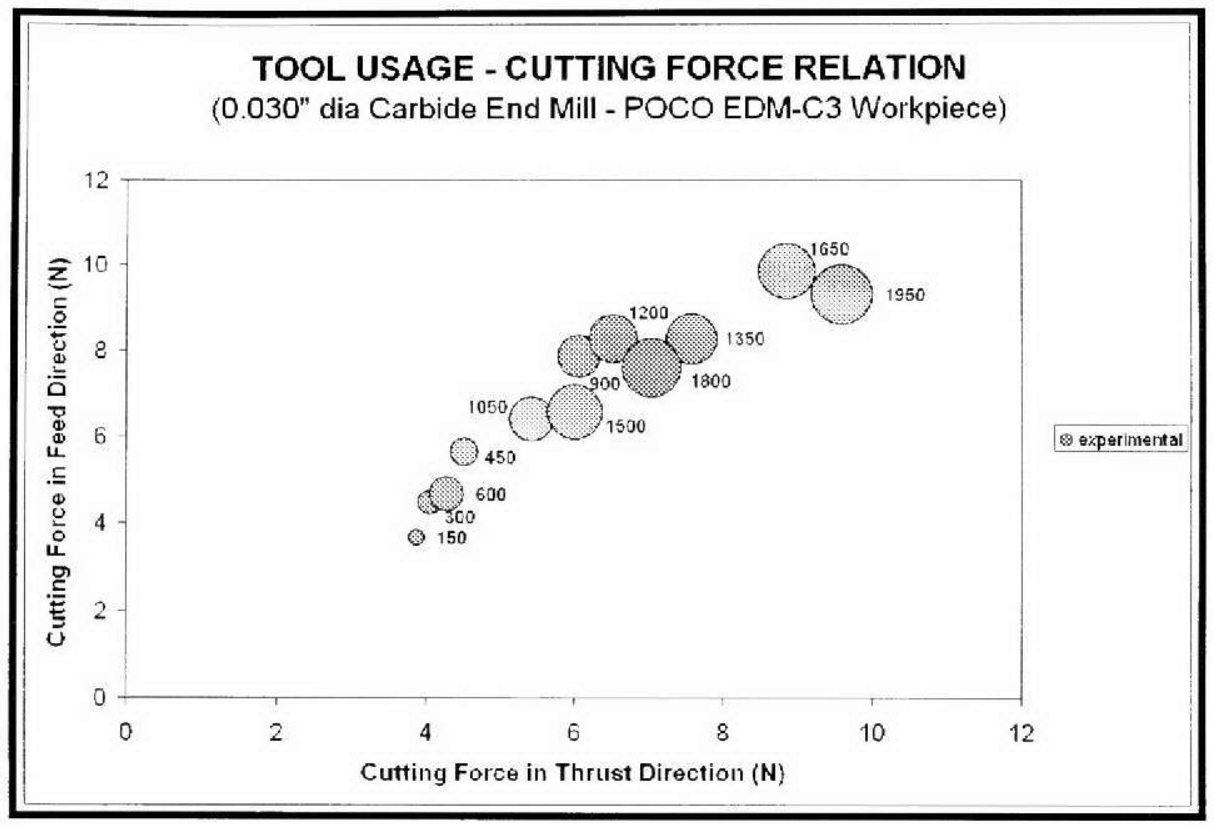

Figure 42. 0.030" Tool Usage and Cutting Force Relation - Experimental Test Results

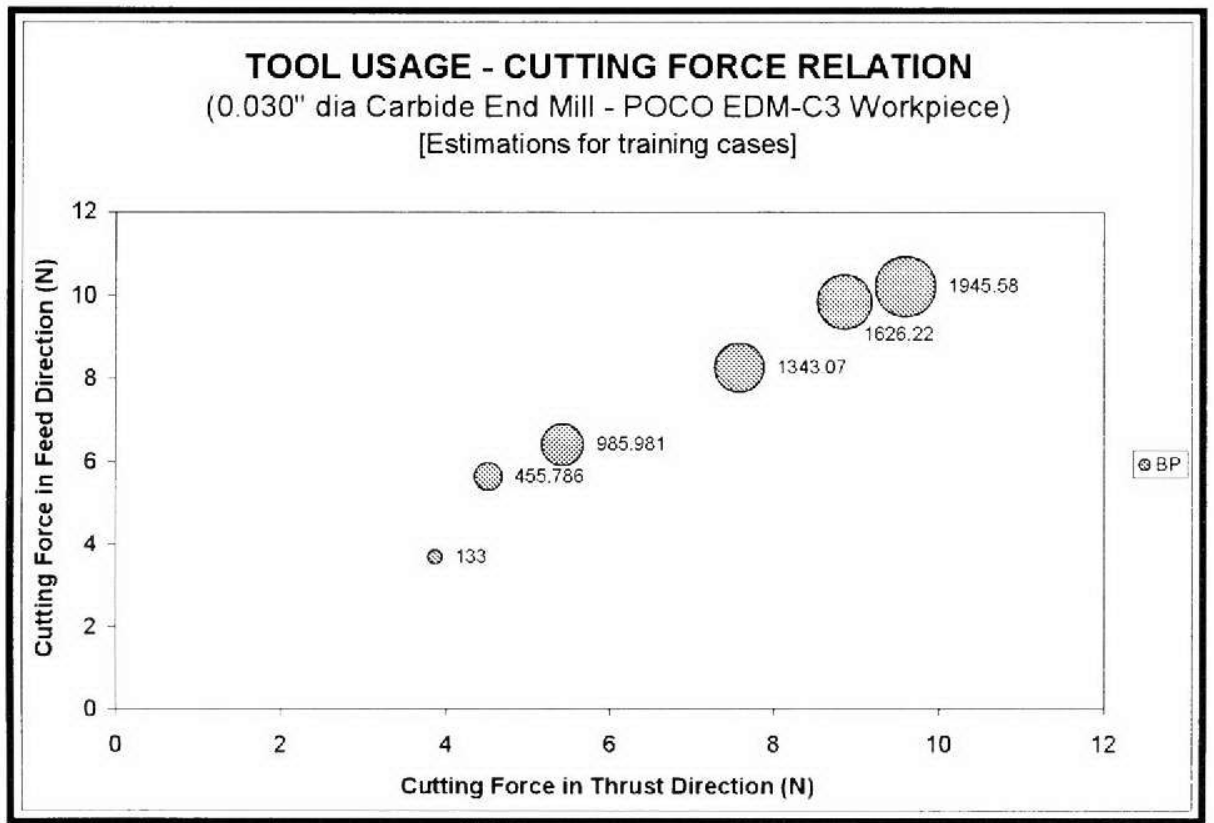

Figure 43.a. Estimated Results of the Training Cases with Analog BP NN for 0.030 " Tool 


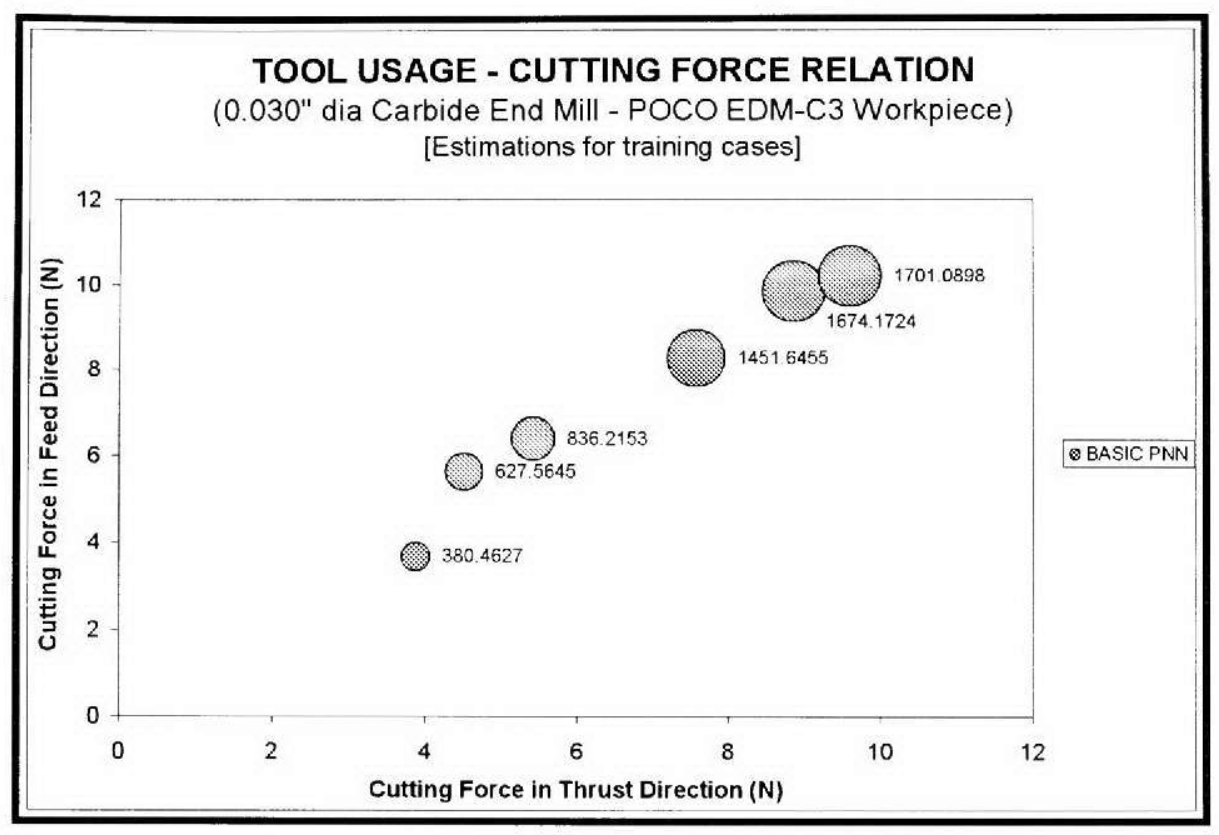

Figure 43.b. Estimated Results of the Training Cases with PNN BASIC for 0.030 " Tool

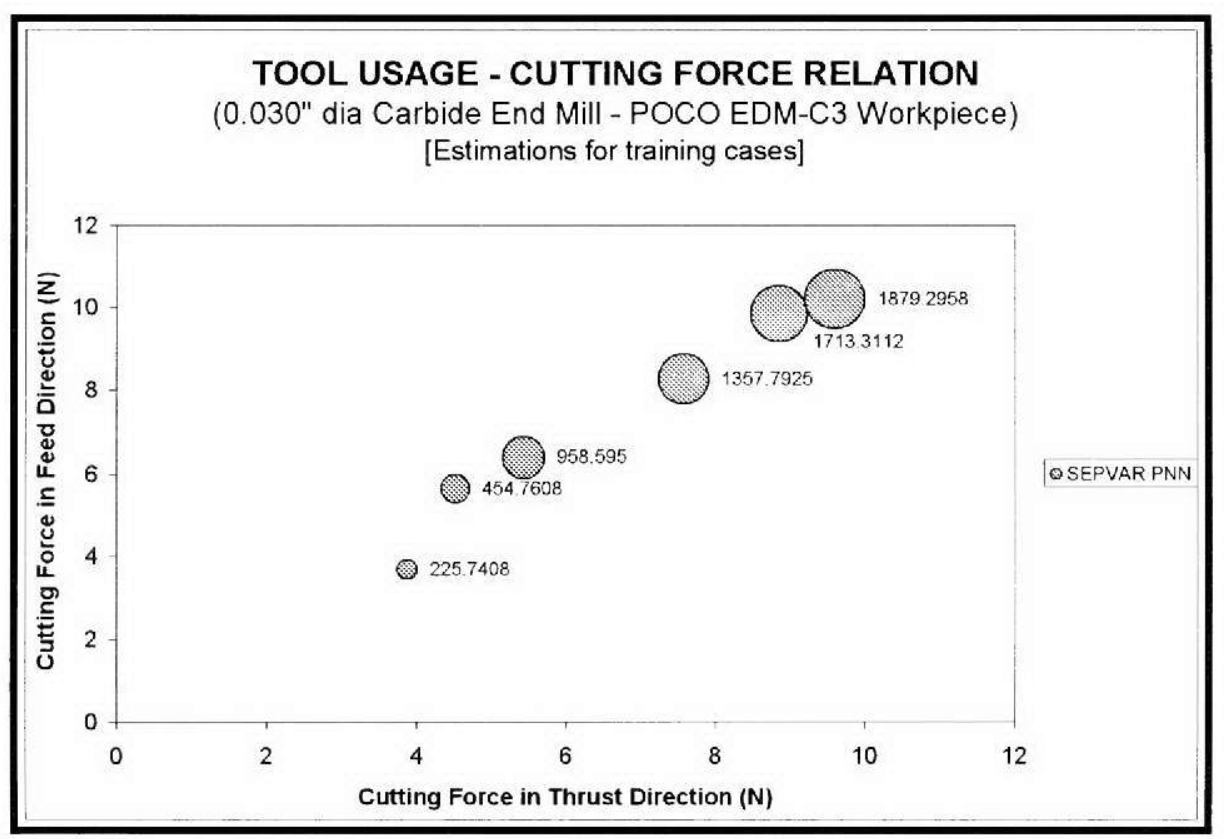

Figure 43.c. Estimated Results of the Training Cases with SEPVAR PNN for 0.030 " Tool 


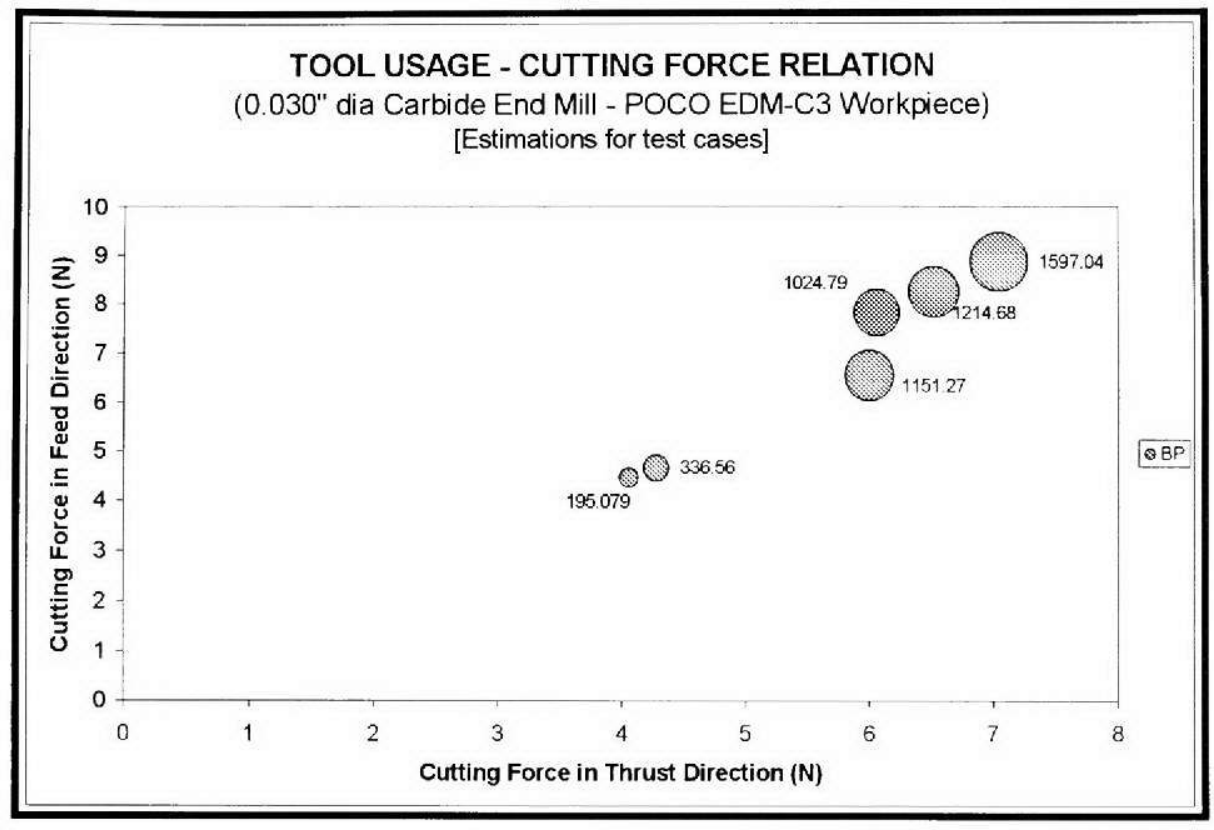

Figure 44.a. Estimated Results of the Test Cases with Analog BP NN for 0.030 " Tool

TOOL USAGE - CUTTING FORCE RELATION (0.030" dia Carbide End Mill - POCO EDM-C3 Workpiece)

[Estimations for test cases]

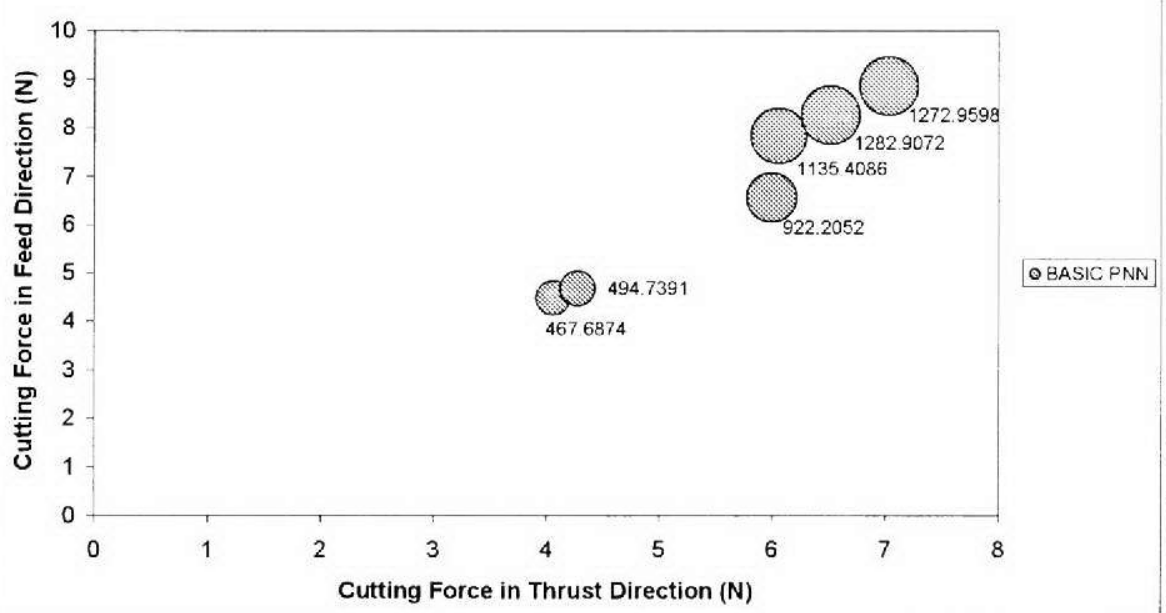

Figure 44.b. Estimated Results of the Test Cases with BASIC PNN for 0.030 " Tool 


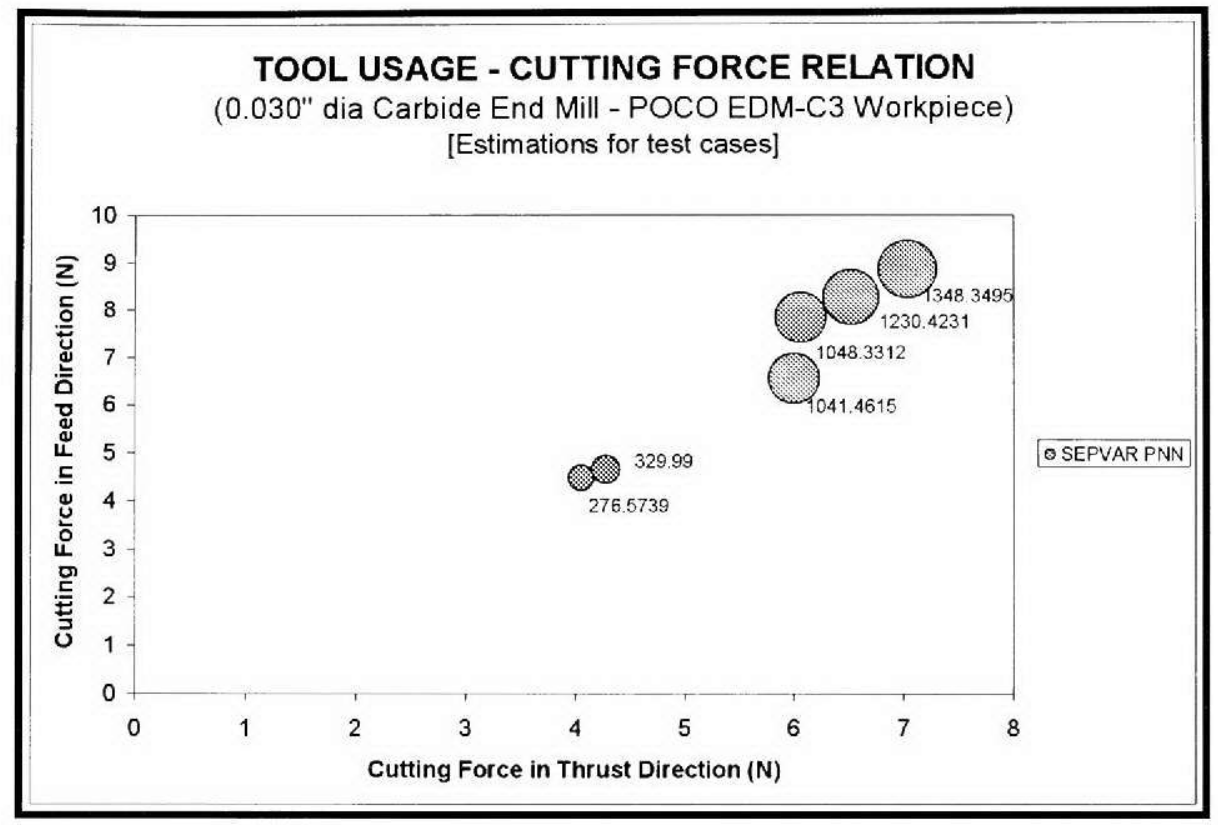

Figure 44.c. Estimated Results of the Test Cases with SEPVAR PNN for 0.030 " Tool

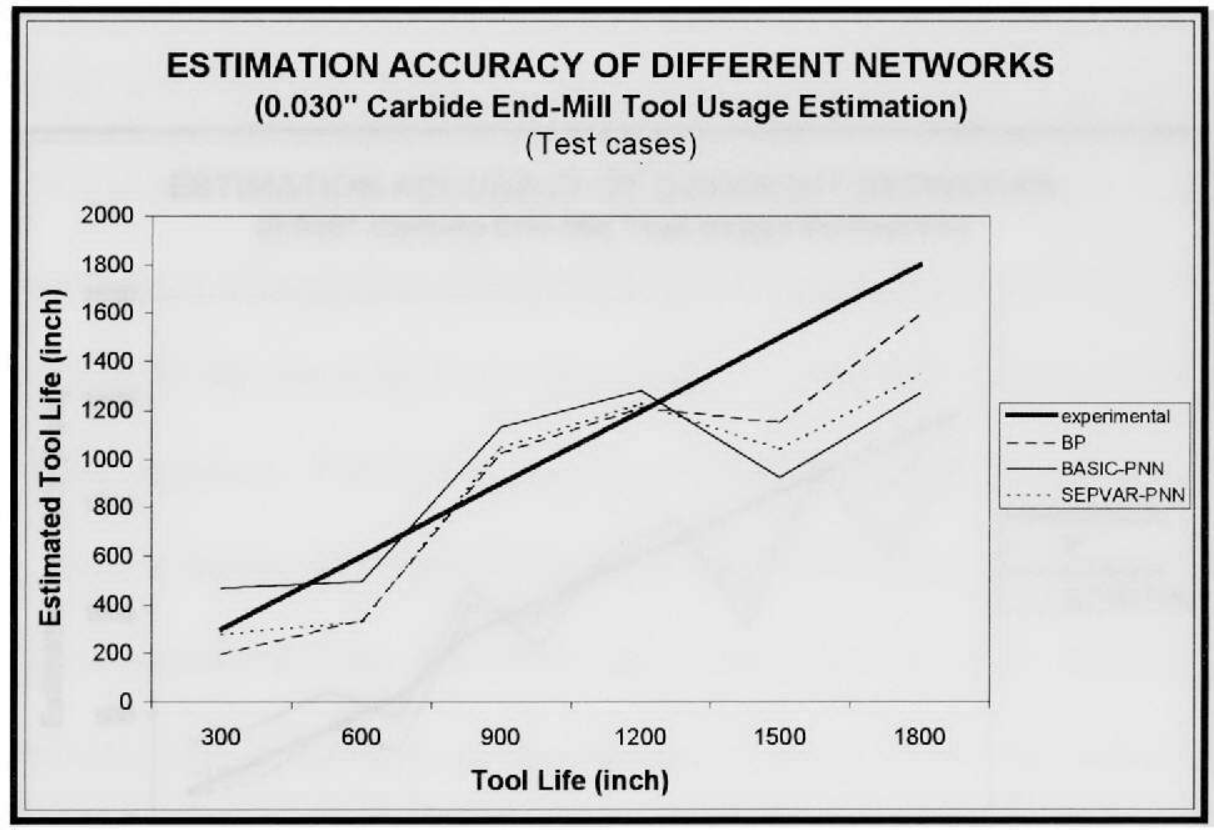

Figure 45.a. Estimation Accuracy Comparison of the Three Different Neural Network with Test Cases Cutting Force Data ( 0.030 " Tool) 


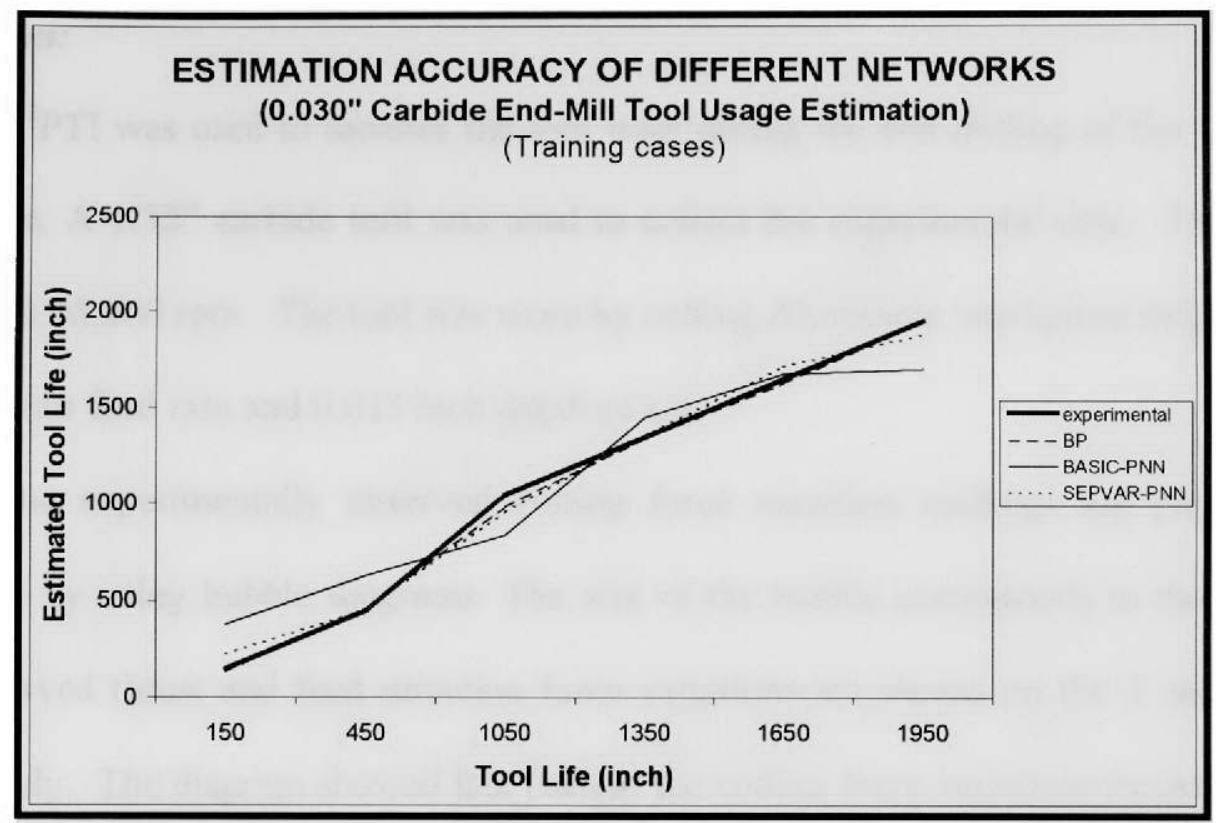

Figure 45.b. Estimation Accuracy Comparison of the Three Different Neural Network with Training Cases Cutting Force Data (0030" Tool)

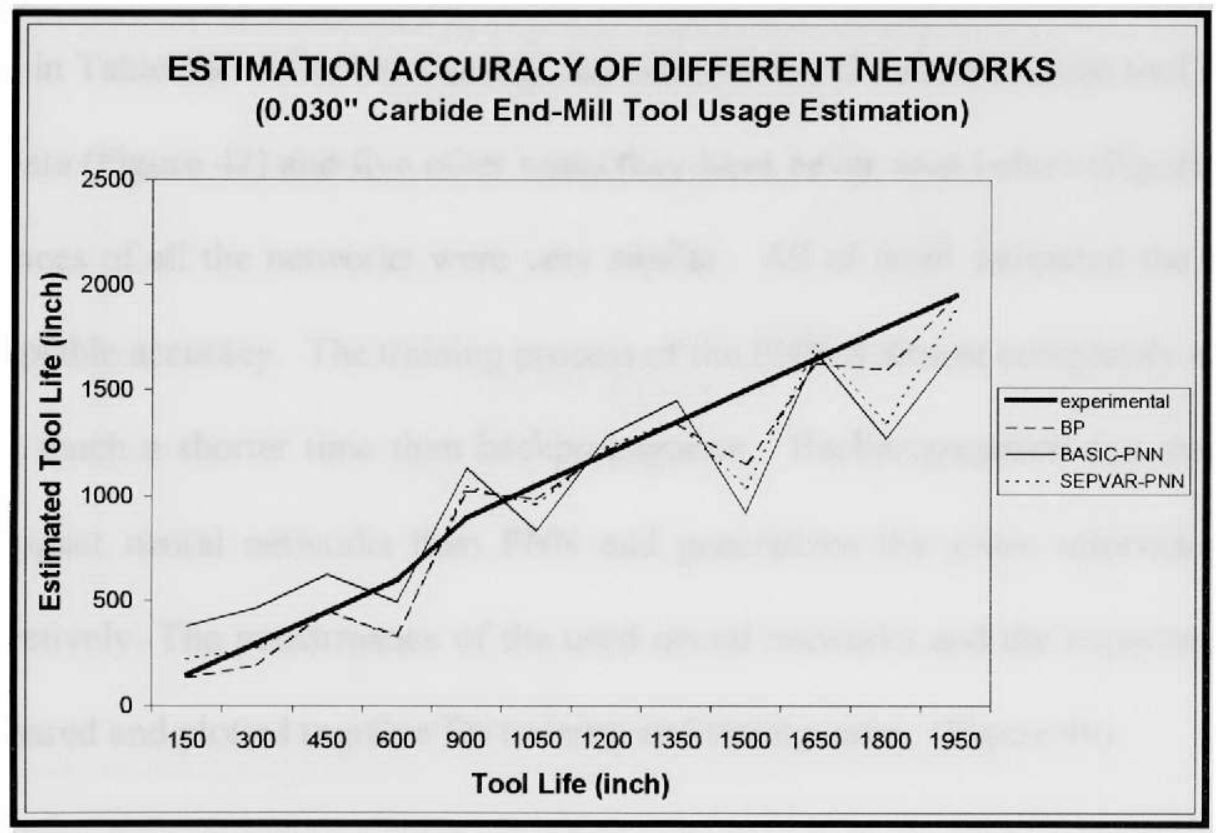

Figure 45.c. Estimation Accuracy of the Three NN for the 0.030 " Tool Life 


\section{Aluminum:}

$\mathrm{N}^{2}$ PTI was used to monitor the tool wear during the end milling of the aluminum workpiece. A 1/32" carbide tool was used to collect the experimental data. The spindle speed was $45,000 \mathrm{rpm}$. The tool was worn by cutting Aluminum workpiece material with a $5 \mathrm{inch} / \mathrm{min}$ feed rate and $0.015 \mathrm{inch}$ depth of cut.

The experimentally observed cutting force variation readings are presented in Figure 46 by using bubble diagrams. The size of the bubble corresponds to the tool life. The observed thrust and feed direction force variations are shown on the $X$ and $Y$ axes, respectively. The diagram showed that both of the cutting force variations increased while the tool wore out. Six cases were given to three different neural networks for training. One of the networks was a backpropagation type neural network and the other two were Probabilistic Neural Networks (PNN). The BASIC PNN used single sigma for both inputs. The SEPVAR used different sigma for each input. The final setup used for training is presented in Table 16. After the training, the neural networks estimated the tool life of the training data (Figure 47) and five other cases they have never seen before (Figure 48). The performances of all the networks were very similar. All of them estimated the test cases with acceptable accuracy. The training process of the PNN is almost completely automated and takes much a shorter time than backpropagation. Backpropagation can create much more compact neural networks than PNN and generalizes the given information much more effectively. The performance of the used neural networks and the experimental data was compared and plotted together for training and testing cases. (Figure 49) 
TOOL USAGE - CUTTING FORCE RELATIONSHIP (1/32" dia. Carbide End Mill - Aluminum Workpiece)

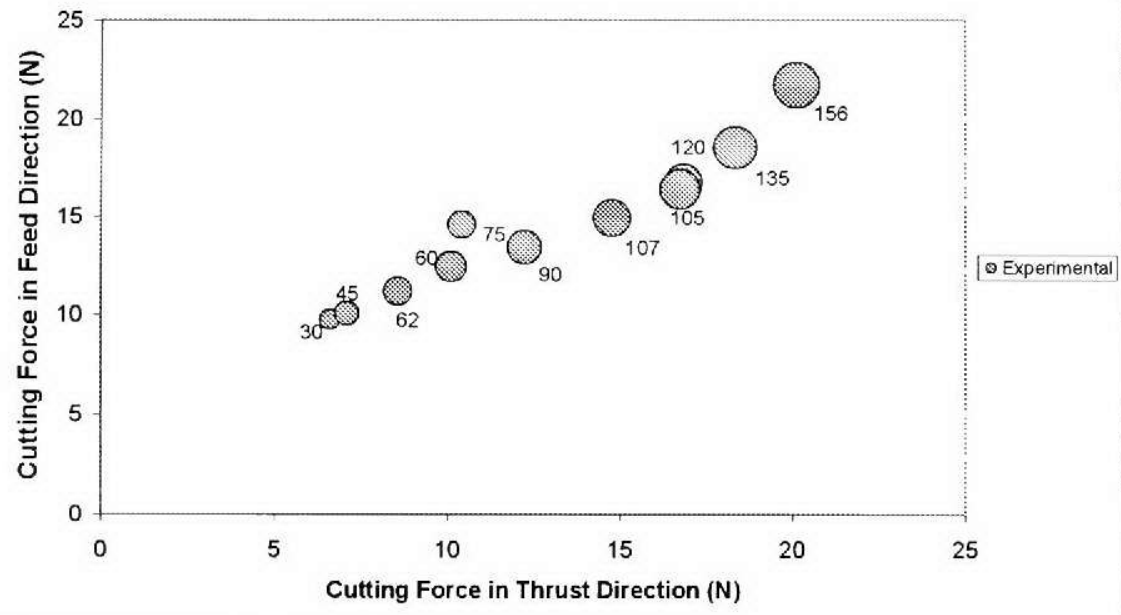

Figure 46. Tool Usage and Cutting Force Relation for Aluminum - Experimental Results

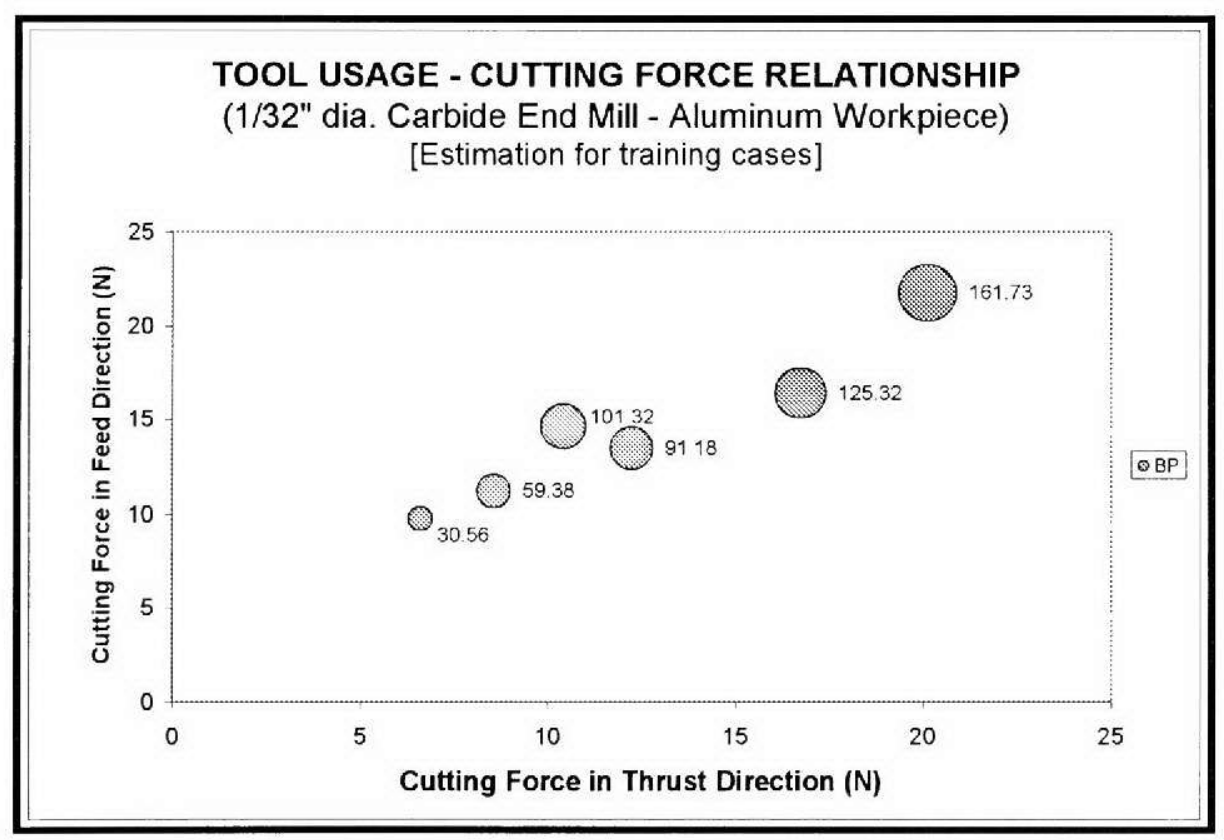

Figure 47.a. Estimated Results of the Training Cases with Analog BP NN for Aluminum 


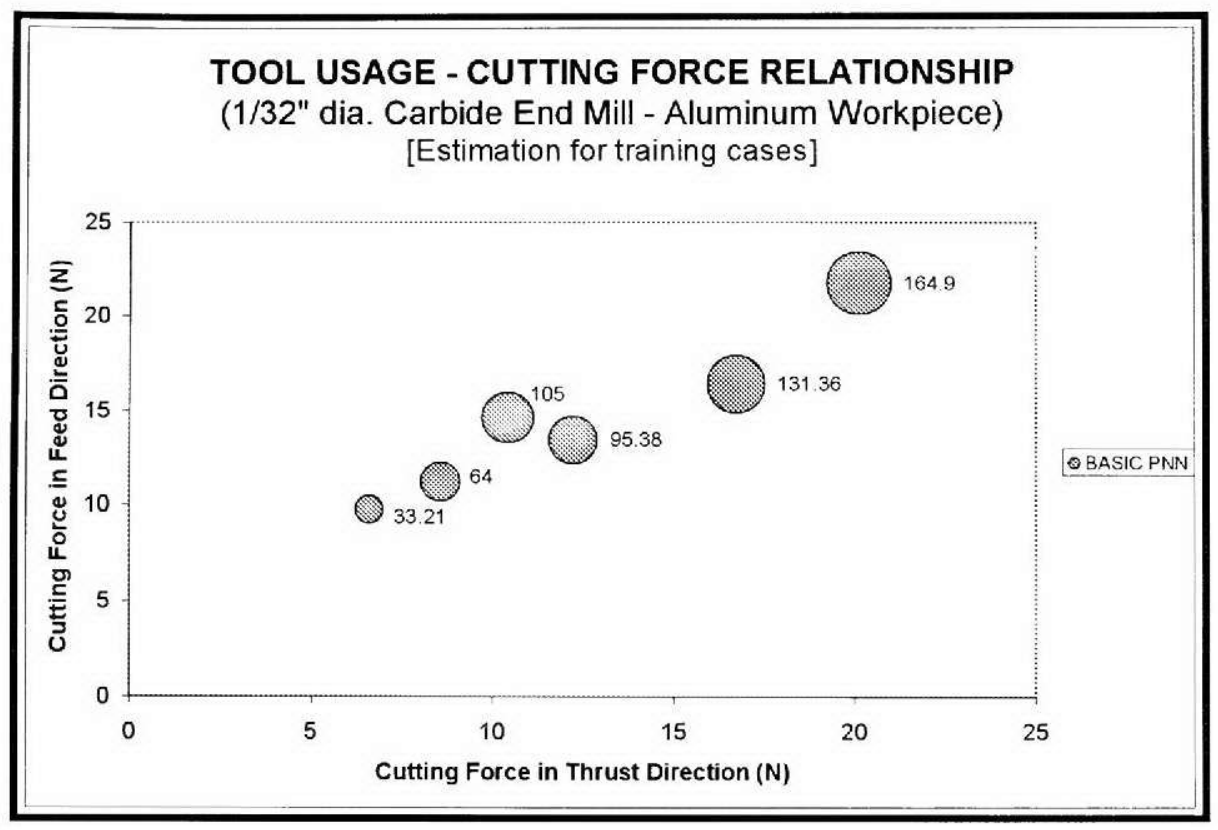

Figure 47.b. Estimated Results of the Training Cases with PNN BASIC for Aluminum

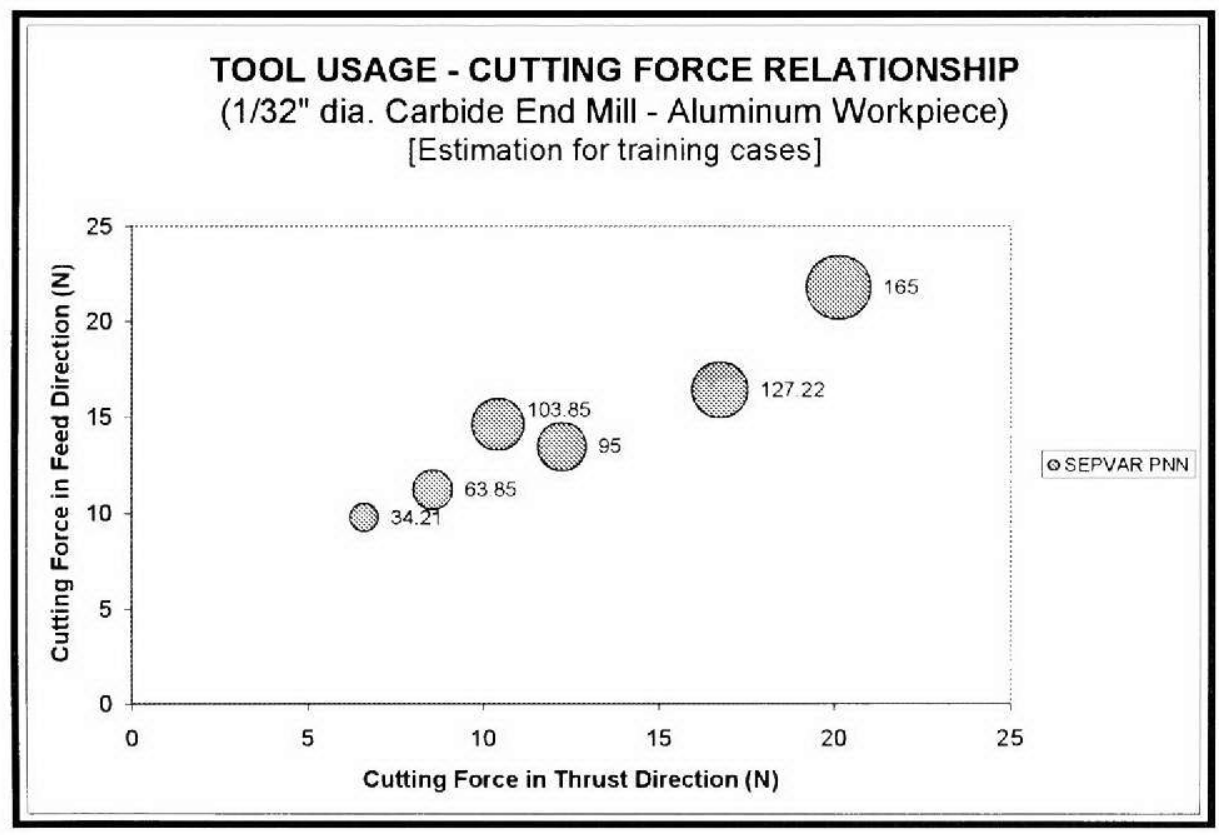

Figure 47.c. Estimated Results of the Training Cases with PNN SEPVAR for Aluminum 


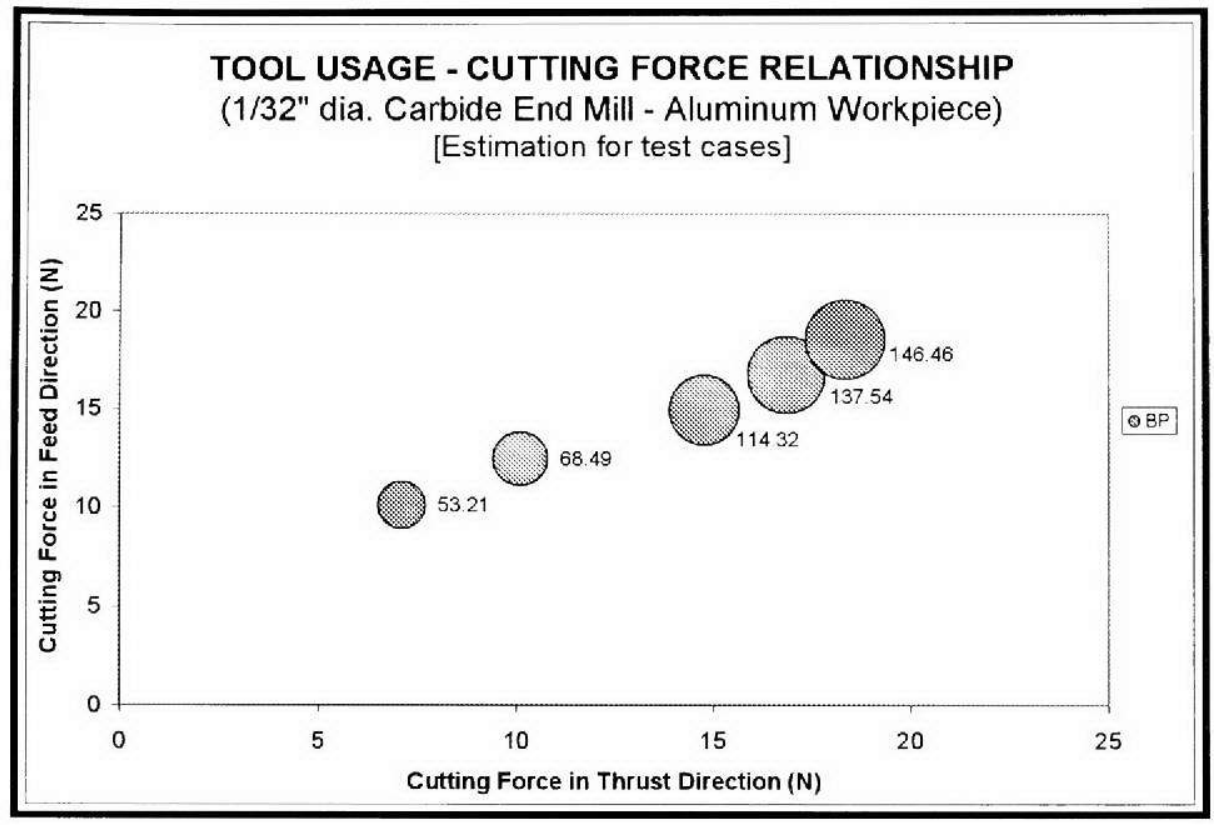

Figure 48.a. Estimated Results of the Test Cases with Analog BP NN for Aluminum

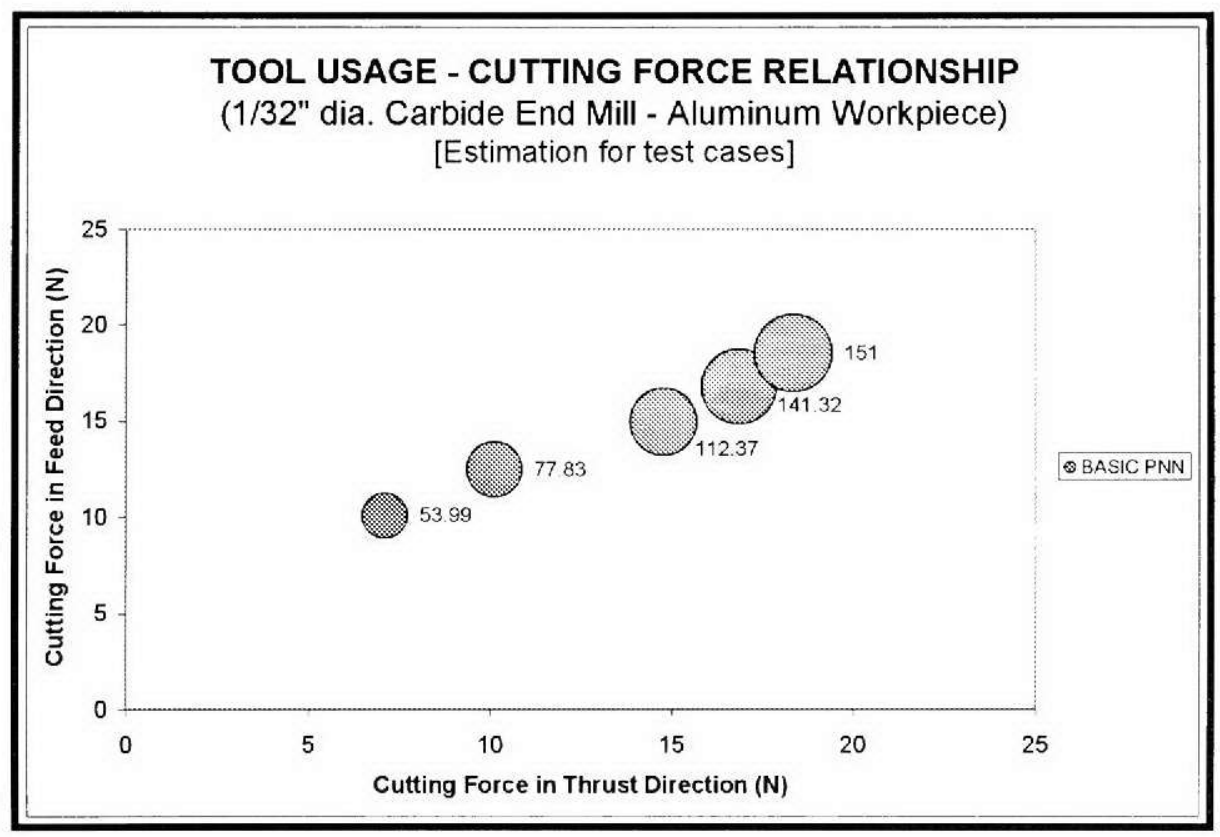

Figure 48.b. Estimated Results of the Test Cases with PNN BASIC for Aluminum 


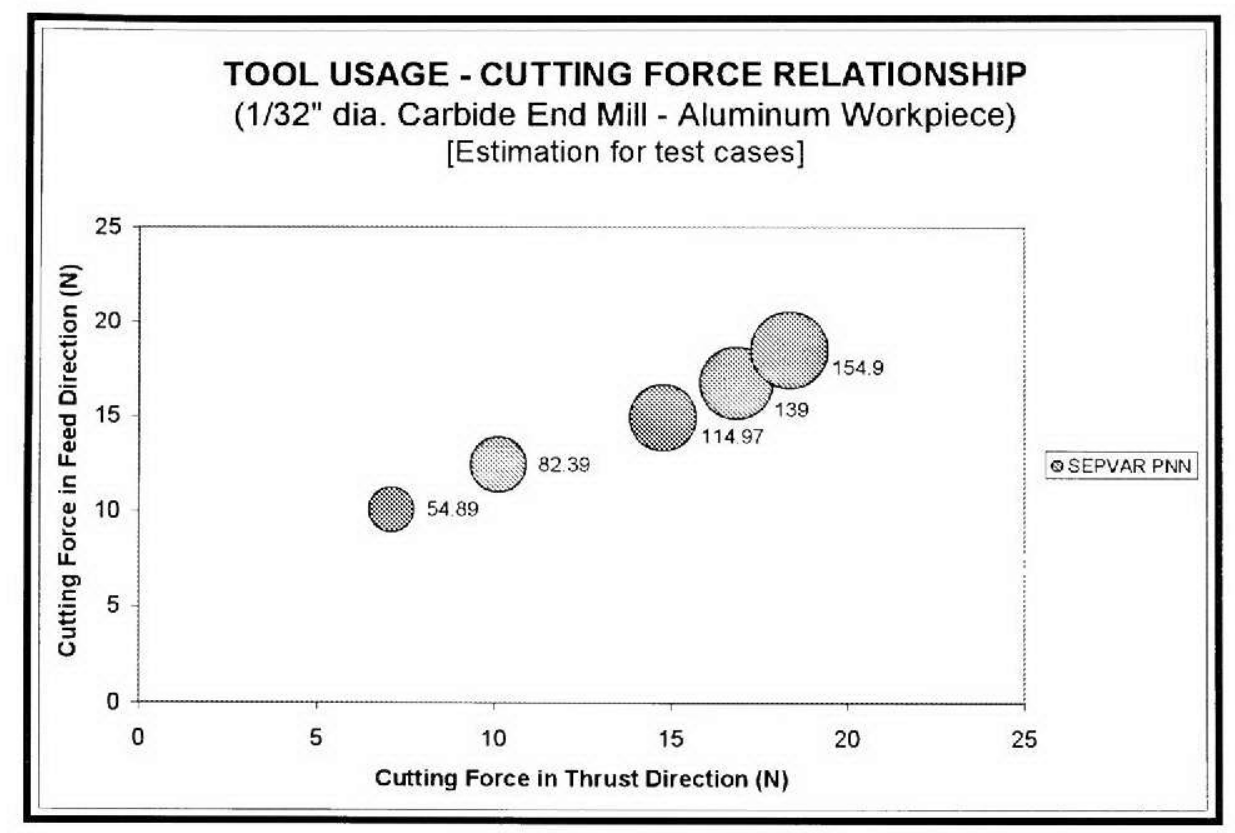

Figure 48.c. Estimated Results of the Test Cases with PNN SEPVAR for Aluminum

Table 15. Comparison of the Experimental Data and Neural Network Estimation Data

\begin{tabular}{|l|l|l|l|l|l|}
\hline \multicolumn{1}{|c|}{ X Direction } & $\begin{array}{l}\text { Y Direction } \\
\text { Force }\end{array}$ & $\begin{array}{c}\text { Experimental } \\
\text { Tool Life }\end{array}$ & $\begin{array}{l}\text { Analog BP } \\
\text { Estimation }\end{array}$ & Basic PNN & Sepvar PNN \\
\hline 6.6 & 9.78 & 30 & 30.56 & 33.21 & 34.21 \\
\hline 7.1 & 10.11 & 45 & 53.21 & 53.99 & 54.89 \\
\hline 10.42 & 14.62 & 60 & 101.32 & 105 & 103.85 \\
\hline 8.56 & 11.23 & 62 & 59.38 & 64 & 63.85 \\
\hline 10.11 & 12.5 & 75 & 68.49 & 77.83 & 82.39 \\
\hline 12.23 & 13.47 & 90 & 91.18 & 95.38 & 95 \\
\hline 16.86 & 16.78 & 105 & 137.54 & 141.32 & 139 \\
\hline 14.78 & 14.96 & 107 & 114.32 & 112.37 & 114.97 \\
\hline 16.74 & 16.41 & 120 & 125.32 & 131.36 & 127.22 \\
\hline 18.35 & 18.54 & 135 & 146.46 & 151 & 154.9 \\
\hline 20.13 & 21.75 & 156 & 161.73 & 164.9 & 165 \\
\hline
\end{tabular}




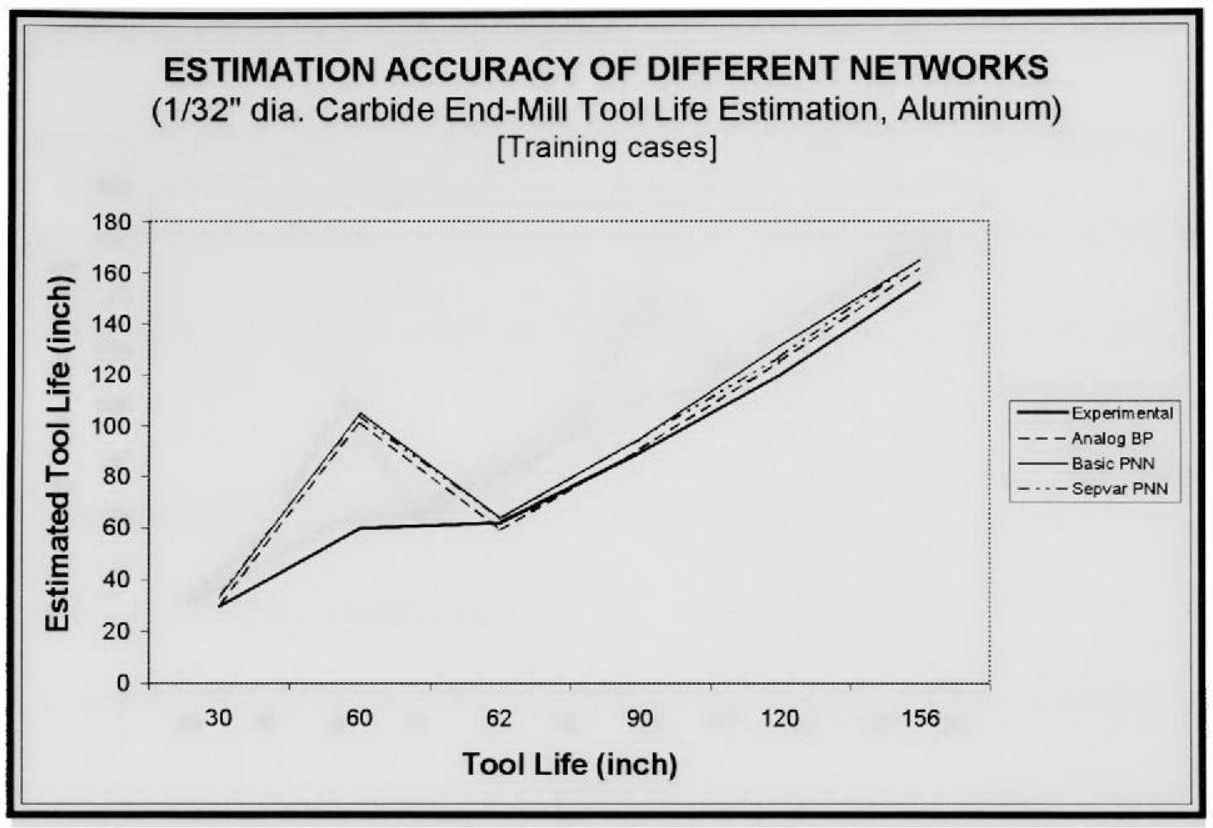

Figure 49.a. Estimation Accuracy Comparison of the Three Different Neural Network with Training Case Cutting Force Data

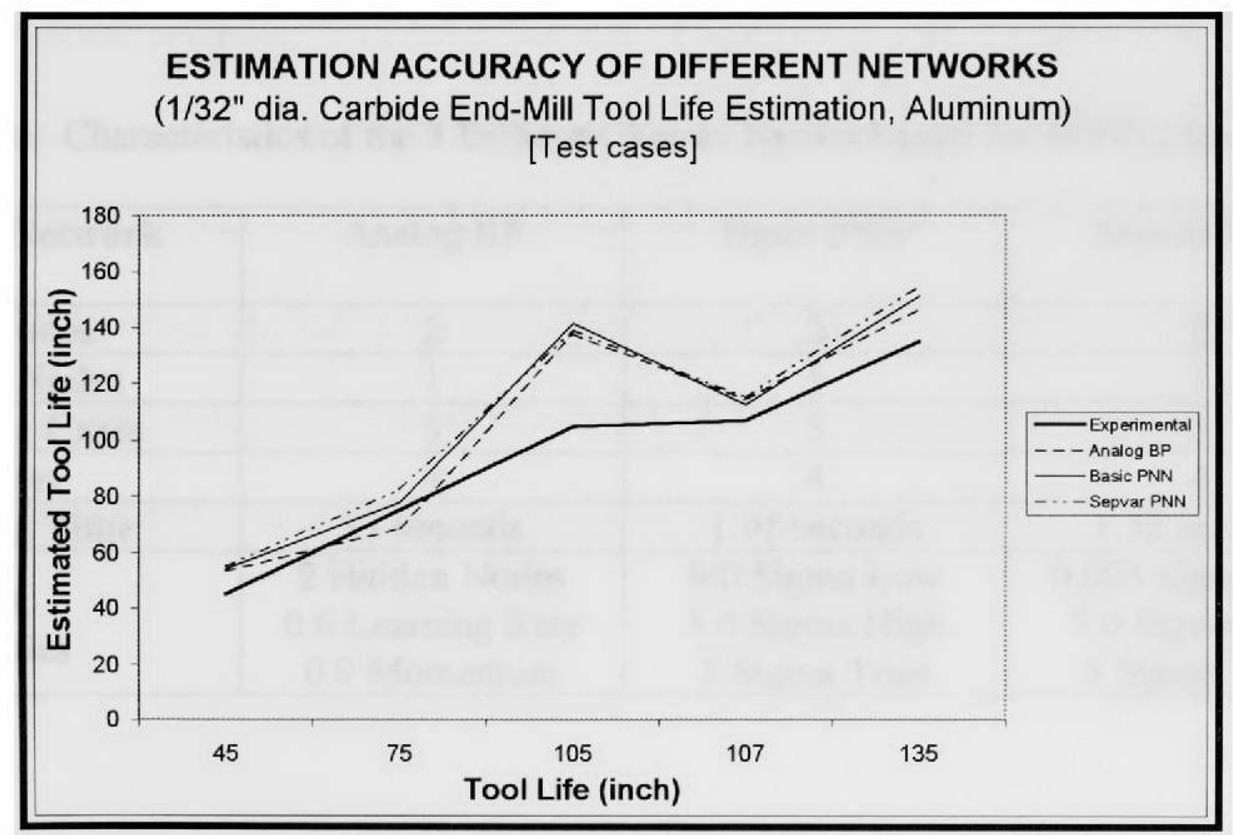

Figure 49.b. Estimation Accuracy Comparison of the Three Different Neural Network with Training Case Cutting Force Data 


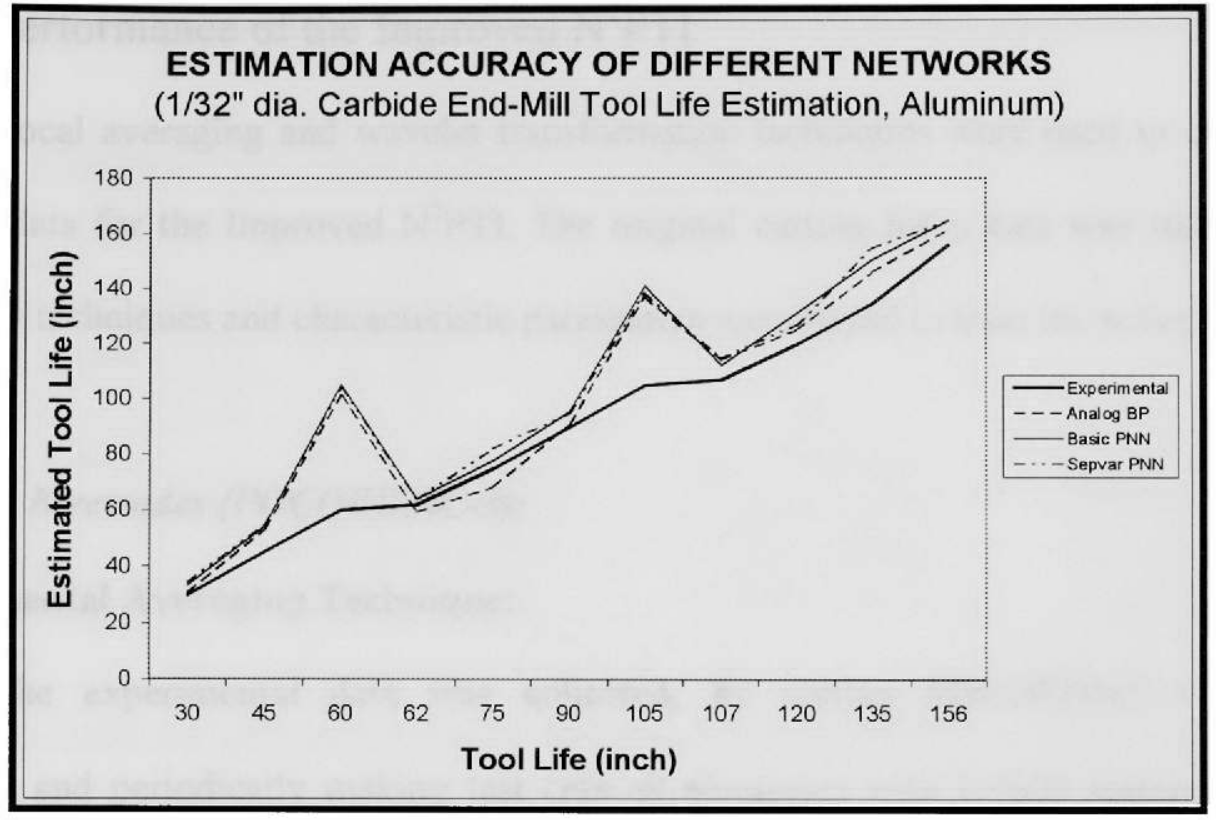

Figure 49.c. Estimation Accuracy Comparison of the Three Different Neural Network for Tool Life

Table 16. Characteristics of the 3 Different Neural Network used for $\mathrm{N}^{2}$ PTI (Aluminum)

\begin{tabular}{|l|c|c|c|}
\hline Neural Network & Analog BP & Basic PNN & Sepvar PNN \\
\hline Input Nodes & 2 & 2 & 2 \\
\hline Output Nodes & 1 & 1 & 1 \\
\hline Training Cases & 5 & 5 & 5 \\
\hline Test Cases & 4 & 4 & 4 \\
\hline Training Time & 13 seconds & 1.91 seconds & 1.52 seconds \\
\hline Network & 2 Hidden Nodes & 0.0 Sigma Low & 0.003 Sigma Low \\
Proprieties & 0.6 Learning Rate & 5.0 Sigma High & 5.0 Sigma High \\
& 0.9 Momentum & 5 Sigma Tries & 5 Sigma Tries \\
\hline
\end{tabular}




\section{V.3. Performance of the Improved $\mathrm{N}^{2} \mathrm{PTI}$}

Local averaging and wavelet transformation techniques were used to obtain the training data for the Improved $\mathrm{N}^{2} \mathrm{PTI}$. The original cutting force data was studied with these two techniques and characteristic parameters were found to train the networks.

\section{Graphite Electrodes (POCOEDMC-3):}

- Segmental Averaging Technique:

The experimental data was collected, by cutting POCOEDMC-3 graphite electrode and periodically making test cuts on aluminum with 0.0625 inches diameter carbide end-mill. The spindle speed for the experiment was $15,000 \mathrm{rpm}$. Data was collected with $20 \mu$ s sampling. In this case, there are 200 data points in each revolution With the local averaging technique, for each case, 20 input values were presented to the Neural Network training.

The neural network was trained with 20 input nodes and 1 output node. The output node was tool life obtained during the wear analysis for POCOEDMC-3. The network was trained on 40 cases and tested on 30 different cases. Backpropagation and Probabilistic neural networks were used. Analog BP, Basic PNN and Sepvar PNN were trained with the normalized data. The final settings of the $\mathrm{NN}$ are listed in Table 17. 
Table 17. Characteristics of the 3 Different Neural Network used for Improved $N^{2}$ PTI (Segmental Averaging)

\begin{tabular}{|c|c|c|c|}
\hline Neural Network & Analog BP & Basic PNN & Sepvar PNN \\
\hline Input Nodes & 20 & 20 & 20 \\
\hline Output Nodes & 1 & 1 & 1 \\
\hline Training Cases & 40 & 40 & 40 \\
\hline Test Cases & 30 & 30 & 30 \\
\hline Training Time & 121.56 seconds & 12.3 seconds & 11.4 seconds \\
\hline $\begin{array}{l}\text { Network } \\
\text { Proprieties }\end{array}$ & $\begin{array}{l}10 \text { Hidden Nodes } \\
\text { 0.6 Learning Rate } \\
0.9 \text { Momentum }\end{array}$ & $\begin{array}{c}\text { 0.0 Sigma Low } \\
\text { 5.0 Sigma High } \\
\text { 5 Sigma Tries }\end{array}$ & $\begin{array}{c}\text { 0.003 Sigma Low } \\
\text { 5.0 Sigma High } \\
\text { 5 Sigma Tries }\end{array}$ \\
\hline
\end{tabular}

The results obtained after the training is represented below. Table 18 shows the estimated values for the training cases and Table 19 shows the testing cases.

The best estimations were obtained with Analog BP and results for each case are presented in Figure 50.

The improved $\mathrm{N}^{2} \mathrm{PTI}$ gave less accurate estimation than the $\mathrm{N}^{2} \mathrm{PTI}$, however the new approach eliminated the influence of the depth of cut by the normalization of the data. The estimation results were still in the acceptable range and error of the estimation is around 10 to $15 \%$ approximately. 
Table 18. Estimation for the Training data (POCOEMDC-3) after the training of $3 \mathrm{NN}$

(Segmental Averaging Technique)

\begin{tabular}{|c|c|c|c|c|c|c|c|}
\hline & $\begin{array}{l}\text { Real } \\
\text { Data }\end{array}$ & $\begin{array}{l}\text { Analog } \\
\text { BP }\end{array}$ & $\begin{array}{l}\text { Basic } \\
\text { PNN }\end{array}$ & $\begin{array}{l}\text { Sepvar } \\
\text { PNN }\end{array}$ & $\begin{array}{l}\text { Analog } \\
\text { Error \% }\end{array}$ & $\begin{array}{l}\text { Basic } \\
\text { Error \% }\end{array}$ & $\begin{array}{l}\text { Sepvar } \\
\text { Error \% }\end{array}$ \\
\hline Case 1 & 450 & 478.71 & 230.12 & 300.25 & 6.38 & 48.86 & 33.28 \\
\hline Case 2 & 450 & 475.54 & 200.73 & 304.22 & 5.68 & 55.39 & 32.40 \\
\hline Case 3 & 450 & 491.21 & 220 & 310.78 & 9.16 & 51.11 & 30.94 \\
\hline Case 4 & 450 & 478.23 & 214.92 & 313.32 & 6.27 & 52.24 & 30.37 \\
\hline Case 5 & 450 & 499.12 & 245.67 & 304.57 & 10.92 & 45.41 & 32.32 \\
\hline Case 6 & 450 & 474.32 & 267.75 & 311 & 5.40 & 40.50 & 30.89 \\
\hline Case 7 & 450 & 512.76 & 289.43 & 313.43 & 13.95 & 35.68 & 30.35 \\
\hline Case 8 & 450 & 501.28 & 287.84 & 321.15 & 11.40 & 36.04 & 28.63 \\
\hline Case 9 & 450 & 503.89 & 301.12 & 319.43 & 11.98 & 33.08 & 29.02 \\
\hline Case 10 & 450 & 489.72 & 299.54 & 317.43 & 8.83 & 33.44 & 29.46 \\
\hline Case 1 & 750 & 812.33 & 999.76 & 875 & 8.31 & 33.30 & 16.67 \\
\hline Case 2 & 750 & 801.21 & 998 & 875.36 & 6.83 & 33.07 & 16.71 \\
\hline Case 3 & 750 & 799.18 & 998.15 & 879.12 & 6.56 & 33.09 & 17.22 \\
\hline Case 4 & 750 & 784.82 & 995.32 & 877.34 & 4.64 & 32.71 & 16.98 \\
\hline Case 5 & 750 & 802.36 & 995.46 & 881.23 & 6.98 & 32.73 & 17.50 \\
\hline Case 6 & 750 & 811.2 & 989.01 & 885 & 8.16 & 31.87 & 18.00 \\
\hline Case 7 & 750 & 803.74 & 987.32 & 882.9 & 7.17 & 31.64 & 17.72 \\
\hline Case 8 & 750 & 788.33 & 985.43 & 884.38 & 5.11 & 31.39 & 17.92 \\
\hline Case 9 & 750 & 793.21 & 982.32 & 890 & 5.76 & 30.98 & 18.67 \\
\hline Case 10 & 750 & 806.85 & 980.26 & 885.43 & 7.58 & 30.70 & 18.06 \\
\hline Case 1 & 1050 & 905.37 & 1154.78 & 1190.54 & 13.77 & 9.98 & 13.38 \\
\hline Case 2 & 1050 & 907.89 & 1155 & 1196.47 & 13.53 & 10.00 & 13.95 \\
\hline Case 3 & 1050 & 905.38 & 1158.35 & 1195.32 & 13.77 & 10.32 & 13.84 \\
\hline Case 4 & 1050 & 910.77 & 1159.43 & 1189.34 & 13.26 & 10.42 & 13.27 \\
\hline Case 5 & 1050 & 930.23 & 1154.32 & 1199.65 & 11.41 & 9.94 & 14.25 \\
\hline Case 6 & 1050 & 927.45 & 1160 & 1195.39 & 11.67 & 10.48 & 13.85 \\
\hline Case 7 & 1050 & 932.12 & 1158.93 & 1200 & 11.23 & 10.37 & 14.29 \\
\hline Case 8 & 1050 & 940.16 & 1161.35 & 1201.12 & 10.46 & 10.60 & 14.39 \\
\hline Case 9 & 1050 & 935.69 & 1158.11 & 1194.21 & 10.89 & 10.30 & 13.73 \\
\hline Case 10 & 1050 & 927.91 & 1154.34 & 1200.43 & 11.63 & 9.94 & 14.33 \\
\hline Case 1 & 1350 & 1391.21 & 1478.95 & 1423.54 & 3.05 & 9.55 & 5.45 \\
\hline Case 2 & 1350 & 1400.12 & 1480 & 1434.55 & 3.71 & 9.63 & 6.26 \\
\hline Case 3 & 1350 & 1364.32 & 1487.32 & 1430.26 & 1.06 & 10.17 & 5.95 \\
\hline Case 4 & 1350 & 1373.98 & 1475.55 & 1427.59 & 1.78 & 9.30 & 5.75 \\
\hline Case 5 & 1350 & 1343.56 & 1477.53 & 1435.21 & 0.48 & 9.45 & 6.31 \\
\hline Case 6 & 1350 & 1366.37 & 1485.44 & 1439 & 1.21 & 10.03 & 6.59 \\
\hline Case 7 & 1350 & 1400 & 1489.59 & 1428.3 & 3.70 & 10.34 & 5.80 \\
\hline Case 8 & 1350 & 1458.74 & 1490.78 & 1425 & 8.05 & 10.43 & 5.56 \\
\hline Case 9 & 1350 & 1402.21 & 1492.96 & 1422 & 3.87 & 10.59 & 5.33 \\
\hline Case 10 & 1350 & 1383.73 & 1489 & 1423.45 & 2.50 & 10.30 & 5.44 \\
\hline
\end{tabular}


Table 19. Estimation for the Testing data (POCOEDMC-3) after the training of $3 \mathrm{NN}$

(Segmental Averaging Technique)

\begin{tabular}{|c|c|c|c|c|c|c|c|}
\hline & $\begin{array}{l}\text { Real } \\
\text { Data }\end{array}$ & $\begin{array}{l}\text { Analog } \\
\text { BP }\end{array}$ & $\begin{array}{l}\text { Basic } \\
\text { PNN }\end{array}$ & $\begin{array}{l}\text { Sepvar } \\
\text { PNN }\end{array}$ & $\begin{array}{l}\text { Analog } \\
\text { Error \% }\end{array}$ & $\begin{array}{l}\text { Basic } \\
\text { Error \% }\end{array}$ & $\begin{array}{l}\text { Sepvar } \\
\text { Error \% }\end{array}$ \\
\hline Case 1 & 600 & 720.62 & 890.45 & 910.15 & 20.10 & 48.41 & 51.69 \\
\hline Case 2 & 600 & 719.34 & 885 & 900.13 & 19.89 & 47.50 & 50.02 \\
\hline Case 3 & 600 & 715.63 & 887.59 & 902.44 & 19.27 & 47.93 & 50.41 \\
\hline Case 4 & 600 & 713.23 & 891.26 & 905 & 18.87 & 48.54 & 50.83 \\
\hline Case 5 & 600 & 712.11 & 895.27 & 902.89 & 18.69 & 49.21 & 50.48 \\
\hline Case 6 & 600 & 711 & 884.43 & 899.18 & 18.50 & 47.41 & 49.86 \\
\hline Case 7 & 600 & 710.96 & 883.17 & 893.24 & 18.49 & 47.20 & 48.87 \\
\hline Case 8 & 600 & 709.99 & 885.38 & 892.32 & 18.33 & 47.56 & 48.72 \\
\hline Case 9 & 600 & 710.55 & 890 & 897.93 & 18.43 & 48.33 & 49.66 \\
\hline Case 10 & 600 & 711.67 & 887.77 & 899 & 18.61 & 47.96 & 49.83 \\
\hline Case 1 & 900 & 1055 & 1234.32 & 1225.32 & 17.22 & 37.15 & 36.15 \\
\hline Case 2 & 900 & 1057.21 & 1230.11 & 1229.67 & 17.47 & 36.68 & 36.63 \\
\hline Case 3 & 900 & 1048.19 & 1229.93 & 1230 & 16.47 & 36.66 & 36.67 \\
\hline Case 4 & 900 & 1045.93 & 1227 & 1227.88 & 16.21 & 36.33 & 36.43 \\
\hline Case 5 & 900 & 1039.19 & 1229.03 & 1226.04 & 15.47 & 36.56 & 36.23 \\
\hline Case 6 & 900 & 1041 & 1230 & 1222 & 15.67 & 36.67 & 35.78 \\
\hline Case 7 & 900 & 1037.55 & 1228.07 & 1224.06 & 15.28 & 36.45 & 36.01 \\
\hline Case 8 & 900 & 1039.93 & 1229 & 1223.93 & 15.55 & 36.56 & 35.99 \\
\hline Case 9 & 900 & 1042.68 & 1224.54 & 1228.67 & 15.85 & 36.06 & 36.52 \\
\hline Case 10 & 900 & 1035.12 & 1125.8 & 1223.06 & 15.01 & 25.09 & 35.90 \\
\hline Case 1 & 1200 & 1368.32 & 1550.46 & 1578.75 & 14.03 & 29.21 & 31.56 \\
\hline Case 2 & 1200 & 1365 & 1547 & 1573.9 & 13.75 & 28.92 & 31.16 \\
\hline Case 3 & 1200 & 1367.18 & 1544.92 & 1570.34 & 13.93 & 28.74 & 30.86 \\
\hline Case 4 & 1200 & 1362.39 & 1548.39 & 1569.32 & 13.53 & 29.03 & 30.78 \\
\hline Case 5 & 1200 & 1359.41 & 1547.1 & 1568.4 & 13.28 & 28.93 & 30.70 \\
\hline Case 6 & 1200 & 1370.32 & 1545 & 1569 & 14.19 & 28.75 & 30.75 \\
\hline Case 7 & 1200 & 1373.95 & 1543.06 & 1571.23 & 14.50 & 28.59 & 30.94 \\
\hline Case 8 & 1200 & 1364.32 & 1544.43 & 1569.03 & 13.69 & 28.70 & 30.75 \\
\hline Case 9 & 1200 & 1363.89 & 1547.9 & 1573.44 & 13.66 & 28.99 & 31.12 \\
\hline Case 10 & 1200 & 1366.77 & 1546 & 1568.32 & 13.90 & 28.83 & 30.69 \\
\hline
\end{tabular}




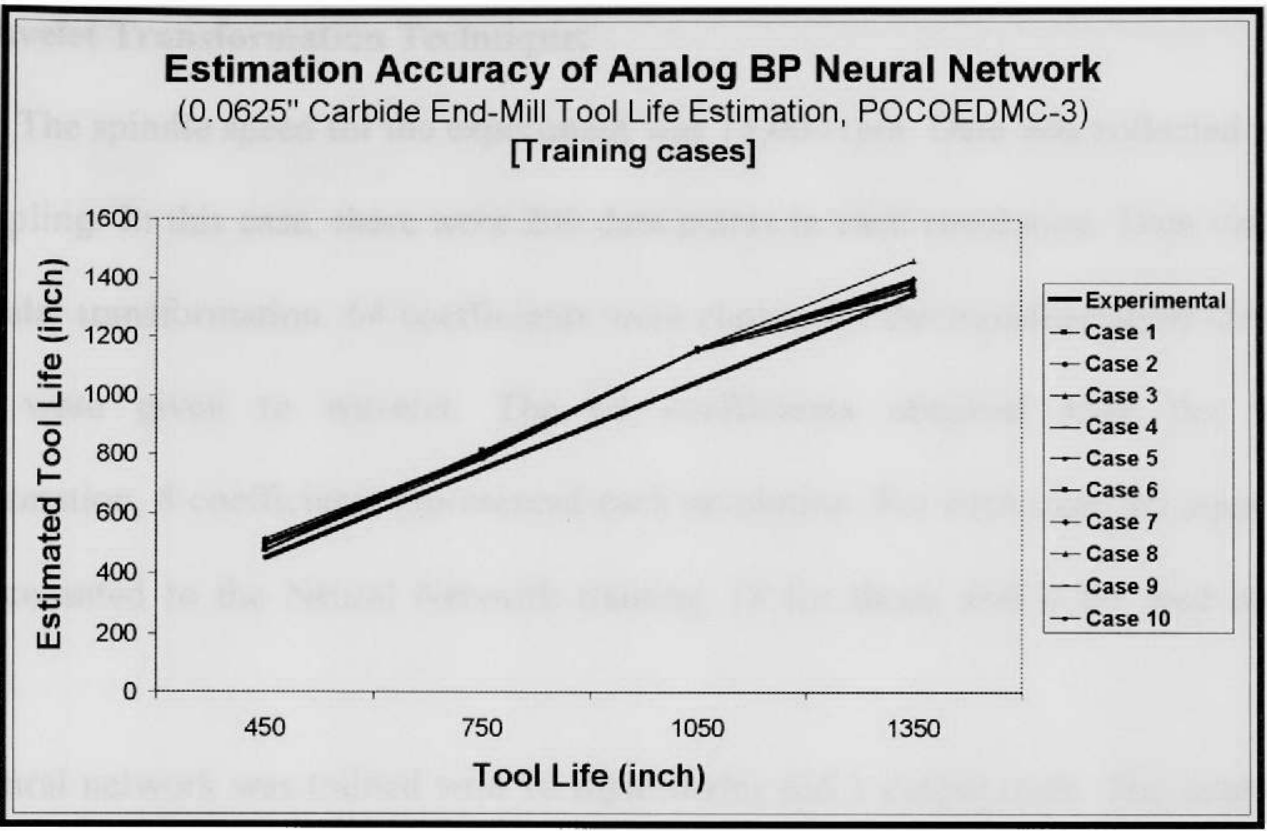

Figure 50.a. Estimation Accuracy of Analog BP for Training Cases with Improved $N^{2}$ PTI (Segmental Averaging)

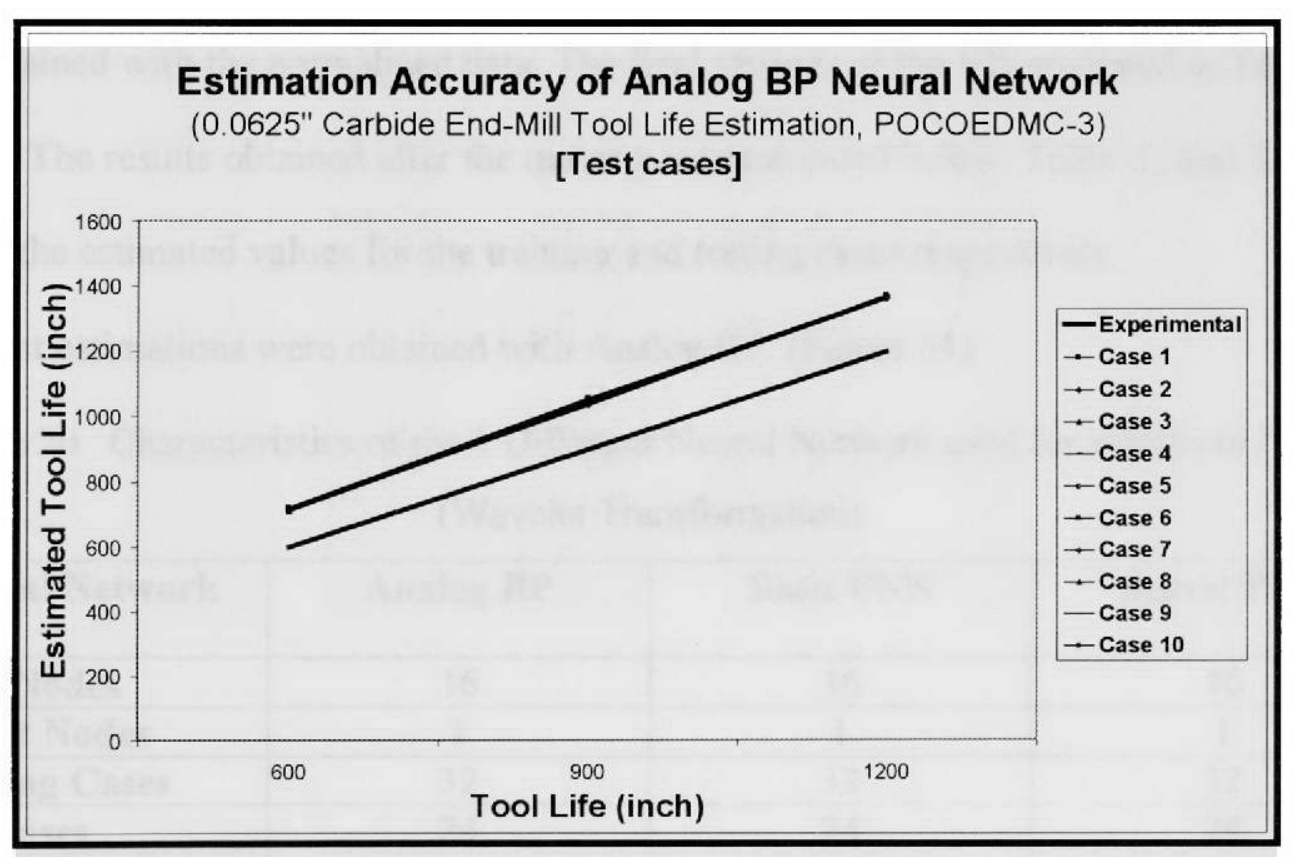

Figure 50.b. Estimation Accuracy of Analog BP for Test Cases with Improved N ${ }^{2}$ PTI (Segmental Averaging) 


\section{- Wavelet Transformation Technique:}

The spindle speed for the experiment was $15,000 \mathrm{rpm}$. Data was collected with 20 $\mu$ s sampling. In this case, there were 200 data points in each revolution. Data was given to wavelet transformation. 64 coefficients were chosen for the transformation. 2048 data points were given to wavelet. The 64 coefficients obtained after the wavelet transformation, 8 coefficients represented each revolution. For each case, 16 input values were presented to the Neural Network training. ( 8 for thrust and 8 for feed direction force)

The neural network was trained with 16 input nodes and 1 output node. The output node was the tool life obtained during the wear analysis for POCOEDMC-3. The network was trained on 32 cases and tested on 24 different cases. The use of Backpropagation and Probabilistic neural networks was evaluated. Analog BP, Basic PNN and Sepvar PNN were trained with the normalized data. The final settings of the NN are listed in Table 20.

The results obtained after the training is represented below. Table 21 and Table 22 shows the estimated values for the training and testing cases respectively.

The best estimations were obtained with Analog BP. (Figure 51)

Table 20. Characteristics of the 3 Different Neural Network used for Improved N2PTI (Wavelet Transformation)

\begin{tabular}{|c|c|c|c|}
\hline Neural Network & Analog BP & Basic PNN & Sepvar PNN \\
\hline Input Nodes & 16 & 16 & 16 \\
\hline Output Nodes & 1 & 1 & 1 \\
\hline Training Cases & 32 & 32 & 32 \\
\hline Test Cases & 24 & 24 & 24 \\
\hline Training Time & 156.21 seconds & 15.35 seconds & 14.21 seconds \\
\hline $\begin{array}{l}\text { Network } \\
\text { Proprieties }\end{array}$ & $\begin{array}{c}8 \text { Hidden Nodes } \\
0.6 \text { Learning Rate } \\
0.9 \text { Momentum }\end{array}$ & $\begin{array}{c}\text { 0.0 Sigma Low } \\
\text { 5.0 Sigma High } \\
5 \text { Sigma Tires }\end{array}$ & $\begin{array}{l}\text { 0.003 Sigma Low } \\
\text { 5.0 Sigma High } \\
5 \text { Sigma Tires }\end{array}$ \\
\hline
\end{tabular}


Table 21. Estimation for the Training data (POCOEMDC-3) after the training of $3 \mathrm{NN}$

(Wavelet Transformation Technique)

\begin{tabular}{|c|c|c|c|c|c|c|c|}
\hline & $\begin{array}{l}\text { Real } \\
\text { Data }\end{array}$ & $\begin{array}{l}\text { Analog } \\
\text { BP }\end{array}$ & $\begin{array}{l}\text { Basic } \\
\text { PNN }\end{array}$ & $\begin{array}{l}\text { Sepvar } \\
\text { PNN }\end{array}$ & $\begin{array}{l}\text { Analog } \\
\text { Error \% }\end{array}$ & $\begin{array}{l}\text { Basic } \\
\text { Error \% }\end{array}$ & $\begin{array}{l}\text { Sepvar } \\
\text { Error \% }\end{array}$ \\
\hline Case 1 & 450.00 & 402.34 & 640.32 & 303.43 & 10.59 & 42.29 & 32.57 \\
\hline Case 2 & 450.00 & 410.24 & 650.23 & 305.43 & 8.84 & 44.50 & 32.13 \\
\hline Case 3 & 450.00 & 414.32 & 653.21 & 311.23 & 7.93 & 45.16 & 30.84 \\
\hline Case 4 & 450.00 & 411.31 & 673.21 & 315.78 & 8.60 & 49.60 & 29.83 \\
\hline Case 5 & 450.00 & 408.56 & 655.00 & 306.74 & 9.21 & 45.56 & 31.84 \\
\hline Case 6 & 450.00 & 408.37 & 651.19 & 311.23 & 9.25 & 44.71 & 30.84 \\
\hline Case 7 & 450.00 & 415.32 & 645.32 & 317.54 & 7.71 & 43.40 & 29.44 \\
\hline Case 8 & 450.00 & 412.75 & 641.32 & 325.32 & 8.28 & 42.52 & 27.71 \\
\hline Case 1 & 750.00 & 789.43 & 523.12 & 923.43 & 5.26 & 30.25 & 23.12 \\
\hline Case 2 & 750.00 & 775.00 & 527.43 & 928.54 & 3.33 & 29.68 & 23.81 \\
\hline Case 3 & 750.00 & 788.43 & 531.21 & 925.00 & 5.12 & 29.17 & 23.33 \\
\hline Case 4 & 750.00 & 798.32 & 521.24 & 927.18 & 6.44 & 30.50 & 23.62 \\
\hline Case 5 & 750.00 & 777.23 & 517.93 & 921.23 & 3.63 & 30.94 & 22.83 \\
\hline Case 6 & 750.00 & 796.43 & 515.16 & 934.61 & 6.19 & 31.31 & 24.61 \\
\hline Case 7 & 750.00 & 801.00 & 519.12 & 933.38 & 6.80 & 30.78 & 24.45 \\
\hline Case 8 & 750.00 & 799.96 & 511.53 & 924.18 & 6.66 & 31.80 & 23.22 \\
\hline Case 1 & 1050.00 & 1026.53 & 841.21 & 1469.29 & 2.24 & 19.88 & 39.93 \\
\hline Case 2 & 1050.00 & 1035.43 & 832.76 & 1453.21 & 1.39 & 20.69 & 38.40 \\
\hline Case 3 & 1050.00 & 1033.00 & 835.43 & 1455.00 & 1.62 & 20.44 & 38.57 \\
\hline Case 4 & 1050.00 & 1029.43 & 837.29 & 1437.54 & 1.96 & 20.26 & 36.91 \\
\hline Case 5 & 1050.00 & 1034.29 & 816.00 & 1447.31 & 1.50 & 22.29 & 37.84 \\
\hline Case 6 & 1050.00 & 1038.42 & 819.92 & 1448.92 & 1.10 & 21.91 & 37.99 \\
\hline Case 7 & 1050.00 & 1034.32 & 811.17 & 1447.21 & 1.49 & 22.75 & 37.83 \\
\hline Case 8 & 1050.00 & 1037.75 & 831.21 & 1444.32 & 1.17 & 20.84 & 37.55 \\
\hline Case 1 & 1350.00 & 1327.43 & 1768.32 & 901.43 & 1.67 & 30.99 & 33.23 \\
\hline Case 2 & 1350.00 & 1333.00 & 1775.74 & 906.53 & 1.26 & 31.54 & 32.85 \\
\hline Case 3 & 1350.00 & 1322.99 & 1750.39 & 911.21 & 2.00 & 29.66 & 32.50 \\
\hline Case 4 & 1350.00 & 1325.83 & 1758.36 & 917.54 & 1.79 & 30.25 & 32.03 \\
\hline Case 5 & 1350.00 & 1319.54 & 1755.00 & 915.00 & 2.26 & 30.00 & 32.22 \\
\hline Case 6 & 1350.00 & 1324.39 & 1753.26 & 919.31 & 1.90 & 29.87 & 31.90 \\
\hline Case 7 & 1350.00 & 1332.11 & 1751.13 & 912.32 & 1.33 & 29.71 & 32.42 \\
\hline Case 8 & 1350.00 & 1327.51 & 1746.48 & 914.36 & 1.67 & 29.37 & 32.27 \\
\hline
\end{tabular}


Table 22. Estimation for the Testing data (POCOEMDC-3) after the training of $3 \mathrm{NN}$

(Wavelet Transformation Technique)

\begin{tabular}{|l|r|r|r|r|r|r|r|}
\hline & \multicolumn{1}{|l|}{$\begin{array}{l}\text { Real } \\
\text { Data }\end{array}$} & \multicolumn{1}{l|}{$\begin{array}{l}\text { Analog } \\
\text { BP }\end{array}$} & $\begin{array}{l}\text { Basic } \\
\text { PNN }\end{array}$ & $\begin{array}{l}\text { Sepvar } \\
\text { PNN }\end{array}$ & $\begin{array}{l}\text { Analog } \\
\text { Error \% }\end{array}$ & \multicolumn{1}{l|}{$\begin{array}{l}\text { Basic } \\
\text { Error \% }\end{array}$} & \multicolumn{1}{l}{$\begin{array}{l}\text { Sepvar } \\
\text { Error \% }\end{array}$} \\
\hline Case 1 & 600 & 514.32 & 276.12 & 321.23 & $\mathbf{1 4 . 2 8}$ & $\mathbf{5 3 . 9 8}$ & $\mathbf{4 6 . 4 6}$ \\
\hline Case 2 & 600 & 515 & 261.16 & 321.67 & $\mathbf{1 4 . 1 7}$ & $\mathbf{5 6 . 4 7}$ & $\mathbf{4 6 . 3 9}$ \\
\hline Case 3 & 600 & 516.87 & 268.43 & 322 & $\mathbf{1 3 . 8 6}$ & $\mathbf{5 5 . 2 6}$ & $\mathbf{4 6 . 3 3}$ \\
\hline Case 4 & 600 & 526.43 & 269.39 & 329.54 & $\mathbf{1 2 . 2 6}$ & $\mathbf{5 5 . 1 0}$ & $\mathbf{4 5 . 0 8}$ \\
\hline Case 5 & 600 & 531.23 & 270 & 341.21 & $\mathbf{1 1 . 4 6}$ & $\mathbf{5 5 . 0 0}$ & $\mathbf{4 3 . 1 3}$ \\
\hline Case 6 & 600 & 525.21 & 275.25 & 333.37 & $\mathbf{1 2 . 4 7}$ & $\mathbf{5 4 . 1 3}$ & $\mathbf{4 4 . 4 4}$ \\
\hline Case 7 & 600 & 528.42 & 274.38 & 341.13 & $\mathbf{1 1 . 9 3}$ & $\mathbf{5 4 . 2 7}$ & $\mathbf{4 3 . 1 5}$ \\
\hline Case 8 & 600 & 529.17 & 273.53 & 319.39 & $\mathbf{1 1 . 8 1}$ & $\mathbf{5 4 . 4 1}$ & $\mathbf{4 6 . 7 7}$ \\
\hline Case 1 & 900 & 1005.78 & 1234.32 & 643.78 & $\mathbf{1 1 . 7 5}$ & $\mathbf{3 7 . 1 5}$ & $\mathbf{2 8 . 4 7}$ \\
\hline Case 2 & 900 & 1007.85 & 1233 & 650.12 & $\mathbf{1 1 . 9 8}$ & $\mathbf{3 7 . 0 0}$ & $\mathbf{2 7 . 7 6}$ \\
\hline Case 3 & 900 & 1015.76 & 1238.43 & 655 & $\mathbf{1 2 . 8 6}$ & $\mathbf{3 7 . 6 0}$ & $\mathbf{2 7 . 2 2}$ \\
\hline Case 4 & 900 & 1017 & 1242.12 & 658.91 & $\mathbf{1 3 . 0 0}$ & $\mathbf{3 8 . 0 1}$ & $\mathbf{2 6 . 7 9}$ \\
\hline Case 5 & 900 & 1013.13 & 1239.31 & 661.23 & $\mathbf{1 2 . 5 7}$ & $\mathbf{3 7 . 7 0}$ & $\mathbf{2 6 . 5 3}$ \\
\hline Case 6 & 900 & 1019.43 & 1235.35 & 662.49 & $\mathbf{1 3 . 2 7}$ & $\mathbf{3 7 . 2 6}$ & $\mathbf{2 6 . 3 9}$ \\
\hline Case 7 & 900 & 1000.94 & 1237.64 & 664.43 & $\mathbf{1 1 . 2 2}$ & $\mathbf{3 7 . 5 2}$ & $\mathbf{2 6 . 1 7}$ \\
\hline Case 8 & 900 & 1002.38 & 1241.42 & 665.02 & $\mathbf{1 1 . 3 8}$ & $\mathbf{3 7 . 9 4}$ & $\mathbf{2 6 . 1 1}$ \\
\hline Case 1 & 1200 & 1298.64 & 1689.31 & 1678 & $\mathbf{8 . 2 2}$ & $\mathbf{4 0 . 7 8}$ & $\mathbf{3 9 . 8 3}$ \\
\hline Case 2 & 1200 & 1300.12 & 1700.12 & 1673.42 & $\mathbf{8 . 3 4}$ & $\mathbf{4 1 . 6 8}$ & $\mathbf{3 9 . 4 5}$ \\
\hline Case 3 & 1200 & 1305.43 & 1696.43 & 1671.21 & $\mathbf{8 . 7 9}$ & $\mathbf{4 1 . 3 7}$ & $\mathbf{3 9 . 2 7}$ \\
\hline Case 4 & 1200 & 1304.32 & 1693.43 & 1675.32 & $\mathbf{8 . 6 9}$ & $\mathbf{4 1 . 1 2}$ & $\mathbf{3 9 . 6 1}$ \\
\hline Case 5 & 1200 & 1297.81 & 1695.01 & 1676.04 & $\mathbf{8 . 1 5}$ & $\mathbf{4 1 . 2 5}$ & $\mathbf{3 9 . 6 7}$ \\
\hline Case 6 & 1200 & 1295 & 1698.83 & 1678.18 & $\mathbf{7 . 9 2}$ & $\mathbf{4 1 . 5 7}$ & $\mathbf{3 9 . 8 5}$ \\
\hline Case 7 & 1200 & 1296.64 & 1689.34 & 1679.93 & $\mathbf{8 . 0 5}$ & $\mathbf{4 0 . 7 8}$ & $\mathbf{3 9 . 9 9}$ \\
\hline Case 8 & 1200 & 1298.11 & 1688.89 & 1678 & $\mathbf{8 . 1 8}$ & $\mathbf{4 0 . 7 4}$ & $\mathbf{3 9 . 8 3}$ \\
\hline
\end{tabular}




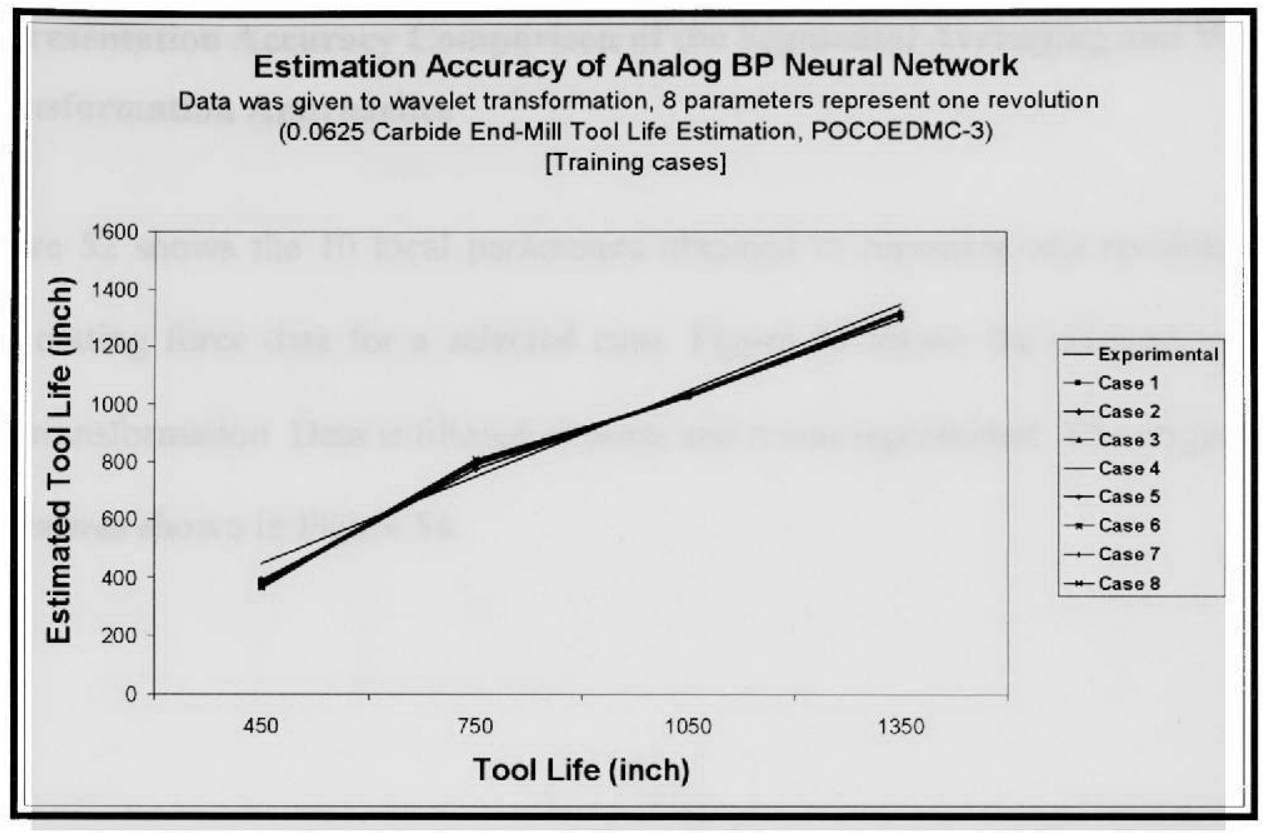

Figure 51.a. Estimation Accuracy of Analog BP for Training Cases with Improved N ${ }^{2}$ PTI (Wavelet Transformation)

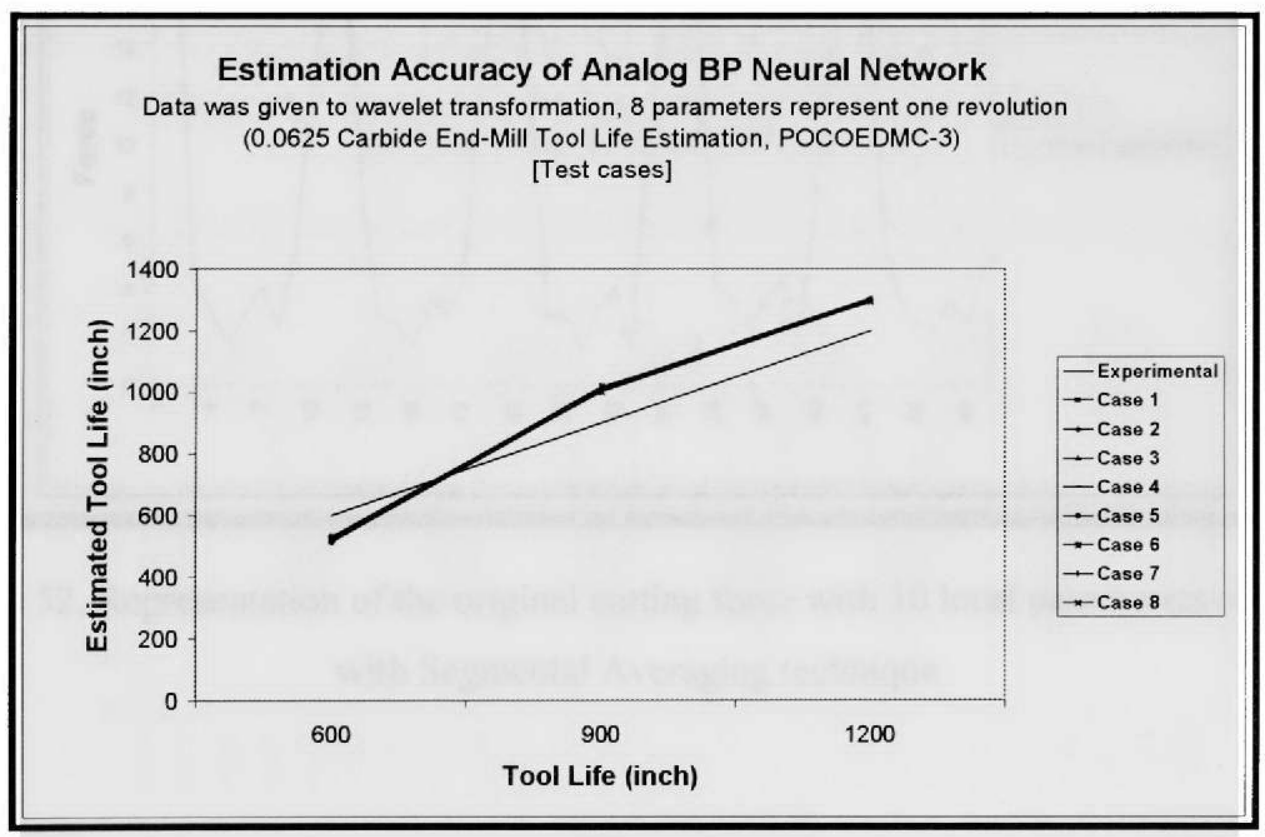

Figure 51.b. Estimation Accuracy of Analog BP for Testing Cases with Improved N ${ }^{2}$ PTI (Wavelet Transformation) 
- Representation Accuracy Comparison of the Segmental Averaging and Wavelet Transformation Approaches

Figure 52 shows the 10 local parameters obtained to represent one revolution of the original cutting force data for a selected case. Figure 53 shows the original signal after wavelet transformation. Data is filtered of noise and it was represented. The original cutting force data was shown in Figure 54.

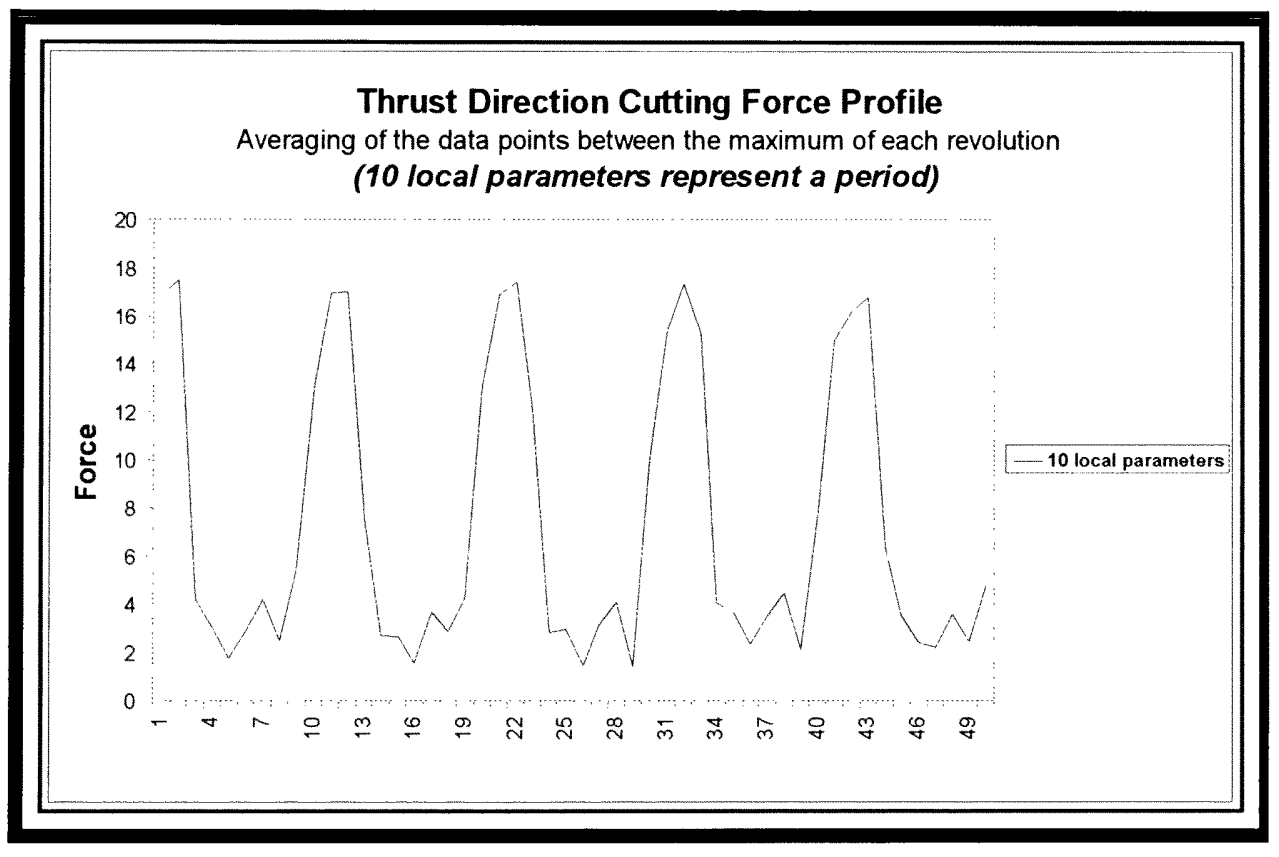

Figure 52. Representation of the original cutting force with 10 local parameters obtained with Segmental Averaging technique 


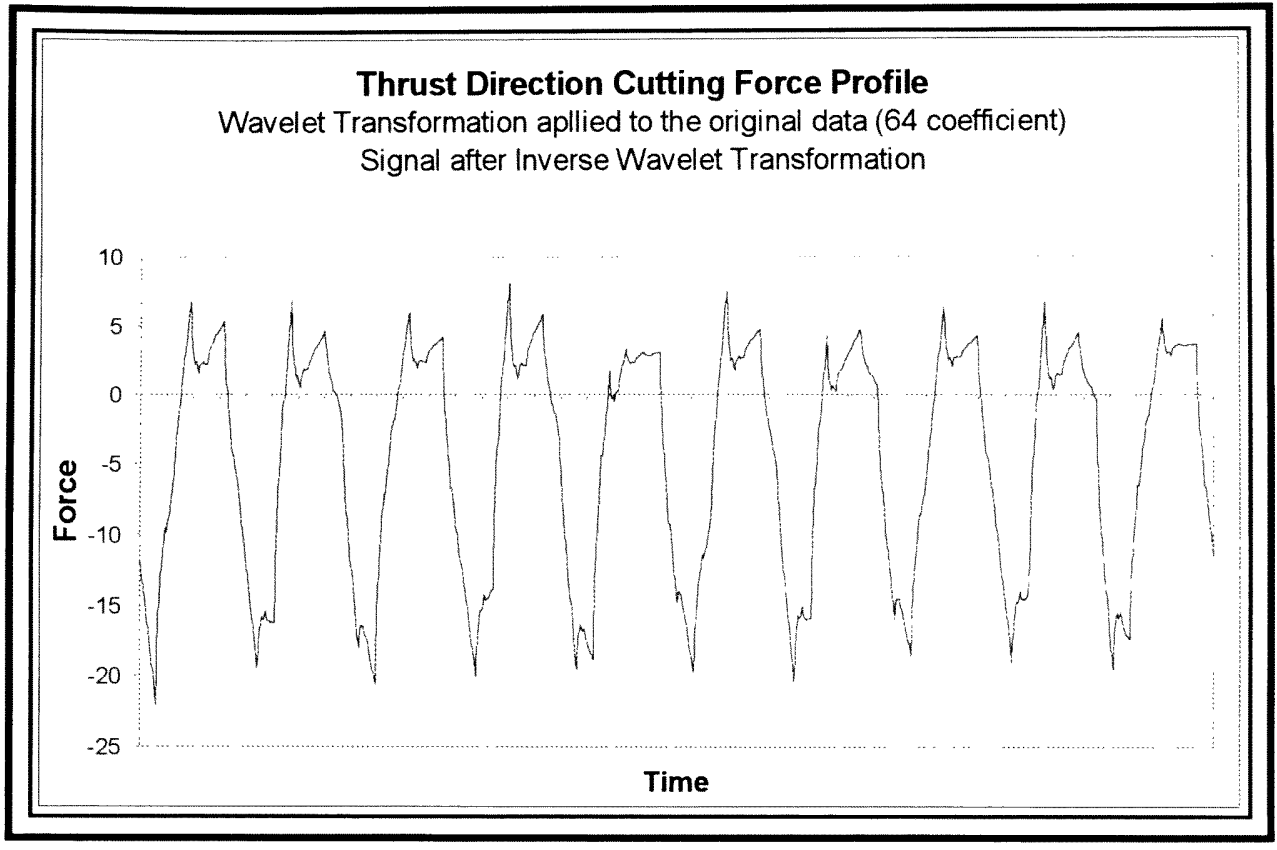

Figure 53. Representation of the original cutting force after wavelet transformation

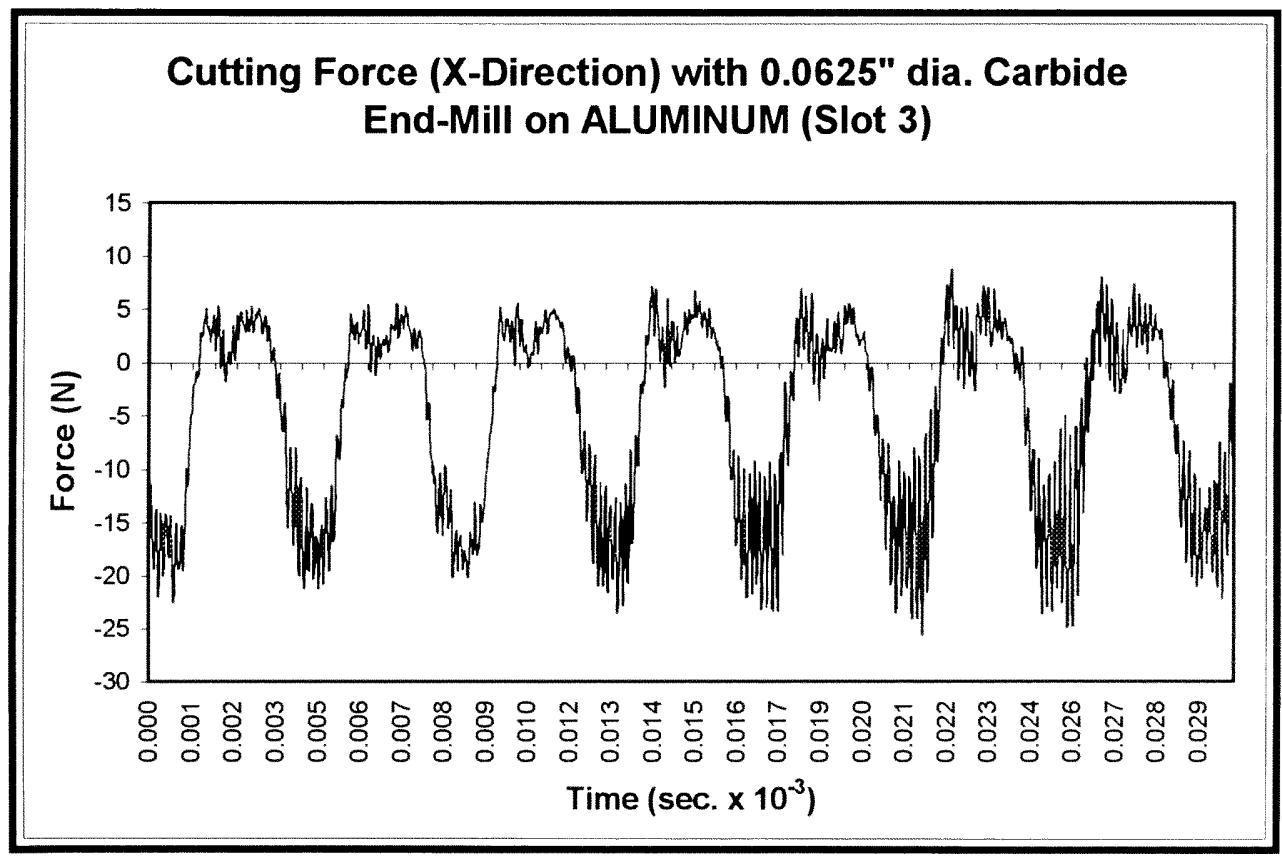

Figure 54. Experimental Cutting Force Data 


\section{Aluminum:}

\section{- Segmental Averaging Technique:}

Improved $\mathrm{N}^{2} \mathrm{PTI}$ was also used to analyze the tool wear during the micro endmilling of the aluminum and POCOEDMC-3 workpiece. Normalization of the cutting force in thrust and feed direction made the $\mathrm{N}^{2} \mathrm{PTI}$ more powerful. The effect of the depth of cut was eliminated with the normalization of the data. The spindle speed for the experiment was $45,000 \mathrm{rpm}$. Data was collected with $10 \mu \mathrm{s}$ sampling. In this case, there are 130 data points in each revolution. For each case, 20 input values were presented to the Neural Network training.

Neural networks were trained with 20 input and 1 output. The 20 input consisted of 10 data, which were obtained with the averaging of the data points between the maximum of each period. 10 data point from thrust and 10 data point from feed direction cutting force were taken. The output node was the tool life obtained. 50 training cases and 40 testing cases were used. The characteristics of the networks used are listed in Table 23. The results obtained for the training and testing cases after the training of 3 different neural networks are presented in Table 24 and 25.

The optimal estimations were obtained with Analog BP and results are presented in Figure 55 . 
Table 23. Characteristics of the 3 Different Neural Network used for Improved $N^{2}$ PTI

(Segmental Averaging)

\begin{tabular}{|c|c|c|c|}
\hline Neural Network & Analog BP & Basic PNN & Sepvar PNN \\
\hline Input Nodes & 20 & 20 & 20 \\
\hline Output Nodes & 1 & 1 & 1 \\
\hline Training Cases & 50 & 50 & 50 \\
\hline Test Cases & 40 & 40 & 40 \\
\hline Training Time & 151.52 seconds & 17.8 seconds & 14.6 seconds \\
\hline $\begin{array}{l}\text { Network } \\
\text { Proprieties }\end{array}$ & $\begin{array}{l}10 \text { Hidden Nodes } \\
\text { 0.6 Learning Rate } \\
0.9 \text { Momentum }\end{array}$ & $\begin{array}{l}\text { 0.0 Sigma Low } \\
\text { 5.0 Sigma High } \\
5 \text { Sigma Tries }\end{array}$ & $\begin{array}{c}\text { 0.003 Sigma Low } \\
\text { 5.0 Sigma High } \\
5 \text { Sigma Tries }\end{array}$ \\
\hline
\end{tabular}


Table 24. Estimation for the Training data (Aluminum) after the training of $3 \mathrm{NN}$

(Segmental Averaging)

\begin{tabular}{|c|c|c|c|c|c|c|c|}
\hline & $\begin{array}{l}\text { Real } \\
\text { Data }\end{array}$ & $\begin{array}{l}\text { Analog } \\
\text { BP }\end{array}$ & $\begin{array}{l}\text { Basic } \\
\text { PNN }\end{array}$ & $\begin{array}{l}\text { Sepvar } \\
\text { PNN }\end{array}$ & $\begin{array}{l}\text { Analog } \\
\text { Error \% }\end{array}$ & $\begin{array}{l}\text { Basic } \\
\text { Error \% }\end{array}$ & $\begin{array}{l}\text { Sepvar } \\
\text { Error \% }\end{array}$ \\
\hline Case 1 & 30 & 35.16 & 62.89 & 65.28 & 17.20 & 109.63 & 117.60 \\
\hline Case 2 & 30 & 35.51 & 63 & 63.23 & 18.37 & 110.00 & 110.77 \\
\hline Case 3 & 30 & 34.76 & 63.44 & 67.91 & 15.87 & 111.47 & 126.37 \\
\hline Case 4 & 30 & 35 & 65.23 & 69 & 16.67 & 117.43 & 130.00 \\
\hline Case 5 & 30 & 35.26 & 64.97 & 72.35 & 17.53 & 116.57 & 141.17 \\
\hline Case 6 & 30 & 34.99 & 66 & 75 & 16.63 & 120.00 & 150.00 \\
\hline Case 7 & 30 & 36.02 & 67.1 & 74.4 & 20.07 & 123.67 & 148.00 \\
\hline Case 8 & 30 & 35.64 & 67.14 & 72.9 & 18.80 & 123.80 & 143.00 \\
\hline Case 9 & 30 & 33 & 62.86 & 69.52 & 10.00 & 109.53 & 131.73 \\
\hline Case 10 & 30 & 35.85 & 68.01 & 64.21 & 19.50 & 126.70 & 114.03 \\
\hline Case 1 & 62 & 68.16 & 102.71 & 96.32 & 9.94 & 65.66 & 55.35 \\
\hline Case 2 & 62 & 70.34 & 105.32 & 99 & 13.45 & 69.87 & 59.68 \\
\hline Case 3 & 62 & 69 & 104.87 & 99.45 & 11.29 & 69.15 & 60.40 \\
\hline Case 4 & 62 & 71.21 & 107.42 & 99.23 & 14.85 & 73.26 & 60.05 \\
\hline Case 5 & 62 & 72.34 & 108.93 & 96.83 & 16.68 & 75.69 & 56.18 \\
\hline Case 6 & 62 & 73.32 & 105.97 & 98.5 & 18.26 & 70.92 & 58.87 \\
\hline Case 7 & 62 & 69.5 & 104.86 & 97 & 12.10 & 69.13 & 56.45 \\
\hline Case 8 & 62 & 68.75 & 103.3 & 95.34 & 10.89 & 66.61 & 53.77 \\
\hline Case 9 & 62 & 71.53 & 101.21 & 93 & 15.37 & 63.24 & 50.00 \\
\hline Case 10 & 62 & 70 & 102 & 94.18 & 12.90 & 64.52 & 51.90 \\
\hline Case 1 & 90 & 107.46 & 115.87 & 123.05 & 19.40 & 28.74 & 36.72 \\
\hline Case 2 & 90 & 107.21 & 118.43 & 128.92 & 19.12 & 31.59 & 43.24 \\
\hline Case 3 & 90 & 106.43 & 119.43 & 125 & 18.26 & 32.70 & 38.89 \\
\hline Case 4 & 90 & 105.84 & 117.75 & 127.4 & 17.60 & 30.83 & 41.56 \\
\hline Case 5 & 90 & 105.87 & 118 & 130.34 & 17.63 & 31.11 & 44.82 \\
\hline Case 6 & 90 & 106.53 & 115.78 & 131.05 & 18.37 & 28.64 & 45.61 \\
\hline Case 7 & 90 & 107.5 & 121.34 & 129.66 & 19.44 & 34.82 & 44.07 \\
\hline Case 8 & 90 & 103.65 & 120.84 & 126.43 & 15.17 & 34.27 & 40.48 \\
\hline Case 9 & 90 & 104.65 & 121.5 & 126.82 & 16.28 & 35.00 & 40.91 \\
\hline Case 10 & 90 & 105 & 119 & 125.1 & 16.67 & 32.22 & 39.00 \\
\hline Case 1 & 120 & 129.54 & 141.9 & 152.03 & 7.95 & 18.25 & 26.69 \\
\hline Case 2 & 120 & 124.54 & 145.86 & 149.54 & 3.78 & 21.55 & 24.62 \\
\hline Case 3 & 120 & 123.93 & 144.44 & 148.47 & 3.28 & 20.37 & 23.73 \\
\hline Case 4 & 120 & 122.3 & 143.38 & 145 & 1.92 & 19.48 & 20.83 \\
\hline Case 5 & 120 & 124.65 & 146.95 & 149.9 & 3.88 & 22.46 & 24.92 \\
\hline Case 6 & 120 & 126 & 145.3 & 148.36 & 5.00 & 21.08 & 23.63 \\
\hline Case 7 & 120 & 127.38 & 145 & 145.77 & 6.15 & 20.83 & 21.48 \\
\hline Case 8 & 120 & 125.55 & 143.1 & 151 & 4.63 & 19.25 & 25.83 \\
\hline Case 9 & 120 & 128 & 142.93 & 150.04 & 6.67 & 19.11 & 25.03 \\
\hline Case 10 & 120 & 125.04 & 141 & 150.5 & 4.20 & 17.50 & 25.42 \\
\hline Case 1 & 156 & 173.49 & 185.93 & 192 & 11.21 & 19.19 & 23.08 \\
\hline Case 2 & 156 & 175 & 191 & 198.54 & 12.18 & 22.44 & 27.27 \\
\hline Case 3 & 156 & 2.12 & 0.99 & 199 & 10.33 & 22.43 & 27.56 \\
\hline Case 4 & 156 & 169.32 & 193.26 & 194.65 & 8.54 & 23.88 & 24.78 \\
\hline Case 5 & 156 & 168.39 & 192.32 & 195.5 & 7.94 & 23.28 & 25.32 \\
\hline Case 6 & 156 & 171.2 & 189.43 & 195 & 9.74 & 21.43 & 25.00 \\
\hline Case 7 & 156 & 173 & 188.04 & 193.28 & 10.90 & 20.54 & 23.90 \\
\hline
\end{tabular}


Table 25. Estimation for the Testing data (Aluminum) after the training of $3 \mathrm{NN}$

(Segmental Averaging)

\begin{tabular}{|c|c|c|c|c|c|c|c|}
\hline & $\begin{array}{l}\text { Real } \\
\text { Data }\end{array}$ & $\begin{array}{l}\text { Analog } \\
\text { BP }\end{array}$ & $\begin{array}{l}\text { Basic } \\
\text { PNN }\end{array}$ & $\begin{array}{l}\text { Sepvar } \\
\text { PNN }\end{array}$ & $\begin{array}{l}\text { Analog } \\
\text { Error \% }\end{array}$ & $\begin{array}{l}\text { Basic } \\
\text { Error \% }\end{array}$ & $\begin{array}{l}\text { Sepvar } \\
\text { Error \% }\end{array}$ \\
\hline Case 1 & 45 & 54.38 & 68.94 & 84.53 & 20.84 & 53.20 & 87.84 \\
\hline Case 2 & 45 & 55.15 & 70.34 & 90.21 & 22.56 & 56.31 & 100.47 \\
\hline Case 3 & 45 & 57.28 & 73 & 92.54 & 27.29 & 62.22 & 105.64 \\
\hline Case 4 & 45 & 58.54 & 71.24 & 93.32 & 30.09 & 58.31 & 107.38 \\
\hline Case 5 & 45 & 54.05 & 74.99 & 91.43 & 20.11 & 66.64 & 103.18 \\
\hline Case 6 & 45 & 53.99 & 74 & 87.54 & 19.98 & 64.44 & 94.53 \\
\hline Case 7 & 45 & 53.95 & 76.43 & 88 & 19.89 & 69.84 & 95.56 \\
\hline Case 8 & 45 & 55 & 75.43 & 83.65 & 22.22 & 67.62 & 85.89 \\
\hline Case 9 & 45 & 54.16 & 68.54 & 85.55 & 20.36 & 52.31 & 90.11 \\
\hline Case 10 & 45 & 53.06 & 71.05 & 83.5 & 17.91 & 57.89 & 85.56 \\
\hline Case 1 & 75 & 68 & 120.45 & 114.3 & 9.33 & 60.60 & 52.40 \\
\hline Case 2 & 75 & 65.32 & 125.04 & 115 & 12.91 & 66.72 & 53.33 \\
\hline Case 3 & 75 & 63.9 & 127.95 & 117.74 & 14.80 & 70.60 & 56.99 \\
\hline Case 4 & 75 & 65 & 128.37 & 118.43 & 13.33 & 71.16 & 57.91 \\
\hline Case 5 & 75 & 62.17 & 126.53 & 117.94 & 17.11 & 68.71 & 57.25 \\
\hline Case 6 & 75 & 60.83 & 126.2 & 114.32 & 18.89 & 68.27 & 52.43 \\
\hline Case 7 & 75 & 63.73 & 125.5 & 116.66 & 15.03 & 67.33 & 55.55 \\
\hline Case 8 & 75 & 64.94 & 122.31 & 117 & 13.41 & 63.08 & 56.00 \\
\hline Case 9 & 75 & 62.18 & 121.74 & 115.7 & 17.09 & 62.32 & 54.27 \\
\hline Case 10 & 75 & 66 & 124 & 113.99 & 12.00 & 65.33 & 51.99 \\
\hline Case 1 & 107 & 128 & 141.2 & 132.04 & 19.63 & 31.96 & 23.40 \\
\hline Case 2 & 107 & 130.26 & 143 & 135 & 21.74 & 33.64 & 26.17 \\
\hline Case 3 & 107 & 132.85 & 142.38 & 132.4 & 24.16 & 33.07 & 23.74 \\
\hline Case 4 & 107 & 133.25 & 145.83 & 136.32 & 24.53 & 36.29 & 27.40 \\
\hline Case 5 & 107 & 131 & 149.63 & 137.83 & 22.43 & 39.84 & 28.81 \\
\hline Case 6 & 107 & 133.73 & 148 & 135.53 & 24.98 & 38.32 & 26.66 \\
\hline Case 7 & 107 & 135.2 & 142.84 & 132 & 26.36 & 33.50 & 23.36 \\
\hline Case 8 & 107 & 133 & 144.06 & 134.45 & 24.30 & 34.64 & 25.65 \\
\hline Case 9 & 107 & 135.32 & 143.9 & 136.78 & 26.47 & 34.49 & 27.83 \\
\hline Case 10 & 107 & 132.63 & 145 & 135.3 & 23.95 & 35.51 & 26.45 \\
\hline Case 1 & 135 & 168.02 & 175.94 & 189.33 & 24.46 & 30.33 & 40.24 \\
\hline Case 2 & 135 & 165.32 & 177 & 191.21 & 22.46 & 31.11 & 41.64 \\
\hline Case 3 & 135 & 164.94 & 181.21 & 190 & 22.18 & 34.23 & 40.74 \\
\hline Case 4 & 135 & 163.26 & 182.32 & 187.17 & 20.93 & 35.05 & 38.64 \\
\hline Case 5 & 135 & 162.03 & 183.21 & 192.32 & 20.02 & 35.71 & 42.46 \\
\hline Case 6 & 135 & 165 & 184 & 190.86 & 22.22 & 36.30 & 41.38 \\
\hline Case 7 & 135 & 167.25 & 179.14 & 194 & 23.89 & 32.70 & 43.70 \\
\hline Case 8 & 135 & 166.24 & 179.99 & 193.32 & 23.14 & 33.33 & 43.20 \\
\hline Case 9 & 135 & 164.52 & 178.23 & 185.43 & 21.87 & 32.02 & 37.36 \\
\hline Case 10 & 135 & 167.17 & 181.19 & 188.85 & 23.83 & 34.21 & 39.89 \\
\hline
\end{tabular}




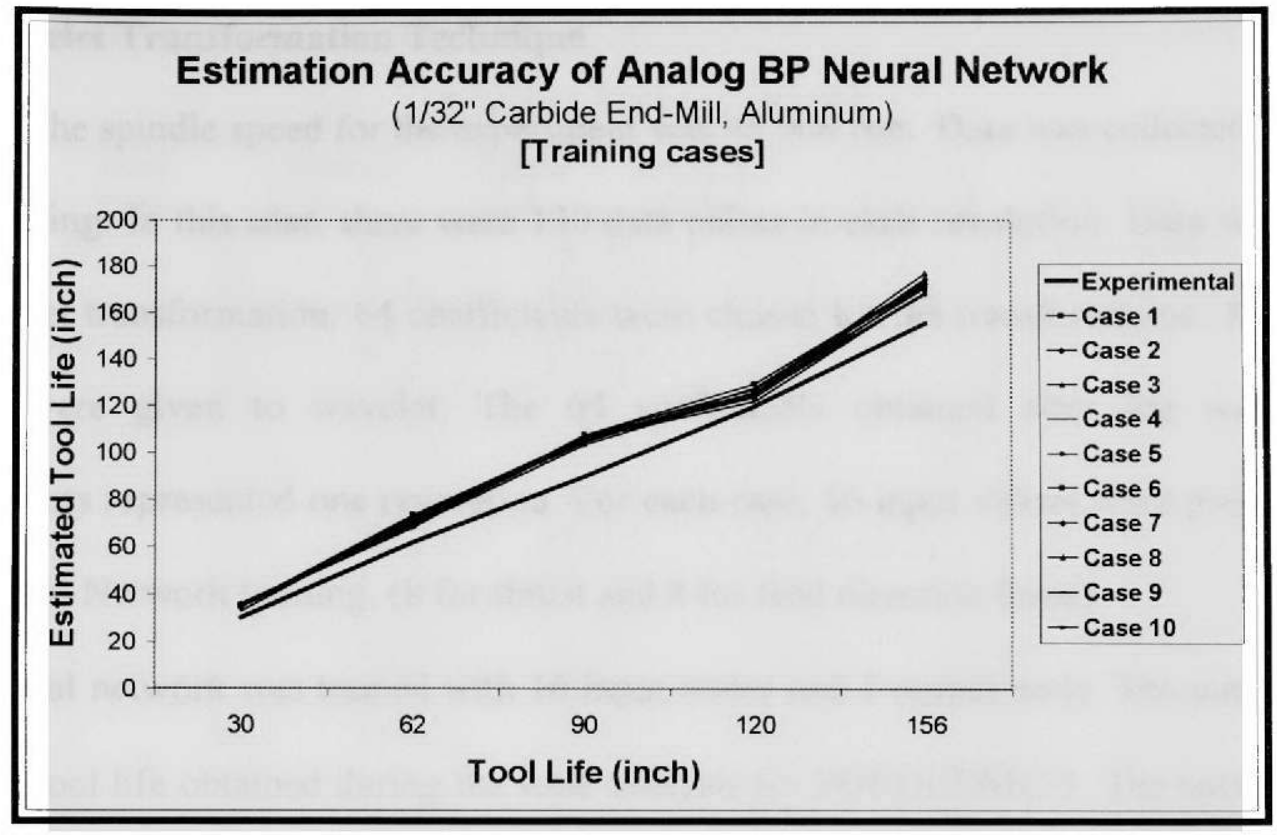

Figure 55.a. Estimation Accuracy of Analog BP for Training Cases with Improved N ${ }^{2}$ PTI (Segmental Averaging)

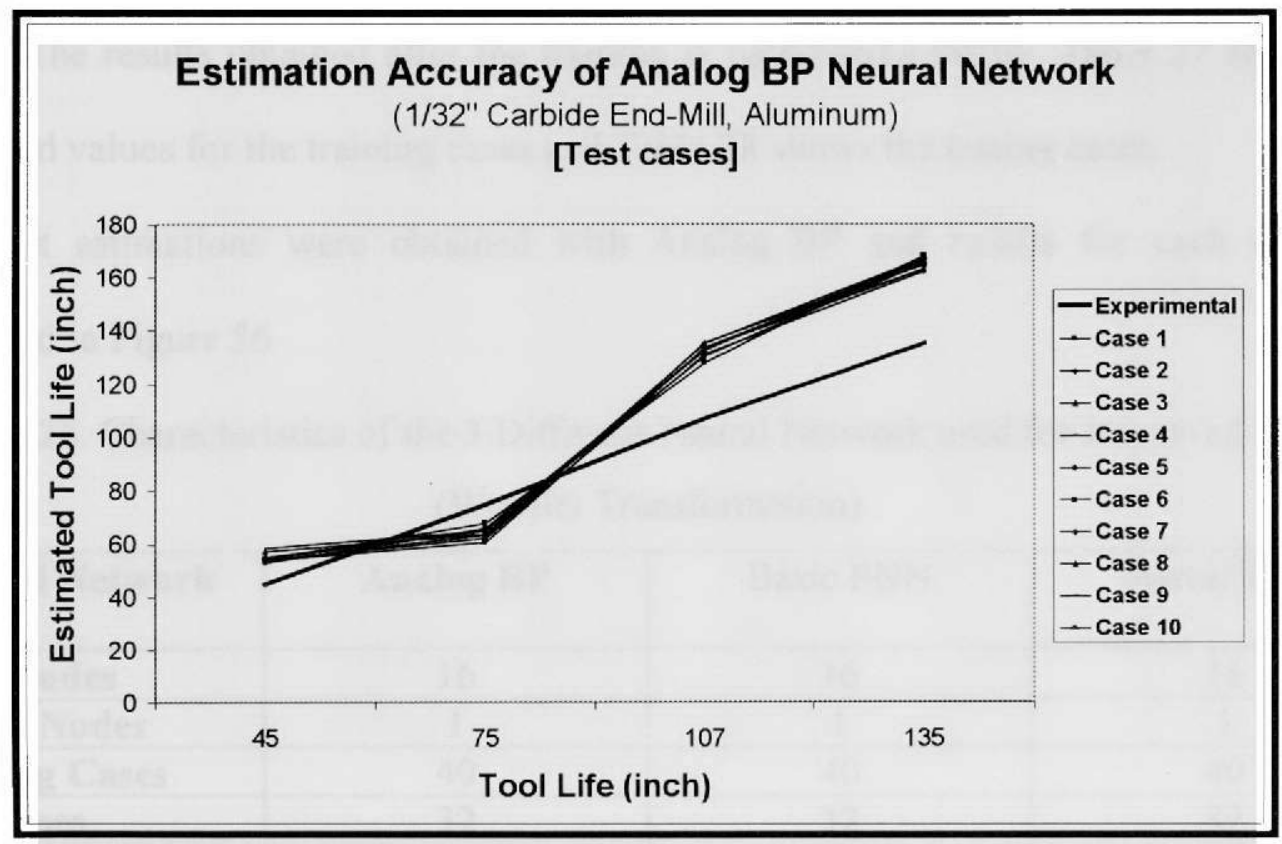

Figure 55.b. Estimation Accuracy of Analog BP for Test Cases with Improved N ${ }^{2}$ PTI (Segmental Averaging) 


\section{- Wavelet Transformation Technique}

The spindle speed for the experiment was 45,000 rpm. Data was collected with 10 $\mu$ s sampling. In this case, there were 130 data points in each revolution. Data was given to wavelet transformation. 64 coefficients were chosen for the transformation. 1024 data points were given to wavelet. The 64 coefficients obtained after the wavelet, 8 coefficients represented one revolution. For each case, 16 input values were presented to the Neural Network training. ( 8 for thrust and 8 for feed direction force)

The neural network was trained with 16 input nodes and 1 output node. The output node was the tool life obtained during the wear analysis for POCOEDMC-3. The network was trained for 40 training and 32 testing cases. Backpropagation and Probabilistic neural networks were evaluated. Analog BP, Basic PNN and Sepvar PNN were trained with the normalized data. The final settings of the NN are listed in Table 26.

The results obtained after the training is represented below. Table 27 shows the estimated values for the training cases and Table 28 shows the testing cases.

The best estimations were obtained with Analog $\mathrm{BP}$ and results for each case are presented in Figure 56.

Table 26. Characteristics of the 3 Different Neural Network used for Improved N ${ }^{2}$ PTI (Wavelet Transformation)

\begin{tabular}{|l|c|c|c|}
\hline Neural Network & Analog BP & Basic PNN & Sepvar PNN \\
\hline Input Nodes & 16 & 16 & 16 \\
\hline Output Nodes & 1 & 1 & 1 \\
\hline Training Cases & 40 & 40 & 40 \\
\hline Test Cases & 32 & 32 & 32 \\
\hline Training Time & 173.18 seconds & 14.17 seconds & 13.96 seconds \\
\hline Network & 8 Hidden Nodes & $\begin{array}{c}\text { 0.0 Sigma Low } \\
\text { Proprieties }\end{array}$ & $\begin{array}{c}\text { 0.6 Learning Rate } \\
\text { 5.0 Sigma High } \\
\text { 5.9 Sigma Sigma Low }\end{array}$ \\
\hline
\end{tabular}


Table 27. Estimation for the Training data (Aluminum) after the training of $3 \mathrm{NN}$

(Wavelet Transformation)

\begin{tabular}{|c|c|c|c|c|c|c|c|}
\hline & $\begin{array}{l}\text { Real } \\
\text { Data }\end{array}$ & $\begin{array}{l}\text { Analog } \\
\text { BP }\end{array}$ & $\begin{array}{l}\text { Basic } \\
\text { PNN }\end{array}$ & $\begin{array}{l}\text { Sepvar } \\
\text { PNN }\end{array}$ & $\begin{array}{l}\text { Analog } \\
\text { Error \% }\end{array}$ & $\begin{array}{l}\text { Basic } \\
\text { Error \% }\end{array}$ & $\begin{array}{l}\text { Sepvar } \\
\text { Error \% }\end{array}$ \\
\hline Case 1 & 30 & 32.18 & 46.32 & 10.21 & 7.27 & 54.40 & 65.97 \\
\hline Case 2 & 30 & 32.94 & 45.00 & 11.21 & 9.80 & 50.00 & 62.63 \\
\hline Case 3 & 30 & 33.15 & 46.12 & 10.86 & 10.50 & 53.73 & 63.80 \\
\hline Case 4 & 30 & 32.85 & 46.78 & 10.03 & 9.50 & 55.93 & 66.57 \\
\hline Case 5 & 30 & 33.03 & 46.91 & 10.45 & 10.10 & 56.37 & 65.17 \\
\hline Case 6 & 30 & 33.12 & 48.37 & 10.57 & 10.40 & 61.23 & 64.77 \\
\hline Case 7 & 30 & 34.08 & 49.99 & 10.91 & 13.60 & 66.63 & 63.63 \\
\hline Case 8 & 30 & 33.13 & 48.03 & 10.38 & 10.43 & 60.10 & 65.40 \\
\hline Case 1 & 62 & 57.43 & 87.16 & 72.24 & 7.37 & 40.58 & 16.52 \\
\hline Case 2 & 62 & 55.01 & 87.93 & 74.25 & 11.27 & 41.82 & 19.76 \\
\hline Case 3 & 62 & 56.74 & 88.00 & 74.59 & 8.48 & 41.94 & 20.30 \\
\hline Case 4 & 62 & 55.93 & 88.18 & 74.42 & 9.79 & 42.23 & 20.04 \\
\hline Case 5 & 62 & 55.00 & 89.16 & 72.62 & 11.29 & 43.81 & 17.13 \\
\hline Case 6 & 62 & 55.21 & 87.38 & 73.88 & 10.95 & 40.94 & 19.15 \\
\hline Case 7 & 62 & 54.08 & 84.69 & 72.75 & 12.77 & 36.60 & 17.34 \\
\hline Case 8 & 62 & 54.86 & 85.55 & 71.51 & 11.52 & 37.98 & 15.33 \\
\hline Case 1 & 90 & 85.13 & 118.12 & 99.00 & 5.41 & 31.24 & 10.00 \\
\hline Case 2 & 90 & 84.38 & 119.91 & 96.69 & 6.24 & 33.23 & 7.43 \\
\hline Case 3 & 90 & 84.56 & 117.83 & 93.75 & 6.04 & 30.92 & 4.17 \\
\hline Case 4 & 90 & 83.91 & 120.34 & 95.55 & 6.77 & 33.71 & 6.17 \\
\hline Case 5 & 90 & 82.99 & 121.23 & 97.76 & 7.79 & 34.70 & 8.62 \\
\hline Case 6 & 90 & 83.00 & 121.00 & 98.29 & 7.78 & 34.44 & 9.21 \\
\hline Case 7 & 90 & 82.84 & 119.93 & 97.25 & 7.96 & 33.26 & 8.05 \\
\hline Case 8 & 90 & 82.04 & 120.04 & 94.82 & 8.84 & 33.38 & 5.36 \\
\hline Case 1 & 120 & 127.81 & 147.81 & 114.02 & 6.51 & 23.18 & 4.98 \\
\hline Case 2 & 120 & 125.93 & 143.38 & 112.16 & 4.94 & 19.48 & 6.54 \\
\hline Case 3 & 120 & 124.00 & 146.95 & 111.35 & 3.33 & 22.46 & 7.21 \\
\hline Case 4 & 120 & 126.84 & 147.93 & 108.75 & 5.70 & 23.28 & 9.38 \\
\hline Case 5 & 120 & 125.95 & 145.94 & 112.43 & 4.96 & 21.62 & 6.31 \\
\hline Case 6 & 120 & 125.75 & 151.21 & 111.27 & 4.79 & 26.01 & 7.28 \\
\hline Case 7 & 120 & 124.93 & 151.99 & 109.33 & 4.11 & 26.66 & 8.89 \\
\hline Case 8 & 120 & 124.78 & 149.93 & 113.25 & 3.98 & 24.94 & 5.63 \\
\hline Case 1 & 156 & 174.57 & 201.12 & 236.16 & 11.90 & 28.92 & 51.38 \\
\hline Case 2 & 156 & 174.93 & 204.43 & 244.20 & 12.13 & 31.04 & 56.54 \\
\hline Case 3 & 156 & 174.00 & 205.87 & 244.77 & 11.54 & 31.97 & 56.90 \\
\hline Case 4 & 156 & 173.06 & 207.93 & 239.42 & 10.94 & 33.29 & 53.47 \\
\hline Case 5 & 156 & 173.57 & 205.74 & 240.47 & 11.26 & 31.88 & 54.14 \\
\hline Case 6 & 156 & 174.01 & 209.21 & 239.85 & 11.54 & 34.11 & 53.75 \\
\hline Case 7 & 156 & 172.94 & 203.33 & 237.73 & 10.86 & 30.34 & 52.39 \\
\hline Case 8 & 156 & 172.99 & 209.42 & 239.16 & 10.89 & 34.24 & 53.31 \\
\hline
\end{tabular}


Table 28. Estimation for the Testing data (Aluminum) after the training of $3 \mathrm{NN}$

(Wavelet Transformation)

\begin{tabular}{|c|c|c|c|c|c|c|c|}
\hline & $\begin{array}{l}\text { Real } \\
\text { Data }\end{array}$ & $\begin{array}{l}\text { Analog } \\
\text { BP }\end{array}$ & $\begin{array}{l}\text { Basic } \\
\text { PNN }\end{array}$ & $\begin{array}{l}\text { Sepvar } \\
\text { PNN }\end{array}$ & $\begin{array}{l}\text { Analog } \\
\text { Error \% }\end{array}$ & $\begin{array}{l}\text { Basic } \\
\text { Error \% }\end{array}$ & $\begin{array}{l}\text { Sepvar } \\
\text { Error \% }\end{array}$ \\
\hline Case 1 & 45 & 38.12 & 65.28 & 78.32 & 15.29 & 45.07 & 74.04 \\
\hline Case 2 & 45 & 38.29 & 63.23 & 79.92 & 14.91 & 40.51 & 77.60 \\
\hline Case 3 & 45 & 37.99 & 67.91 & 80.12 & 15.58 & 50.91 & 78.04 \\
\hline Case 4 & 45 & 39.94 & 69.00 & 83.32 & 11.24 & 53.33 & 85.16 \\
\hline Case 5 & 45 & 38.88 & 72.35 & 91.43 & 13.60 & 60.78 & 103.18 \\
\hline Case 6 & 45 & 37.84 & 75.00 & 87.54 & 15.91 & 66.67 & 94.53 \\
\hline Case 7 & 45 & 38.00 & 74.40 & 88.93 & 15.56 & 65.33 & 97.62 \\
\hline Case 8 & 45 & 38.27 & 72.90 & 87.43 & 14.96 & 62.00 & 94.29 \\
\hline Case 1 & 75 & 87.39 & 132.04 & 114.30 & 16.52 & 76.05 & 52.40 \\
\hline Case 2 & 75 & 88.00 & 135.00 & 114.82 & 17.33 & 80.00 & 53.09 \\
\hline Case 3 & 75 & 86.99 & 132.40 & 117.74 & 15.99 & 76.53 & 56.99 \\
\hline Case 4 & 75 & 86.53 & 136.32 & 118.43 & 15.37 & 81.76 & 57.91 \\
\hline Case 5 & 75 & 86.17 & 137.83 & 117.94 & 14.89 & 83.77 & 57.25 \\
\hline Case 6 & 75 & 85.94 & 135.53 & 126.22 & 14.59 & 80.71 & 68.29 \\
\hline Case 7 & 75 & 83.16 & 132.00 & 116.66 & 10.88 & 76.00 & 55.55 \\
\hline Case 8 & 75 & 84.00 & 134.45 & 118.46 & 12.00 & 79.27 & 57.95 \\
\hline Case 1 & 107 & 125.27 & 141.20 & 194.34 & 17.07 & 31.96 & 81.63 \\
\hline Case 2 & 107 & 126.99 & 143.00 & 191.21 & 18.68 & 33.64 & 78.70 \\
\hline Case 3 & 107 & 126.75 & 142.38 & 190.00 & 18.46 & 33.07 & 77.57 \\
\hline Case 4 & 107 & 127.00 & 145.83 & 187.17 & 18.69 & 36.29 & 74.93 \\
\hline Case 5 & 107 & 126.15 & 149.63 & 192.32 & 17.90 & 39.84 & 79.74 \\
\hline Case 6 & 107 & 125.94 & 148.00 & 190.86 & 17.70 & 38.32 & 78.37 \\
\hline Case 7 & 107 & 125.76 & 142.84 & 194.00 & 17.53 & 33.50 & 81.31 \\
\hline Case 8 & 107 & 126.38 & 144.06 & 193.32 & 18.11 & 34.64 & 80.67 \\
\hline Case 1 & 135 & 157.19 & 175.94 & 268.92 & 16.44 & 30.33 & 99.20 \\
\hline Case 2 & 135 & 155.00 & 177.00 & 261.39 & 14.81 & 31.11 & 93.62 \\
\hline Case 3 & 135 & 156.16 & 181.21 & 261.94 & 15.67 & 34.23 & 94.03 \\
\hline Case 4 & 135 & 156.00 & 182.32 & 259.11 & 15.56 & 35.05 & 91.93 \\
\hline Case 5 & 135 & 158.13 & 183.21 & 267.81 & 17.13 & 35.71 & 98.38 \\
\hline Case 6 & 135 & 156.39 & 184.00 & 265.03 & 15.84 & 36.30 & 96.32 \\
\hline Case 7 & 135 & 155.99 & 179.14 & 266.00 & 15.55 & 32.70 & 97.04 \\
\hline Case 8 & 135 & 157.17 & 179.99 & 268.18 & 16.42 & 33.33 & 98.65 \\
\hline
\end{tabular}




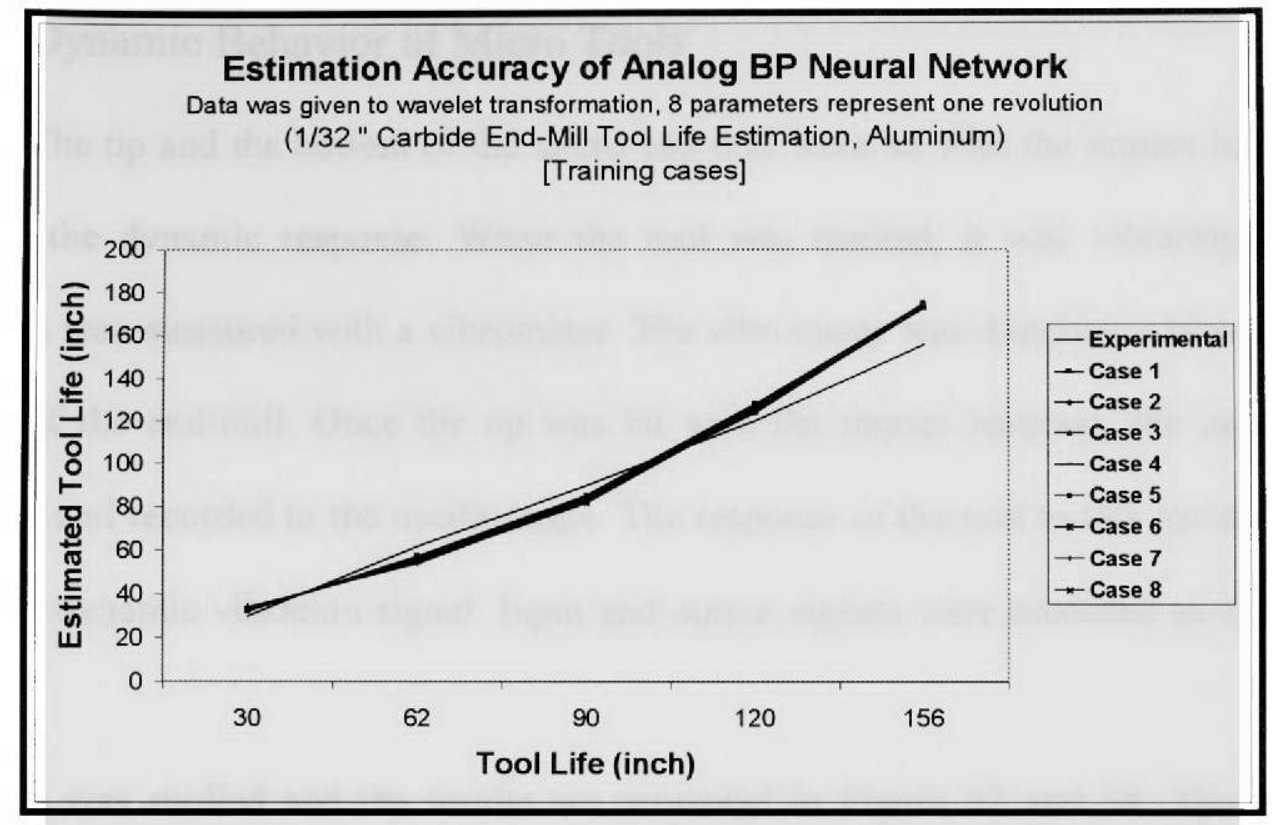

Figure 56.a. Estimation Accuracy of Analog BP for Training Cases with Improved $N^{2}$ PTI (Wavelet Transformation)

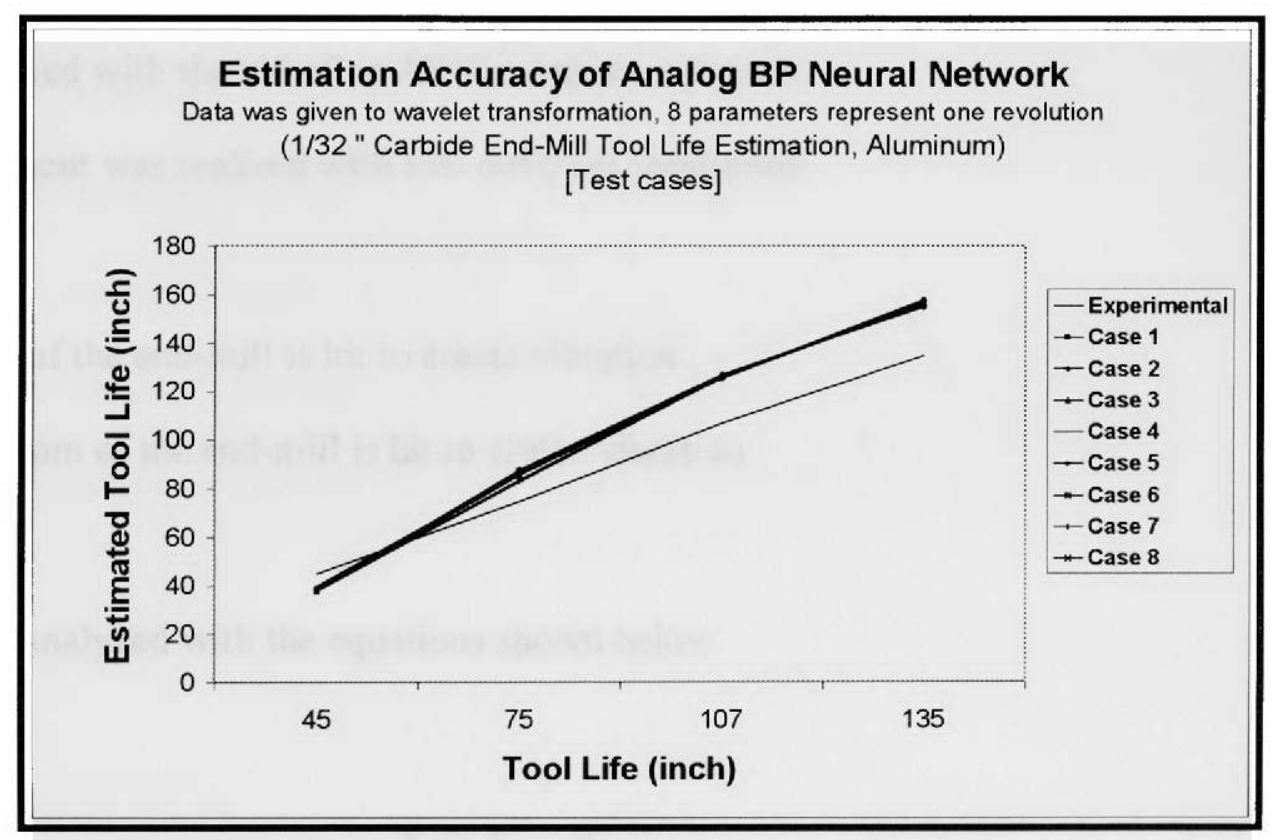

Figure 56.b. Estimation Accuracy of Analog BP for Test Cases with Improved $N^{2}$ PTI (Wavelet Transformation) 


\section{V.4. Dynamic Behavior of Micro Tools}

The tip and the bottom of the micro end-mill were hit with the impact hammer to analyze the dynamic response. When the tool was excited, it was vibrating and the vibration was measured with a vibrometer. The vibrometer was directing a laser beam to the tip of the end-mill. Once the tip was hit with the impact hammer, the impact was digitized and recorded to the oscilloscope. The response of the tool to this excitation was a typical dynamic vibration signal. Input and output signals were recorded as 4,000 data points.

The data was studied and the results are presented in Figure 57 and 58. The dynamic characteristics of the end-mills were calculated from the variation of the output signal amplitude versus time. The natural-angular frequency and the damping factor of the tools were calculated analytically and numerically. Transfer function of the system was established with the aid of an ARV computer program.

Experiment was realized with two different conditions:

1. Tip of the end-mill is hit to create vibration

2. Bottom of the end-mill is hit to create vibration

Data is analyzed with the equations shown below:

$$
\mathrm{y}=\mathrm{y}^{*} \cdot \mathrm{e}^{-\zeta \omega_{n} t}
$$




$$
\begin{aligned}
& \zeta=-\left(1 / \omega_{n} \cdot t\right) \cdot \ln \left(y / y^{*}\right) \\
& \omega_{\mathrm{n}}=2 \cdot \pi \cdot \mathrm{f}_{\mathrm{n}} \\
& \mathrm{t}=\mathrm{n} \cdot 1 / \mathrm{f}_{\mathrm{n}} \\
& \zeta=-\ln \left(\mathrm{y} / \mathrm{y}^{*}\right) / 2 \cdot \pi \cdot n
\end{aligned}
$$

Where:

$$
\begin{array}{ll}
\mathrm{y} & =\text { Amplitude at time } \mathrm{t} \\
\mathrm{y}^{*} & =\text { Amplitude at time } \mathrm{t}_{0} \\
\zeta & =\text { Damping factor } \\
\omega_{\mathrm{n}} & =\text { Angular Frequency } \\
\mathrm{f}_{\mathrm{n}} & =\text { Natural Frequency } \\
\mathrm{n} & =\text { Number of period }
\end{array}
$$




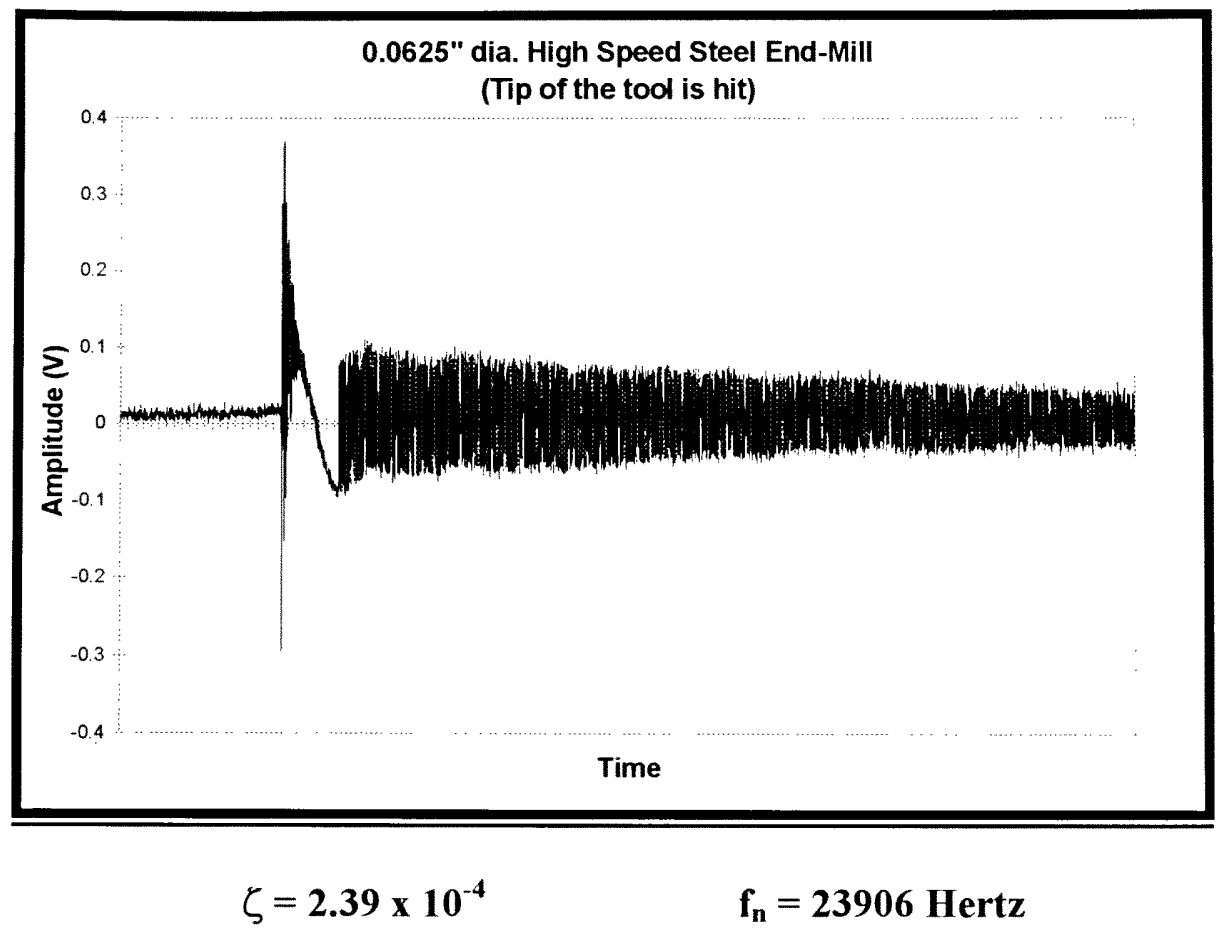

Figure 57.a. 0.0625 " Diameter HSS End-Mill (Tip of the tool was hit)

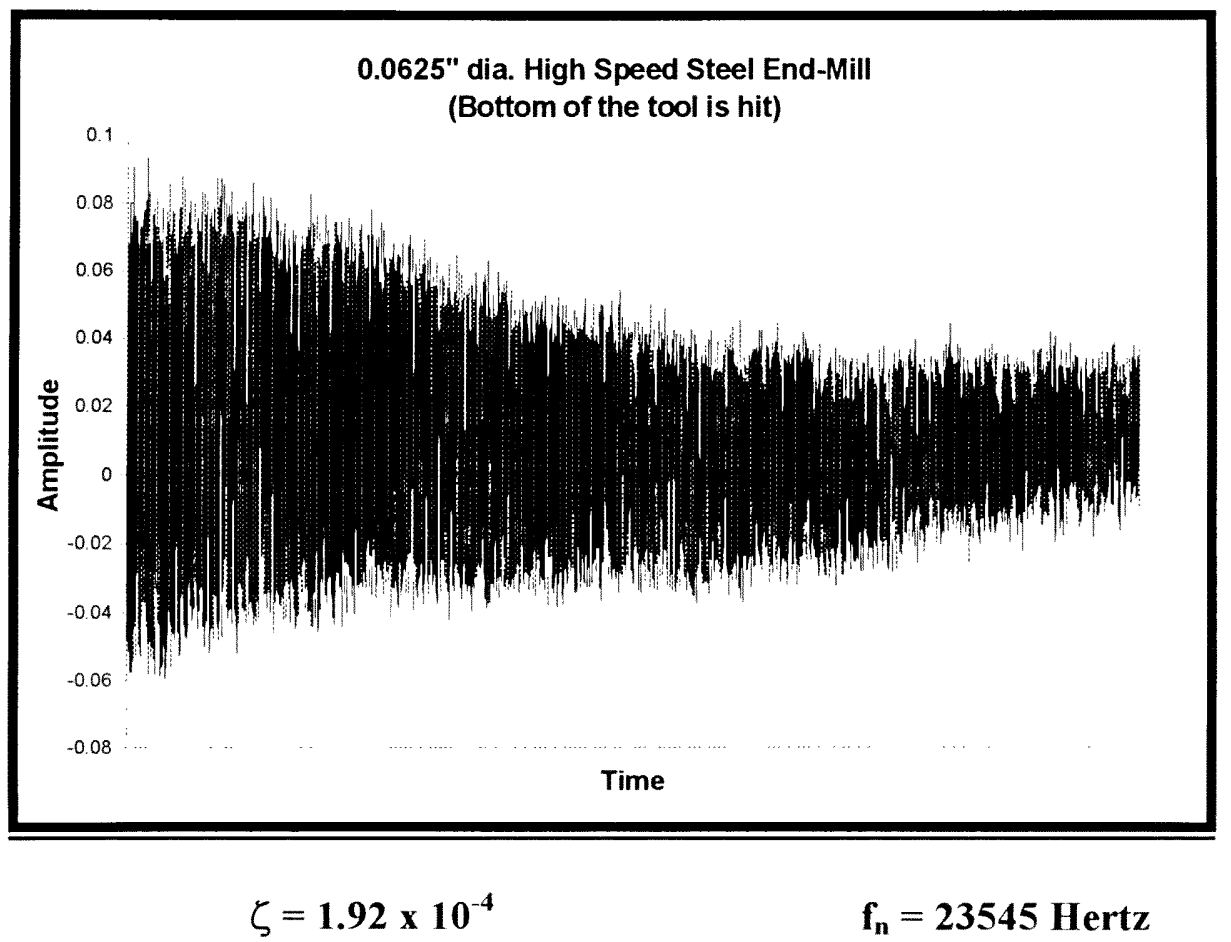

Figure 57.b. $0.0625 "$ Diameter HSS End-Mill (Bottom of the tool was hit) 


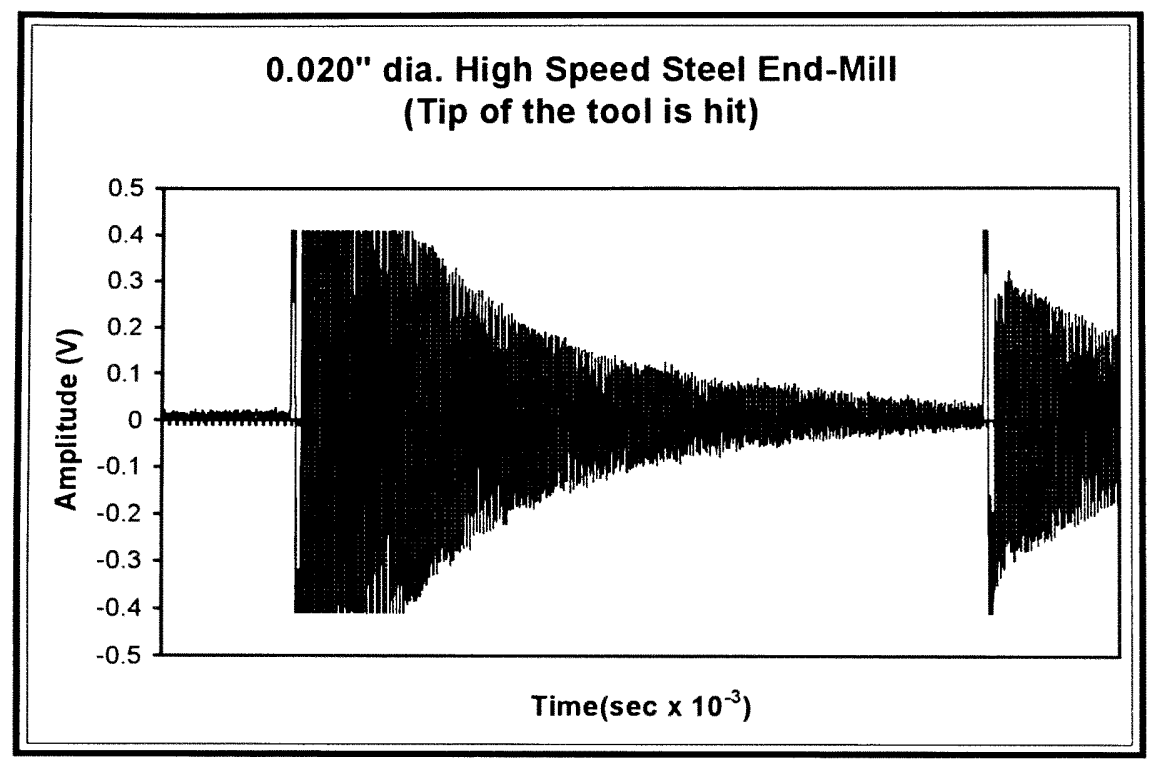

$$
\zeta=2.55 \times 10^{-3} \quad f_{n}=8245 \text { Hertz }
$$

Figure 58.a. $\quad 0.020$ " Diameter (Tip of the tool was hit)

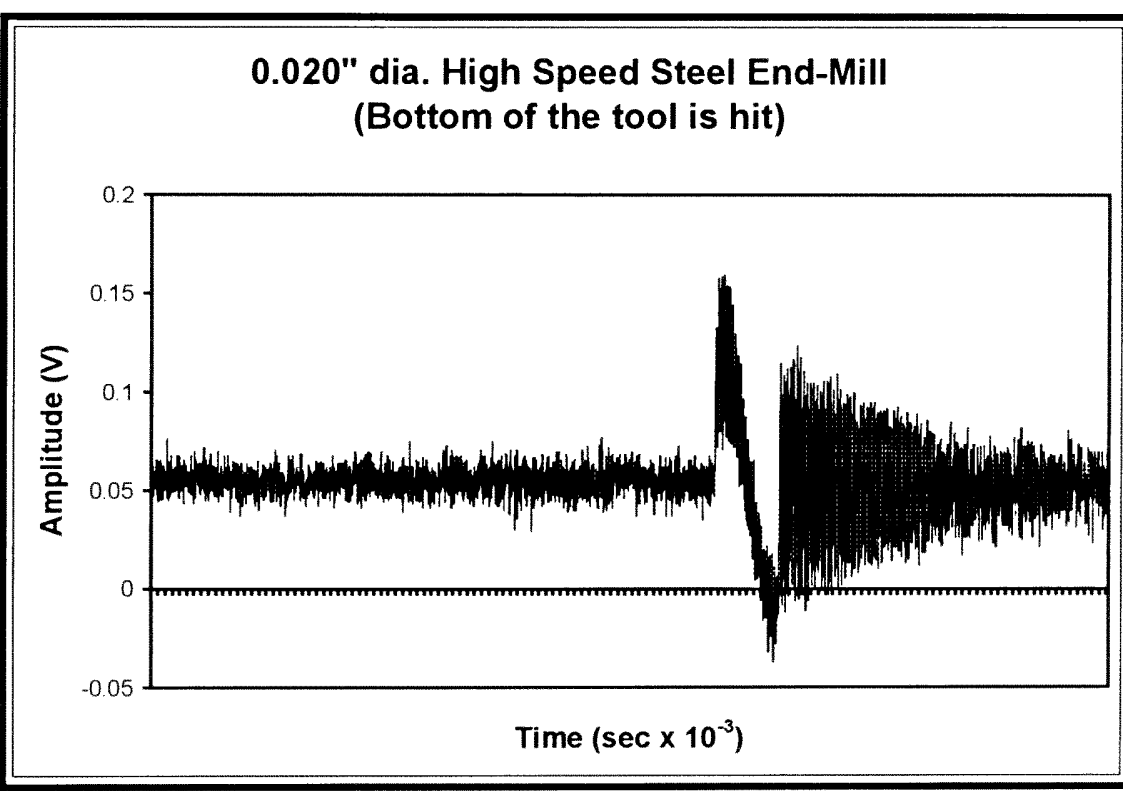

$$
\zeta=2.07 \times 10^{-3} \quad f_{n}=8470 \text { Hertz }
$$

Figure 58.b. $\quad 0.020$ " Diameter (Bottom of the tool was hit) 
Results of these dynamic experiments showed that the natural frequency of the microtools used in the machinability and tool wear test was not critical because they were much bigger than the spindle frequency.

Experimental data fed to the ARV computer program. The results obtained for the natural frequency of the 0.0625 inches HSS micro end-mill are represented in Figure 59.

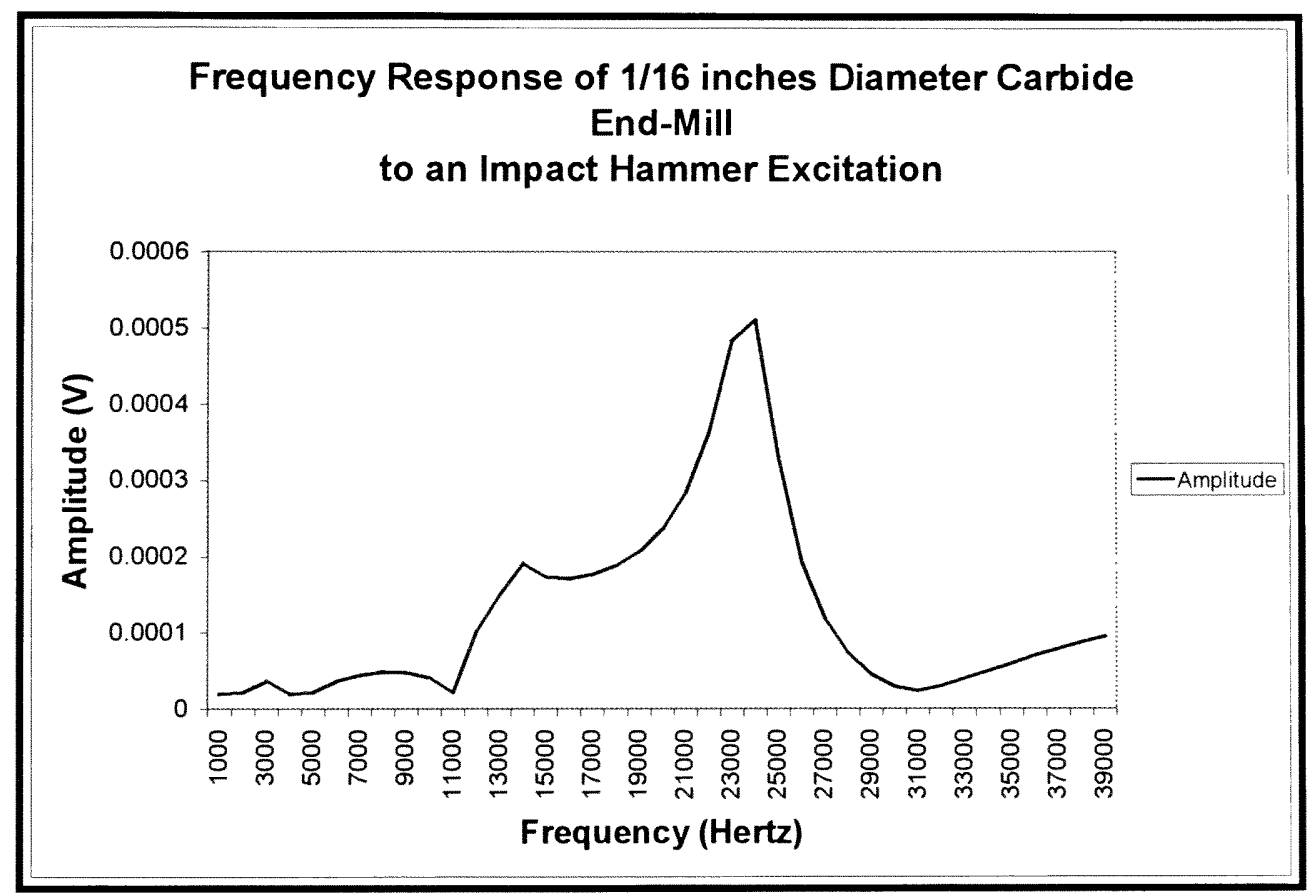

Figure 59. Frequency Response of the 1/16 inches Diameter Carbide End-Mill -ARV Computer Program Output Results 


\section{V.5. Static Behavior of Micro Tools}

The same kind of micro tools used in the machinability experiments were used in this test. High speed steel (HSS) and Carbide $0.0625,0.03125,0.020$ inches diameter two flutes end-mills were analyzed under the static loading conditions. The tool was attached to a Bridgeport Milling machine with an end-mill holder. The workpiece was clamped to the dynamometer. The dynamometer was tightened to a vise that is fixed on the X-Y table of the milling machine. A linear displacement sensor was clamped on the vise with respect to the tool holder. The sensor supposed to measure the linear table displacement during the experiment. The sensor with its signal conditioner was connected to a Nicolet 310 digital oscilloscope. The dynamometer was connected to a charge amplifier and to the oscilloscope also. Force and displacement data were collected and recorded. The main purpose of these experiments was to find out the stiffness of the micro-tools and use this data in cutting force displacement relationship. The new machinability method required the calculation of the maximum static bending force that can be applied to the tool. The

results obtained for every tool - workpiece combinations are presented in the following figures. 


\subsection{0" HIGH SPEED STEEL END-MILL STIFFNESS WITH POCO 3 WORKPIECE}

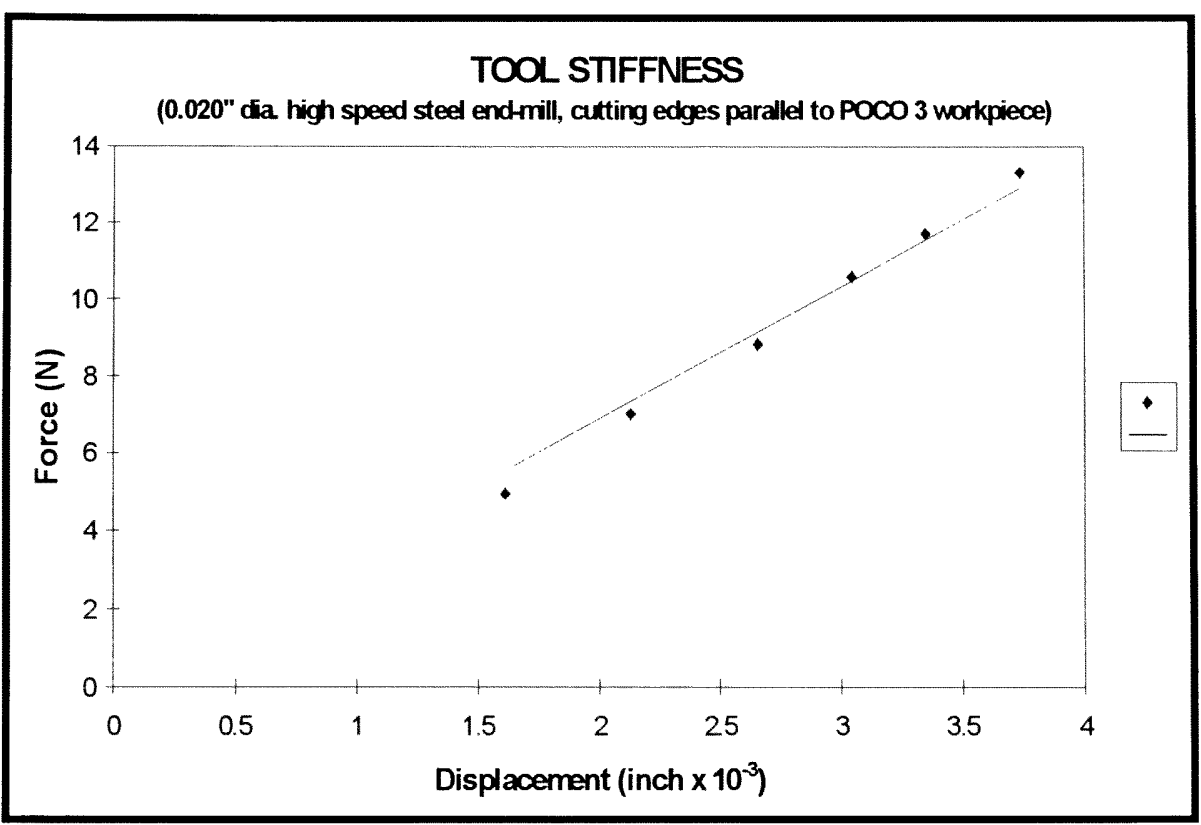

Figure 60.a. Cutting edges of the tool were parallel to the workpiece $($ slope $=3.44$ )

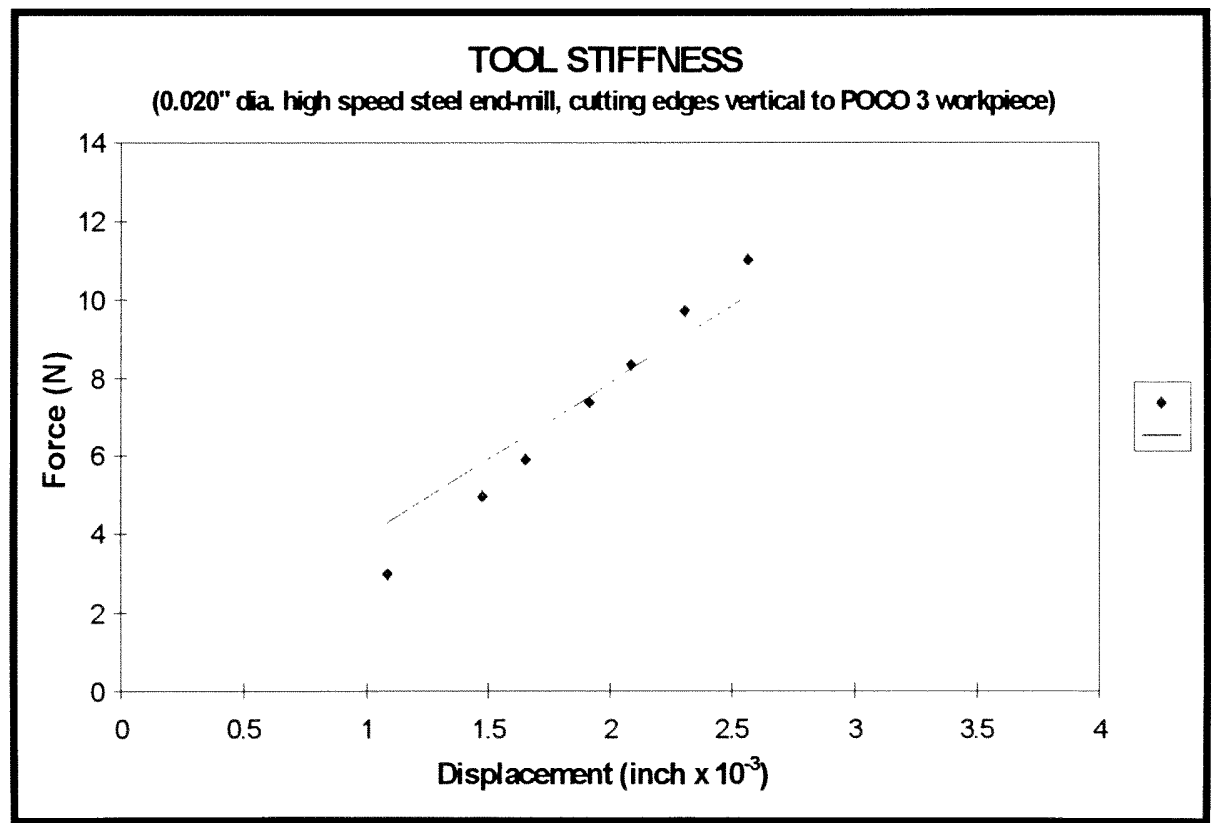

Figure $60 . \mathrm{b}$. Cutting edges of the tool were vertical to the workpiece $($ slope $=3.94)$ 


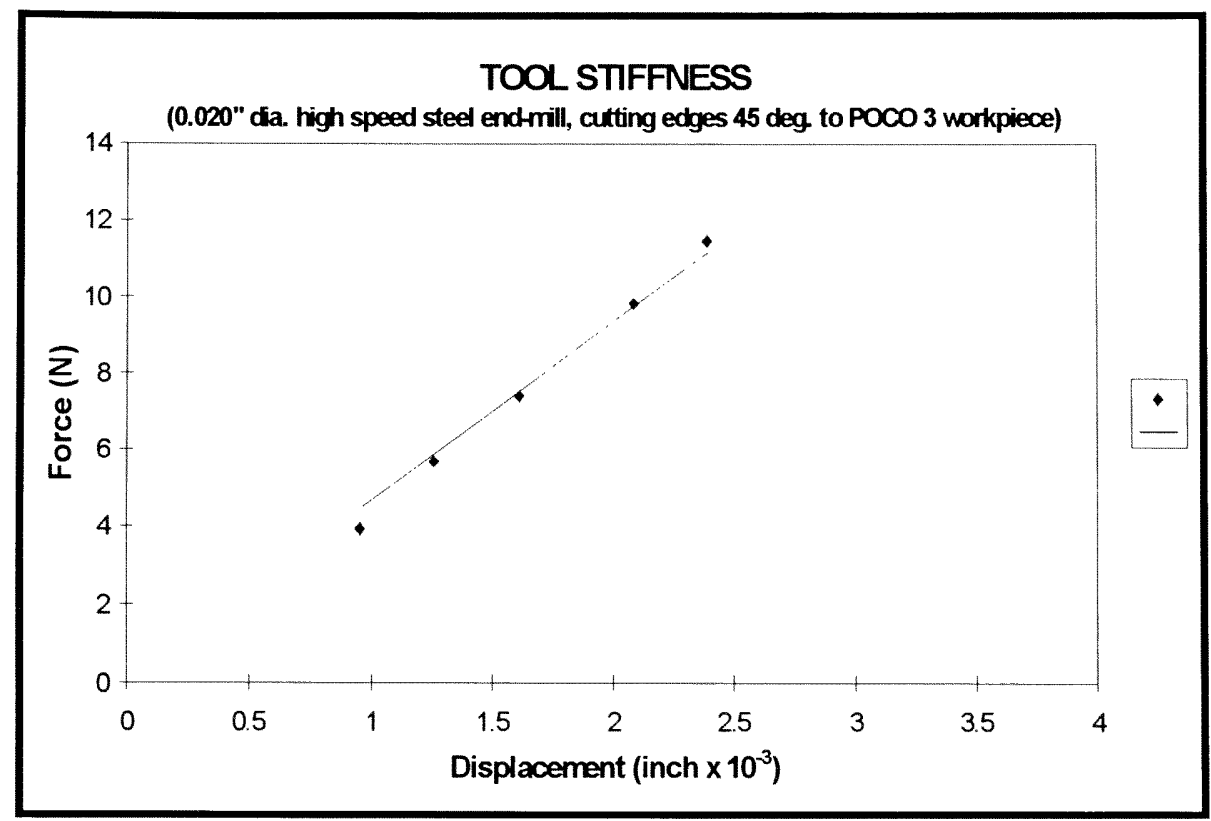

Figure 60.c. Cutting edges of the tool were 45 degree to the workpiece (slope $=4.5$ )

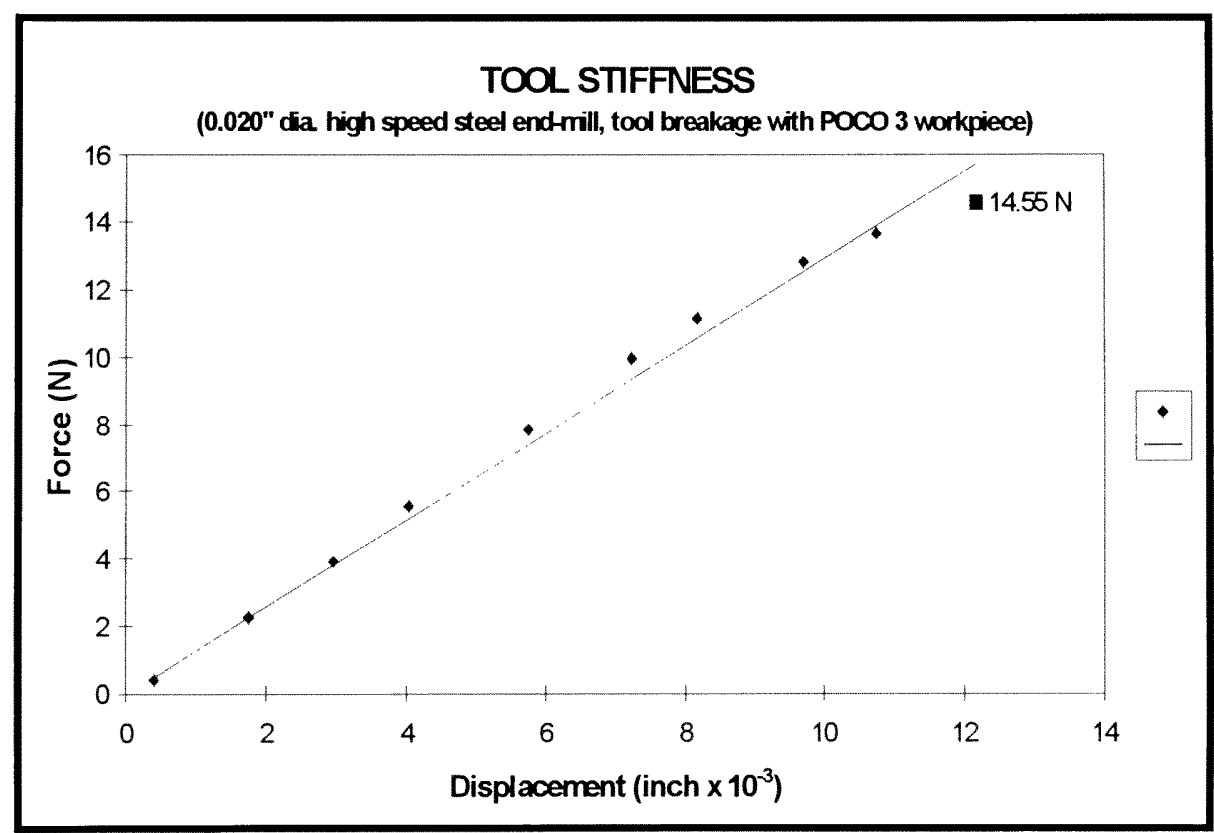

Figure 60.d. Tool breakage occurred at $14.55 \mathrm{~N}($ slope $=1.3)$ 


\subsection{5” HIGH SPEED STEEL END-MILL STIFFNESS WITH POCO3 WORKPIECE}

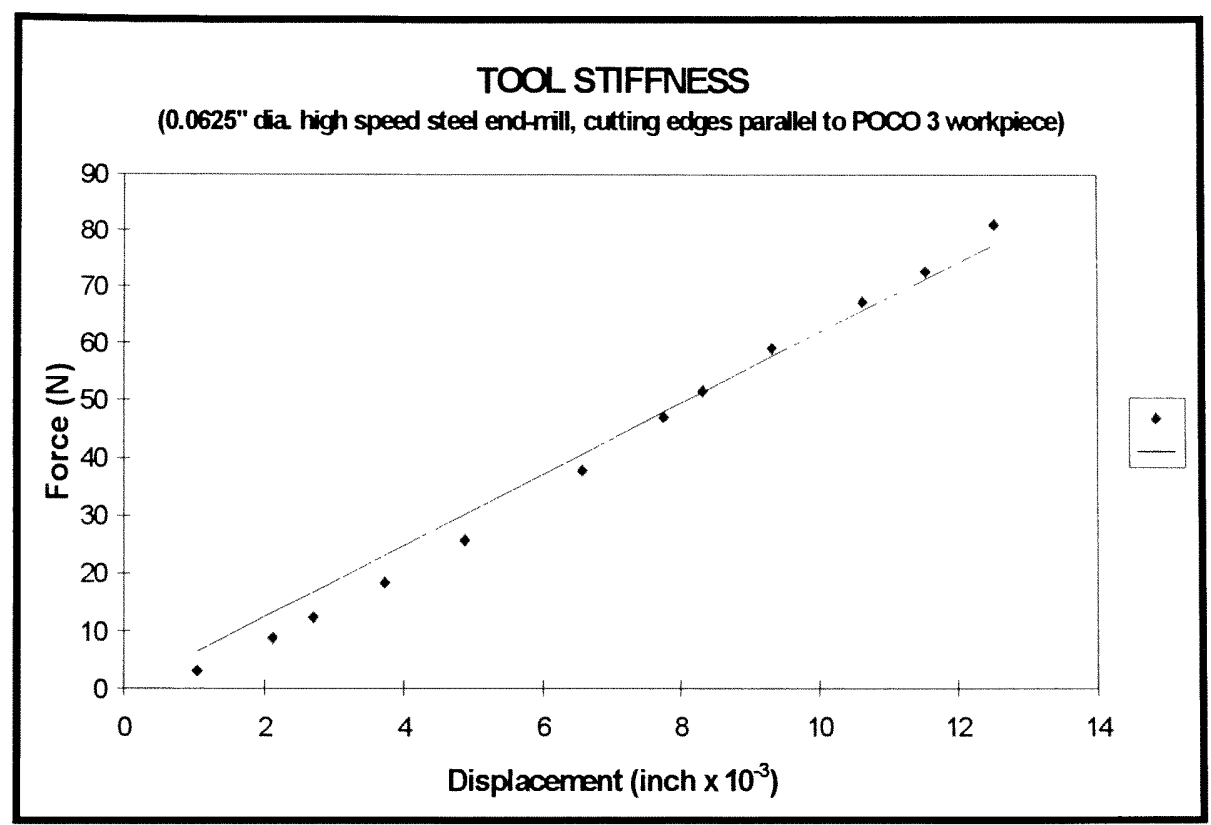

Figure 61.a. Cutting edges of the tool were parallel to the workpiece $($ slope $=6.20)$

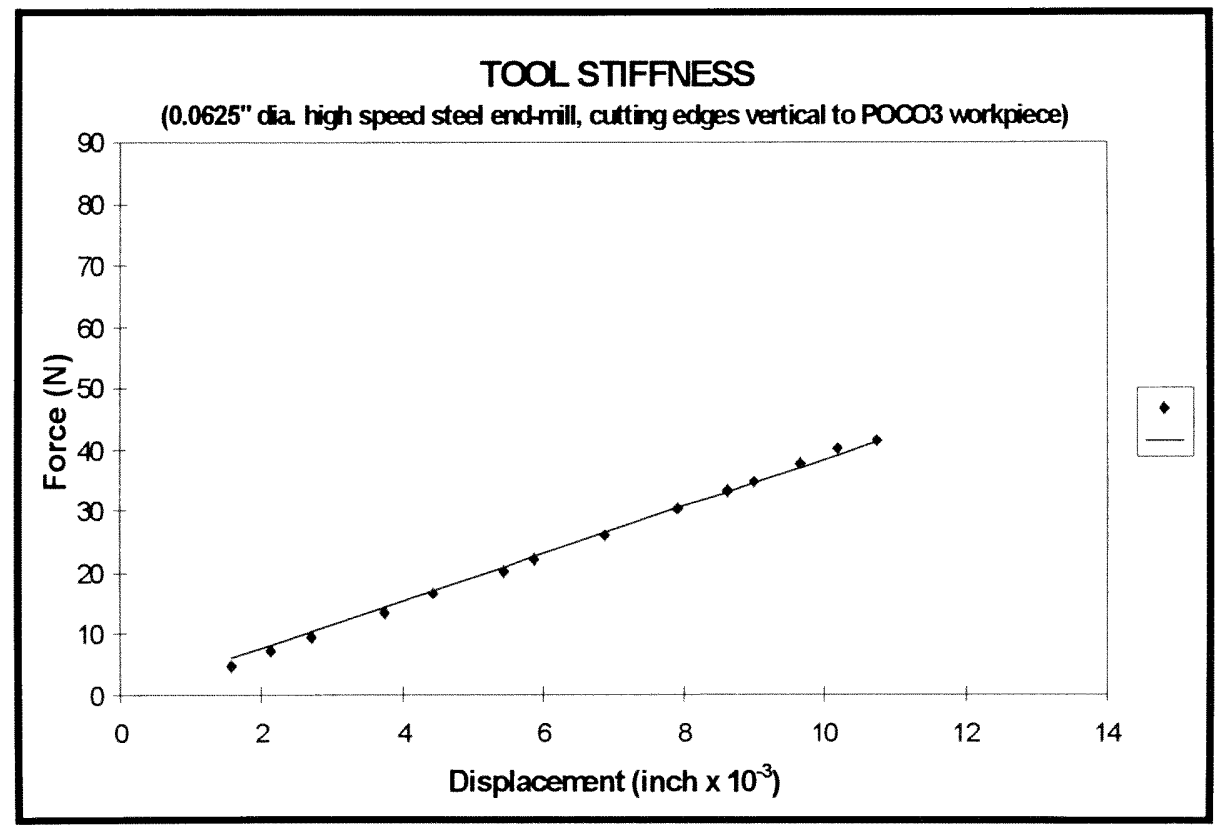

Figure 61.b. Cutting edges of the tool were vertical to the workpiece (slope $=3.95$ ) 




Figure 61.c. Cutting edges of the tool were 45 degree to the workpiece $($ slope $=6.50)$

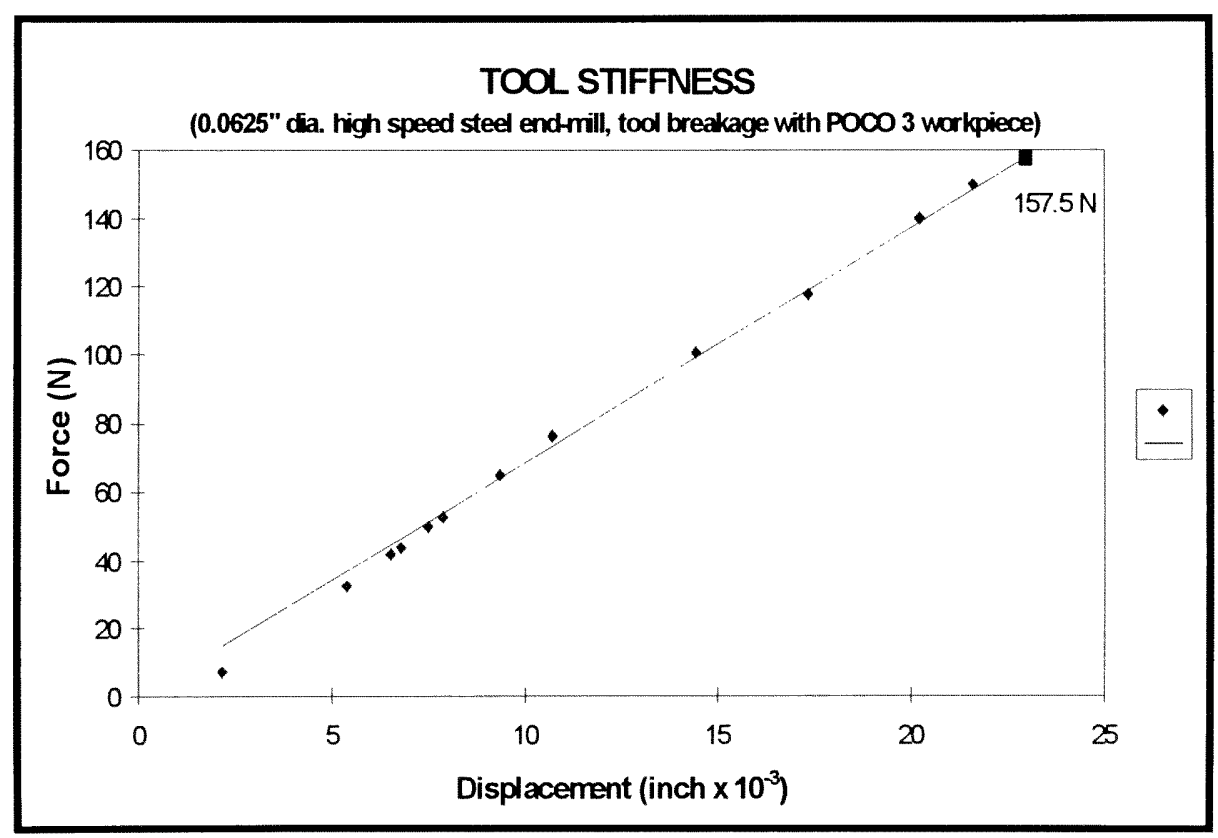

Figure 61.d. Tool breakage occurred at $157.5 \mathrm{~N}($ slope $=6.86)$ 


\subsection{0" CARBIDE END-MILL STIFFNESS WITH ALUMINUM WORKPIECE}

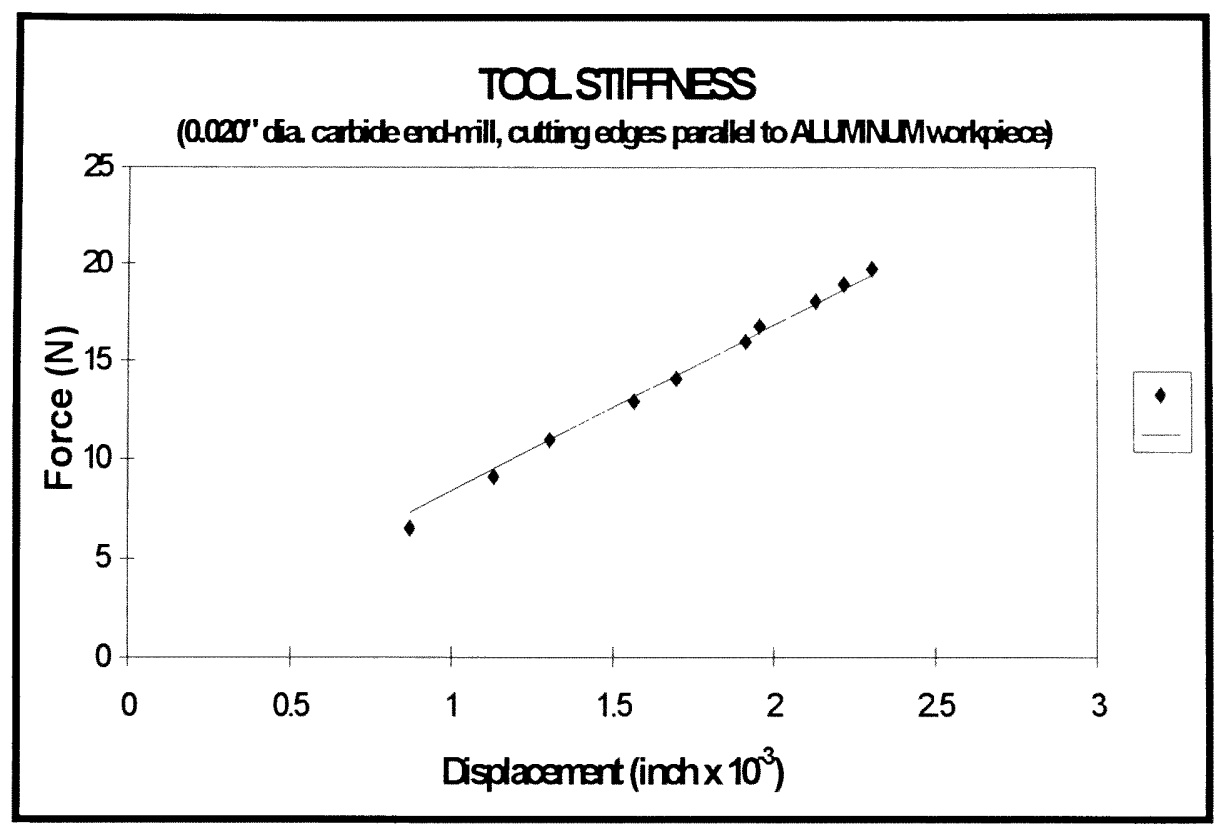

Figure 62.a. Cutting edges of the tool were parallel to the workpiece $($ slope $=8.43$ )

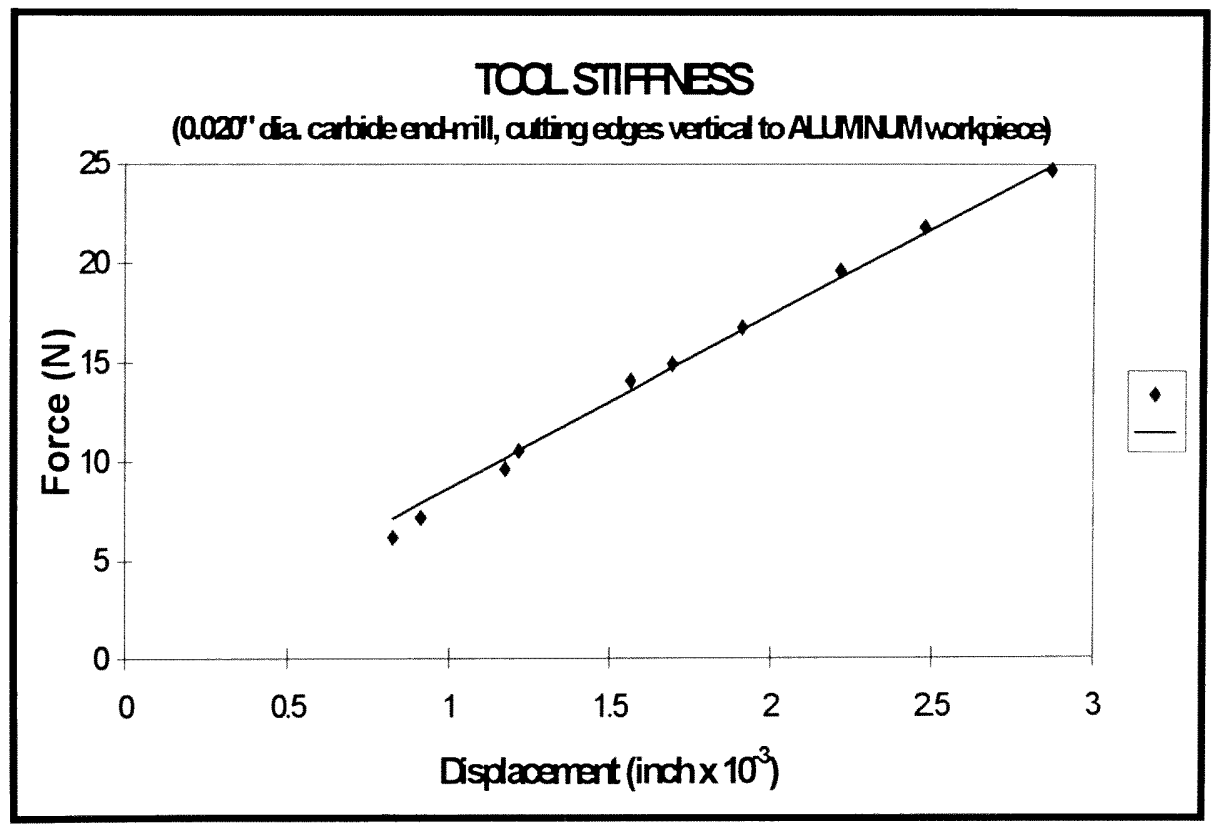

Figure 62.b. Cutting edges of the tool were vertical to the workpiece (slope $=8.68$ ) 


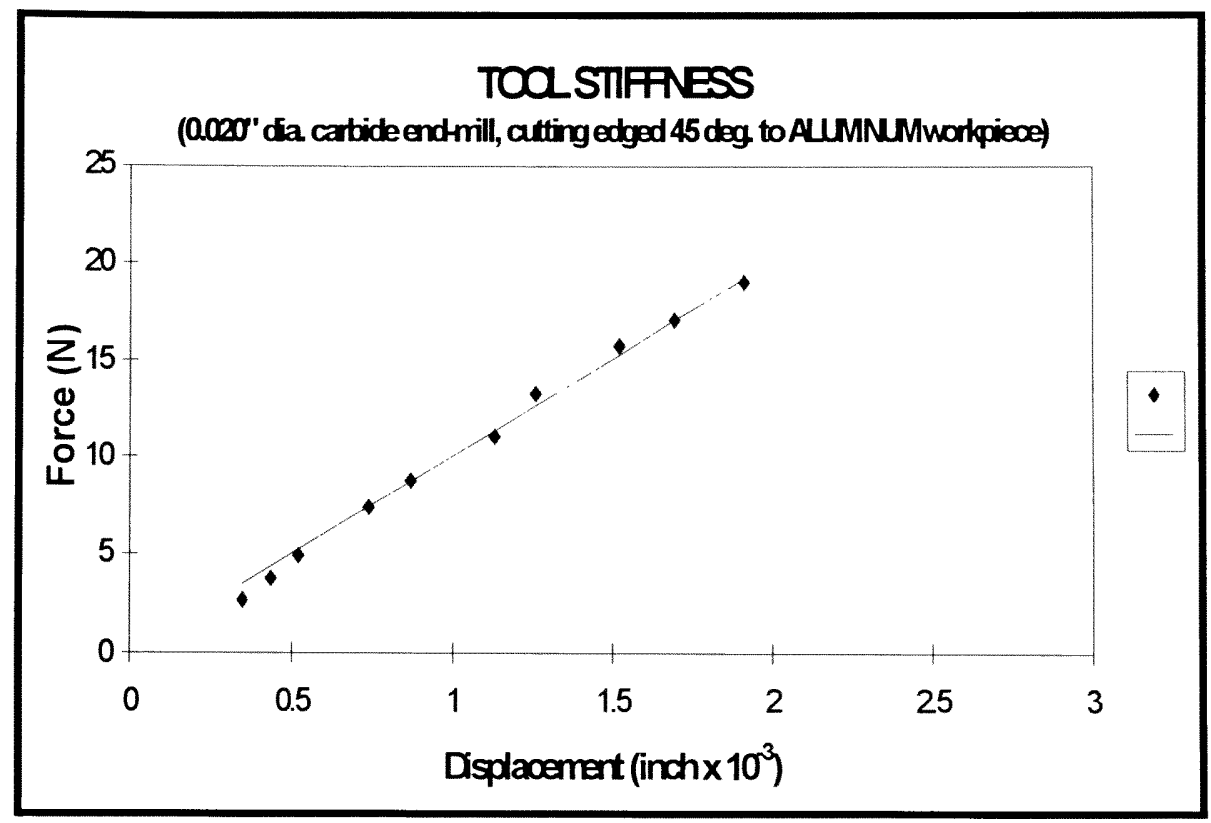

Figure 62.c. Cutting edges of the tool were 45 degree to the workpiece (slope $=10.04$ )

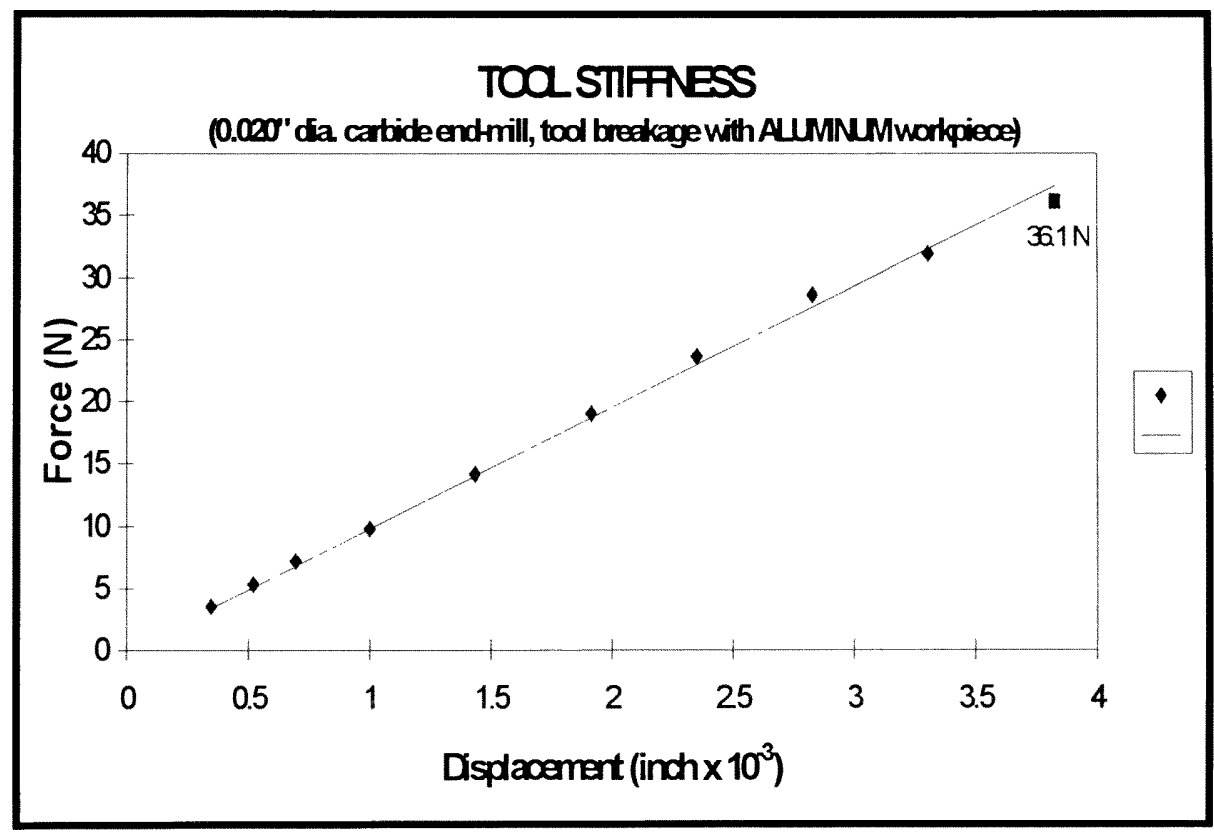

Figure 62.d. Tool breakage occurred at $36.1 \mathrm{~N}($ slope $=9.75)$ 


\subsection{5" CARBIDE END-MILL STIFFNESS WITH ALUMINUM WORKPIECE}

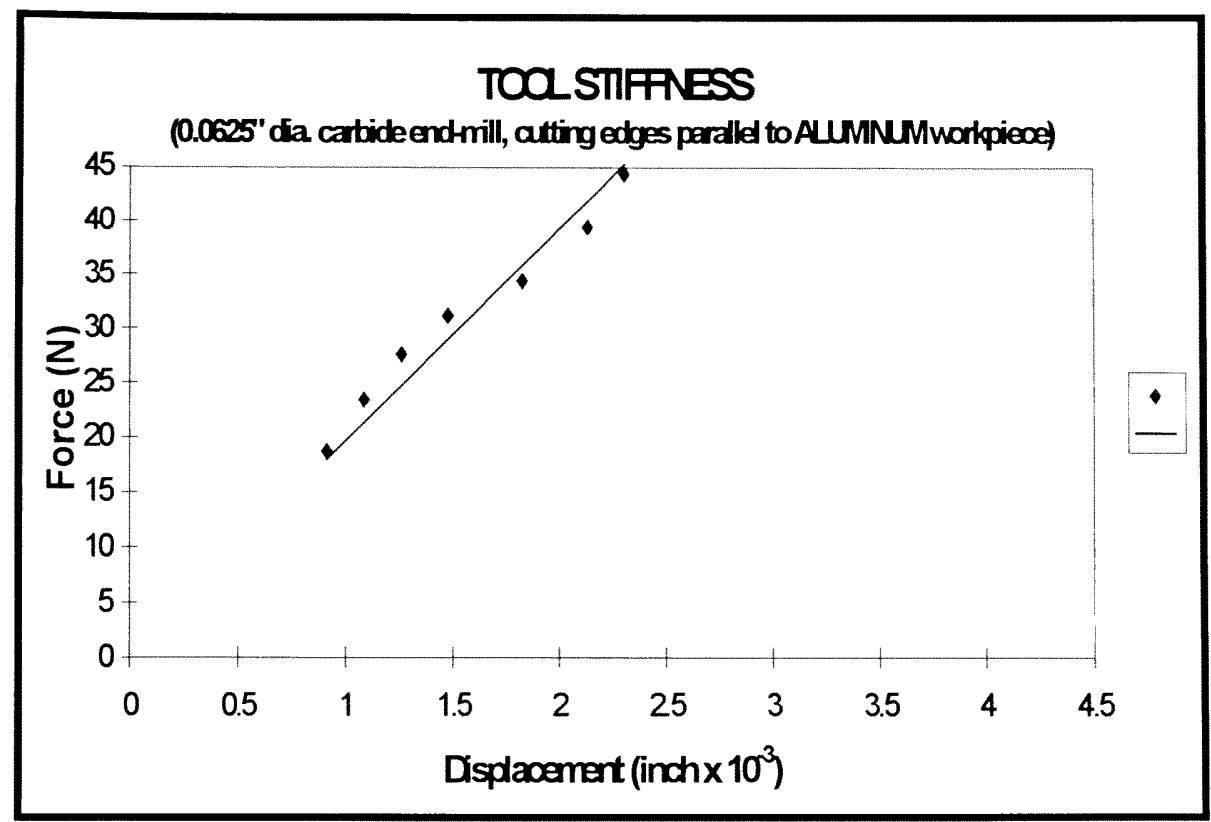

Figure 63.a. Cutting edges of the tool were parallel to the workpiece $($ slope $=19.6)$

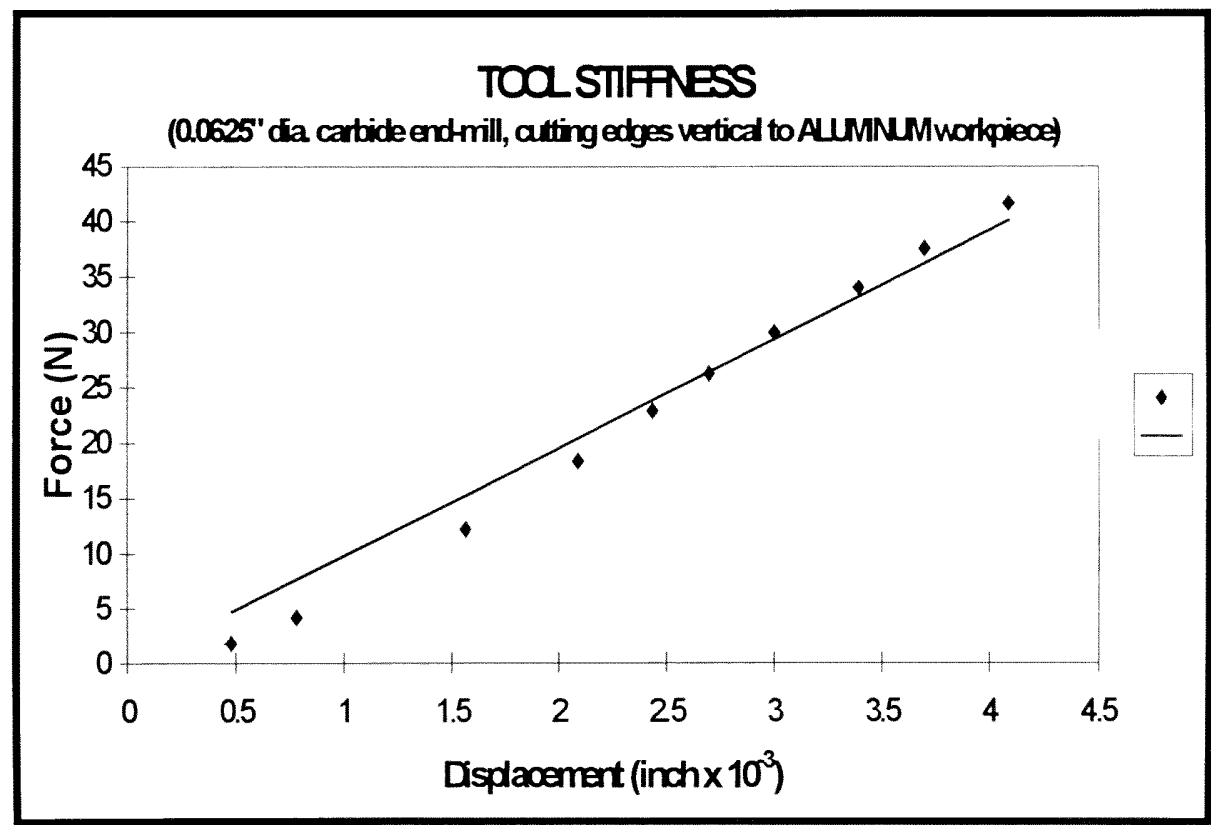

Figure 63.b. Cutting edges of the tool were vertical to the workpiece $($ slope $=9.79)$ 


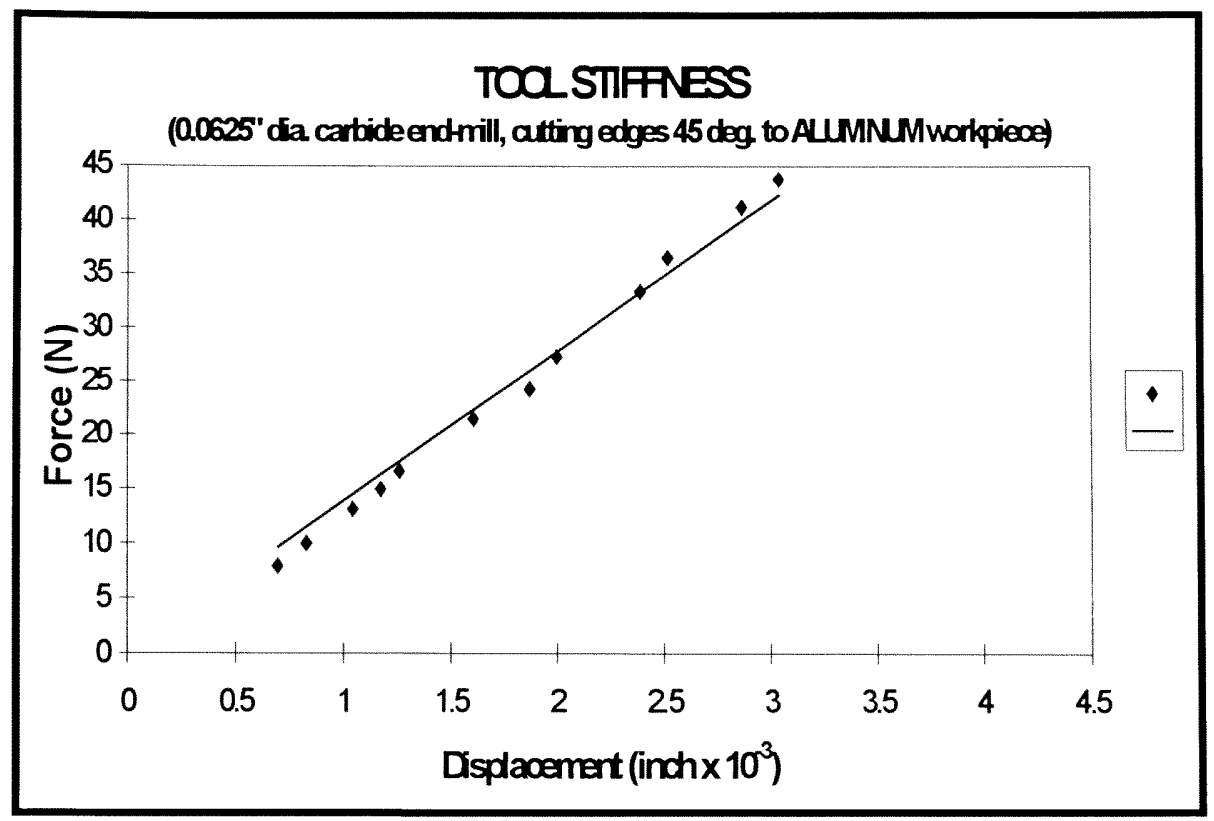

Figure 63.c. Cutting edges of the tool were 45 degree to the workpiece (slope $=13.89$ )

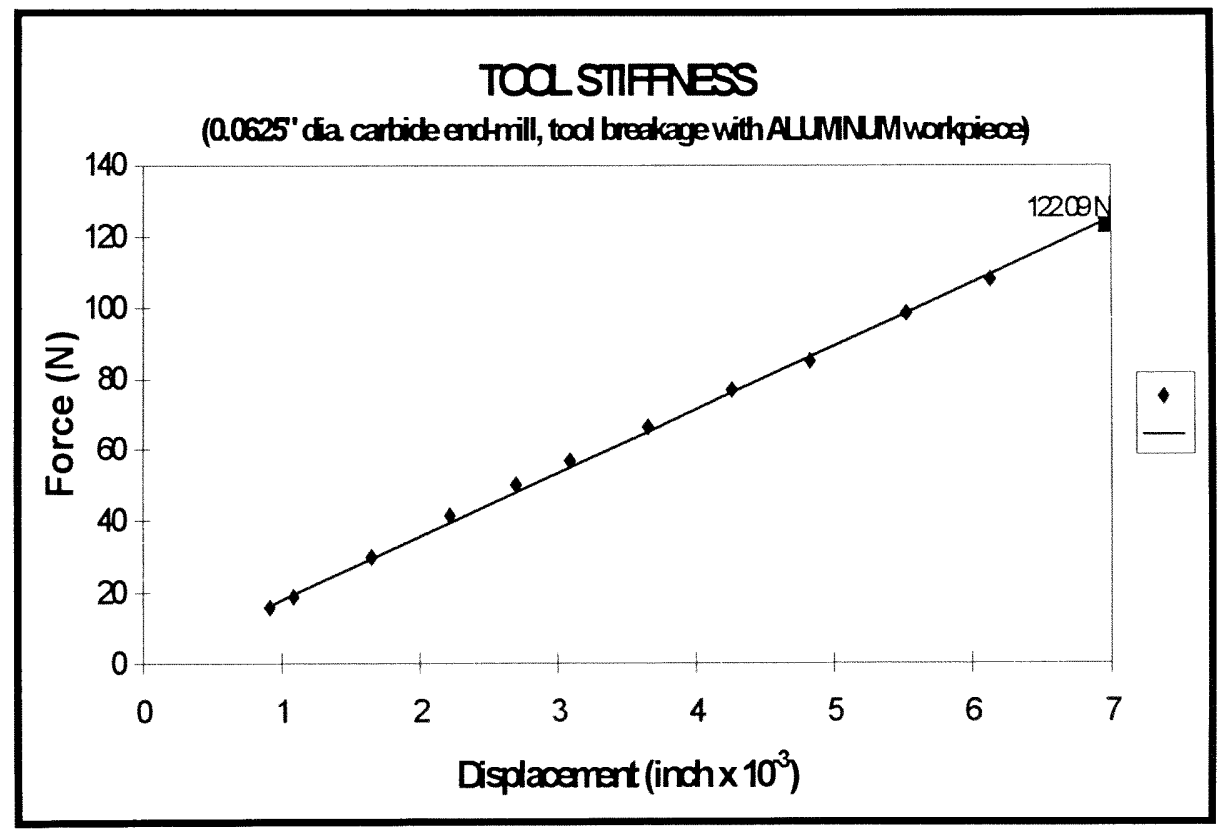

Figure 63.d. Tool breakage occurred at $122.09 \mathrm{~N}($ slope $=17.83)$ 


\subsection{0” HIGH SPEED STEEL END-MILL STIFFNESS WITH STEEL WORKPIECE}

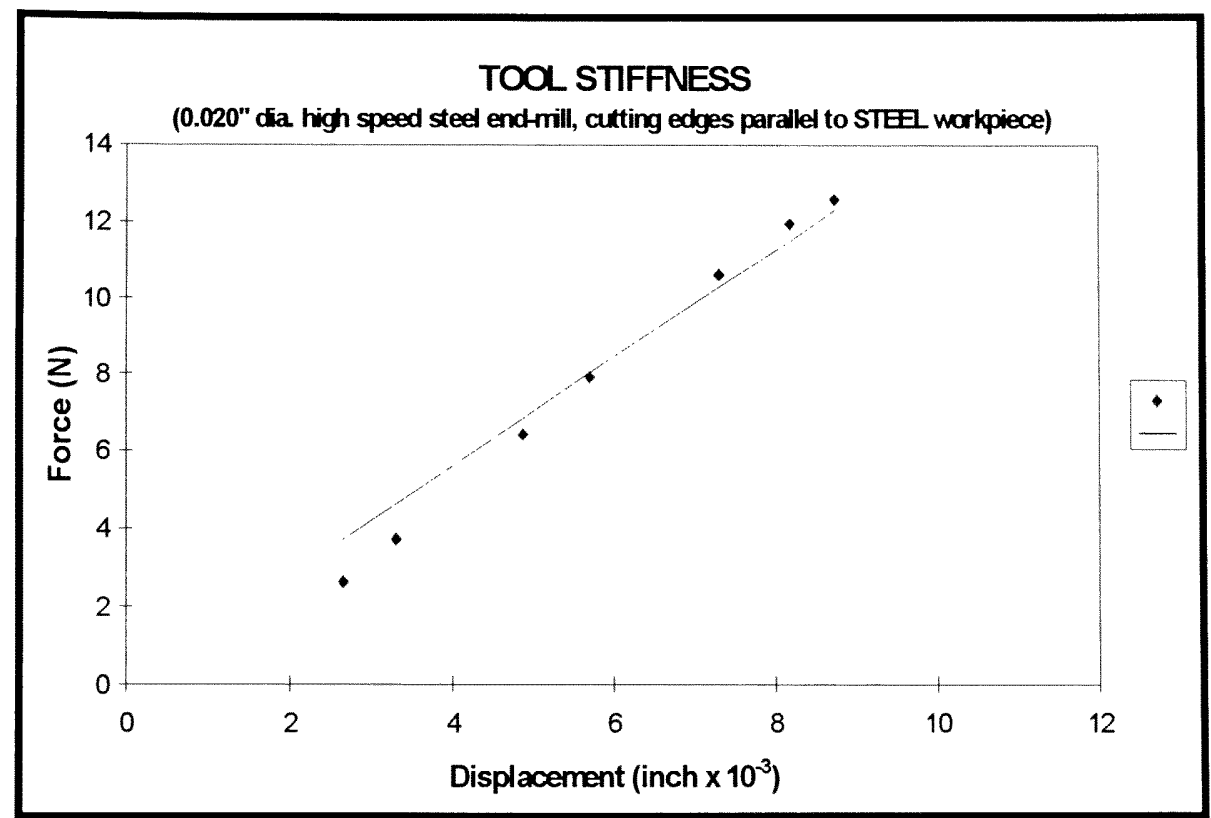

Figure 64.a. Cutting edges of the tool were parallel to the workpiece $($ slope $=1.41)$

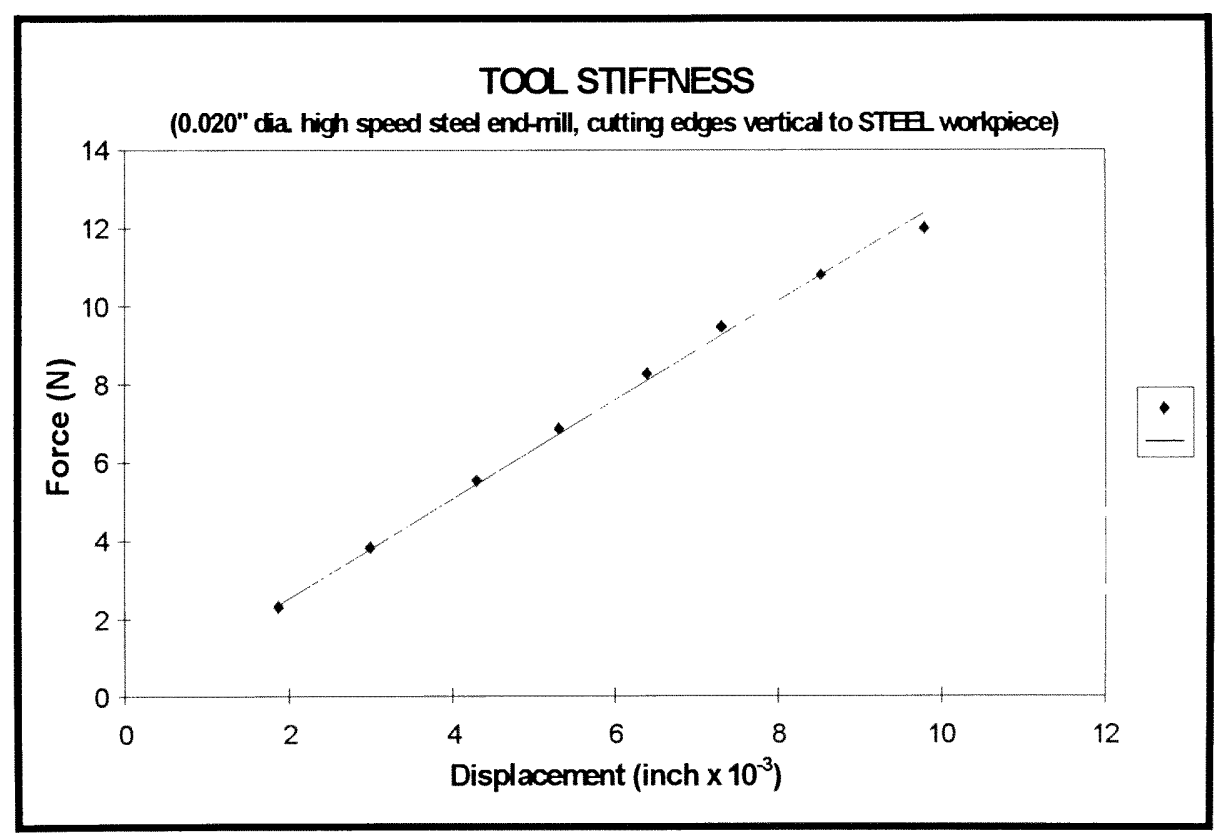

Figure 64.b. Cutting edges of the tool were vertical to the workpiece $($ slope $=1.27)$ 


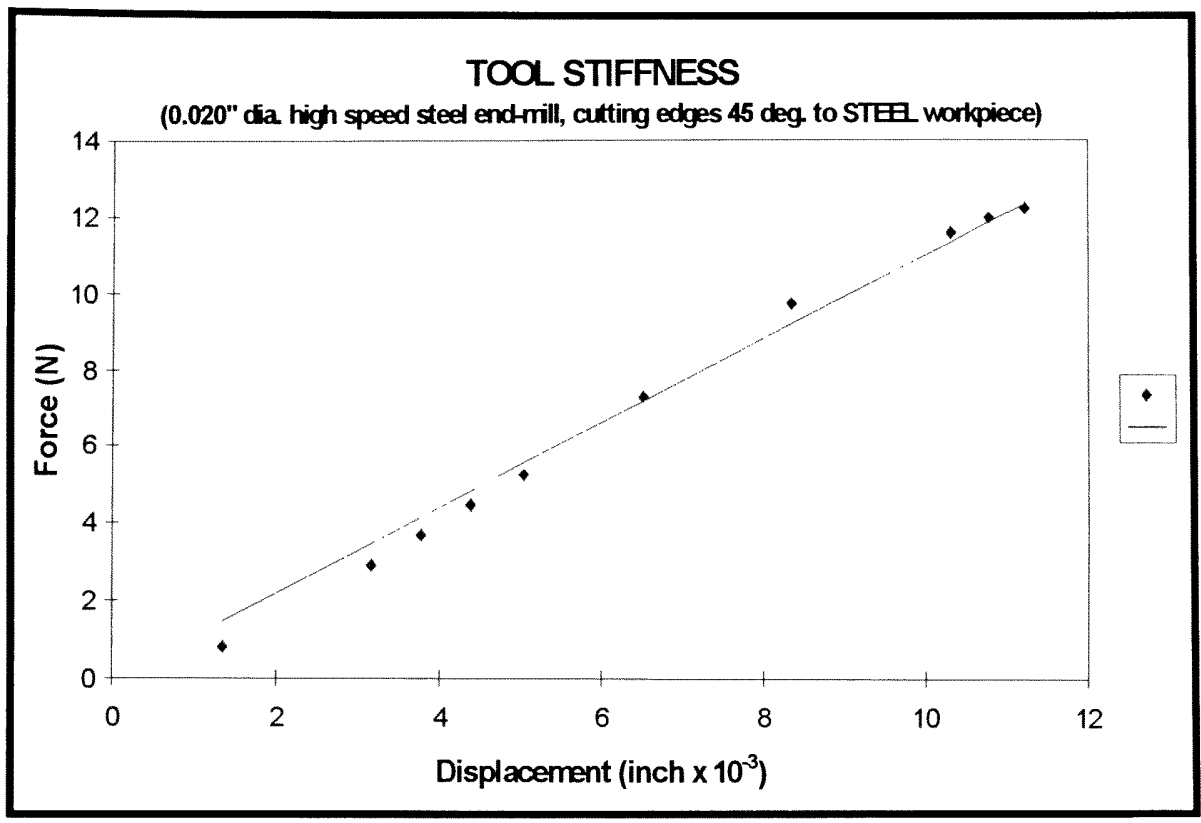

Figure 64.c. Cutting edges of the tool were 45 degree to the workpiece $($ slope $=1.09$ )

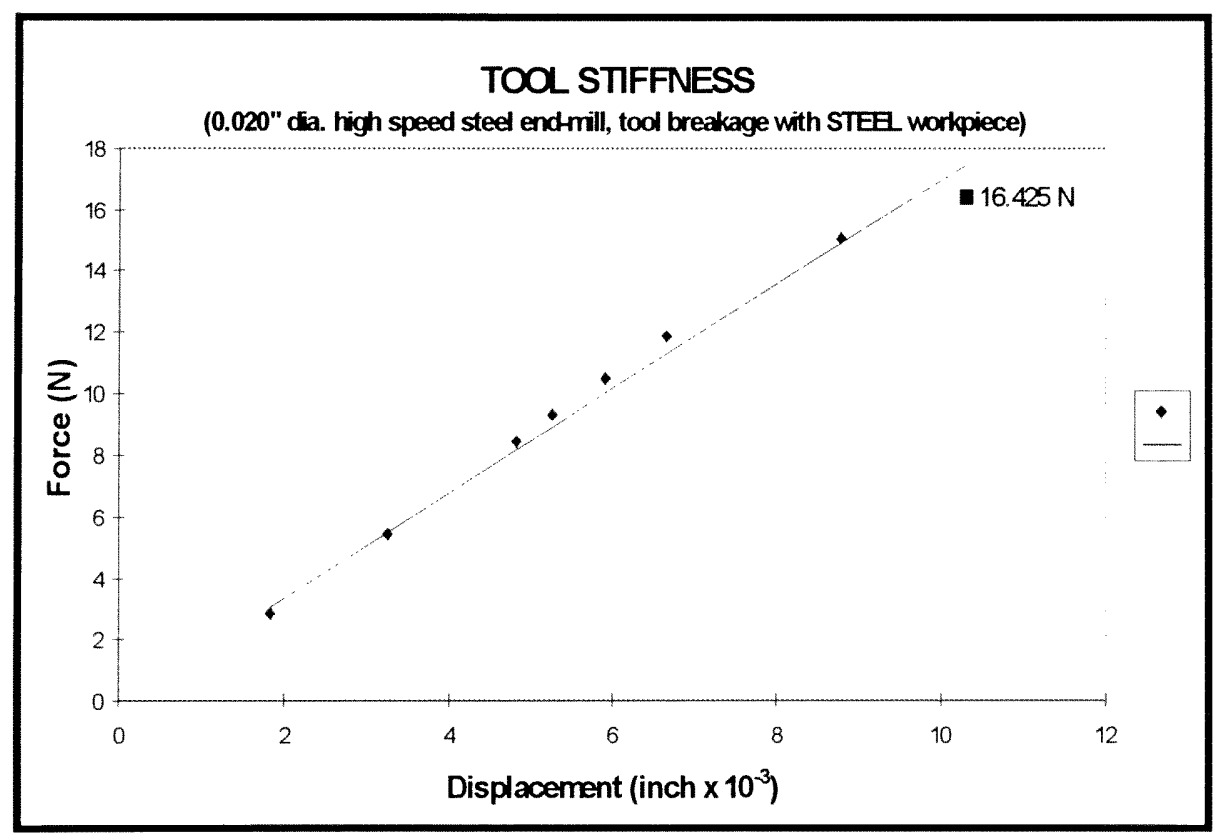

Figure 64.d. Tool breakage occurred at $16.425 \mathrm{~N}($ slope $=1.69)$ 


\subsection{0" CARBIDE END-MILL STIFFNESS WITH STEEL WORKPIECE}

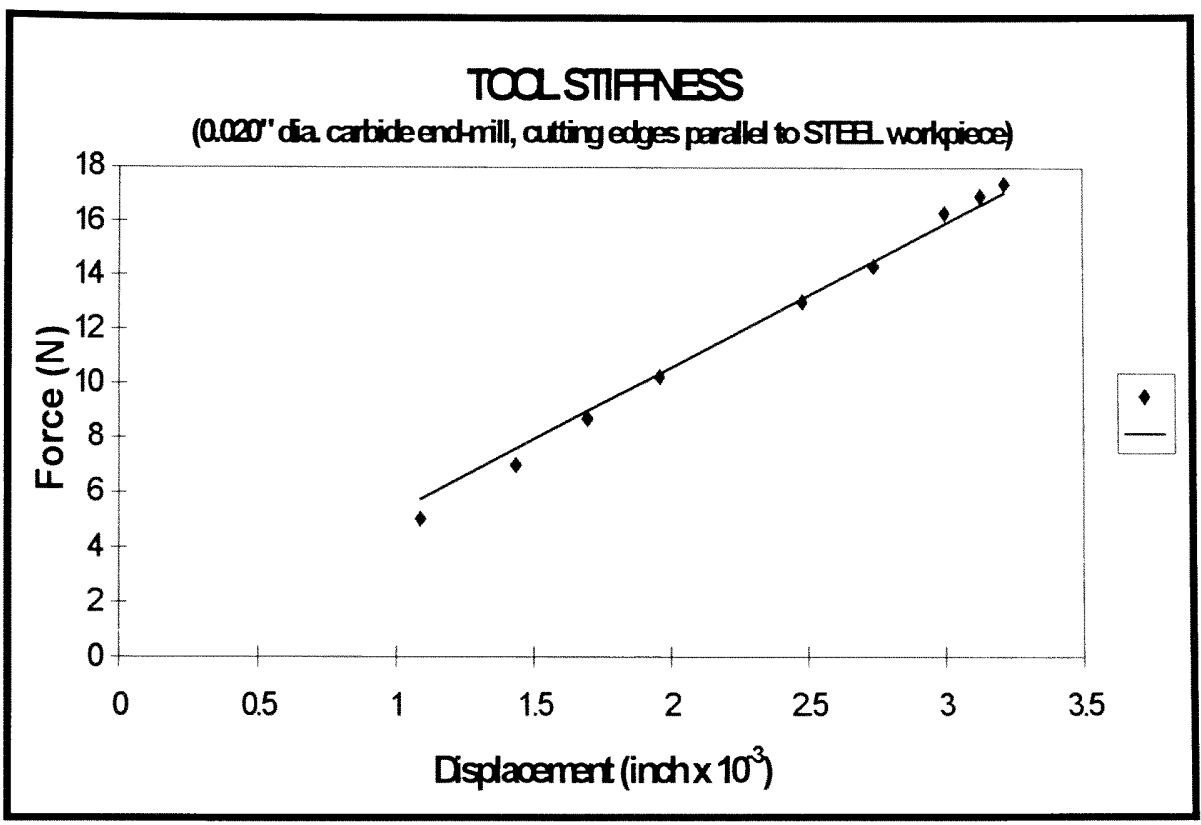

Figure 65.a. Cutting edges of the tool were parallel to the workpiece $($ slope $=5.30)$

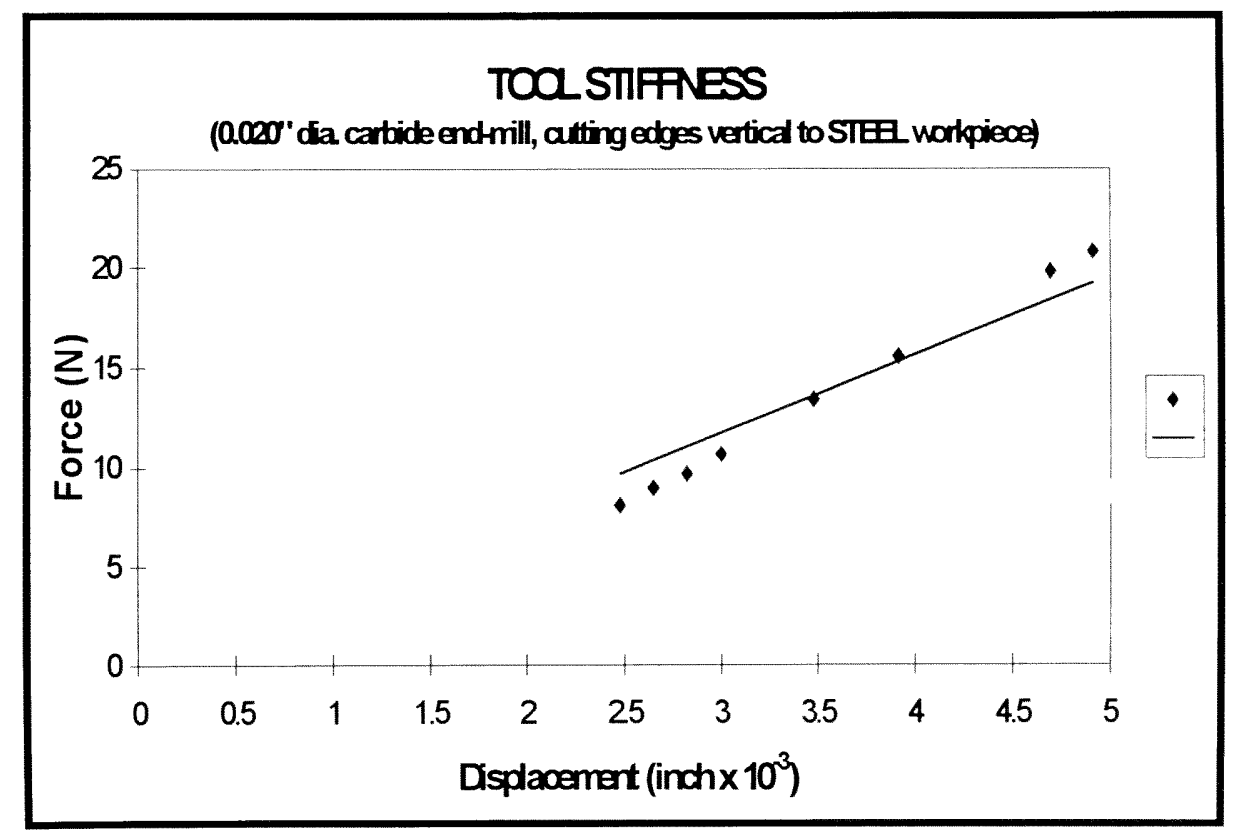

Figure 65.b. Cutting edges of the tool were vertical to the workpiece $($ slope $=3.91)$ 


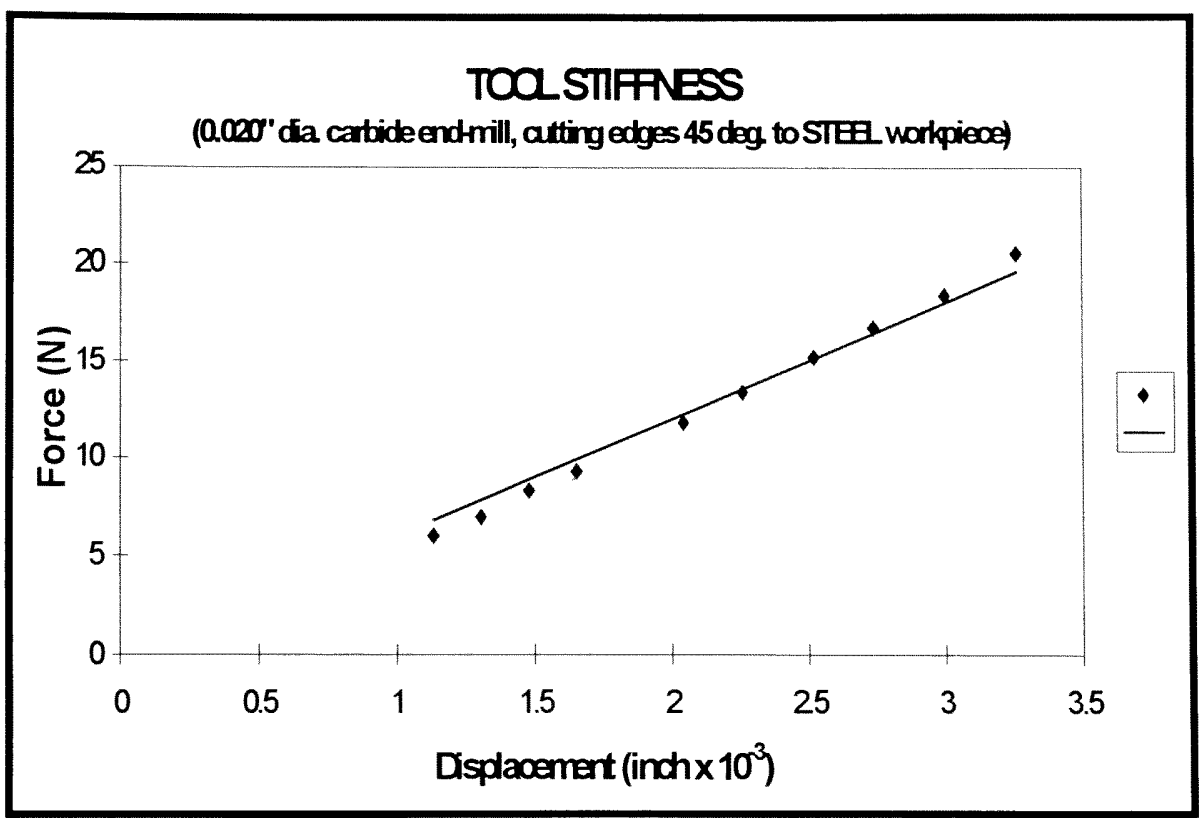

Figure 65.c. Cutting edges of the tool were 45 degree to the workpiece $($ slope $=6.01$ )

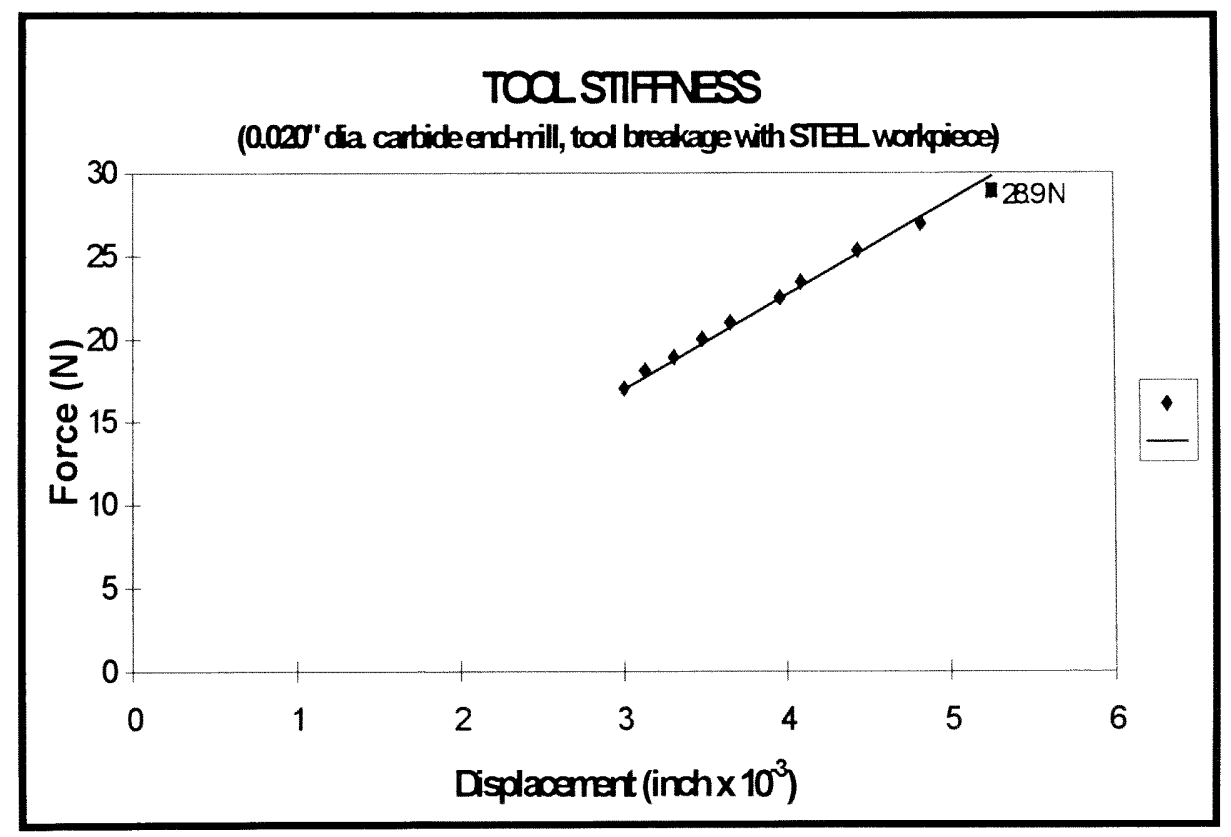

Figure $65 . \mathrm{d}$. Tool breakage occurred at $28.9 \mathrm{~N}($ slope $=5.66)$ 


\subsection{5" HIGH SPEED STEEL END-MILL STIFFNESS WITH STEEL WORKPIECE}

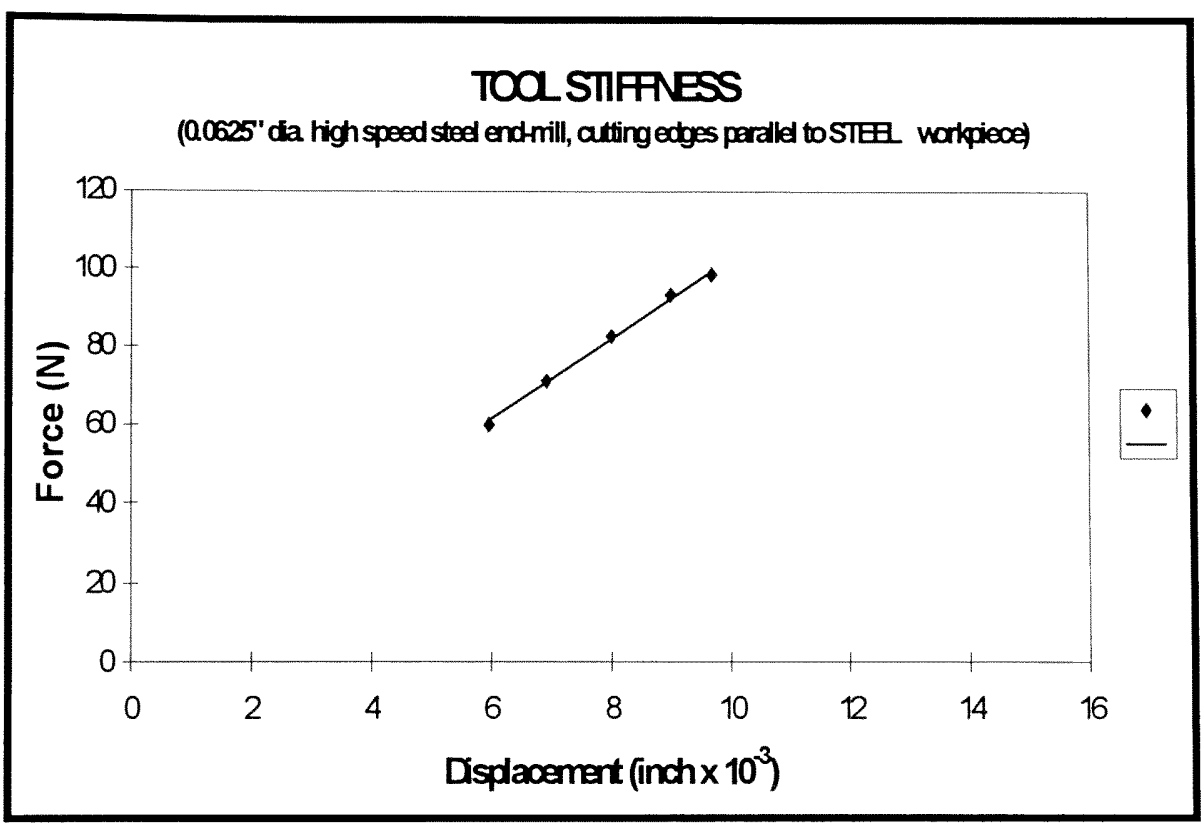

Figure 66.a. Cutting edges of the tool were parallel to the workpiece $($ slope $=10.25)$

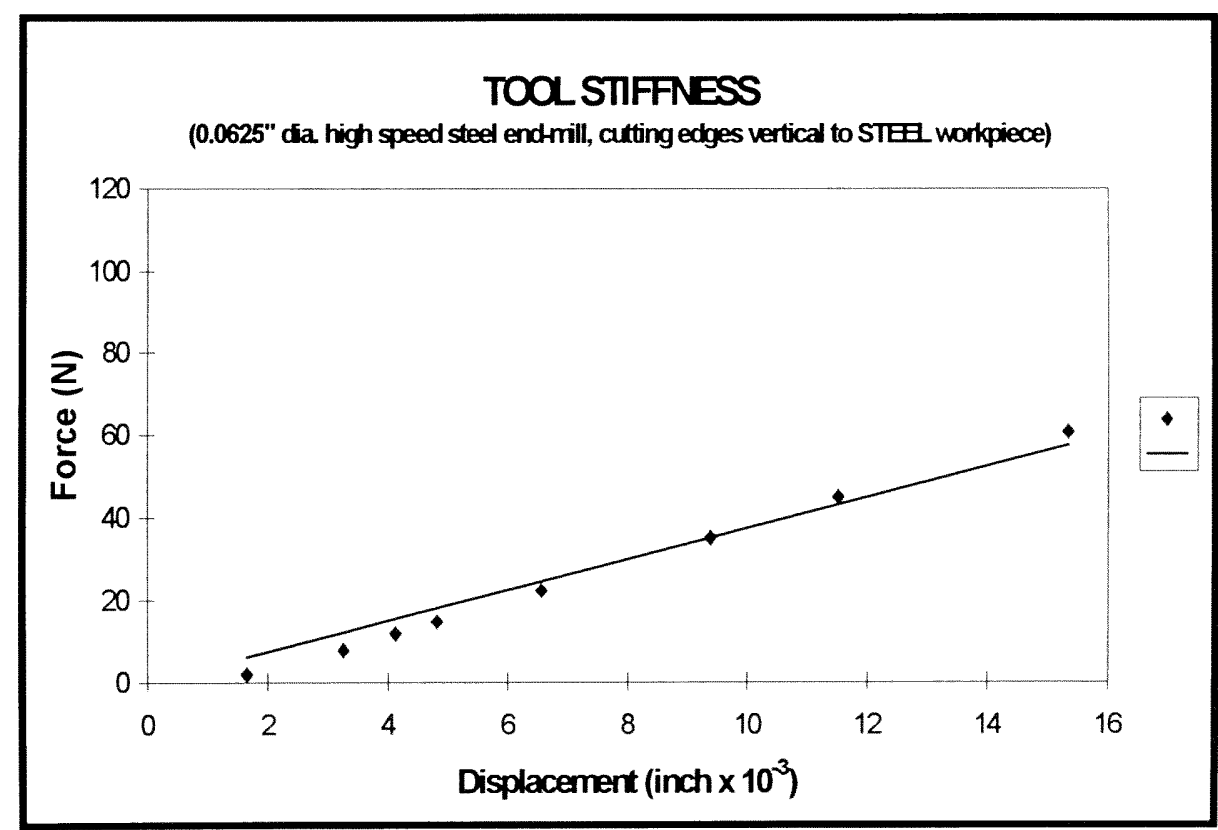

Figure 66.b. Cutting edges of the tool were vertical to the workpiece $($ slope $=3.75)$ 


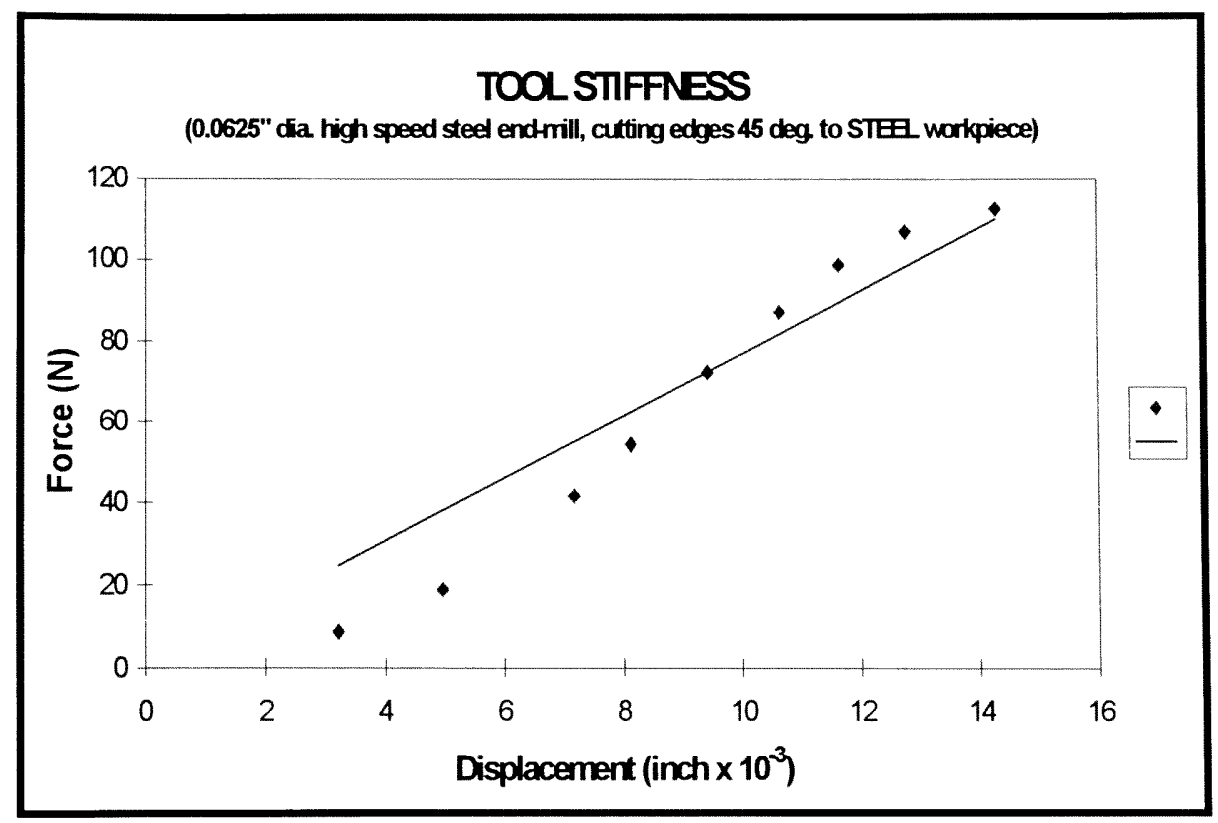

Figure 66.c. Cutting edges of the tool were 45 degree to the workpiece (slope $=7.69$ ) 


\subsection{5" CARBIDE END-MILL STIFFNESS WITH STEEL WORKPIECE}

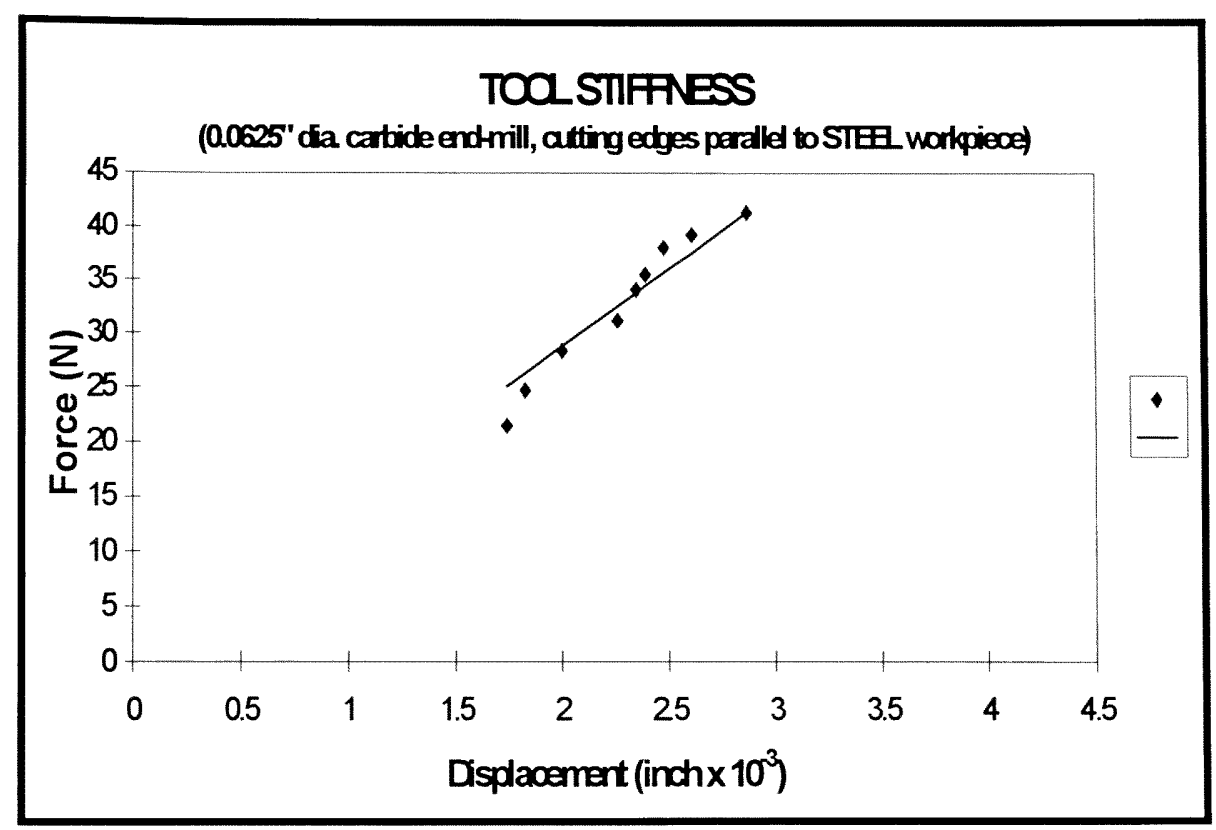

Figure 67.a. Cutting edges of the tool were parallel to the workpiece $($ slope $=14.40)$

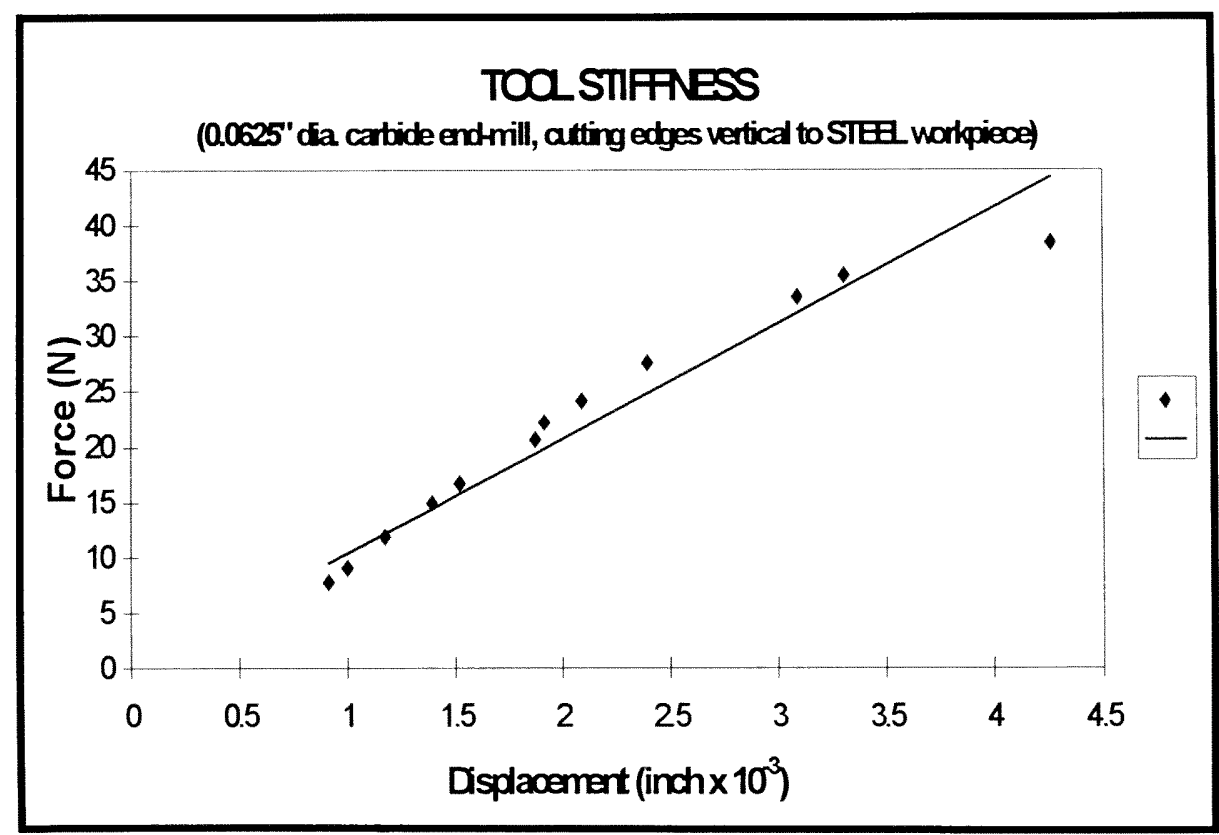

Figure 67.b. Cutting edges of the tool were vertical to the workpiece $($ slope $=10.39)$ 


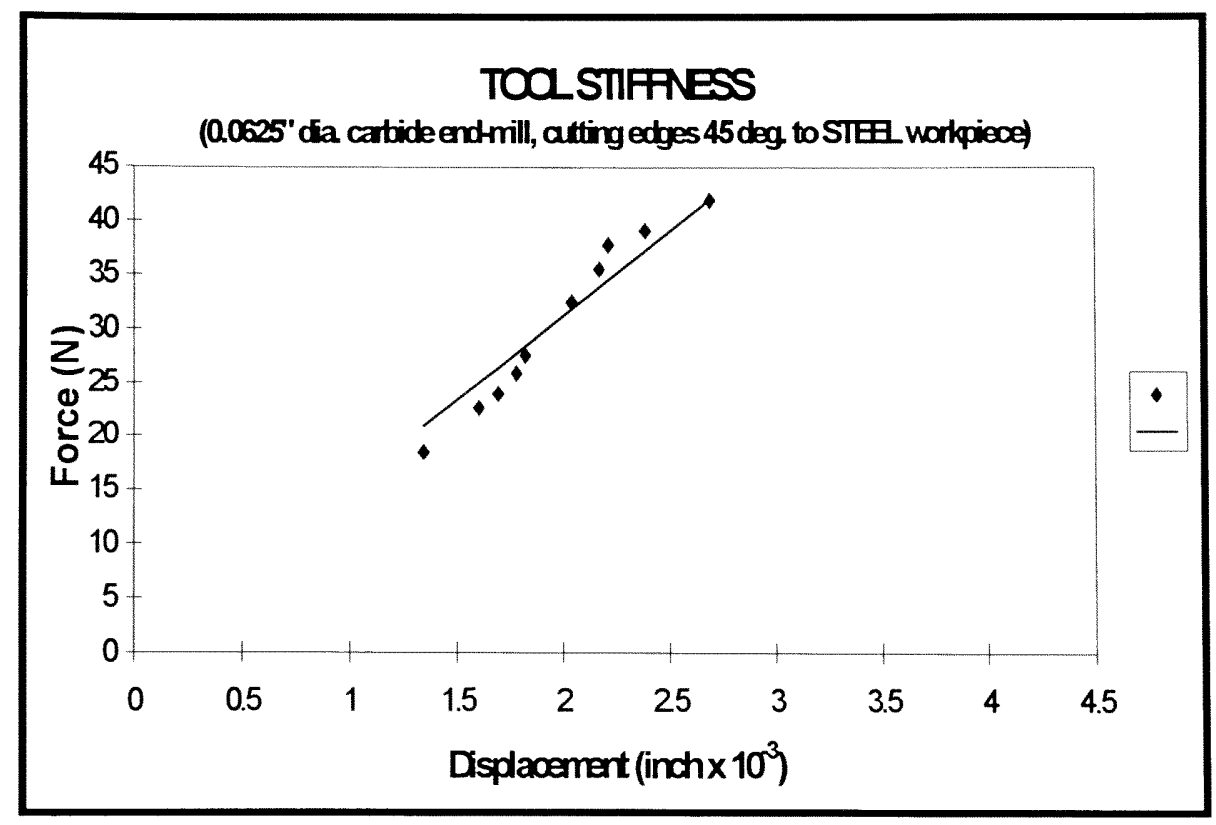

Figure 67.c. Cutting edges of the tool were 45 degree to the workpiece $($ slope $=15.57$ )

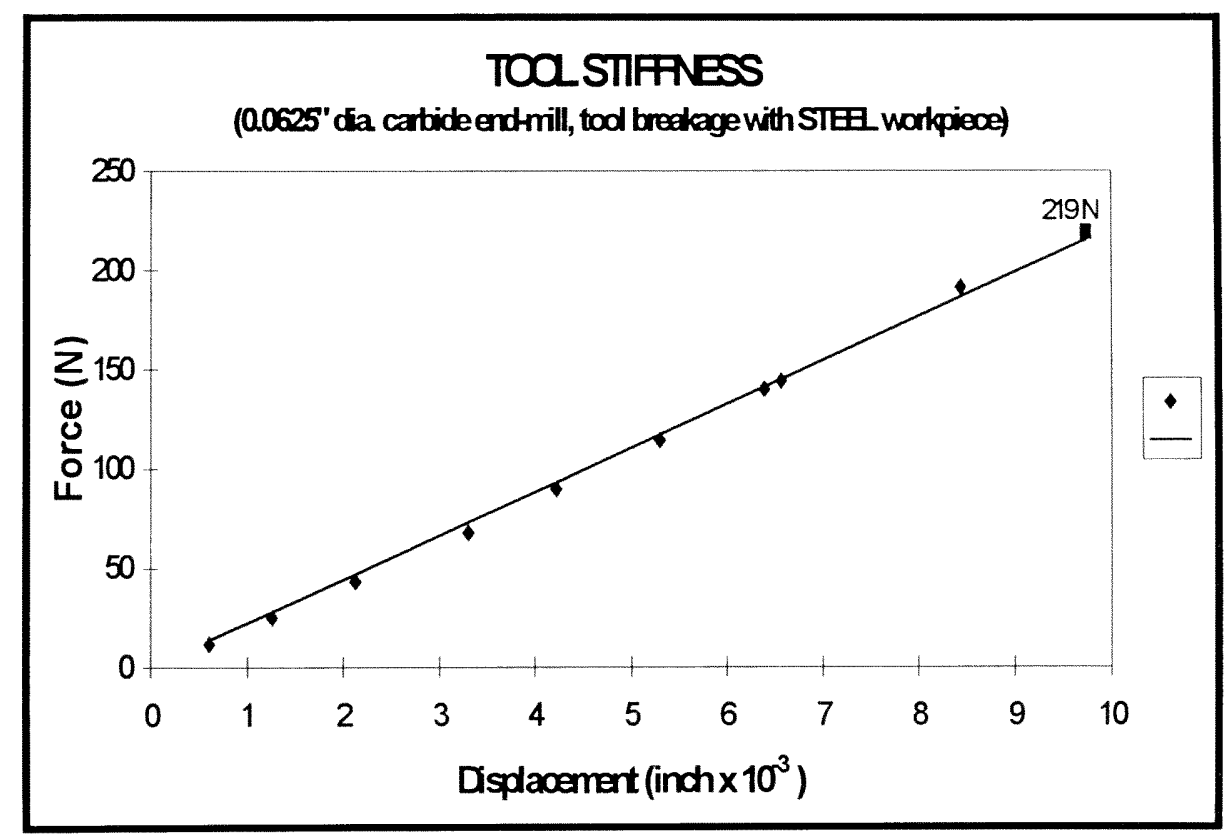

Figure 67.d. Tool breakage occurred at $219 \mathrm{~N}($ slope $=22.1)$ 


\section{Chapter VI}

\section{Conclusion}

Micro machining have been widely used in biomedical, aerospace and consumer product manufacturing. In this study, the characteristics of cutting forces and micro-tool structures were studied to develop low cost machinability and tool life evaluation methods

The new machinability method is developed to evaluate the optimal cutting conditions to avoid premature tool breakage during micro end milling. The developed method repeats the machining tests with different cutting conditions until the targeted cutting force variation is obtained. The developed machinability method was applied during the micro machining of graphite electrodes (POCO-3, POCOEDMC-3), aluminum and steel (NAK 55). The new method required less experiment than the conventional machinability tests and tool life was at the acceptable levels.

The optimal cutting conditions were used during the evaluation of the tool wear. Cutting force amplitude variation during the micro machining of the workpiece was monitored at the different stages of tool life. As the tool wears out, the thrust and feed direction cutting forces had the tendency to increase. The cutting force amplitude increased $350 \%$ for POCOEDMC-3 after 1350 inches of cutting and 300\% for aluminum after 155 inches of cutting. The recorded data was used to develop a new tool wear estimation method by using new neural networks. The Neural Network Based Periodic Tool Inspector $\left(\mathrm{N}^{2} \mathrm{PTI}\right)$ estimated the tool wear with an acceptable accuracy for both POCOEDMC-3 and aluminum workpieces. To select the best paradigm accuracy, 3 
different neural networks [Backpropagation neural network (Analog BP) and probabilistic neural network (Basic PNN, Sepvar PNN were evaluated.

Analog BP neural network took more time for training, however, the estimations were more accurate ( 4 to $5 \%$ while PNN had 8 to $9 \%$ ) than the PNN neural networks. The proposed $N^{2}$ PTI could only estimate the tool wear, if the spindle speed, feed rate and depth of cut are constant. To improve the $\mathrm{N}^{2} \mathrm{PTI}$, the effect of the depth of cut was eliminated by normalizing the thrust and feed direction cutting forces. The normalized data were used to train Analog BP, Basic and Sepvar PNN. The results were less accurate than the previous case study without normalization, but still estimations were in an acceptable error range. (10 to $13 \%$ for POCOEMDC-3 and $12-15 \%$ for Aluminum) Elimination of the constant depth of cut requirement allows on-line monitoring of micro machining of graphite electrodes and aluminum workpieces.

The elasticity and the critical static bending force (which breaks the tool) of Carbide and HSS end-mills were tested. The deflection and the critical bending force that breaks the micro end-mill were found. Carbide end-mills showed a brittle behavior. HSS tools are more ductile and their stiffness was higher. The carbide tools were 2 times more rigid than HSS tools ( $k=15.5$ versus $k=7.5$ for 0.0625 " tool) Also, carbide tools broke 1.5 times higher forces than the HSS tools. However, the deflection of HSS tools were 3 to 4 times bigger than the carbide tools. ( 16 inch $\times 10^{-3}$ versus 4.45 inch $\times 10^{-3}$ for 0.0625 " tool) Dynamic behavior of the micro tools was also studied to measure the natural frequency and the first natural frequencies were found at $23,000 \mathrm{HZ}$ for 0.0625 " HSS tools and $8,000 \mathrm{HZ}$ for 0.020 " HSS tools. The resonance problem was not critical at the commonly used spindle speeds. 
To represent the characteristics of the cutting forces in more compact way, segmental averaging and wavelet transformation methods were used. 8 wavelet coefficients were representing the characteristics of one revolution for each cutting force more accurately than 10 segmental averages.

The performance of the Improved $\mathrm{N}^{2} \mathrm{PTI}$ is outlined in Table 29 for POCOEEDMC- 3 and in Table 30 for Aluminum.

The main objective of the study was to develop new methods to improve productivity and quality in industrial operations. The developed machinability analysis technique and $\mathrm{N}^{2} \mathrm{PTI}$ can be easily used in industrial applications. Low hardware cost, simple and reliable algorithms are the main advantages of the proposed methods in real life applications. 
Table 29. Performance of the $\mathrm{N}^{2} \mathrm{PTI}$ - POCOEDMC-3

\begin{tabular}{|l|l|c|c|c|c|}
\hline \multicolumn{2}{|c|}{$N^{2} P T I-P O C O E M D C-3$} & \multicolumn{2}{c|}{ Segmental Averaging } & \multicolumn{2}{c|}{ Wavelet Transformation } \\
\hline \multirow{2}{*}{ Cases } & Error \% & $\begin{array}{c}\text { Original } \\
\text { Data }\end{array}$ & $\begin{array}{c}\text { Normalized } \\
\text { Data }\end{array}$ & $\begin{array}{c}\text { Original } \\
\text { Data }\end{array}$ & $\begin{array}{c}\text { Normalized } \\
\text { Data }\end{array}$ \\
\hline \multirow{2}{*}{$\begin{array}{l}\text { Training } \\
(40 \text { cases })\end{array}$} & Average & 6.5 & 7.25 & 4.5 & 6.7 \\
\cline { 2 - 6 } & Minimum & 1.4 & 2.15 & 1.1 & 1.95 \\
\cline { 2 - 6 } & Maximum & 12.6 & 14.3 & 9.5 & 13.8 \\
\hline \multirow{3}{*}{$\begin{array}{l}\text { Testing } \\
(30 \text { cases })\end{array}$} & Average & 8.75 & 9.5 & 6.8 & 9.25 \\
\cline { 2 - 6 } & Minimum & 2.7 & 3 & 1.9 & 2.5 \\
\cline { 2 - 6 } & Maximum & 15.5 & 17.8 & 11.4 & 16.9 \\
\hline
\end{tabular}

Table 30. Performance of the $\mathrm{N}^{2} \mathrm{PTI}$ - Aluminum

\begin{tabular}{|c|c|c|c|c|c|}
\hline \multicolumn{2}{|c|}{$N^{2} P T I-$ Aluminum } & \multicolumn{2}{|c|}{ Segmental Averaging } & \multicolumn{2}{|c|}{ Wavelet Transformation } \\
\hline Cases & Error \% & $\begin{array}{c}\text { Original } \\
\text { Data }\end{array}$ & $\begin{array}{c}\text { Normalized } \\
\text { Data }\end{array}$ & $\begin{array}{c}\text { Original } \\
\text { Data }\end{array}$ & $\begin{array}{c}\text { Normalized } \\
\text { Data }\end{array}$ \\
\hline \multirow{3}{*}{$\begin{array}{l}\text { Training } \\
\text { (50 cases) }\end{array}$} & Average & 8.25 & 9.82 & 7.58 & 8.86 \\
\hline & Minimum & 1.7 & 2.25 & 0.95 & 1.75 \\
\hline & Maximum & 14.6 & 16.74 & 11.5 & 14.63 \\
\hline \multirow{3}{*}{$\begin{array}{l}\text { Testing } \\
\text { (40 cases) }\end{array}$} & Average & 9.65 & 10.25 & 8.64 & 9.82 \\
\hline & Minimum & 3.3 & 3.78 & 2.27 & 3.07 \\
\hline & Maximum & 16.65 & 18.25 & 15.07 & 17.95 \\
\hline
\end{tabular}




\section{REFERENCES}

1. J. Tlusty and P. MacNeil, "Dynamics of Cutting Forces in End Milling," Annals of the CIRP, v24, n1, 1975, pp.21-25.

2. P.E. Gygax, "Dynamics of Single-Tooth Milling", Annals of CIRP, v28, n1, 1979, pp. 65-70.

3. F. Ismail and A. Bastami, "Improving Stability of Slender End Mills Against Chatter," Trans. of ASME, Jour. of Eng. for Ind., Vol. 108, 1986, pp. 264-268.

4. J. Tlusty and, F. Ismail, "Special Aspects of Chatter in Milling," Jour. of Eng. for Ind., Trans. of the ASME, Vol. 105, 1983, pp. 24-32.

5. W. A. Kline and R. E. DeVor, "The Effect of Cutter Run-out On Cutting Geometry and Forces in End Milling," Int. Jour. of Mach. Tool Des. and Res., Vol. 23, 1983, pp. 123-148.

6. J. W. Sutherland and R. E. DeVor, "An Improved Method for Cutting Force and Surface Error Prediction in Flexible End Milling Systems," ASME Journal of Eng. for Ind., Vol. 108, 1986, pp. 269-27.

7. T. I. Liu, "Automated Visual Inspection of Drill Wear," presented at the ASME Manufacturing International 90 Conference, Atlanta Georgia, 1990.

8. S. Y. Liang and D. A. Dornfeld, "Tool Wear Detection Using Time Series Analysis of Acoustic Emission," Trans. of ASME, Jour. of Eng. for Ind., Vol. 111, 1989, pp. 199-205. 
9. Zheng, L., Luo, Z. B., Wu, Y., et al., "Research and Development on Synthetic Cutting Tool Monitoring with AE Signal," Transactions of NAMRI/SME, 1990, pp.360-365.

10. Koning, W., Kutzner K., Shehl, U., "Tool Monitoring of Small Drills With Acoustic Emission," International Journal of Machine Tools Manufacture Vol. 32, No. 4, pp. 487-493, Pergamon Press, Great Britain, 1992.

11. Vajpayee S., Sampath, A., "Acoustic Emission as an Indirect Parameter for Tools Monitoring," Proceedings of Manufacturing International '88, Symposium on Product and Process Design, Vol. 1, Atlanta, Georgia, 1988.

12. M. Liu, "Analytical modeling of acoustic emission for monitoring of peripheral milling process," Inter. Journal of Mach. Tools \& Manufacture, Vol.31, No.4, 1991, p.589.

13. M. Liu, S.Y. Liang, "Monitoring of Peripheral Milling Using Acoustic Emission," Trans. of NAMRI/SME, 1990, pp.120-127.

14. Klaiber, J. R., Dornfeld, D. A., Liu, J. J., "Acoustic Emission Feedback for Diamond Turning," Transactions of NAMRI/SME, 1990, pp.113-119.

15. J.J. Liu, D.A. Dornfeld, "Monitoring of Micro-machining Process using Acoustic Emission," Trans. of NAMRI/SME, 1992, pp.189-195.

16. Diniz, A. E., Liu, J. J., Dornfeld, D. A., "Correlating Tool Life, Tool, Wear and Surface Roughness by Monitoring Acoustic Emission in Finish Turning," Wear No. 152, pp 395-407, 1992. 
17. Hutton, D. V., "A Non-contact Acoustic Emission Sensing System For RotatingCutter Machining Process," Experimental Techniques, Nov/Dec, 1991

18. R.H. Osuri, S. Chatterjee, S. Chndrashekhar, "On-line condition monitoring of tool wear in end milling using acoustic emission," International journal of production research, Vol.29, No.7, 1991, p.1339.

19. Rangwala, S., Dornfeld, D., "A Study of Acoustic Emission Generated During Orthogonal Metal Cutting - 1:Energy Analysis," International Journal of Mechanical Science Vol. 33, No. 6 pp. 471-487, Pergamon Press, Great Britain, 1991.

20. Rangwala, D.A. Dornfeld, "A study of acoustic emission generated during orthogonal metal cutting-2: spectral analysis," International journal of mechanical sciences, V 33 n 6, 1991, p.489.

21. S.Y. Liang, D.A. Dornfeld, "Tool Wear Detection Using Time Series Analysis of Acoustic Emission", Jour. of Eng. for Ind., Transactions of ASME, Vol.111, No.3, 1986, pp.199-204.

22. E. Emel and E. Kannetey Assibu, Jr., "Characterization of Tool Wear and Breakage by Pattern Recognition Analysis of Acoustic Emission Signal," Proc. of 14th NAMR Conf., 1986, pp. 266-272.

23. I.N. Tansel and C. McLaughlin, "Identification of Tool Breakage with Time Series Analysis in Milling Operations" Control of Manufacturing Process, Editors: K. Danai and S. Malkin, DSC-Vol.28, PED-Vol.52, ASME, 1991, pp. 59-65. 
24. D.E. Rumelhart, G. Hilton and R.J. Williams, "Learning Internal Representations by Error Propagation, "Parallel Distributed Processing" Explorations in the Microstructure of Cognition, Vol.1, Ed. E. Rumelhart, J.L. McClelland, MIT Press, 1986.

25. D. Specht, "Probabilistic Neural Networks," Neural Networks, Vol. 3, 1990, pp. $109-118$

26. I.N. Tansel and C. McLaughlin, "Detection of Tool Breakage in Milling OpeartionsNeural Network Approach," Int. Journal of Machine Tools Manufact., Vol. 33, n. 4, 1993, pp. 545-558.

27. I.N. Tansel and C. McLaughlin, "Detection of Tool Breakage in Milling OperationsTime Series Approach," Int. Journal of Machine Tools Mamufact., Vol. 33, n. 4, 1993, pp. 531-544.

28. I.N. Tansel, M.E. Trujillo, W.Y. Bao, T.T Arkan, "Detection of Tool Breakage in Micro-End-Milling Operations by Monitoring Acoustic Emission," Transaction of ASME, NAMRI, 1997, MR97-180.

29. I.Tansel, W.Y. Bao, T.T. Arkan, B. Shisler, M. McCool, and D Smith, "Neural Network Based Cutting Force Estimators for Micro-End-Milling Operations," to be presented at the Artificial Neural Networks In Engineering (ANNIE '97) and to be published at the "Smart Engineering System Design: Neural Networks, Fuzzy Logic, and Evolutionary Programming, edited by Drs. Dagli, Akay, Ersoy, Fernandez, and Smith, ASME Press, New York, 1997. 
30. I.Tansel, W.Y. Bao, T.T. Arkan, B. Shisler, M. McCool, A. Jinks, and D. Smith, "Wear Estimation for Micro-Machining of Non-Metal Materials," to be presented at the Artificial Neural Networks In Engineering (ANNIE '97) and to be published at the "Smart Engineering System Design: Neural Networks, Fuzzy Logic, and Evolutionary Programming, edited by Drs. Dagli, Akay, Ersoy, Fernandez, and Smith, ASME Press, New York, 1997.

31. T.A. Carolan, D.P. Hand, J.S. Barton, "Assessment of Tool Wear in Milling Using Acoustic Emission Detected by a Fiber-Optic Interferometer," Journal of Mamufacturing Science and Engineering, 1996, Vol. 118, Transaction of ASME.

32. J.C. Principe, T. Yoon, "A New Algorithm for the Detection of Tool Breakage in Milling," Int. Journal of Machine Tools \& Manufacturing, Vol. 31, No. 4, pp. 443-454, Great Britain, 1991

33. R. Hecht-Nielsen, "Neuro-computing," Addison-Wesley, January 1991

34. "Fundamentals of Tool Design," Third Edition, SME Publication, David T. Reid, P. Administrator, 1991.

35. E.M. Trent, "Metal Cutting," $3^{\text {rd }}$ Edition, Butterworth-Heinemann, 1991

36. M.C. Shaw, "Metal Cutting Principles," Oxford Series Advanced Manufacturing 3,1986

37. Serope Kalpakjian, "Manufacturing Engineering and Technology", AddisonWesley Publishing Company, 1989.

38. I.N. Tansel, Ghaleb A. Satar, "A Fast Procedure for the Identification of Complex Mode Shapes in the Time Domain". 
39. M.A. Cody, "The Fast Wavelet Transform," Dr. Dobb’s Journal, April 1992, pp. 1628

40. I. Daubechies, "Orthonormal Bases of Wavelets with Finite Support-Connection with Discrete Filters," Wavelets, Edited by J.M. Combes, New York, 1989, pp. 3867

41. I. Daubechies, "The Wavelet Transform, Time-Frequency Localization and Signal Analysis," IEEE Transactions on Information Theory, Vol. 36, No. \%, 1990, pp. 961-1005 